DANIEL JORGE CAETANO

\title{
UM SISTEMA INFORMATIZADO DE APOIO A USUÁRIOS DE TRANSPORTE COLETIVO
}

\author{
Dissertação apresentada à \\ Escola Politécnica da \\ Universidade de São Paulo \\ para obtenção do título de \\ Mestre em Engenharia.
}

São Paulo 
DANIEL JORGE CAETANO

\title{
UM SISTEMA INFORMATIZADO DE APOIO A USUÁRIOS DE TRANSPORTE COLETIVO
}

\author{
Dissertação apresentada à \\ Escola Politécnica da \\ Universidade de São Paulo \\ para obtenção do título de \\ Mestre em Engenharia. \\ Área de Concentração: \\ Engenharia de Transportes \\ Orientador: \\ Professor Doutor \\ Nicolau D. Fares Gualda
}

São Paulo 
À Danielle Scherer Schneider, por me apresentar à Engenharia Civil e mostrar-me o quão maior e mais belo pode ser o mundo, se analisado por seu aspecto humano. 


\section{AGRADECIMENTOS}

Ao amigo e orientador Prof. Dr. Nicolau Dionísio Fares Gualda, pelo auxílio na definição das diretrizes deste trabalho e constante apoio.

À CAPES, pelo apoio financeiro durante grande parte do tempo de desenvolvimento deste trabalho.

Ao amigo Prof. Dr. Cláudio Barbieri da Cunha, pela grande ajuda na compreensão do problema tratado e aos muitos esclarecimentos em diversas e importantes questões.

Aos amigos Adriano Cunha, Ludmilson Mendes, Marcelo Bastos, Marco Talarico e à namorada Patrícia Arima, cujo apoio técnico e emocional foi imprescindível para a finalização deste trabalho.

E, finalmente, aos meus pais Plínio e Dalva, pelo apoio constante, financeiro e emocional, aos quais serei eternamente grato. 


\section{RESUMO}

A falta de informação sobre a estrutura e operação do sistema de transporte coletivo, sob o ponto de vista do usuário, ocasiona muitas vezes em um uso inadequado deste, reduzindo a qualidade do sistema de transporte como um todo. $\mathrm{O}$ principal objetivo desta pesquisa é o desenvolvimento de uma ferramenta para o auxílio na escolha modal pelos usuários de transporte público, na forma de um sistema de informações eletrônico. Uma vez que as informações devem ser fornecidas em tempo real, é importante que tal sistema seja de operação simples, rápido e apresente opções e critérios que auxiliem o usuário na melhor escolha dentre as alternativas possíveis.

As alternativas analisadas e as soluções geradas devem se basear nas informações fornecidas pelo usuário quanto à origem e ao destino da viagem pretendida. As consultas realizadas serão armazenadas e poderão ser usadas para o planejamento tático e/ou estratégico do sistema de transporte considerado. Para tanto, este problema multimodal será modelado para a solução através do algoritmo de fluxo em rede Label Correcting e implementado em uma linguagem de programação

orientada a objetos. Embora direcionado para um sistema de transporte genérico, o sistema de informações será implementado e testado com base nas alternativas de transporte disponíveis e na malha viária da Cidade Universitária Armando de Salles Oliveira, e poderá ser disponibilizado ao usuário para consultas pela internet. 


\begin{abstract}
The lack of information about the structure and operation of the transportation system from the user's point of view usually causes misuse of this system, which means a reduction in the overall quality of the transportation system. The main target of this master of science research is the development of a tool to help on modal selection by the public transportation users, which will be implemented as an eletronic information system. Since the infomation must be provided in real time to the user, it is important to the system to be fast and easy to use. It is also a requirement that the system presents options and information to help the user on the selection of the best choice among all possible ones.
\end{abstract}

The alternatives to be considered and generated solutions shall be based on the user requests related to origin and destination of the desired trip. The requests will be stored and could be used for tactic and/or strategic planning of the concerned system of transport. This multimodal problem will be modeled to be solved with the Label Correcting network flow algorithm and implemented using an object oriented language. Although addressed to a generic transport system, it will be implemented and tested based on the available transport alternatives and street mesh of the Cidade Universitária Armando de Salles Oliveira. The system may be available to users through internet. 


\section{SUMÁRIO}

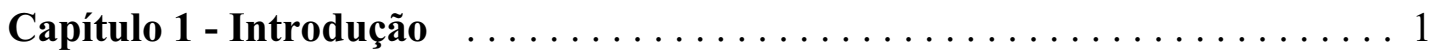

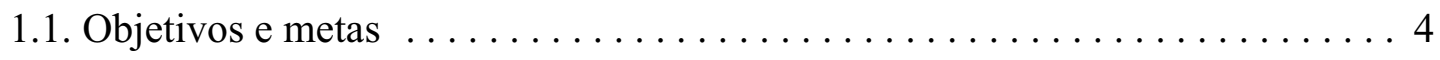

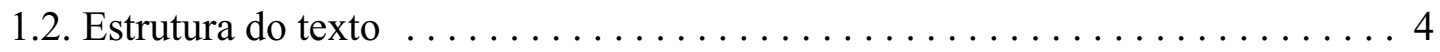

Capítulo 2 - Revisão bibliográfica $\ldots \ldots \ldots \ldots \ldots \ldots \ldots \ldots \ldots \ldots \ldots \ldots \ldots \ldots \ldots$

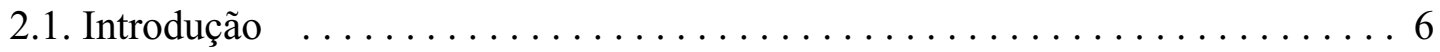

2.2. Motivação e aspectos gerais do problema $\ldots \ldots \ldots \ldots \ldots \ldots \ldots$

2.3. O problema na literatura $\ldots \ldots \ldots \ldots \ldots \ldots \ldots \ldots \ldots \ldots \ldots \ldots \ldots \ldots \ldots$

2.4. Percepção da qualidade pelo usuário $\ldots \ldots \ldots \ldots \ldots \ldots \ldots \ldots \ldots \ldots \ldots$

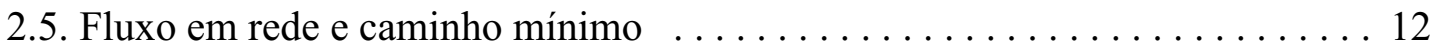

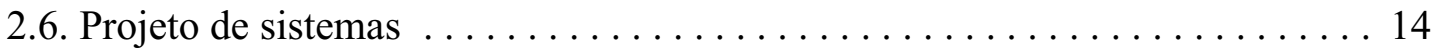

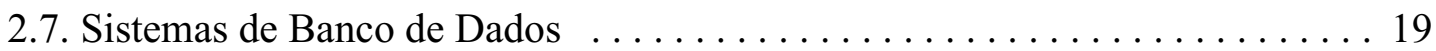

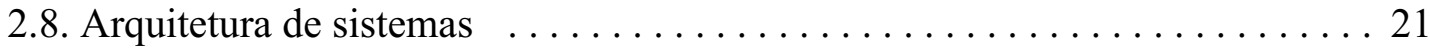

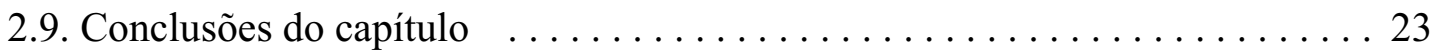

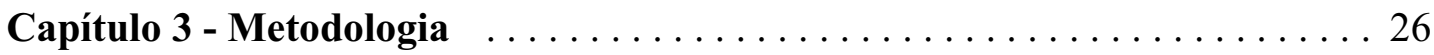

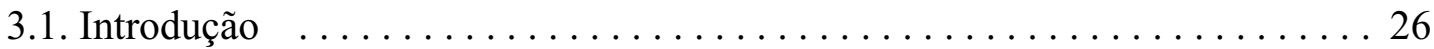

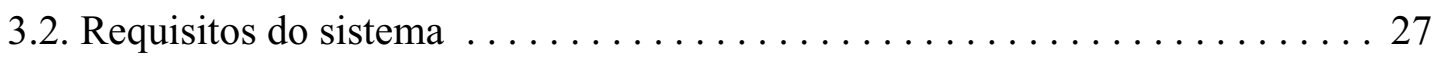

3.2.1. Requisitos de "usabilidade" „..................... 28

3.2.2. Requisitos para avaliação do sistema de transportes $\ldots \ldots \ldots \ldots 28$

3.3. Estruturação global do sistema $\ldots \ldots \ldots \ldots \ldots \ldots \ldots \ldots \ldots \ldots$

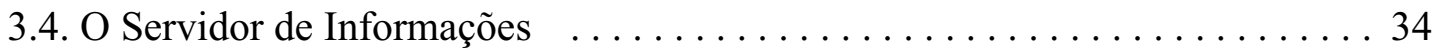

3.4.1. Informações para composição da rede .............. 36

3.4.2. Armazenamento de soluções . . ..................... 39

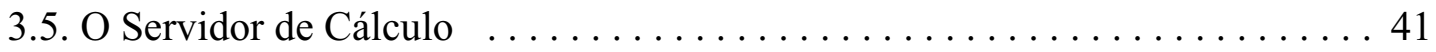

3.5.1. Estrutura de Funcionamento $\ldots \ldots \ldots \ldots \ldots \ldots \ldots \ldots \ldots \ldots \ldots$

3.5.1.1. Requisição dos Dados e Construção da Rede ............. 42

3.5.1.2. Configuração da Rede para a Solução . . . . . . . . . . . . 43

3.5.1.3. Resolução do Caminho Mínimo ................. 44 
3.5.1.4. Construção da Saída ...................... 44

3.5.2. Estruturação dos Objetos $\ldots \ldots \ldots \ldots \ldots \ldots \ldots \ldots \ldots \ldots \ldots \ldots$

3.5.2.1. Classe cTMode ............................ 49

3.5.2.2. Classe cBus ...................... 50

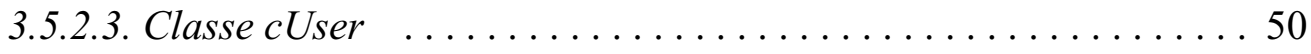

3.5.2.4. Classe cLinkListElement ................... 51

3.5.2.5. Classe cNode ....................... 52

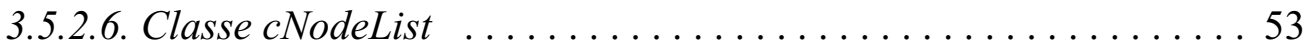

3.5.2.7. Classe cArc ... . . . . . . . . . . . . . . . . . . . 54

3.5.2.8. Classe cArcList .................... 55

3.5.2.9. Classe cNetwork ..................... 56

3.5.2.10. Template tStackElement . ................ 57

3.5.2.11. Template tStack ..................... 57

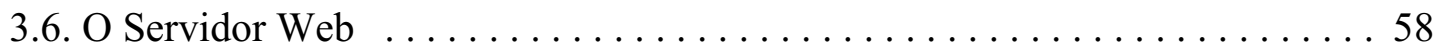

3.6.1. Estrutura de Funcionamento . .................. 60

3.6.1.1. A interface com o usuário como uma Máquina de Estados

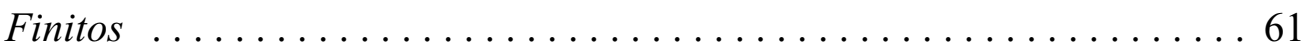

3.6.1.2. O protocolo de descrição de rotas . ............665

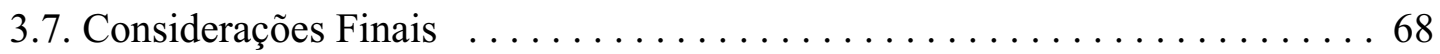

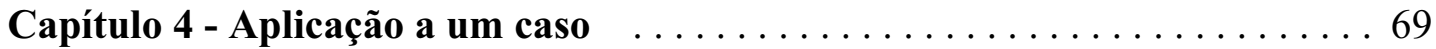

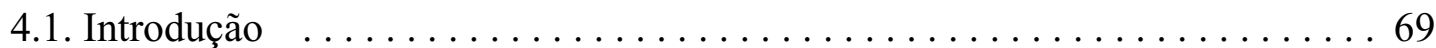

4.2. O Transporte na Cidade Universitária $\ldots \ldots \ldots \ldots \ldots \ldots \ldots \ldots$

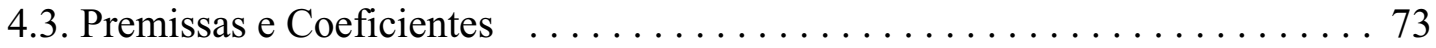

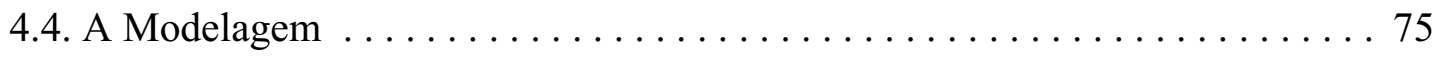

4.5. Análise de Dados e Resultados . . . . . . . . . . . . . . . . . . 78

4.5.1. Desempenho de Cálculo _....................... 79

4.5.1.1. Teste de desempenho para requisição única .......... 81

4.5.1.2. Teste de desempenho para requisições múltiplas $\ldots \ldots \ldots 85$

4.5.2. Teste de Apresentação $\ldots \ldots \ldots \ldots \ldots \ldots \ldots \ldots \ldots \ldots \ldots \ldots \ldots \ldots \ldots \ldots$

4.5.2.1. Da Portaria 1 até o MAE .................... 93 
4.5.2.2. Da Casa de Cultura Japonesa até o Terminal de Ônibus Urbano 97

4.5.2.3. Do Acesso de Pedestres FEPASA até o Instituto Oceanográfico $\quad .100$ 4.5.2.4. Do Prédio da Engenharia Civil até o IPEN _............... 103

4.5.2.5. Do Acesso a Pedestres Vila Indiana até o Terminal de Ônibus

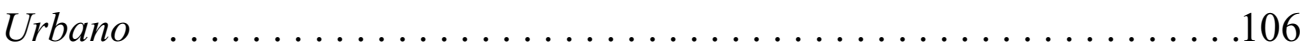

4.5.2.6. Do CRUSP até o Acesso a Pedestres Vila Indiana . . . . . . . . 109

4.5.3. Resumo dos Resultados de Apresentação ... . . . . . . . . . . . . .111

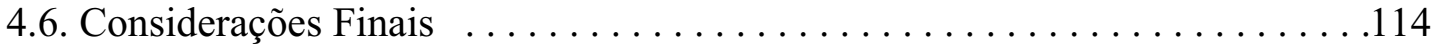

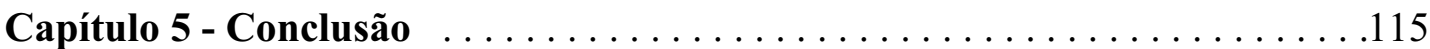

5.1. Extensões Futuras e Recomendações … . . . . . . . . . . . . . . 117

Anexo A - Conforto do usuário e custo generalizado $\ldots \ldots \ldots 122$

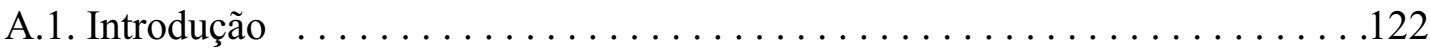

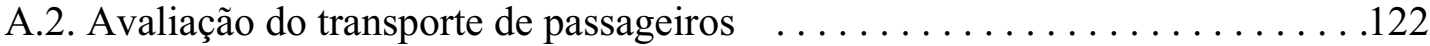

A.3. Características ligadas ao tempo de viagem $\ldots \ldots \ldots \ldots \ldots \ldots \ldots \ldots \ldots . \ldots \ldots$

A.3.1. Tempo de espera ..............................124

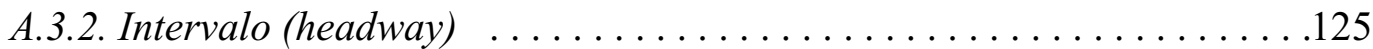

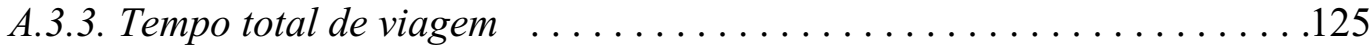

A.3.4. Disponibilidade de veículos para substituição . . . . . . . . . . . . 126

A.3.5. Regularidade dos horários . . . . . . . . . . . . . . . . . . 127

A.4. Características ligadas ao desempenho do sistema $\ldots \ldots \ldots \ldots \ldots \ldots \ldots$

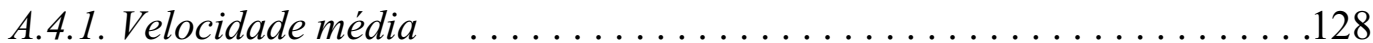

A.4.2. Custo da viagem .................................. . . . . . . . .

A.4.3. Acessibilidade e distância média entre pontos de parada .......131

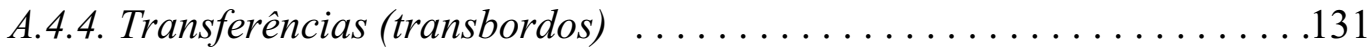

A.5. Características ligadas ao conforto do usuário $\ldots \ldots \ldots \ldots \ldots \ldots \ldots \ldots \ldots$

A.6. Características mais influentes na opção de modo $\ldots \ldots \ldots$. . . . . . . . 132

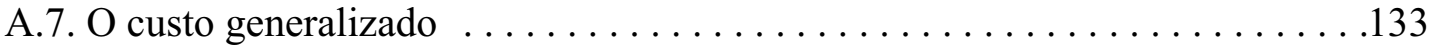

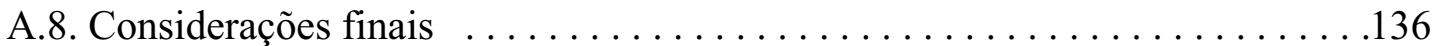

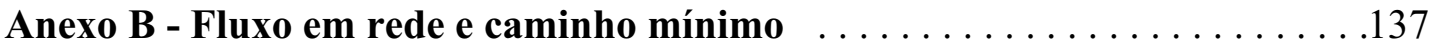

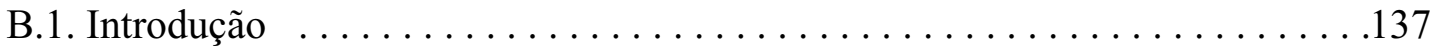




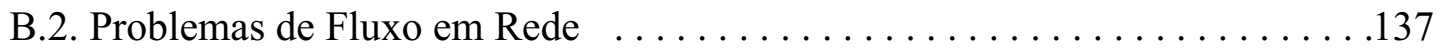

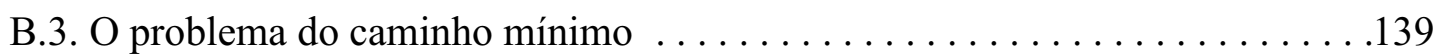

B.3.1. Modelagem de um problema de caminho mínimo monomodal . . . . . .140

B.3.1.1. O algoritmo Label Setting . . . . . . . . . . . . . . . . . . 144

B.3.1.2. O problema dos ciclos ....................... 145

B.3.1.3. O algoritmo Label Correcting . . . . . . . . . . . . . . . . . . 147

B.3.2. Modelagem de um problema de caminho mínimo multimodal ... . . 148

B.3.2.1. Arcos e nós com atributos de modo . . . . . . . . . . . . . . . . 149

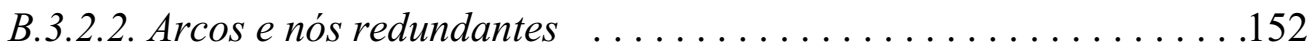

B.3.2.3. Uma comparação entre as duas formas de modelagem .......153

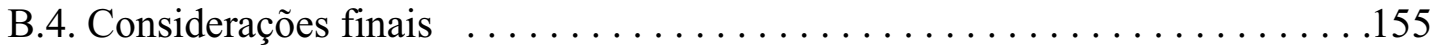

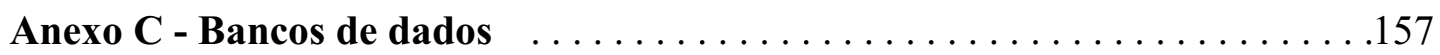

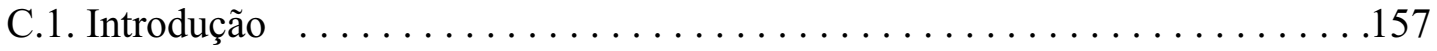

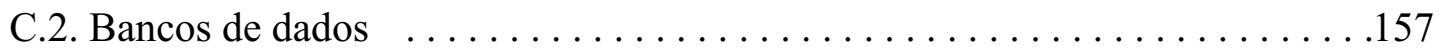

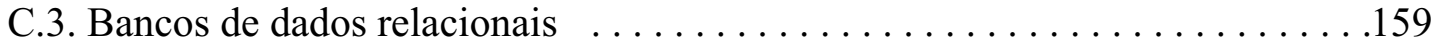

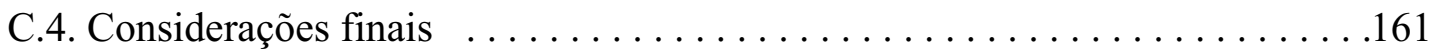

Anexo D - Análise e projeto orientado a objetos $\ldots \ldots \ldots \ldots \ldots \ldots \ldots \ldots \ldots$

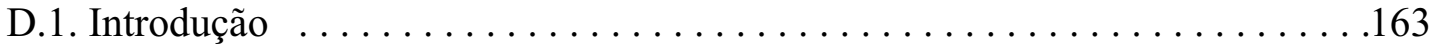

D.2. A "evolução" da Análise de Sistemas . . . . . . . . . . . . . . . . . 163

D.2.1. Análise de Sistemas "clássica" . . . . . . . . . . . . . . . . . . . 164

D.2.2. A Orientação a Objetos ... . . . . . . . . . . . . . . . . 165

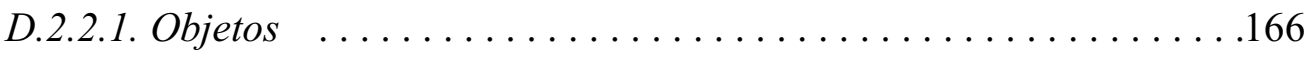

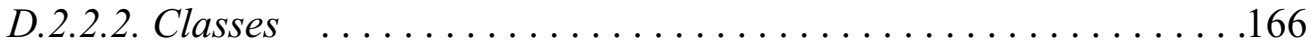

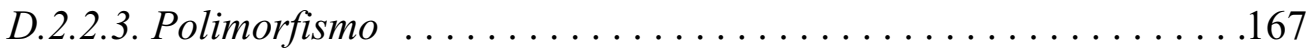

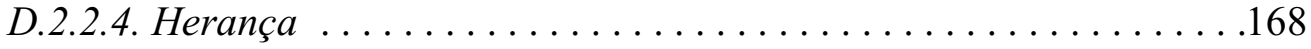

D.2.3. Análise Baseada em Objetos ... . . . . . . . . . . . . . . . . 169

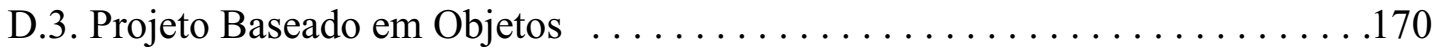

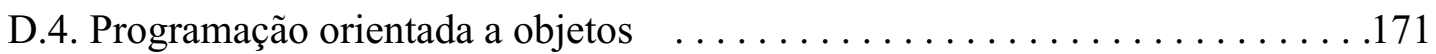

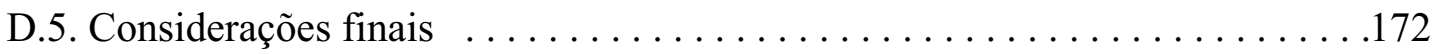

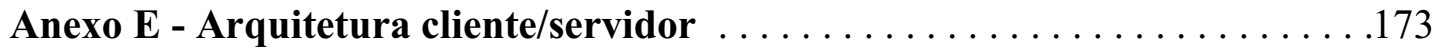




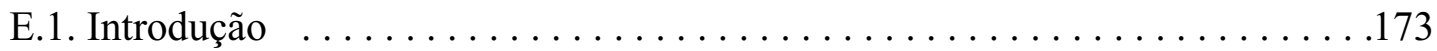

E.2. Características e vantagens da arquitetura cliente/servidor ............173

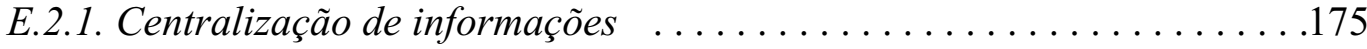

E.2.1.1. Uso misto de servidor remoto e servidor local ..............178

E.2.2. Independência entre a interface de um serviço e o serviço em si . ....179

E.2.3. Execução de processamento intensivo em equipamento(s) adequado(s) 181

E.2.4. Maior facilidade de processamento distribuido ................182

E.2.5. Racionalização dos recursos computacionais ................183

E.3. Considerações finais . ...................................184

Anexo F - Máquinas de Estados Finitos $\ldots \ldots \ldots \ldots \ldots \ldots \ldots \ldots \ldots \ldots$

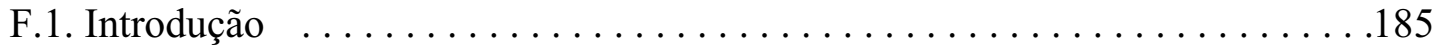

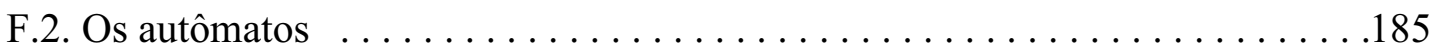

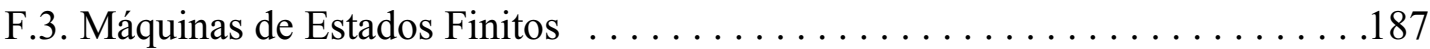

F.3.1. A máquina de Estados Finitos Deterministica ................188

F.3.2. O uso de MEFs no controle de fluxo de um programa ............190

F.3.2.1. A estrutura de um programa orientado a estados ............193

F.4. Considerações finais . .....................................194

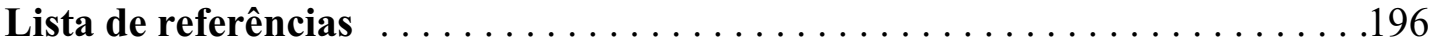

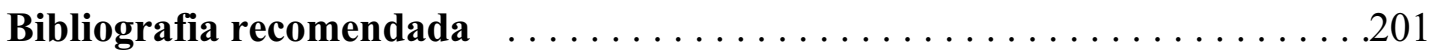




\section{CAPÍTULO 1 - INTRODUÇÃO}

Desde os primórdios da vida, o transporte sempre consistiu num problema crucial para as atividades do homem. As grandes distâncias sempre limitaram a expansão humana, embora esse limite, ano a ano, tenha sido expandido muito além dos patamares imaginados no passado. Se nos primórdios as grandes distâncias dificultavam a manutenção de uma lavoura, o contínuo avanço tecnológico permite que, nos dias de hoje, seja possível até mesmo ir à Lua.

Mesmo em uma escala menor, quando é considerada apenas uma região do globo como o Brasil ou o Estado de São Paulo, mudanças significativas ocorreram nos sistemas de transporte ao longo do tempo, tendo como resultado o complexo sistema de transportes existente na atualidade (CAMARGO, 1993).

Entretanto, não foi apenas a expansão das atividades humanas que tais mudanças provocaram: quase como uma conseqüência desta expansão veio também uma democratização dos transportes. Assim, a evolução do sistema de transportes permite que, nos dias atuais, um indivíduo possa se deslocar para praticamente qualquer ponto do globo, dado que arque com os dispêndios necessários; tal evolução também proporcionou uma redução do custo de transporte, ampliando o acesso da população em geral ao transporte de curta distância.

Essa democratização manifestou-se, ao longo dos anos, não só através do transporte público coletivo, mas também no crescimento da frota de veículos de transporte particulares. Apesar dos aspectos positivos inerentes a tal democratização, ela também provocou o surgimento de diversos problemas, como os congestionamentos, decorrentes do grande tráfego nos conglomerados urbanos.

É possível verificar uma relação direta entre o crescimento do transporte particular e o crescimento dos problemas de tráfego (MARQUES, 1998) e, apesar de 
grande parte das viagens motorizadas diárias serem realizadas por transporte público coletivo (PADILHA, 1998 apud MARQUES, 1998), as conseqüências do constante incremento da demanda por transportes já são nítidas, em especial nas grandes cidades.

Além das questões financeiras e ambientais envolvidas, os congestionamentos são muito incômodos, porque vêm a ressaltar um fato muitas vezes esquecido: a melhor solução para o problema de deslocamentos seria reduzir a necessidade de transporte.

Uma vez que nem sempre é possível atuar no sentido de minimizar as necessidades de transporte, é pertinente buscar outros recursos para tornar o transporte mais eficiente de forma global, bem como garantir que seja confortável para cada um dos indivíduos que se utilizam do mesmo.

Uma das maneiras de atacar este problema é pelo aumento da eficácia do transporte público coletivo. Muito tem sido feito neste sentido: ampliações das malhas de transporte coletivo, criação de corredores expressos para transporte coletivo, integração dos diversos sistemas e modos de transporte visando à redução dos custos ao usuário, etc.

Entretanto, a evolução de sistemas visando à informação do usuário de transporte coletivo não acompanhou o ritmo de evolução das redes de transporte. A razão para esta disparidade está no fato que "informar ao usuário" é, muitas vezes, uma tarefa bastante complexa (TIMPF, 2002). A falta de sistemas de informação compatíveis com a complexidade das redes de transporte atuais tem se tornado um obstáculo cada vez maior para que o usuário possa utilizar o transporte coletivo, uma vez que tal usuário pode não conseguir obter informações adequadas sobre a estrutura e a operação do sistema de transporte. 
Como conseqüência da dificuldade em obter informações, o usuário pode deixar de fazer a melhor escolha quanto às alternativas e rotas que lhe são oferecidas, podendo ocasionar uma redução da eficácia deste sistema, não só sob o ponto de vista do usuário. Assim, o uso incorreto do sistema pode vir a comprometer até mesmo sua eficiência global, fugindo à sua função original (GRAY, 1975 apud STRAMBI, 1991).

Em conjunto, estes fatores podem ser até mesmo uma causa da queda de demanda pelo transporte coletivo, fazendo com que estes usuários migrem para outras alternativas de locomoção como, por exemplo, os veículos particulares. Visto que esta migração tende a piorar ainda mais o nível de serviço do sistema de transporte, informar aos usuários deste sobre a forma mais eficiente e eficaz de utilizá-lo pode contribuir efetivamente para uma melhoria do sistema como um todo. Em outras palavras, uma alternativa para mitigar os problemas de transporte nas grandes cidades seria aumentar a atratividade do transporte coletivo, não só pelo do aumento de opções e da qualidade do transporte, mas também com a disponibilização de um adequado sistema de informações.

Neste sentido, como uma ferramenta complementar às medidas de ampliação de malha e opções de transporte, este trabalho propõe um sistema informatizado de apoio a usuários de transporte coletivo. Explicitamente, a finalidade de tal sistema é auxiliar o usuário em sua escolha modal, propiciando que ele utilize o sistema de transportes de forma eficiente e eficaz.

Além disso, o uso de um sistema de informações automatizado torna possível o armazenamento das consultas realizadas pelos usuários, possibilitando a extração de informações que possam vir a subsidiar modificações e otimizações do sistema de transporte, ampliando ainda mais a utilidade do sistema de informações proposto. 


\subsection{Objetivos e metas}

O principal objetivo deste trabalho é o desenvolvimento de um software (um sistema de informações) com as seguintes finalidades diretas:

- Informar o usuário, de forma simples e rápida, para que ele utilize melhor o sistema de transporte coletivo, fornecendo rotas para viagens de tempo mínimo ou custo mínimo, sem deixar de levar em conta o conforto do usuário.

- Criar condições de avaliação do sistema de transporte atual, colhendo informações que possam vir a apoiar futuras modificações no sistema de transporte coletivo.

\subsection{Estrutura do texto}

Este texto está dividido em treze seções principais:

O Capítulo 1 introduz o problema e sua importância, apresenta informações gerais sobre este trabalho, bem como seus objetivos e metas.

O Capítulo 2 traz um breve resumo da revisão bibliográfica, indicando as principais publicações e assuntos verificados. Maiores detalhes sobre cada um dos tópicos do capítulo estão presentes nos Anexos A a F.

O Capítulo 3 apresenta detalhes do projeto do sistema realizado neste trabalho, visando à sua implementação para testes.

O Capítulo 4 apresenta o estudo de caso, incluindo os testes realizados sobre a implementação, resultados obtidos e conclusões sobre tais resultados. 
O Capítulo 5 apresenta as conclusões sobre o trabalho realizado, bem como as propostas para futuras extensões do sistema.

O Anexo A apresenta um resumo sobre o conforto do usuário de transporte coletivo e também sobre o conceito de custo e tempo generalizados.

O Anexo B apresenta o método do caminho mínimo, detalhando os algoritmos Label Setting e Label Correcting, baseados no algoritmo de Dijkstra.

O Anexo $\mathrm{C}$ apresenta alguns conceitos básicos dos bancos de dados relacionais.

O Anexo D apresenta alguns dos conceitos básicos de análise, projeto e programação orientada a objetos.

O Anexo E apresenta alguns dos conceitos básicos da arquitetura de sistemas do tipo cliente/servidor, focando na aplicação deste trabalho.

O Anexo $\mathrm{F}$ apresenta os conceitos básicos do modelo computacional de máquinas de estados finitos. 


\section{CAPÍTULO 2 - REVISÃO BIBLIOGRÁFICA}

\subsection{Introdução}

Um dos objetivos de um sistema de apoio ao usuário de transporte é possibilitar que tal usuário encontre pelo menos uma alternativa satisfatória para seu deslocamento.

Entretanto, para que a informação apresentada seja considerada adequada, é necessário não só que ela esteja correta, mas também que o usuário a compreenda e, ao mesmo tempo, que atenda às suas necessidades. Falhando em qualquer um destes quesitos, um sistema de apoio ao usuário será ineficaz e dificilmente atingirá seu objetivo.

Para atender a estes requisitos, uma ampla variedade de temas foi pesquisada e, uma vez que a relação entre todos eles não é direta, a revisão bibliográfica será apresentada nas seções a seguir, onde cada tema é apresentado individualmente.

\subsection{Motivação e aspectos gerais do problema}

A existência dos problemas de transporte não é uma novidade, sendo que a maioria destes problemas pode ser associada ao crescimento dos sistemas de transporte, tendo este ocorrido de forma relativamente desordenada, ao longo do tempo (CAMARGO, 1993). Não sendo possível frear seu crescimento, sempre se buscou alternativas para mitigar os problemas de tais sistemas, mesmo no Brasil.

Apesar desta origem histórica, uma das maiores conseqüências deste crescimento desordenado surgiu apenas recentemente, na forma dos congestionamentos nas grandes cidades. 
Entretanto, não se pode associar este problema apenas ao crescimento desordenado da infra-estrutura de transporte, sendo possível observar uma relação entre o crescimento dos problemas de tráfego e o crescimento do uso do transporte particular individual. Tal relação é visível até mesmo no Brasil: com a estabilidade econômica atingida no país a partir da década de 1990, a população teve maior acesso a veículos próprios; ao mesmo tempo, problemas como os congestionamentos se intensificaram bastante (MARQUES, 1998), tornando necessárias medidas severas como a imposição do rodízio automotivo.

A preocupação com a evolução deste tipo de problema torna-se ainda maior diante do fato que a proporção das viagens motorizadas diárias realizadas por meio de transporte particular vem crescendo nos últimos anos. Assim, é de grande relevância criar meios para evitar que a proporção de viagens por meio de veículos particulares se amplie ainda mais (PADILHA, 1998 apud MARQUES, 1998).

Uma das alternativas para enfrentar o aumento de viagens realizadas por transporte particular individual é o aumento da atratividade do transporte público coletivo. Dentre as diversas maneiras de atingir tal objetivo, uma delas é a adoção de um sistema que vise a ampliar a acessibilidade dos usuários e potenciais usuários às informações sobre tal sistema de transporte (MARQUES, 1998).

Além de criar condições para que o usuário utilize corretamente o sistema de transportes, a disponibilização de informações permite que o usuário possa planejar suas viagens, proporcionando um alívio das ansiedades deste através da auxílio no controle de sua jornada (CAR; PELLS, 1995 apud MARQUES, 1998); (SILVA; LINDAU, 1997 apud MARQUES, 1998). Em outras palavras, é interessante para o usuário poder reduzir as incertezas de suas viagens, algo em que um adequado sistema de informações é ferramenta de grande importância. 
Devido a estes fatos, a maioria das empresas brasileiras de transportes que atuam nos grandes centros urbanos adota algum sistema de informações ao usuário, seja fornecendo informações por telefone ou por escrito em folhetos e placas (ANTP, 1997b apud MARQUES, 1998). Ainda que um sistema de apoio ao usuário não seja necessariamente eficaz em evitar uma queda de demanda, sua utilização denota a preocupação das empresas com relação a este tema.

Esta preocupação das empresas não tem apenas relação com a situação do tráfego, mas também com o fato que uma redução na demanda por transporte público pode torná-lo deficitário, exigindo um aumento da tarifa ou uma redução na qualidade do serviço. Com isso, é possível que o serviço se torne ainda pior sob o ponto de vista do usuário, que pode passar a considerar a tarifa ainda mais inadequada. A conseqüência é que o usuário passará a ter mais motivos para migrar para o transporte particular individual, formando um ciclo degenerativo do sistema de transporte público coletivo (STRAMBI, 1991).

Por outro lado, um crescimento da demanda por transporte público coletivo, em conjunto com a utilização eficiente e planejada deste sistema de transporte, permite que as empresas de transporte e o poder público possam reordená-lo, buscando redução de custos e ampliação do nível de serviço. Tal resultado é positivo, já que a redução do custo unitário da operação do transporte público coletivo é um dos objetivos de uma política tarifária adequada, tendendo a tornar o sistema mais eficiente e eficaz (GRAY, 1975 apud STRAMBI, 1991).

\subsection{O problema na literatura}

Paralelamente ao aumento de complexidade dos sistemas de transportes como um todo, também o sistema de transporte público coletivo tornou-se mais e mais complexo. Tal complexidade se manifesta em duas formas, sob o ponto de vista do 
usuário: nenhuma alternativa aparente para realizar sua viagem, ou, então, muitas alternativas com trajetos completamente distintos, tornando a escolha uma tarefa bastante complexa. São situações como estas que motivam a existência de sistemas de apoio ao usuário.

No entanto, os sistemas de apoio a usuários de transporte público pouco evoluíram até recentemente, quando diversos autores (CAR; PELLS, 1995 apud MARQUES); (SILVA; LINDAU, 1997 apud MARQUES, 1998); (MARQUES, 1998); (MCCORMACK, 1999); (TIMPF, 2002) passaram a pesquisar e contribuir para a evolução dos mesmos.

Mesmo assim, os avanços nesta área ainda são limitados, em decorrência da dificuldade representada pelo pequeno conhecimento que, em geral, o usuário comum possui sobre o sistema de transportes; insuficiente para interpretar as informações colocadas à sua disposição (TIMPF, 2002).

A dificuldade em interpretar informações, diante da falta de conhecimento, se torna crítica em situações de viagens não rotineiras, quando o usuário está ou pretende ir a um lugar pouco conhecido, uma vez que nestes casos o conhecimento do sistema pelo usuário tende a ser ainda menor (MARQUES, 1998).

Desta forma, um dos aspectos mais importantes num sistema de apoio ao usuário de transporte é sua eficácia na comunicação com o usuário, para que este seja capaz de compreender as informações que lhe são fornecidas, seja qual for o tipo de viagem a ser realizada, rotineira ou não (MARQUES, 1998).

Como uma forma de superar as dificuldades de comunicação com o usuário, alguns trabalhos (MARQUES, 1998); (MCCORMACK, 1999) propõem um sistema baseado na interação humana, através de consultas telefônicas. Nestes sistemas, o usuário liga para uma central de atendimento telefônico das empresas de transporte e 
pede a informação que deseja. $\mathrm{O}$ atendente, uma pessoa treinada para isso, consulta um sistema, baseado na plataforma TransCAD em conjunto com um Sistema de Informações Geográficas, interpreta o resultado e o transmite ao usuário. Tal sistema constitui um serviço similar ao fornecido pela SPTrans no município de São Paulo, informando linhas de ônibus que atendem às necessidades do usuário.

Um outro serviço oferecido pela SPTrans, atualmente disponível pela da internet (http://www.sptrans.com.br/, na seção itinerários, consultado em 11 de Abril de 2005), constitui-se de uma simples consulta a um banco de dados, com cruzamento de dados, não levando em conta nenhum fator que tenda a maximizar a qualidade ou minimizar o tempo de jornada do usuário. Além disso, este sistema específico apresenta uma solução muito pobre em termos de interface de comunicação com o usuário, que é bastante complexa e de difícil compreensão, possivelmente sendo inacessível à grande maioria dos usuários.

\subsection{Percepção da qualidade pelo usuário}

Quando existem diversas opções de transporte para realizar uma mesma viagem, uma das maneiras de compreender as escolhas modais realizadas pelos usuários é através da consideração do nível de serviço oferecido por cada modo de transporte.

Para avaliar o nível de serviço de um modo de transporte, é fundamental compreender e determinar quais são os fatores que influenciam a percepção do usuário, para que se leve em conta as medidas físicas e psicrométricas dos usuários do transporte coletivo (FARIA, 1985); (MARQUES, 1998).

É preciso também que a análise de nível de serviço também incorpore fatores exógenos ao próprio sistema de transporte público, como fatores sociais e financeiros 
(FARIA, 1991); (MARQUES, 1998), uma vez que a percepção de conforto pelo ser humano é advinda do tipo e quantidade de informações que recebe sobre o mundo (FARIA, 1991).

Tais fatores tornam complexa a avaliação do nível de serviço percebido pelo usuário apenas com variáveis objetivas, fazendo necessária uma cuidadosa consideração dos mesmos na resolução de problemas de transporte de passageiros, tornando-os distintos dos problemas de transporte de cargas, ainda que seja possível algum tipo de associação.

Com o objetivo de levar em conta o nível de serviço dos diferentes modos, as características influentes podem ser agrupadas em uma função de custo generalizado, onde as considerações sobre transbordo e tarifas fixas ou variáveis, por exemplo, também podem ser feitas (GIACAGLIA, 1993).

Assim, uma das maneiras de considerar o nível de serviço percebido pelo usuário é através consideração do custo generalizado, como o calculado pela form.(1), baseada naquelas existentes na literatura (NOVAES, 1986); (FARIA, 1985); (FARIA, 1991):

$$
\mathrm{CTGV}=\mathrm{TTGV} \times \mathrm{CT}
$$

Onde:

CTGV - Custo total generalizado de viagem

TTGV - Tempo total generalizado de viagem

CT - Custo monetário por unidade de tempo

Na form.(1), o TTGV é composto pela soma dos tempos percebidos pelo usuário em cada etapa da viagem e uma parcela de tempo que reflete o custo monetário da viagem. O tempo percebido é o tempo físico multiplicado por um fator que reflete a percepção do usuário, podendo ser considerada uma penalidade 
temporal para transferências. Tal fator tende a ser tão maior quanto mais desconfortável for o trecho da viagem ao qual o tempo se refere.

Pelo fato do Tempo Generalizado Total de Viagem ser proporcional ao Custo Generalizado Total de Viagem, ambos podem ser utilizados com a mesma finalidade. Em sistemas onde não são envolvidos custos monetários, pode ser mais interessante trabalhar com o Tempo Generalizado Total de Viagem, por ser possível eliminar facilmente a parcela relativa ao custo monetário deste, evitando lidar com a questão do custo do tempo dos usuários.

Maiores detalhes sobre a percepção do usuário e custo generalizado podem ser verificados no Anexo A.

\section{$\underline{\text { 2.5. Fluxo em rede e caminho mínimo }}$}

O problema de encontrar uma "melhor rota" para um usuário de transporte ir de um ponto a outro pode ser associado ao problema de encontrar um caminho mínimo. Quando a questão é resolver este tipo de problema, normalmente é possível definir uma modelagem matemática de equilíbrio de fluxo nos nós, visando a uma resolução por programação linear, usando-se o método Simplex (BRADLEY; HAX; MAGNANTI, 1977); (WINSTON, 1994).

Entretanto, para problemas com muitos nós e arcos, o método Simplex pode se tornar bastante ineficiente, ainda que eficaz. É por isso que, na pesquisa operacional, é comum a utilização de modelos matemáticos e algoritmos que tirem proveito de alguma característica especial do problema, para que soluções ótimas possam ser obtidas com um menor custo computacional e de tempo. 
Vários métodos e algoritmos já foram propostos como alternativa à solução direta pelo método Simplex, para problemas de fluxo em rede, desde algoritmos como o Network Simplex (BRADLEY; HAX; MAGNANTI,1977); (CHVATAL, 1983); (WINSTON, 1994) até heurísticas de inteligência artificial (RICH; KNIGHT, 1993).

Um outro algoritmo para problemas de fluxo em rede bastante conhecido é o Out-of-Kilter, que tem como principal objetivo a resolução de problemas capacitados de circulação em rede (GUALDA, 1975). Apesar de complexo, o algoritmo Out-of-Kilter é bastante flexível, já tendo sido utilizado inclusive para a solução de problemas de programação de veículos, com a aplicação de uma técnica de geração de arcos, onde a solução inicial é calculada para uma rede reduzida e posteriormente vão sendo adicionados arcos que venham a permitir melhorias na solução (SILVA, 2001).

Entretanto, o algoritmo mais comumente utilizado para resolução de problemas em que se busca o caminho mínimo é o chamado Label Setting (BRADLEY; HAX; MAGNANTI, 1977); (GALLO; PALLOTINO, 2003) ou sua variante, o Label Correcting. Este algoritmo, também denominado "Algoritmo de Dijkstra", é bastante eficiente para resolução de problemas não capacitados e proporciona a consideração de diversos fatores, através de modificações em suas operações de cálculo, como a consideração de janelas de tempo para planejamento de viagens multimodais (HORN, 2003) e até mesmo a consideração de variação do tempo de viagem utilizando-se lógica fuzzy (CHUANG; KUNG, 2003).

Apesar de sua grande flexibilidade, o sucesso do Algoritmo de Dijkstra depende bastante da modelagem utilizada para a rede na qual tais algoritmos serão aplicados. Uma das situações em que este algoritmo pode apresentar dificuldades é em problemas multimodais, com uma modelagem de rede clássica, onde os modos de transporte disponíveis de um nó a outro são meros atributos do arco. Em casos como 
este, surge a dificuldade em lidar com a questão de dominância de um modo de transporte sobre outro (HORN, 2003).

Uma das alternativas para solucionar parcialmente este problema é a realização de alterações no Algoritmo de Dijkstra, como a variação Dijkstra Forward (HORN, 2003). Outra alternativa é a adoção de artifícios de modelagem, como a utilização de arcos distintos para modos de transporte distintos, com ou sem geração de arcos de transferência de modo durante a solução (GUALDA, 1975); (GIACAGLIA, 1993); (SILVA, 2001).

Uma vez que a modelagem da rede tem relativa influência no desempenho do Algoritmo de Dijkstra, deve ser ainda maior a preocupação com a modelagem, caso seja utilizado este algoritmo. Tendo em vista esta necessidade, existem muitos benefícios em se realizar uma modelagem de rede orientada a objetos, em conjunto com um sistema gerenciador de banco de dados. Dentre estes benefícios destacam-se a flexibilidade de utilização e relativa facilidade na manutenção, quando comparada a outras formas de modelagem (GIACAGLIA, 1993).

Maiores detalhes sobre algumas das variações do Algoritmo de Dijkstra e modelagem de redes de transporte podem ser verificados no Anexo B.

\subsection{Projeto de sistemas}

O primeiro passo para o desenvolvimento de um sistema é uma análise dos requisitos do mesmo, seguido pela estruturação do sistema e projeto de implementação, e, finalmente, pelas etapas de implementação e teste.

Para a realização das etapas de estruturação e projeto de implementação, usualmente chamadas de "análise e projeto de sistema", existem basicamente duas 
diretrizes fundamentais de planejamento: a metodologia bottom-up e a metodologia top-down (YOURDON, 2005).

$\mathrm{Na}$ metodologia denominada bottom-up são definidos os detalhes de cada módulo e, posteriormente, como estes módulos serão integrados. Já na metodologia denominada top-down, o sistema é definido globalmente e, posteriormente, são definidos os detalhes de cada módulo que o compõe. A adoção de uma destas formas de projeto depende bastante do objetivo, forma de desenvolvimento do sistema, etc.

Em ambos os casos é possível tratar o problema de acordo com uma perspectiva funcional, em que os módulos são definidos de acordo com as funções que devem executar, ou pela perspectiva do fluxo de dados, em que os módulos são definidos de acordo com o tipo de processamento de dados a ser realizado (COAD; YOURDON, 1992). Apesar de clássicas, estas abordagens apresentam problemas na manutenção e extensão do projeto final, uma vez que sua estruturação é voltada à função do sistema: se esta função mudar, é possível que seja necessária também uma mudança completa na estrutura do sistema (JACOBSON et al., 1992).

Entretanto, existe uma terceira perspectiva para a definição da estrutura do sistema: é possível definí-lo de tal forma que cada componente individual represente um componente do problema a ser tratado, ou seja, modelar o sistema como um conjunto de objetos que interagem entre si. Esta abordagem é denominada modelagem orientada a objetos e o projeto que a utiliza é denominado projeto orientado a objetos (JACOBSON et al., 1992).

A modelagem orientada a objetos é mais flexível, facilitando a manutenção e a expansão do sistema, uma vez que os componentes do sistema são definidos de acordo com os objetos que fazem parte do mesmo, e não na forma como o problema em si é resolvido. Essa caraterística é positiva, uma vez que muitas vezes a função do sistema como um todo sofre alterações ao longo da sua vida útil, mas os elementos 
que são utilizados para cumprir esta função são relativamente mais estáveis (JACOBSON et al., 1992).

Assim, quando o objetivo é desenvolver um sistema complexo, de grande porte, possuindo um grande número de componentes, em especial quando existe a necessidade de garantir flexibilidade, possibilidades de expansão e facilidade de manutenção futura, um projeto orientado a objetos torna-se praticamente uma necessidade (COAD; YOURDON, 1992); (JACOBSON et al., 1992); (YOURDON; ARGILA, 1999).

Uma característica inerente ao projeto de sistema orientado a objetos é sua modularidade. Em outras palavras, seus componentes são relativamente estanques e, uma vez que as necessidades de interação com outros objetos seja respeitada, a estrutura interna de cada um de seus componentes é irrelevante para o funcionamento do sistema como um todo. Tal característica permite grande flexibilidade na implementação de cada componente e, ao mesmo tempo, garante o funcionamento adequado do sistema como um todo, facilitando também a divisão de tarefas em sua manutenção (COAD; YOURDON, 1992); (JACOBSON et al., 1992); (HOLZNER, 1995); (YOURDON; ARGILA, 1999).

Esta característica torna o projeto prévio, que descreve o funcionamento global do sistema e é resultado da análise de sistemas, semanticamente mais próximo do projeto de implementação, que descreve detalhes de implementação e é resultado da etapa de projeto de sistemas. Esta proximidade simplifica a tarefa de relacionar os componentes entre cada uma das fases de projeto. Tal facilidade é bastante interessante, uma vez que, normalmente, as etapas de análise e projeto possuem um grau de paralelismo e esta proximidade permite que ambas as equipes de análise e projeto trabalhem com documentações coerentes (JACOBSON et al., 1992). Além disso, expansões do sistema são, usualmente, planejadas com base no projeto prévio, e a similaridade semântica entre as documentações do projeto prévio e do projeto de 
implementação facilita a transposição das mudanças feitas em um deles para o outro (REICH, 1995).

Por outro lado, a flexibilidade de implementação de cada componente, garantida por um projeto orientado a objetos, também é importante para que cada componente seja, internamente, implementado na forma mais adequada à sua função. Componentes críticos quanto ao tempo de processamento devem ser desenvolvidos em uma linguagem compilada, enquanto outros meramente decorativos podem ser implementados em linguagens interpretadas, se, por exemplo, tal escolha for interessante (HOLZNER, 1995); (REICH, 1995).

Além da flexibilidade na escolha de linguagens de programação para cada componente, este "encapsulamento" também permite que diferentes modelos computacionais sejam adotados para o funcionamento de cada um destes componentes, de acordo com sua função, visando a um aumento de sua eficiência e eficácia. Assim, o modelo de orientação a eventos, baseado no modelo computacional das Máquinas de Estados Finitos, pode ser utilizado em módulos cuja função primordial é a interação com o usuário (YAO, 1995), enquanto a programação estruturada linear pode ser usado para módulos não-interativos de um sistema, seja ela baseada em múltiplas filas de execução ou não (REICH, 1995).

Entretanto, para uma especificação de componentes realmente eficientes, é preciso ir além dos modelos computacionais: é preciso também conhecer os ambientes e sistemas operacionais sobre os quais o sistema a ser desenvolvido irá operar. Esta necessidade se deve ao fato que, para obter maior desempenho, a implementação específica de cada módulo deve ser feita de forma a se utilizar de todos os recursos disponíveis em seu ambiente de operação (REICH, 1995).

Neste sentido, um cuidado adicional deve ser tomado no desenvolvimento de um sistema que tem como objetivo funcionar adequadamente no maior número de 
plataformas possível, ou seja, sistemas multiplataforma. Neste caso, a busca pela utilização do maior número de recursos possível ainda deve ser observada; entretanto, os recursos a serem considerados são apenas aqueles que estejam disponíveis na grande maioria dos ambientes e sistemas operacionais atuais (REICH, 1995). Diversos autores (SILBERCHATZ; GALVIN, 2000); (TANENBAUM, 2003b) listam a maior parte destes recursos, explicando com algum detalhe os mecanismos de funcionamento, vantagens e desvantagens de cada um destes, nos sistemas operacionais disponíveis atualmente.

Ainda com relação a sistemas multiplataforma, também não se deve utilizar recursos de hardware exclusivos de algum tipo de equipamento. Além disso, a troca de um código legível por um código complexo, visando à sua eficiência em um equipamento específico, se justifica apenas nos trechos mais críticos da implementação, sendo inadequado abandonar a portabilidade (YOURDON; ARGILA, 1999); (HYDE, 2003).

Dada a grande quantidade de detalhes a serem observados nas etapas de análise e projeto de sistemas, não é incomum que elas sejam negligenciadas. É exatamente pela grande quantidade de detalhes a serem observados que as etapas de projeto do sistema devem ser realizadas com extremo cuidado; a falha em fazê-lo pode ocasionar a necessidade de redesenho de todo o sistema, muitas vezes implicando a necessidade de reprogramação de grandes trechos do software. Assim, é adequado que a maior parte do tempo do ciclo de desenvolvimento de um sistema seja voltada para sua análise e projeto, evitando ao máximo a necessidade de reprojeto e reimplementação (REICH, 1995).

Maiores detalhes sobre os projeto de sistemas orientados a objetos, programação orientada a objetos, bem como bibliografia complementar, podem ser verificados no Anexo D. Maiores detalhes sobre modelos de Orientação a Eventos e 
Máquinas de Estados Finitos, bem como bibliografia complementar sobre modelos computacionais, podem ser verificados no Anexo F.

\subsection{Sistemas de Banco de Dados}

Sempre que um sistema tem a necessidade de manipular uma quantidade grande de informações e estas informações devem ser acessadas por diferentes componentes do sistema, desenvolvidos pela mesma equipe ou não, é interessante a utilização de um Sistema Gerenciador de Banco de Dados Relacionais (SGBD-R), onde as informações são armazenadas como relações (BUTZEN; FORBES, 1997).

$\mathrm{O}$ armazenamento das informações na forma de relações permite que elas sejam consultadas de forma sistemática, independente da estrutura física (interna) de armazenamento dos dados. Esta é uma característica de grande valia, uma vez que o SGBD-R acaba se tornando apenas mais um componente do sistema, cuja interface de comunicação com outros componentes do sistema é a linguagem de consulta do SGBD-R (BUTZEN; FORBES, 1997), associada à sua estrutura lógica de armazenamento dos dados.

Uma vez que a estrutura lógica de armazenamento tem influência no protocolo de comunicação do componente banco de dados com outros componentes do sistema, a estrutura lógica merece cuidado, em especial se o banco de dados possuir diferentes usos. Isto ocorre quando o SGBD-R é utilizado, por exemplo, por diversos níveis decisórios dentro de um mesmo órgão administrativo. Embora esta interoperabilidade de um banco de dados não seja comum nos dias atuais, ela é desejável e benéfica, pois tende a aumentar a consistência das informações (GIACAGLIA, 1998). 
Assim, é interessante que a estruturação lógica dos dados dentro do SGBD-R seja definida de forma a garantir a flexibilidade de manipulação das informações (GIACAGLIA, 1998). Para que isso seja conseguido, a estruturação lógica dos dados deve ser baseada em uma lógica própria, independente da sua lógica de utilização tanto quanto possível, desde que isso não cause um grande impacto negativo na eficiência e eficácia do sistema. Uma estrutura lógica de dados baseada na lógica das informações armazenadas, ao invés de baseada na lógica de uso, torna o banco de dados mais flexível (BUTZEN; FORBES, 1997), facilitando a utilização dos dados para funções não previstas inicialmente e contribuindo com a flexibilidade do sistema como um todo. Esta possibilidade de uso das informações para outras aplicações é especialmente interessante em grandes bancos de dados, dado seu alto custo de implementação.

Em bancos de dados não-relacionais, a manutenção e o uso para outras aplicações são complexos e, muitas vezes, inviáveis, uma vez que nestes casos as consultas aos dados dependem de sua estrutura física de armazenamento e alterações em tal estrutura usualmente implicam modificações na estrutura lógica dos dados. O impacto disto é uma conseqüente modificação no protocolo de comunicação deste componente com os outros do sistema, exigindo modificações em todos os software que se utilizam deste banco de dados (BUTZEN; FORBES, 1997), limitando assim sua utilidade.

Em outras palavras, os SGBD-Rs, por permitirem que alguns tipos de modificações sejam feitos na estrutura física de armazenamento dos dados sem que isso cause alterações na estrutura lógica das informações, evitam que sejam necessárias mudanças constantes nos componentes que se utilizem do banco de dados. Como conseqüência, quanto melhor planejada for a estrutura lógica do banco de dados relacional, menor a necessidade de manutenção dos componentes que se utilizam deste banco de dados (BUTZEN; FORBES, 1997). 
Mas os cuidados no projeto da estruturação lógica do armazenamento do banco de dados vão além da flexibilidade, uma vez que tal estruturação tem grande impacto na eficiência do SGBD-R. Assim, a necessidade de flexibilidade deve ser balanceada com a necessidade de eficiência, buscando uma organização lógica que facilite a obtenção de informações que precisem ser extraídas com maior freqüência (BUTZEN; FORBES, 1997).

Com relação à eficiência, também os elementos de estruturação física do SGBD-R merecem atenção especial. Mesmo sendo transparentes para os componentes do sistema, definições de tipos de relações e listas de indexação, dentre outras, possuem forte influência no desempenho do SGBD-R e, portanto, não devem ser feitas sem uma cuidadosa análise da utilização dos dados (BUTZEN; FORBES, 1997).

Maiores detalhes sobre bancos de dados, bancos de dados relacionais e bibliografia complementar podem ser verificados no Anexo C.

\subsection{Arquitetura de sistemas}

Num sistema computacional, tão importante quanto seus componentes e sua estrutura interna é a sua arquitetura. $\mathrm{Na}$ realidade, é a arquitetura que define, em geral, grande parte do funcionamento do sistema, sendo que seus componentes são fortemente influenciados por ela. Neste caso, arquitetura refere-se ao conjunto de conceitos e tecnologias nos quais o sistema é baseado (JACOBSON et al., 1992).

Com relação à distribuição física do processamento, a arquitetura de um sistema pode definí-lo como um sistema de processamento centralizado ou um sistema de processamento distribuído. (SILBERCHATZ; GALVIN, 2000). 
Um sistema de processamento centralizado é aquele em que todo o processamento é realizado em um único equipamento, em especial, por um único processador. Um sistema de processamento distribuído, por sua vez, é aquele em que o processamento é realizado em diversas unidades de processamento distintas, estejam no mesmo equipamento ou não (WIKIPEDIA, 2005b).

Quando um sistema é composto por um único módulo ou um pequeno número de componentes de demandas similares e não concorrentes, a implementação mais usual é a de processamento centralizado, economizando recursos sem comprometer o funcionamento do sistema. Por outro lado, quando existe a possibilidade de concorrência de processamento de módulos diferentes e o desempenho é uma condição fundamental, uma arquitetura distribuída usualmente se mostra mais adequada, em especial se o volume de troca de informações entre os diversos módulos é pequena.

Quando os componentes de um sistema possuem demandas similares, é usual a utilização de clusters, que são conjuntos de computadores interconectados para realizar as operações paralelamente. Entretanto, se os componentes de um sistema possuem grandes diferenças quanto às demandas por recursos computacionais, uma arquitetura de processamento distribuído do tipo cliente-servidor se mostra mais adequada. A utilização de uma arquitetura multi-tier, um tipo específico de arquitetura cliente-servidor, permite que cada componente do sistema possa ser executado em um equipamento mais adaptado às suas necessidades por recursos específicos, sendo este tipo de arquitetura muito comum na estruturação de serviços da internet (WIKIPEDIA, 2005b).

A distribuição de tarefas entre várias unidades de processamento em um mesmo equipamento, o multiprocessamento simétrico, é uma forma relativamente comum de processamento distribuído. Este recurso é suportado por uma grande variedade de sistemas operacionais atuais como Linux, Windows NT, MacOS X, 
BeOS, OS/2, etc. (WIKIPEDIA, 2005b), sendo seu uso automático em implementações com múltiplas linhas de execução (multi-threaded) ou com múltiplos processos (multi-process).

Por outro lado, apesar de alguns sistemas operacionais disponibilizarem processamento distribuído em diversos equipamentos de forma transparente (SILBERCHATZ; GALVIN, 2000), esta não é uma característica comum nos sistemas operacionais atuais. No entanto, este tipo de processamento distribuído pode ser alcançado em praticamente qualquer sistema atual com uma implementação baseada na arquitetura cliente-servidor multi-tier (SILBERCHATZ; GALVIN, 2000); (WIKIPEDIA, 2005d) utilizando uma estrutura de comunicação em rede, permitindo não só o uso de qualquer sistema operacional, mas também a interoperabilidade de equipamentos e sistemas operacionais diferentes, desde que se utilizem um mesmo protocolo de comunicação (TANENBAUM, 2003a).

Maiores detalhes arquitetura cliente-servidor, bem como bibliografia complementar sobre arquitetura de sistemas, podem ser verificados no Anexo E.

\subsection{Conclusões do capítulo}

Observando a evolução histórica do crescente problema dos congestionamentos e considerando a influência, neste processo, da migração do usuário de transporte coletivo para o particular, são bastante desejáveis alternativas que tornem o transporte coletivo mais atraente, mais eficiente e eficaz do ponto de vista do usuário. Neste sentido, um sistema de apoio ao usuário pode ser positivo, embora não como uma medida isolada.

A utilidade de um sistema de informações deste tipo fica aparente não apenas pela complexidade das decisões para a determinação do caminho, mas também pela 
existência prática deste tipo de sistema de informação. Entretanto, os sistemas existentes são, via de regra, pouco interativos (centrais de atendimentos) ou não possuem interatividade alguma (folhetos, mapas, guias impressos, etc.). No primeiro caso o usuário pode não se sentir confortável com a solução, por não participar ativamente do processo decisório; no outro caso, o usuário é ativo na tomada de decisões, mas nem sempre possui condições de avaliar as informações que estão disponíveis.

Assim, é pertinente o desenvolvimento de um sistema de apoio ao usuário de transporte coletivo que não só encontre soluções ótimas, mas também que permita ao usuário comum planejar sua jornada ativamente, sem necessitar do auxílio técnico. Além disso, se o sistema visa à obtenção de soluções ótimas do ponto de vista do usuário, situação em que a consideração apenas do tempo físico ou do desembolso monetário pode não ser a mais adequada, é interessante considerar, conjuntamente, os tempos e custos percebidos pelo usuário.

A literatura apresenta diversos algoritmos para a resolução de problemas de fluxo em rede e, para problemas específicos de caminho mínimo entre dois pontos, os algoritmos mais utilizados são Label Setting e Label Correcting. Além de eficientes e eficazes, tais algoritmos permitem a implementação de funções de custo genéricas, permitindo a consideração de custo e tempo generalizados, que levam em conta a percepção do usuário, adequando-se aos propósitos pretendidos por este trabalho.

Partindo do pressuposto que tais algoritmos e considerações sejam suficientes para resolver o problema de cada usuário, atendendo às suas necessidades atuais, é interessante que o sistema tenha flexibilidade, de forma a garantir sua expansibilidade e manutibilidade. Tais condições conduzem em direção a uma implementação modular, sugerindo a realização de um projeto orientado a objetos. 
A consideração de uma implementação modular e da necessidade do sistema proposto de ter acesso às informações sobre o sistema de transporte conduzem à definição de um componente que mantenha todas as informações relativas a este sistema de transporte. Além disso, é interessante que este componente proporcione facilidade de manutenção dos dados, bem como uma relativa flexibilidade no uso dos mesmos. Tais considerações tornam a adoção de um sistema gerenciador de banco de dados relacionais atraente e em consonância com os objetivos do sistema pretendido.

Finalmente, as vantagens de uma arquitetura de implementação to tipo cliente-servidor (multi-tier) aparecem de acordo com as necessidades do sistema, permitindo que ele venha a ser disponibilizado ao usuário por diversos meios (internet, telefones celulares, quiosques, etc.). Além disso, tal arquitetura traz uma flexibilidade à estrutura física do sistema, permitindo um melhor aproveitamento de recursos, reduzindo os custos de implantação. 


\section{CAPÍTULO 3 - METODOLOGIA}

\subsection{Introdução}

Neste capítulo são apresentadas a metodologia e as diretrizes da estrutura do sistema proposto, ambas calcadas em recomendações dos diversos trabalhos da pesquisa bibliográfica realizada.

Tal estruturação, apresentada a partir da seção 3.3, foi definida segundo o enfoque sistêmico (CHURCHMAN, 1972), respeitando também as recomendações da análise e projeto orientados a objetos (JACOBSON et al., 1992). Por esta razão, este capítulo introduz também uma descrição mais detalhada de cada um dos módulos do sistema, explicitando seus objetivos e a interação entre cada um deles.

O processo de pesquisa-análise-projeto-implementação não foi, entretanto, do tipo "cascata" (JACOBSON et al., 1992), sendo que houve algumas iterações entre estas etapas. Assim, para facilitar a compreensão de desenvolvimento e processo metodológico, é apresentado o fluxograma da figura 3.1, que tem por objetivo apresentar toda a seqüência de etapas do desenvolvimento deste trabalho.

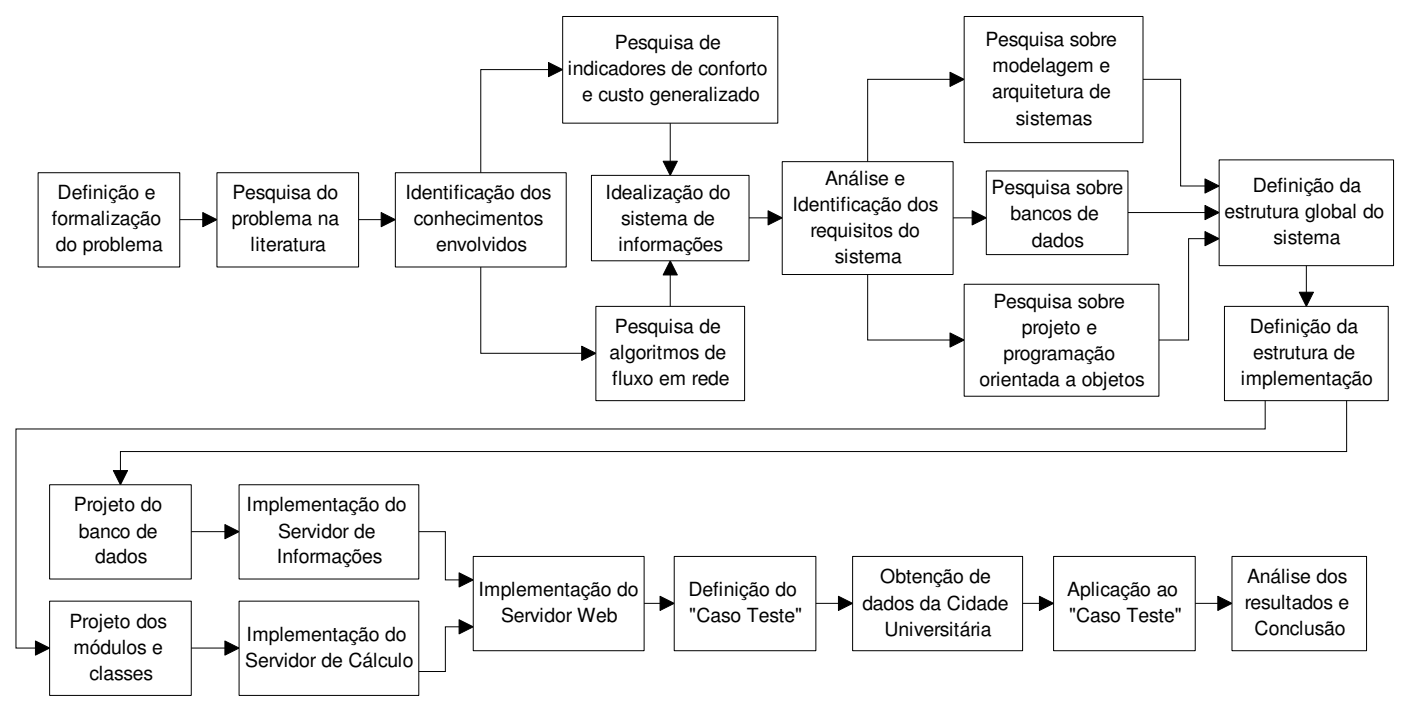

Fig. 3.1 - Etapas do desenvolvimento e implementação do sistema 
Resumidamente, a metodologia de implementação pode ser descrita nas seguintes etapas:

- Análise dos requisitos de sistema.

- Estruturação global.

- Detalhamento dos componentes.

- Implementação, aplicação e teste.

As três primeiras etapas serão descritas com detalhes nas seções seguintes e a última será detalhada no capítulo 4, sendo que o objetivo deste capítulo é apresentar as premissas e informações necessárias para a implementação do sistema com sucesso. Informações de análise e projeto mais detalhadas serão apresentadas quando pertinente.

\subsection{Requisitos do sistema}

A primeira etapa de desenvolvimento de qualquer sistema deve ser, necessariamente, a compreensão das atividades e funções que o mesmo deve atender. Para que isto seja possível, é fundamental explicitar quais são os requisitos deste sistema (JACOBSON et al., 1992).

Tais requisitos não só servirão para nortear todas as outras etapas do desenvolvimento, mas também para que seja possível, ao fim do processo, avaliar até que ponto o sistema atingiu seus objetivos que, neste caso específico, são: informar ao usuário satisfatoriamente e obter informações sobre as consultas realizadas pelos usuários que possam contribuir para a melhoria do sistema de transportes em questão. 


\subsubsection{Requisitos de "usabilidade"}

Como o sistema proposto é um sistema de apoio ao usuário, os requisitos mais importantes são aqueles que garantem que o sistema seja eficaz em sua comunicação com o usuário, atendendo à sua função primordial. Tais requisitos são denominados requisitos de "usabilidade" e foram definidos como:

- Ser rápido para possibilitar a consulta em tempo real. Um tempo de resposta de até 10 s, após o fim da coleta de dados com o usuário, foi adotado como aceitável.

- Ser eficaz, fornecendo soluções adequadas para que o usuário fique satisfeito com a informação que lhe for apresentada.

- Ser de operação simples, para maximizar o número de usuários que possam se beneficiar do sistema.

- Fornecer trajetos em linguagem simples, que contenham as informações necessárias para a realização dos transbordos nos locais adequados.

- Possibilitar a geração de várias alternativas de trajeto, permitindo ao usuário escolher a que melhor se adapta ao seu perfil.

- Fornecer informações de apoio à decisão do usuário, como o tempo real da viagem, custo de viagem, etc.

- Estar disponível, ou seja, é preciso que o sistema seja acessível, por meio de serviços de internet, quiosques, telefones celulares, etc.

\subsubsection{Requisitos para avaliação do sistema de transportes}

É desejável que um sistema deste tipo possua outras funções e utilidades, além da função primordial de informar ao usuário. Com esta finalidade, foram definidos requisitos que proporcionem a formação de bancos de dados e ferramentas de análise estatística, com os quais seja possível obter informações para compreender melhor os seus usuários e suas necessidades. 
Tais informações visam permitir que os órgãos administrativos do sistema de transportes possam avaliar o sistema sob o ponto de vista do usuário, fornecendo subsídios para a melhora de sua funcionalidade. Os requisitos foram assim definidos:

- Registrar as buscas realizadas pelos usuários, armazenando informações sobre as viagens pesquisadas.

- Ser expansível, para possibilitar a criação de módulos adicionais, como um gerador de rotas personalizadas, que levem em conta características individuais da viagem e do usuário (viagem a trabalho, usuário deficiente, etc.), permitindo a coleta de informações detalhadas dos usuários, bem como suas preferências.

\section{$\underline{\text { 3.3. Estruturação global do sistema }}$}

De acordo com a metodologia top-down, as características necessárias aos componentes do sistema tornam-se mais claras quando é definida a estrutura global deste sistema, sendo que tal estrutura deve ser planejada com base nos requisitos de sistema propostos.

Com base no requisito de disponibilidade, tendo em mente os custos de implantação do serviço, o modelo adotado para a estruturação global do sistema foi o de sistema distribuído através de uma rede de comunicação por pacotes de dados (TANENBAUM, 2003a).

A estruturação dos componentes deste sistema distribuído será baseada nos modelos orientados a objeto (COAD; YOURDON, 1992); (YOURDON; ARGILA, 1999), visando não só a melhores condições de implementação, mas também a cumprir o requisito de expansibilidade do sistema (JACOBSON et al., 1992). 
Seguindo as recomendações de uma modelagem orientada a objetos, é necessário considerar, na determinação dos componentes, as características específicas do problema a ser resolvido (COAD; YOURDON, 1992); (JACOBSON et al., 1992); (YOURDON; ARGILA, 1999). É importante então, mais uma vez, ressaltar que o problema apresentado neste estudo é o de informar ao usuário a melhor alternativa de rota para um dado deslocamento em um sistema de transporte, permitindo também que o usuário explore outras alternativas.

Para atender a estas funções, o sistema deve contar com um repositório de dados, onde ficarão armazenadas as informações do sistema de transporte como um todo, e um subsistema de cálculo de rotas. Considerando que um repositório de dados que represente um rede de transportes recebe, relativamente, bem mais atualizações que um subsistema de cálculo, além do fato de que os requisitos de processamento de um repositório de dados são bastante distintos dos requisitos de um subsistema de cálculo, torna-se interessante a adoção de dois componentes independentes: um para o armazenamento de dados e outro para cálculo.

Entretanto, apenas estes componentes não são suficientes. Considerando como premissa que o principal objetivo do sistema é informar ao usuário, um dos pilares de sua operação é a interação com esse usuário. Assim, não basta ter componentes que produzam a informação necessária: a interação com o usuário também precisa ocorrer da melhor forma possível, para que o software proposto atinja seus objetivos de forma plena.

Para que a interação com o usuário tenha sucesso, partindo do pressuposto que o usuário comum pode ter pouca ou nenhuma familiaridade com a estrutura e o funcionamento do sistema de transporte disponível (TIMPF, 2002), é importante que o fornecimento de dados pelos usuários seja tão simples quanto possível. Além disso, 
as alternativas de soluções apresentadas ao usuário devem ser compatíveis com os conhecimentos necessários à entrada de dados.

Esta é uma preocupação importante, uma vez que é neste ponto que outros software especialistas, como o EMME/2 e o TransCAD (MARQUES, 1998), falham como um sistema de informações voltado ao público geral. Tais software podem ser programados para realizar o cálculo de caminhos mínimos, entretanto seu uso é direcionado ao público técnico, ou seja, exigem uma grande quantidade de informações e conhecimentos especializados para que algum resultado seja obtido e, posteriormente, interpretado.

A grande importância da comunicação com o usuário sugere que exista um componente especial para realizar esta tarefa, em especial porque a interface com o usuário é uma das partes do sistema que mais sofre alterações (JACOBSON et al., 1992); (REICH, 1995).

Uma vez que tanto o componente de cálculo quanto o componente de comunicação com o usuário precisam ter acesso às informações do sistema, a existência de um componente que armazena as informações do sistema acaba trazendo um novo benefício: elimina a redundância de informações, facilitando a manutenção.

De acordo com as informações apresentadas acima, os três módulos básicos propostos para a estruturação do sistema distribuído são:

- Servidor de Informações

- Servidor de Cálculo

- Terminal de Consulta 
Estes módulos se relacionam segundo o modelo de arquitetura apresentado no Anexo E, do tipo multi-tier (cliente-servidor), que pode ser visto na figura 3.2, onde as setas indicam a direção em que os dados fluem entre cada um dos módulos.

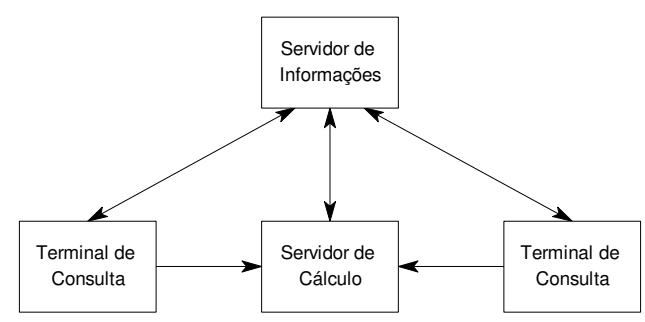

Fig. 3.2 - Um modelo genérico de arquitetura para um sistema de informações ao usuário

Nesta estruturação, o Servidor de Informações tem como função prover dados para os outros módulos, o que torna natural a definição deste módulo como um servidor de banco de dados, cujas principais características e vantagens são apresentadas no Anexo C. Neste servidor de banco de dados estarão contidas todas as informações necessárias aos cálculos e à interação com o usuário, como por exemplo as informações sobre o arruamento do sistema, modos de transporte disponíveis, etc. Este servidor estará disponível para consulta tanto para o Servidor de Cálculo quanto para o Terminal de Consulta. A estrutura e o funcionamento do Servidor de Informações serão detalhados na seção 3.4.

O Servidor de Cálculo tem como finalidade realizar os cálculos para determinar o(s) caminho(s) mínimo(s) entre os pontos de início e fim da viagem desejada pelo usuário. Sua operação será baseada nas informações fornecidas pelo Servidor de Informações e dados fornecidos pelo usuário através do Terminal de Consulta, sendo estas informações as bases para a configuração da rede com os diversos modos de transporte possíveis. Tal rede será então utilizada na obtenção da solução, a qual será repassada para o Terminal de Consulta para apresentação ao usuário. A estrutura e o funcionamento do Servidor de Cálculo serão detalhados na seção 3.5 . 
O Terminal de Consulta será utilizado pelo usuário para fornecer os dados de entrada a serem enviados para o Servidor de Cálculo, além de apresentar a solução calculada pelo Servidor de Cálculo. O Terminal de Consulta deve usar também o Servidor de Informações para transformar a resposta obtida pelo Servidor de Cálculo em informações claras para o usuário. Maiores detalhes sobre o Terminal de Consulta serão apresentados na seção 3.7 .

Visando a atender ao requisito de disponibilidade, a implementação pretendida para este trabalho usará uma interface web (web-service), de forma que ele seja acessível a qualquer equipamento que possua acesso à internet e à world wide web. Desta forma, há a necessidade de adaptar a estrutura apresentada, surgindo a necessidade de se criar um Servidor Web que, por simplicidade de implementação, será um serviço executado no mesmo equipamento que o Servidor de Cálculo.

Considerando estas características, a arquitetura de implementação proposta está representada pelo diagrama da figura 3.3, onde mais uma vez as setas indicam o fluxo de dados entre os módulos.

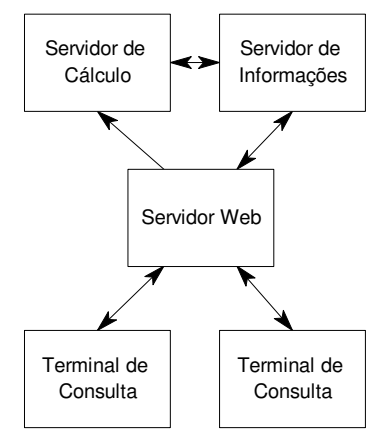

Fig. 3.3 - Arquitetura proposta para o sistema

Nesta nova estrutura, o Servidor Web terá a função de conectar o Terminal de Consulta com os Servidores de Cálculo e de Informações, ajustando as entradas do usuário para que elas sejam utilizadas pelo Servidor de Cálculo e seus dados de saída, 
para que eles possam ser visualizados pelo usuário de forma conveniente. Vale ressaltar que será considerado conveniente que o sistema possa ser adaptado para a execução do Servidor Web em uma máquina diferente do Servidor de Cálculo, podendo até mesmo vir a ser executado no próprio Terminal de Consulta. A estrutura e o funcionamento do Servidor Web serão detalhados na seção 3.6.

As seções seguintes fornecerão mais detalhes sobre cada um dos módulos, já introduzindo detalhes de implementação dentro das necessidades do modelo global proposto.

\subsection{O Servidor de Informações}

O Servidor de Informações é um módulo que terá como principal objetivo armazenar informações sobre o arruamento e as opções de transporte disponíveis neste arruamento, bem como armazenar informações que auxiliem na identificação de locais de origem e destino pelos usuários do sistema. É importante definir que arruamento, neste caso, refere-se a uma descrição de todos os caminhos pelos quais é possível transitar por algum meio de transporte ou mesmo a pé. Este arruamento é definido por nós (pontos de interseção entre os caminhos ou de importância para referência) e arcos que indicam as conexões entre tais nós, ditando os deslocamentos efetivamente possíveis.

O Servidor de Informações será um Servidor de Banco de Dados, acessado tanto pelo Servidor de Cálculo quanto pelo Servidor Web, contendo todas as informações necessárias para descrever o sistema de transportes para o cálculo de soluções e para a interação com o usuário.

Devido às restrições de tempo, será adotado para desenvolvimento e teste um sistema de transporte de pequeno porte. Considerando esta condição, o Sistema 
Gerenciador de Banco de Dados (SGBD) escolhido é o MySQL, pela sua facilidade de operação e interação com $\mathrm{C} / \mathrm{C}++$ e linguagens de interface do Servidor Web. Também tornou-se importante na escolha o fato de este ser um produto de código e uso livre para fins não comerciais, bem como sua compatibilidade com o padrão ANSI-SQL, garantindo a portabilidade de informações para outros SGBDs no futuro, se necessário.

Detalhes sobre o SGBD MySQL podem ser obtidos no site oficial do projeto MySQL (http://dev.mysql.com/, consultado em 13 de Abril de 2005). Maiores esclarecimentos sobre o significado e a importância dos software livres (Free Software) podem ser obtidos no site oficial da Free Software Foundation na internet (http://www.fsf.org, consultado em 13 de Abril de 2005), onde podem ser verificadas algumas das diretrizes filosóficas que nortearam várias das alternativas adotadas neste trabalho.

Considerando-se que o banco de dados conterá apenas centenas ou milhares de tuplas, também deverá ser possível simplificar a implementação do sistema executando o SGBD no mesmo equipamento do Servidor de Cálculo. Para sistemas de transporte maiores, entretanto, poderá se tornar inadequado o uso do mesmo equipamento para ambas as funções, uma vez que as exigências do SGBD podem se tornar especialmente altas, perturbando o desempenho do Servidor de Cálculo.

Uma outra possibilidade, para o caso de grandes sistemas de transporte, é a adoção de um SGBD mais robusto como mSQL, DB/2 ou mesmo Oracle. Em conjunto com a adoção de um servidor dedicado para o SGBD, tal alternativa é especialmente recomendada no caso de grandes demandas de consulta, com numerosos acessos simultâneos. Há sites na internet (WIKIPEDIA, 2005a) que apresentam diversas informações comparativas entre os diversos tipos e sistemas gerenciadores de bancos de dados. 


\subsubsection{Informações para composição da rede}

Para garantir que o banco de dados atenda às necessidades do sistema de informações pretendido sejam atendidas, foi desenvolvido o Diagrama Entidade-Relacionamento (DER) apresentado na figura 3.4 (CHEN, 1976 apud ELMASRI; NAVATHE, 1994). Tal modelo apresenta as entidades envolvidas na descrição de uma rede de transportes, visando a uma posterior implementação em um banco de dados relacional.

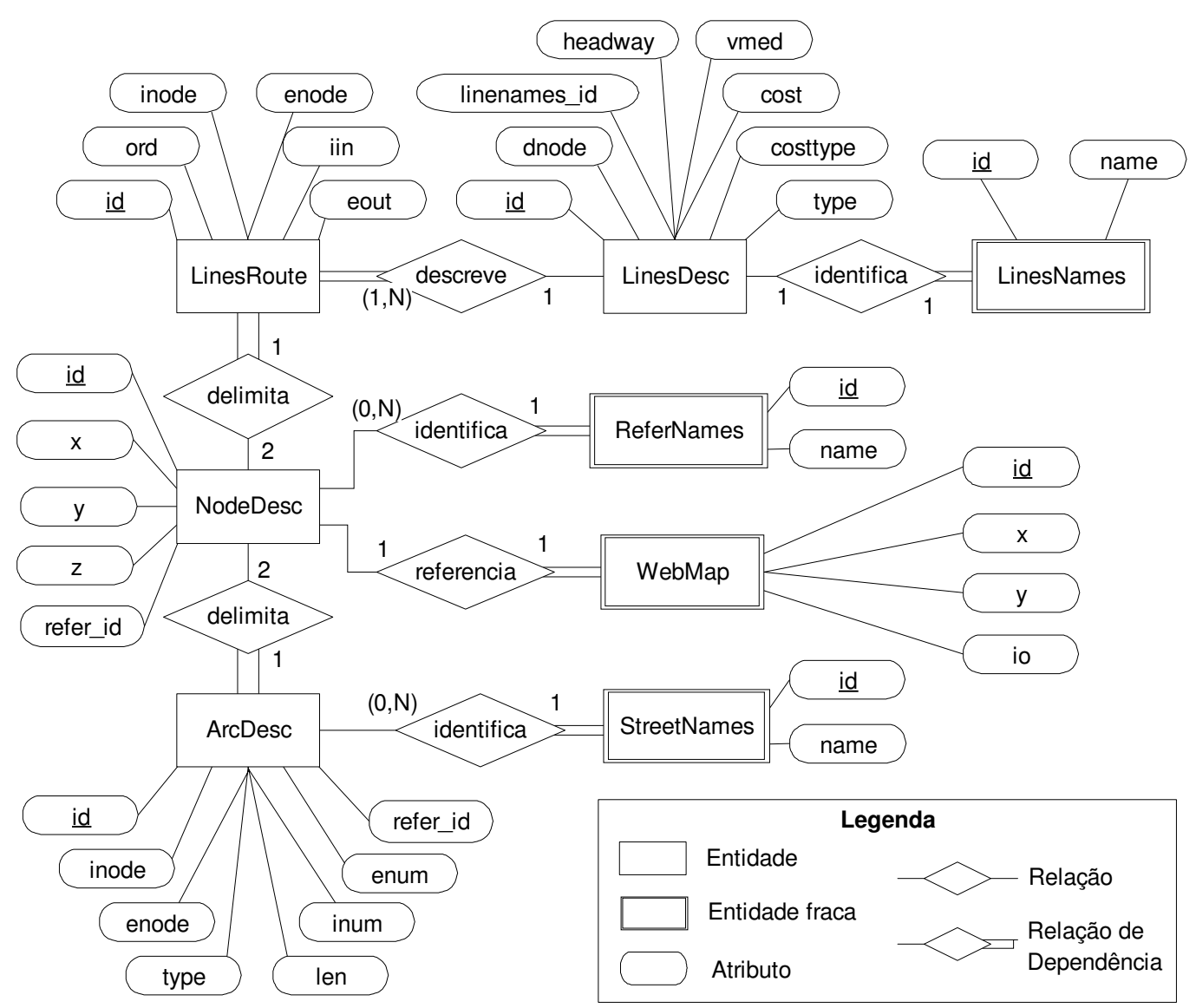

Fig. 3.4 - Diagrama Entidade-Relacionamento do Banco de Dados do Servidor de Informações

Neste DER, as relações principais são as de nomes LinesDesc, LinesRoute, ArcsDesc e NodeDesc. NodeDesc situa espacialmente todos os nós e ArcsDesc descreve todos os arcos disponíveis na rede, para algum tipo de tráfego. LinesDesc 
descreve as linhas de transporte existentes e LinesRoute indica cada um dos arcos ocupados por cada uma destas linhas.

Como relações complementares existem StreetNames, WebMap, ReferNames, LineNames. StreetNames, ReferNames e LineNames meramente associam nomes às entidades definidas nas relações principais e WebMap associa os nós a uma posição em um mapa qualquer, sem a necessidade de georreferenciamento.

As relações apresentadas no diagrama estão melhor detalhadas a seguir e a função de algumas delas serão também explicitadas nas seções seguintes.

\section{$\underline{\operatorname{ArcDesc}}$}

$I D$ : Identificação do arco (segmento de logradouro). Chave Primária.

INODE: Nó inicial do arco. Chave Estrangeira.

ENODE: Nó final do arco. Chave Estrangeira.

TYPE: Tipo de arco (direção e modos básicos).

$L E N$ : Comprimento do arco.

INUM: Número do logradouro no ponto do INODE.

ENUM: Número do logradouro no ponto do ENODE.

STREETNAME_ID: Identificação do nome de logradouro. Chave Estrangeira.

\section{NodeDesc}

ID: Identificação do nó (ponto de referência). Chave Primária.

$X$ : Posição X no espaço definido para solução da rede.

$Y$ : Posição Y no espaço definido para solução da rede.

$Z$ : Posição $\mathrm{Z}$ no espaço definido para solução da rede.

REFER_ID: Identificação do nome de referência. Chave Estrangeira. 


\section{LinesDesc}

ID: Identificação da Linha de Transporte. Chave Primária.

$D N O D E$ : Número de nó inicial para a linha.

LINENAME_ID: Identificação do nome de linha. Chave Estrangeira.

HEADWAY: Tempo entre a passagem de dois veículos da linha, em minutos.

$V M E D$ : Velocidade média dos veículos da linha, em quilômetros por hora.

COST: Custo monetário para o usuário do veículo.

COSTTYPE: Tipo de custo (tipos de tarifas do trecho).

TYPE: Tipo de modo de transporte.

\section{$\underline{\text { LinesRoute }}$}

ID: Identificação da linha de transporte. Chave Estrangeira. Chave Primária com em composição com ORD.

$O R D$ : Numero de ordem (seqüência) do arco da linha.

INODE: Nó inicial do arco da linha de transporte. Chave Estrangeira.

ENODE: Nó final do arco da linha de transporte. Chave Estrangeira.

IIN: Define se o nó inícial é um ponto de subida na linha de transporte.

EOUT: Define se o nó final é um ponto de descida na linha de transporte.

\section{WebMap}

ID: Identificação do nó. Chave Estrangeira.

$X$ : Posição $\mathrm{X}$ do nó no mapa.

Y: Posição Y do nó no mapa.

$I O$ : Indica se o nó é ponto de entrada/saída da rede.

\section{ReferNames}

ID: Identificação do ponto de referência. Chave Primária.

NAME: Nome do ponto de referência.

\section{StreetNames}

ID: Identificação do logradouro. Chave Primária.

NAME: Nome do logradouro. 


\section{LineNames}

ID: Identificação da linha de transporte.

NAME: Nome da linha de transporte.

\subsubsection{Armazenamento de soluções}

Com o objetivo de fornecer informações para o órgão gestor do sistema de transporte, o Sistema de Informações deve, também, armazenar informações sobre as consultas realizadas, criando assim um repositório de dados. Com esta finalidade, também foi desenvolvido o diagrama apresentado na figura 3.5, definindo as entidades e atributos a serem armazenados.

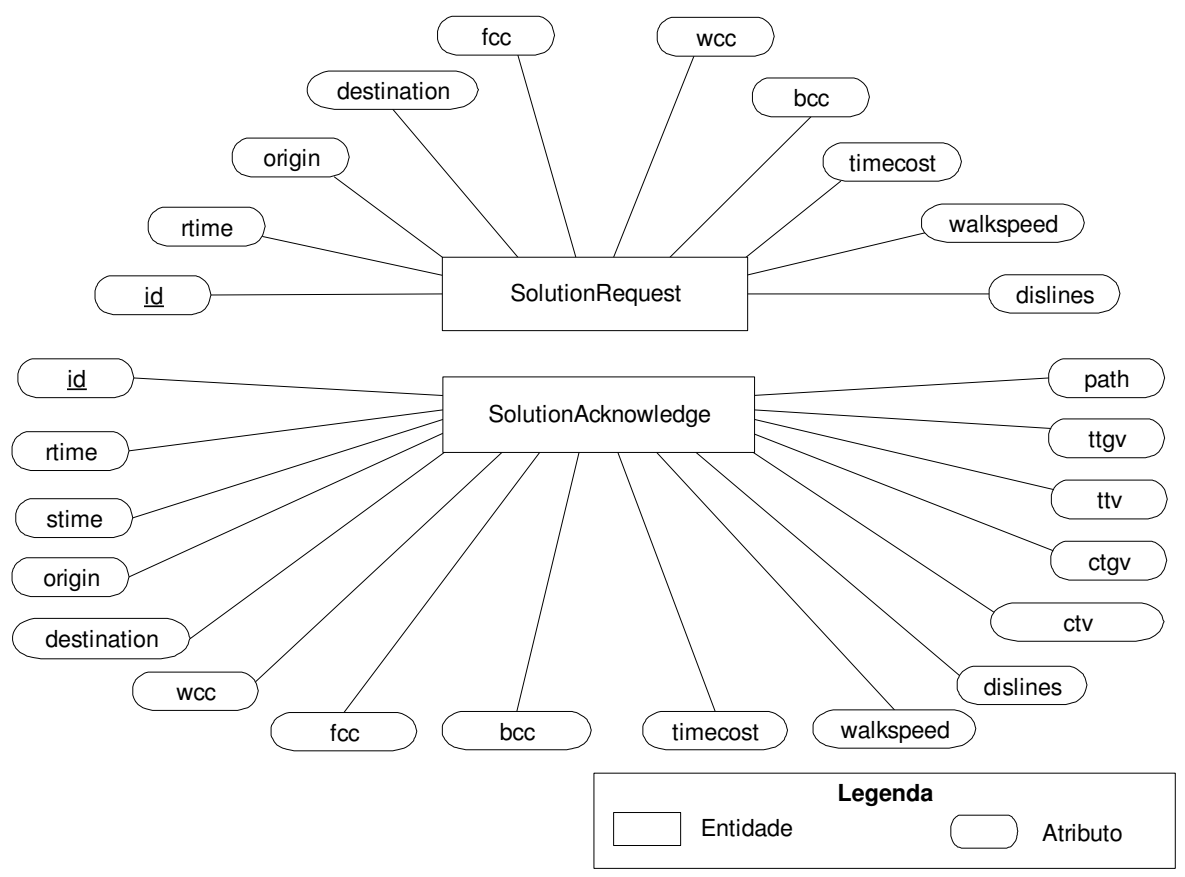

Fig. 3.5 - Diagrama das entidades do repositório de dados

Neste diagrama há duas entidades fundamentais: a entidade SolutionRequest, que armazena as solicitações iniciais dos usuários, que ainda não foram atendidas, e a entidade SolutionAcknowledge, que armazena não apenas os dados da solicitação do 
usuário, mas também o caminho apresentado como solução e custos associados. Seus atributos são detalhados a seguir.

\section{$\underline{\text { SolutionRequest }}$}

$I D$ : Identificação da requisição de solução. Chave Primária.

RTIME: Momento em que a requisição foi feita.

ORIGIN: Nó inicial da viagem.

DESTINATION: Nó final da viagem.

WCC: Coeficiente de custo do tempo de espera.

FCC: Coeficiente de custo do tempo de caminhada.

$B C C$ : Coeficientes de custo do tempo nos modos de transporte.

TIMECOST: Custo do tempo.

WALKSPEED: Velocidade de caminhada.

DISLINES: Linhas de transporte a desabilitar na solução.

\section{SolutionAcknowledge}

$I D$ : Identificação da requisição de solução. Chave Primária.

RTIME: Momento em que a requisição foi feita.

STIME: Momento em que a solução foi apresentada.

ORIGIN: Nó inicial da viagem.

DESTINATION: Nó final da viagem.

WCC: Coeficiente de custo do tempo de espera.

FCC: Coeficiente de custo do tempo de caminhada.

$B C C$ : Coeficientes de custo do tempo nos modos de transporte.

TIMECOST: Custo do tempo.

WALKSPEED: Velocidade de caminhada.

DISLINES: Linhas de transporte a desabilitar na solução.

CTV: Custo total de viagem.

$C T G V$ : Custo total generalizado de viagem.

TTV: Tempo total de viagem.

$T T G V$ : Tempo total generalizado de viagem.

PATH: Rota de solução. 


\subsection{O Servidor de Cálculo}

O Servidor de Cálculo é o módulo onde o problema de fluxo em rede será resolvido, baseado nos dados de rede fornecidos pelo Servidor de Informações a nas informações fornecidas pelo usuário, já devidamente tratadas pelo Servidor Web.

Por simplicidade, na implementação atual o Servidor de Cálculo será desenvolvido como um aplicativo auxiliar (cgi). Isso significa que o funcionamento dele estará atrelado ao funcionamento do Servidor Web, sendo que este último terá o controle sobre sua execução.

Como será visto, isso significa que para cada requisição de solução, o Servidor de Cálculo irá construir toda a rede, resolvê-la e, após armazenar a solução, irá destruí-la. Embora em redes de pequeno e médio porte isso não seja um grande problema, em redes de grande porte este tempo extra de construção da rede antes de cada solução pode ser especialmente problemático, prejudicando muito o tempo de resposta do sistema.

Este fato, aliado ao grande consumo de processamento deste módulo, sugerem que, idealmente, ele deva operar em equipamento(s) independente(s), separado(s) de todos os outros módulos. Para isso, tal módulo deve ser reescrito como um "servidor de fato", ou seja, operar como um programa que é executado uma única vez, constrói a rede uma única vez e se mantém ativo durante todo o tempo, recebendo e atendendo às requisições de cálculo originadas nos Terminais de Consulta, só sendo finalizado quando o sistema for desligado. 


\subsubsection{Estrutura de Funcionamento}

Ao ser executado, o Servidor de Cálculo terá operação de maneira linear, segundo o fluxograma da figura 3.6. A seguir, cada uma das etapas será descrita com maiores detalhes.

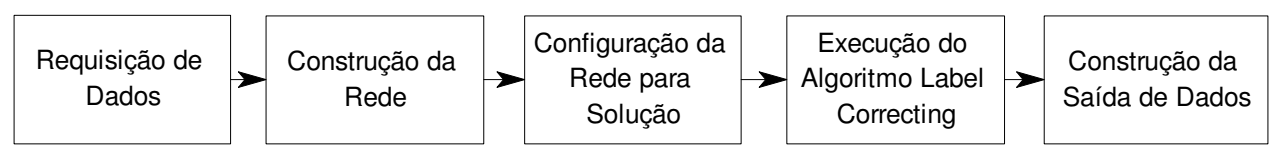

Fig. 3.6 - Fluxograma de Operação do Servidor de Cálculo

\subsubsection{Requisição dos Dados e Construção da Rede}

Para que se possa resolver o problema através de um algoritmo de caminho mínimo, primeiramente é preciso consultar o Servidor de Informações para obter os dados que descrevem a rede e construí-la. A principal função destas etapas é justamente realizar esta tarefa.

Como um primeiro passo, deve ser solicitada a lista de nós da rede base (pontos de referência, cruzamentos, etc.), da relação NodeDesc, os quais serão devidamente adicionados à estrutura da rede. A seguir deve ser solicitada, da relação ArcDesc, a lista de arcos que definem logradouros por onde se pode trafegar a pé ou de carro, para uma ou outra direção e, com estas informações, devem ser construídas as redes básicas (a pé ou de carro).

O próximo passo deve ser solicitar da relação LinesRoute, para cada linha existente em LinesDesc, os arcos que a compõe e criar a rede de cada linha de transporte. Para que as transferências entre os modos de transporte possam ser computadas, devem ser criados os arcos fictícios de transferência entre modos de transporte (GUALDA, 1975), com custos baseados nos dados da relação LinesDesc. 
Ao final deste processo, a rede estará completa para a solução do problema de caminho mínimo entre dois pontos, faltando apenas a sua configuração com os valores fornecidos pelo usuário.

\subsubsection{Configuração da Rede para a Solução}

Nesta etapa os valores fornecidos pelo usuário na consulta, inseridos pelo Servidor Web no Servidor de Informações, serão lidos da relação SolutionRequest e incorporados na rede.

Ainda nesta etapa devem ser ligadas e desligadas linhas de transporte específicas e também modos de transporte, de acordo com as opções do usuário, como uma das formas de atender ao requisito de permitir soluções alternativas para um mesmo problema. A maneira de executar esta operação será varrer todos os arcos e marcá-los como ativos ou inativos.

Em seguida, devem ser selecionadas algumas opções quanto ao algoritmo de solução (por exemplo, se ele irá trabalhar com listas ordenadas ou listas não-ordenadas), sendo que a opção de maior desempenho depende do tamanho da rede. Para redes pequenas, listas não-ordenadas tendem a ser mais eficientes. Para redes grandes, listas ordenadas tendem a ser mais eficientes. Devido ao caráter estritamente técnico, esta opção não estará disponível ao usuário, cabendo ao desenvolvedor optar por uma ou outra alternativa.

Finalmente, antes de seguir para a próxima etapa, devem ser realizadas modificações nos coeficientes para cálculo de custo generalizado, ajustes de tempo de viagem nos horários de pico e quaisquer outras informações que possam influenciar a solução. 


\subsubsection{Resolução do Caminho Mínimo}

Com a rede construída e configurada, nesta etapa os dados serão processados para a obtenção da solução desejada: o caminho mínimo entre os dois pontos indicados na solicitação do usuário, considerando-se os critérios fornecidos.

O algoritmo selecionado como base na implementação foi o Label Correcting (GALLO; PALLOTINO, 1984), sendo que as principais razões para sua escolha foram a rapidez e flexibilidade, estando de acordo com os requisitos globais do sistema. Maiores detalhes sobre o algoritmo Label Correcting e Label Setting, no qual o Label Correcting é baseado, podem ser verificados no Anexo B.

O fluxograma da figura 3.7 descreve o funcionamento desta etapa, apresentando o processo iterativo referente ao algoritmo implementado, baseado no Label Correcting. Na implementação, o "custo" de cada arco, utilizado na definição da melhor rota, foi o custo ou o tempo generalizado do respectivo trecho da viagem. É importante ressaltar que, embora este tenha sido selecionado como critério para seleção da melhor alternativa, estes valores não devem ser apresentados aos usuários, que devem receber como informação o tempo físico e o custo monetário real. Tal medida visa uma comunicação mais eficaz com o usuário, dado que este pode não saber interpretar corretamente os valores utilizados no cálculo. Detalhes sobre o cálculo de tempo e custo generalizados podem ser verificados no Anexo A.

\subsubsection{Construção da Saída}

A última fase do processamento do Servidor de Cálculo, após o cálculo propriamente dito, corresponde à construção de uma saída padronizada, que possa ser identificada, interpretada e processada pelo software que requisitou a informação, visando à sua posterior apresentação ao usuário. 
Para facilidade de manipulação das informações, ao final da execução do algoritmo Label Correcting já deverão estar disponíveis os nós da solução em uma pilha (fila LIFO, Last In First Out), de forma que, ao serem extraídos desta pilha, eles já representarão a solução, na ordem correta.

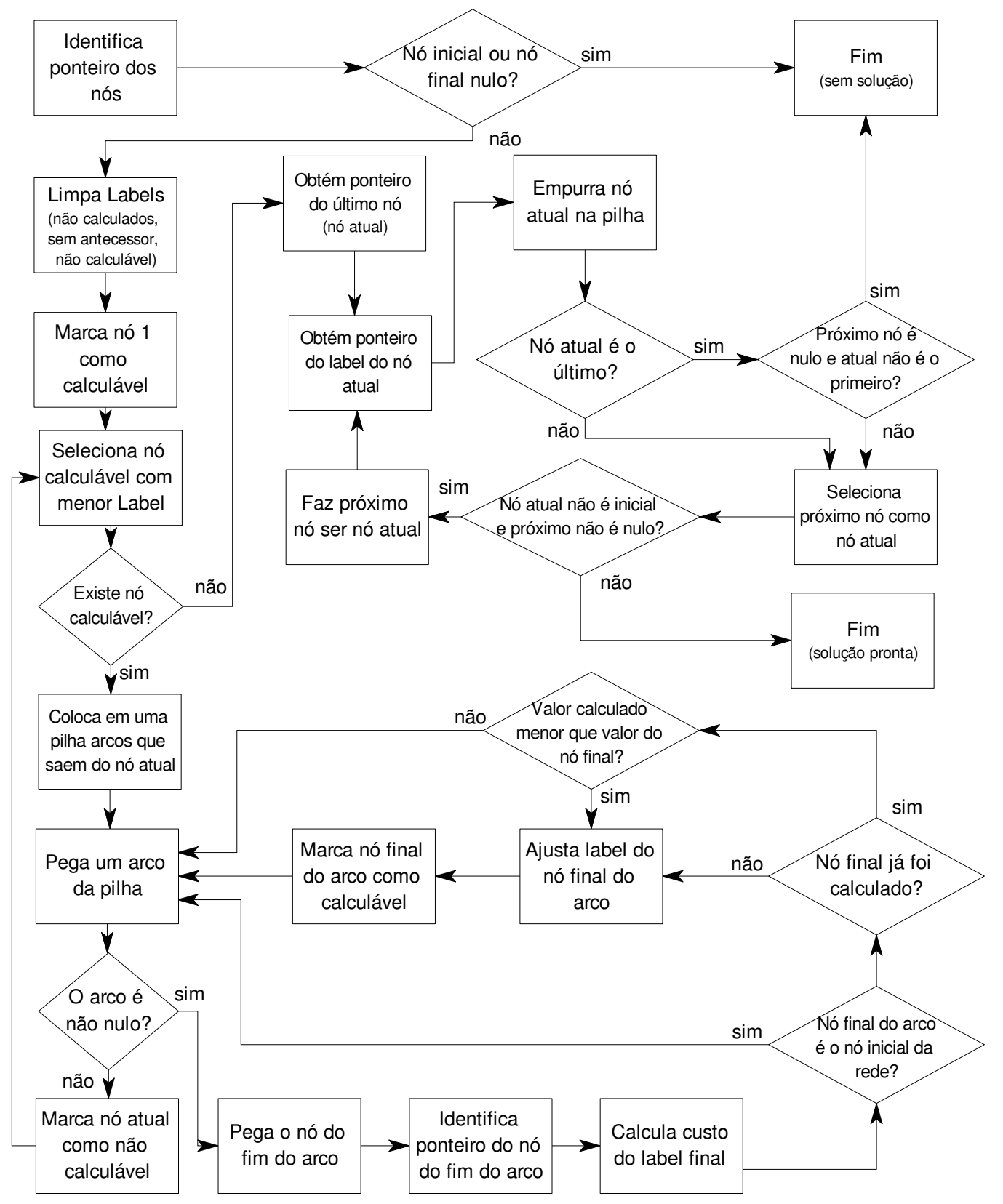

Fig. 3.7 - Fluxograma de solução pelo algoritmo Label Correcting 
Assim, esta etapa do processamento deverá transferir os dados da requisição da relação SolutionRequest para a relação SolutionAcknowledge no Servidor de Informações, acrescentando a esta última os valores da pilha, que representam a solução, bem como os valores de custo relativos a esta solução, que podem ser apresentados ao usuário para auxiliá-lo em sua tomada de decisão. O formato de armazenamento destas soluções no banco de dados é descrito na seção 3.6.1.2.

A utilização da relação SolutionAcknowledge para armazenar os resultados permite que a aplicação que requisitou o cálculo prossiga sua operação consultando o Servidor de Informações, ao mesmo tempo em que é constituído um repositório de dados com as consultas realizadas.

\subsubsection{Estruturação dos Objetos}

Em consonância com os preceitos de modularização, manutibilidade e flexibilidade, o desenvolvimento do software do Servidor de Cálculo seguiu a filosofia do desenvolvimento orientado a objetos. Sendo assim, seu funcionamento foi modelado como objetos que interagem entre si, facilitando sua implementação em uma linguagem orientada a objetos, como o $\mathrm{C}++$.

Tal modelagem tem o objetivo de simplificar a implementação do algoritmo e isolar componentes funcionais específicos, seguindo a ideologia de projeto e implementação orientados a objetos (COAD; YOURDON, 1992); (JACOBSON et al., 1992); (YOURDON e ARGILA, 1999), bem como a inspiração em modelos orientados a objetos voltados à área de transportes (GIACAGLIA, 1993). Maiores detalhes sobre análise, projeto e programação orientados a objetos podem ser verificados no Anexo D. 
Objetivando a resolução de um problema de fluxo em rede, os objetos da modelagem serão relativos à representação e solução deste tipo de problema, e não àqueles do problema real do transporte público. Neste contexto, as classes de objetos foram assim definidas:

- cTMode (ctmode.dll)

- cBus (cbus.dll)

- cUser (cuser.dll)

- cLinkListElement (cllel.dll)

- cNode / cNodeList (cnodlist.dll)

- cArc / cArcList (carclist.dll)

- cNetwork (cnetwork.dll)

Além destas classes, também deve ser definidos os templates tStackElement e tStack. Um template é uma classe definida para um tipo genérico de dado, sendo que os supracitados servirão para a constituição de classes de pilha para diversos tipos de dado necessários para a execução do algoritmo.

Essas classes serão distribuídas em diversas "bibliotecas de ligação dinâmica" (Dynamic Link Libraries, ou simplesmente DLLs). Esta abordagem tem por objetivo isolar grupos de classes que possam ser úteis em mais de uma parte do software, bem como possam vir a ser úteis na implementação de outros software, garantindo a propriedade de reuso de código. $\mathrm{Na}$ lista acima, os nomes entre parêntesis representam o nome da DLL na qual a classe será encapsulada.

O diagrama que representa as relações entre as classes, bem como a constituição de cada uma delas, é apresentado na figura 3.8. A descrição das características de cada uma das classes é feita a seguir. 


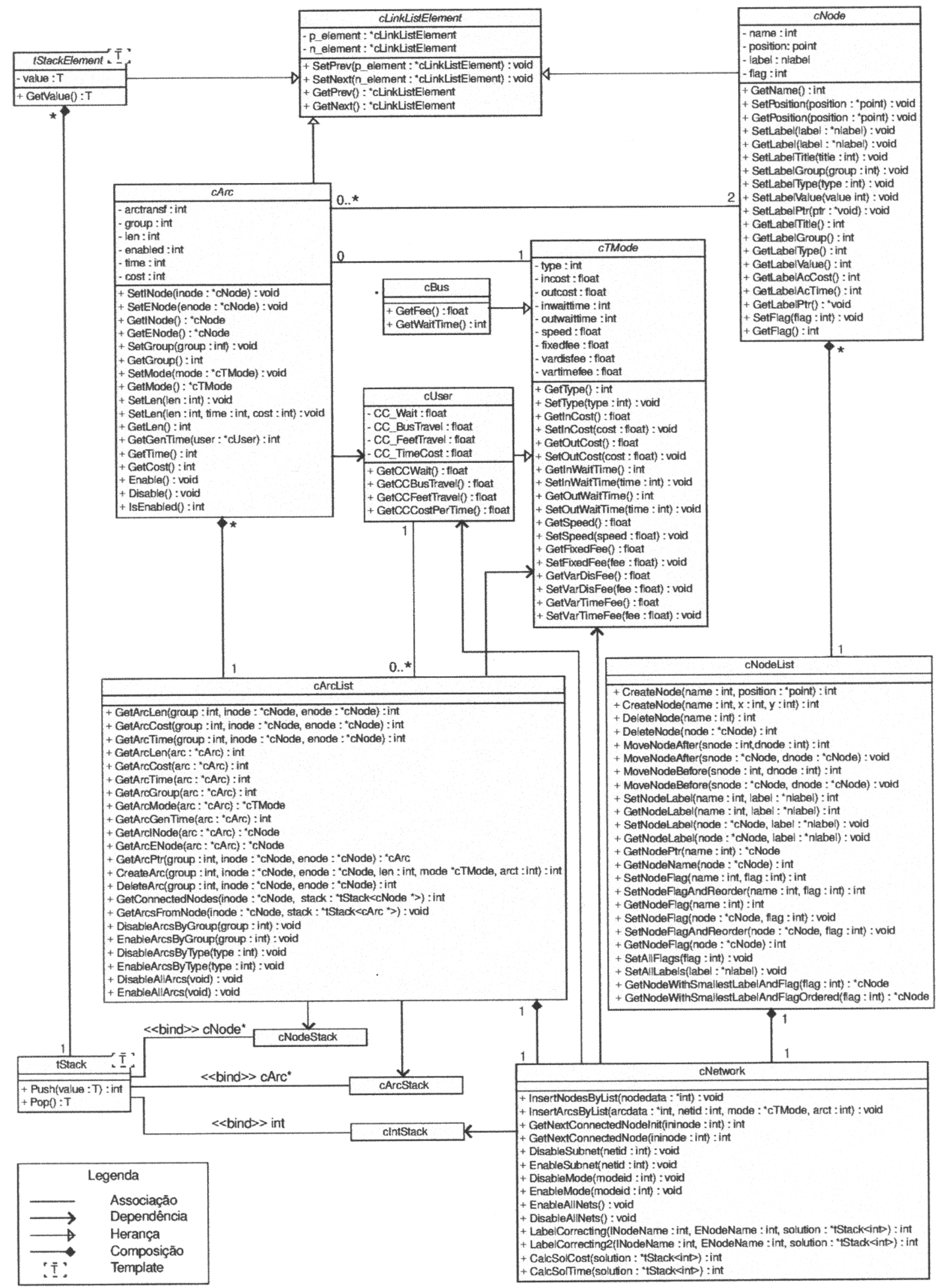

Fig. 3.8 - Diagrama de relacionamento das classes 


\section{3..5.2.1. Classe cTMode}

A classe cTMode descreve um modo de transporte genérico. Esta classe não tem como objetivo seu uso direto, mas sim sua derivação (ou especialização) para composição de classes de modos de transporte específicos. Essencialmente, ela é uma classe básica que provê variáveis e métodos básicos de um modo de transporte genérico. A saber:

\section{Variáveis Privativas:}

type: O tipo do modo de transporte

incost: Custo para entrar no meio de transporte.

outcost: Custo para sair do meio de transporte.

inwaittime: Tempo de espera para entrar no meio de transporte.

outwaittime: Tempo de espera para sair do meio de transporte.

speed: Velocidade do meio de transporte.

fixedfee: Tarifa fixa para usar o meio de transporte.

vardistfee: Tarifa variável com a distância percorrida no modo de transporte.

vartimefee: Tarifa variável com o tempo de permanência no modo de transporte.

\section{Métodos Públicos:}

GetType: Recupera o número de tipo do modo de transporte.

SetType: Modifica o número de tipo do modo de transporte.

GetInCost: Recupera o custo de entrada no modo de transporte.

SetInCost: Modifica o custo de entrada no modo de transporte.

GetOutCost: Recupera o custo de saída do modo de transporte.

SetOutCost: Modifica o custo de saída do modo de transporte.

GetInWaitTime: Recupera o tempo de espera de entrada no modo de transporte.

SetInWaitTime: Modifica o tempo de espera de entrada no modo de transporte.

GetOutWaitTime: Recupera o tempo de espera de saída do modo de transporte.

SetOutWaitTime: Modifica o tempo de espera de saída do modo de transporte.

GetSpeed: Recupera o valor da velocidade do modo de transporte. 
SetSpeed: Modifica o valor da velocidade do modo de transporte.

GetFixedFee: Recupera a tarifa fixa do modo de transporte.

SetFixedFee: Modifica a tarifa fixa do modo de transporte.

GetVarDisFee: Recupera a tarifa variável com a distância percorrida do modo de transporte.

SetVarDisFee: Modifica a tarifa variável com a distância percorrida do modo de transporte.

GetVarTimeFee: Recupera a tarifa variável com o tempo do modo de transporte.

SetVarTimeFee: Modifica a tarifa variável com o tempo do modo de transporte.

\subsubsection{Classe cBus}

A classe cBus é uma classe derivada (ou especializada) da classe cTMode. Ela tem como herança toda a estrutura de um modo de transporte genérico, à qual adiciona alguns elementos especiais da descrição do modo de transporte por ônibus. Em outras palavras, a classe cBus descreve objetos do modo de transporte ônibus. Os elementos que esta classe adiciona aos da cTMode são:

\section{Métodos Públicos:}

GetFee: Recupera o valor da tarifa fixa do ônibus.

GetWaitTime: Recupera o tempo de espera de entrada no ônibus.

\subsubsection{Classe cUser}

A classe cUser é uma classe derivada (ou especializada) da classe cTMode. Ela tem como herança toda a estrutura de um modo de transporte genérico, à qual adiciona uma série de outros elementos utilizados para descrever um usuário, que é também um modo de transporte por si só. Os elementos que esta classe adiciona aos da cTMode são: 


\section{Variáveis Privativas:}

CC_Wait: Coeficiente de tempo generalizado para tempo de espera.

CC_BusTravel: Coeficiente de tempo generalizado para tempo em ônibus.

CC_FeetTravel: Coeficiente de tempo generalizado para tempo de caminhada.

CC_TimeCost: Custo do tempo do usuário.

\section{Métodos Públicos:}

GetCCWait: Recupera o coeficiente de tempo de espera.

GetCCBusTravel: Recupera o coeficiente de tempo de viagem em ônibus.

GetCCFeetTravel: Recupera o coeficiente de tempo de caminhada.

GetCCTimeCost: Recupera o custo do tempo do usuário.

\subsubsection{Classe cLinkListElement}

A classe cLinkListElement descreve objetos que representam elementos de uma lista bi-ligada. Esta classe não tem como objetivo seu uso direto, mas sim sua derivação (ou especialização) para composição de classes de listas bi-ligadas de qualquer natureza. Essencialmente, ela é uma classe básica que provê variáveis e métodos básicos de controle e manipulação de uma lista bi-ligada. A saber:

\section{Variáveis Privativas:}

p_element: Um ponteiro para o elemento anterior da lista ligada.

n_element: Um ponteiro para o próximo elemento da lista ligada.

\section{Métodos Públicos:}

SetPrev: Modifica o ponteiro que aponta para o elemento anterior da lista.

SetNext: Modifica o ponteiro que aponta para o próximo elemento da lista. GetPrev: Recupera o ponteiro que aponta para o elemento anterior da lista. GetNext: Recupera o ponteiro que aponta para o próximo elemento da lista. 


\subsubsection{Classe cNode}

A classe cNode é uma classe derivada (ou especializada) da classe cLinkListElement. Ela tem como herança toda a estrutura de lista bi-ligada da sua classe pai, à qual adiciona uma série de outros elementos utilizados para descrever um nó de rede. Em outras palavras, a classe cNode descreve objetos que são elementos de uma lista bi-ligada de nós de rede (ou mesmo um nó simples, que seria uma lista com um único elemento). Os elementos que esta classe adiciona aos da cLinkListElement são:

\section{$\underline{\text { Variáveis Privativas: }}$}

name: Número do Nó

position: Posição do nó, no plano/espaço cartesiano (ponto).

label: Uma etiqueta que contém informações específicas sobre o nó.

flag: Uma flag genérica para uso de algoritmos.

\section{Métodos Públicos:}

GetName: Recupera o nome de um dado nó.

SetPosition: Muda a posição do nó no plano/espaço cartesiano.

GetPosition: Recupera posição do nó no plano/espaço cartesiano.

SetLabel: Modifica a etiqueta do nó.

GetLabel: Recupera a etiqueta do nó.

SetLabelTitle: Modifica o título numérico da etiqueta.

SetLabelGroup: Modifica o grupo numérico da etiqueta.

SetLabelType: Modifica o tipo numérico da etiqueta.

SetLabelValue: Modifica o valor numérico da etiqueta.

SetLabelPtr: Modifica o ponteiro da etiqueta.

GetLabelTitle: Recupera o título numérico da etiqueta.

GetLabelGroup: Recupera o grupo numérico da etiqueta.

GetLabelType: Recupera o tipo numérico da etiqueta.

GetLabelValue: Recupera o valor numérico da etiqueta. 
GetLabelAcCost: Recupera o custo atual indicado na etiqueta.

GetLabelAcTime: Recupera o tempo atual indicado na etiqueta.

GetLabelPtr: Recupera o ponteiro da etiqueta.

SetFlag: Modifica o valor da flag do nó.

GetFlag: Recupera o valor da flag do nó

\subsubsection{Classe cNodeList}

A classe cNodeList é uma classe que descreve um objeto que é uma lista de nós, ou seja, uma lista de elementos cNode. Esta classe encapsula várias funções de alto nível para a manipulação de listas de nós, facilitando muito a implementação de algoritmos que se utilizam deste tipo de estrutura de dados. Os elementos que essa classe possui são:

\section{Métodos Públicos:}

CreateNode: Adiciona ou modifica um nó da lista.

DeleteNode: Remove um nó da lista.

MoveNodeAfter: Move um nó para depois de um determinado nó da lista.

MoveNodeBefore: Move um nó para antes de um determinado nó da lista.

SetNodeLabel: Modifica a etiqueta de um dado nó da lista.

GetNodeLabel: Recupera a etiqueta de um dado nó da lista.

GetNodePtr: Recupera o ponteiro para um determinado nó da lista.

GetNodeName: Recupera o nome de um dado nó da lista.

SetNodeFlag: Modifica a flag de um dado nó.

SetNodeFlagAndReorder: Modifica a flag de um dado nó e reordena a lista pelos flags.

GetNodeFlag: Recupera o valor da flag de um dado nó.

SetAllFlags: Modifica o valor das flags de todos os nós da lista.

SetAllLabels: Modifica as etiquetas de todos os nós da lista.

GetNodeWithSmallestLabelAndFlag: Recupera o ponteiro para o nó com menor valor na etiqueta e com um dado flag. 
GetNodeWithSmallestLabelAndFlagOrdered: Recupera o ponteiro para o nó com menor valor na etiqueta e com um dado flag, considerando uma lista ordenada por flags.

\subsubsection{Classe cArc}

A classe cArc é uma classe derivada (ou especializada) da classe cLinkListElement. Ela tem como herança toda a estrutura de lista bi-ligada da sua classe pai, à qual adiciona uma série de outros elementos utilizados para descrever um arco de rede. Em outras palavras, a classe cArc descreve objetos que são elementos de uma lista bi-ligada de arcos de rede (ou mesmo um arco simples, que seria uma lista com um único elemento). Os elementos que esta classe adiciona aos da cLinkListElement são:

\section{Variáveis Privativas:}

arctransf: Indica se o arco é um arco de transferência (fictício).

group: O grupo, ou a sub-sub-rede, deste arco. Por exemplo: uma dada linha de um dado modo de transporte.

len: Comprimento do arco.

enabled: Indica se o arco está ligado, ou seja, se ele pode ser usado na solução de problemas de fluxo em rede.

time: Tempo necessário para percorrer o arco.

cost: Custo monetário necessário para percorrer o arco.

\section{Métodos Públicos:}

SetINode: Altera o ponteiro do nó inicial do arco.

SetENode: Altera o ponteiro do nó final do arco.

GetINode: Recupera o ponteiro do nó inicial do arco.

GetENode: Recupera o ponteiro do nó final do arco.

SetGroup: Altera o grupo ao qual o arco pertence.

GetGroup: Recupera o grupo ao qual o arco pertence. 
SetMode: Altera o modo de transporte relativo ao arco.

GetMode: Recupera o modo de transporte relativo ao arco.

SetLen: Altera o comprimento do arco.

GetLen: Recupera o comprimento do arco.

GetGenTime: Recupera o tempo generalizado relativo ao arco.

GetTime: Recupera o tempo para percorrer o arco.

GetCost: Recupera o custo monetário para percorrer o arco.

Enable: Habilita um arco.

Disable: Desabilita um arco.

IsEnabled: Verifica se um arco está habilitado.

\subsubsection{Classe cArcList}

A classe cArcList é uma classe que descreve um objeto que é uma lista de arcos, ou seja, uma lista de elementos cArc. Esta classe encapsula várias funções de alto nível para a manipulação de listas de arcos, facilitando muito a implementação de algoritmos que se utilizam deste tipo de estrutura de dados. Os elementos que essa classe possui são:

\section{Métodos Públicos:}

GetArcLen: Recupera o comprimento de um dado arco.

GetArcCost: Recupera o custo monetário de percorrer um dado arco.

GetArcTime: Recupera o tempo de percorrer um dado arco.

GetArcGroup: Recupera o grupo ao qual pertence um dado arco.

GetArcMode: Recupera o modo de transporte relativo a um dado arco.

GetArcGenTime: Recupera o tempo generalizado relativo a um dado arco.

GetArcINode: Recupera o nó inicial de um dado arco.

GetArcENode: Recupera o nó final de um dado arco.

GetArcPtr: Recupera o ponteiro para um dado arco.

CreateArc: Adiciona ou modifica um arco da lista.

DeleteArc: Elimina um dado arco da lista. 
GetConnectedNodes: Recupera todos os nós que estejam ligados por arcos a um dado nó.

GetArcsFromNode: Recupera os arcos que saem de um dado nó.

DisableArcsByGroup: Desabilita todos os arcos de um dado grupo.

EnableArcsByGroup: Habilita todos os arcos de um dado grupo.

DisableArcsByType: Desabilita todos os arcos de um dado tipo de transporte.

EnableArcsByType: Habilita todos os arcos de um dado tipo de transporte.

DisableAllArcs: Desabilita todos os arcos da lista.

EnableAllArcs: Habilita todos os arcos da lista.

\subsubsection{Classe cNetwork}

A classe cNetwork é uma classe que descreve um objeto de rede, incluindo suas listas de arcos (cArcList) e nós (cNodeList). Esta classe é a que faz interface com o programa principal, para a resolução de problemas de caminho mínimo. Esta classe encapsula várias funções de alto nível para a manipulação de redes, facilitando muito a implementação de algoritmos que se utilizam deste tipo de estrutura de dados. Os elementos que essa classe possui são:

\section{Métodos Públicos:}

InsertNodesByList: Insere nós na rede.

InsertArcsByList: Insere arcos na rede.

GetNextConnectedNodeInit: Inicializa uma máquina de estados de obtenção de nós conectados a um dado nó.

GetNextConnectedNode: Comanda a máquina de estados para a obtenção dos próximos nós conectados a um dado nó, um a um.

DisableSubnet: Desabilita uma sub-rede (rota).

EnabelSubnet: Habilita uma sub-rede (rota).

DisableMode: Desabilita um modo de transporte.

EnableMode: Habilita um modo de transporte.

DisableAllNets: Desabilita todas as redes. 
EnableAllNets: Habilita todas as redes.

LabelCorrecting: Rotina que executa método iterativo de cálculo do caminho mínimo.

CalcSolCost: Rotina que calcula o custo monetário de uma solução.

CalcSolTime: Rotina que calcula o tempo real de uma solução.

\subsubsection{Template tStackElement}

O template tStackElement é um template derivado (ou especializado) da classe cLinkListElement. Ela tem como herança toda a estrutura de lista bi-ligada da sua classe pai, à qual adiciona uma série de outros elementos utilizados para descrever um elemento de pilha. Em outras palavras, o template tStackElement descreve classes que descrevem elementos de pilha. Os elementos que este template adiciona aos da cLinkListElement são:

\section{Variáveis Privativas:}

value: $\mathrm{O}$ valor do elemento da pilha.

\section{Métodos Públicos:}

GetValue: Recupera o valor do elemento da pilha.

\subsubsection{Template tStack}

O template tStack é um template que descreve uma classe de pilha genérica. Este template encapsula as várias funções de alto nível de manipulação de pilhas, facilitando a implementação de algoritmos que se utilizam deste tipo de estrutura de dados. Os elementos que esse template possui são:

\section{Métodos Públicos:}

Push: Insere um valor na pilha.

Pop: Recupera um valor da pilha. 


\subsection{O Servidor Web}

O Servidor Web é o módulo responsável por três funções principais:

- Gerenciar as requisições e conexões dos terminais de consulta através da internet.

- Realizar o pré-processamento dos dados fornecidos pelo usuário para fornecê-los ao Servidor de Cálculo.

- Realizar o pós-processamento dos dados fornecidos pelo Servidor de Cálculo, antes de enviá-los ao Terminal de Consulta para apresentação ao usuário.

Para cumprir a primeira função, como servidor de conexões, e servir de base para as outras duas, como servidor de páginas web, será utilizado o software Apache Web Server. Informações detalhadas sobre o Apache Web Server, bem como o próprio software e seu código fonte, podem ser obtidos no site da Apache Software Foundation ( http://www.apache.org/, consultado em 13 de Abril de 2005).

Dentre os diversos fatores que influenciaram na escolha do Apache Web Server, destacam-se:

- A robustez do Apache permite com que seja capaz de lidar com tráfego maciço e diversas requisições simultâneas, com baixos tempos de resposta.

- $\underline{O}$ grande número de recursos, incluindo expansibilidade através de módulos, torna o Apache adaptável às mais diversas necessidades.

- A alta segurança, minimizando a chance de ataques de hackers aos servidores em que o serviço opera.

- Multiplataforma, evitando que o sistema desenvolvido esteja "preso" a um único tipo de hardware/software. 
- Código aberto, possibilitando que eventuais falhas sejam corrigidas rapidamente, ou mesmo uma adaptação ou expansão de seus recursos, se necessário.

- Uso gratuito, reduzindo o custo total do sistema.

Apesar destas características, em sua distribuição padrão, o Apache fornece apenas os serviços de gerenciamento de conexões e funções básicas para a manutenção de páginas web, não oferecendo recursos avançados para a geração de páginas com conteúdo dinâmico, mais adaptadas à aplicação desejada. Entretanto, como dito anteriormente, existe a possibilidade de expandí-lo com o uso de módulos específicos.

Assim, como um complemento ao Apache, deverá ser utilizado o módulo PHP. Este módulo adiciona a linguagem interpretada PHP ao Apache, permitindo que esta seja utilizada facilmente na criação de páginas web, proporcionando que tais páginas possam modificar-se de acordo com a situação e/ou tipo de requisição do usuário. Maiores informações sobre a linguagem PHP, bem como o próprio módulo PHP e seu código fonte, podem ser obtidos no site oficial do Projeto PHP na internet (http://www.php.net/, consultado em 13 de Abril de 2005).

Dentre os diversos fatores que influenciaram na escolha da linguagem PHP, destacam-se:

- Facilidade de interação com os servidores web disponíveis, o que simplifica a operação integrada de ambos.

- Facilidade de manipulação de entradas de dados do usuário, o que simplifica a programação da interface com o usuário.

- Facilidade de manipulação de imagens, permitindo o desenvolvimento de uma interface gráfica com o usuário dentro do tempo disponível.

- Facilidade de integração com bancos de dados, permitindo sua utilização dentro do contexto proposto por este trabalho. 
- Multiplataforma, evitando que o sistema desenvolvido esteja "preso" a um único tipo de hardware/software.

- Semelhança com $\mathrm{C} / \mathrm{C}++$, possibilitando coerência de sintaxe e estrutura utilizada no módulo de cálculo, desenvolvido em $\mathrm{C}++$.

- Código aberto, possibilitando que eventuais falhas sejam corrigidas rapidamente, ou mesmo que a linguagem seja adaptada e expandida, se necessário.

- Uso gratuito, reduzindo o custo total do sistema.

Com esta combinação, o Servidor Web pode ser descrito como um servidor de conexões (Apache), que servirá de suporte para a utilização do módulo PHP e lidará com as requisições do usuário, bem como sua entrada de dados. A função específica do módulo PHP será processar entradas de dados do usuário, realizar a requisição de cálculo ao Servidor de Cálculo e, posteriormente, processar os dados da solução para produzir uma informação simples e facilmente compreensível. As etapas deste processo, bem como seu encadeamento, serão vistos com maiores detalhes nas seções seguintes.

\subsubsection{Estrutura de Funcionamento}

Como visto anteriormente, o Servidor Web será composto de duas partes principais: o servidor de páginas (Apache) e o módulo de processamento (PHP). O fluxograma da figura 3.9 mostra, em linhas gerais, o funcionamento deste sistema.

Primeiramente, o servidor de conexões fica em regime de espera, aguardando uma requisição de conexão, que terá origem no Terminal de Consulta, através da ação do usuário. Quando uma solicitação de conexão for detectada, o servidor de conexões receberá então as informações transmitidas pelo usuário e as repassará para o módulo PHP, que deverá agir sobre elas. A seguir, o servidor de conexões intermediará o envido do resultado do processamento para o Terminal de Consulta. 


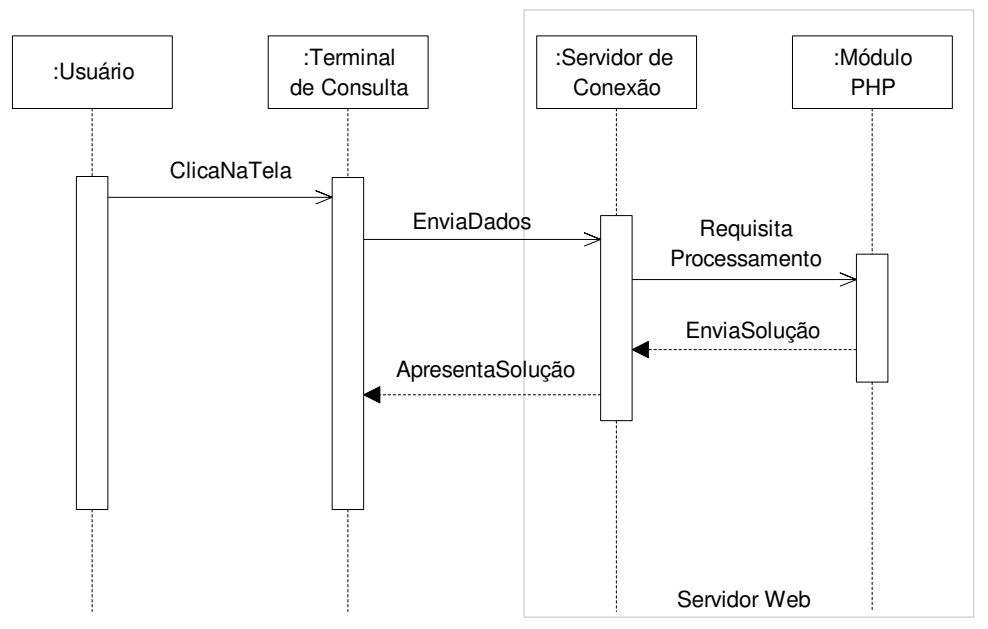

Fig. 3.9 - Diagrama de funcionamento do Servidor Web

Como é possível observar, o software servidor de conexões apenas cuidará da tramitação dos dados e será o módulo PHP o responsável pela geração do conteúdo a ser exibido. Entretanto, o módulo PHP é apenas um interpretador, sendo necessário um script para especificar as entradas possíveis, sua operação e quais serão suas saídas. A estrutura de funcionamento de tal script será proposta a seguir.

\subsubsection{A interface com o usuário como uma Máquina de Estados Finitos}

Como dito anteriormente, a ação do interpretador PHP depende diretamente do script que ele executa. Um script $\mathrm{PHP}$ é bastante similar a um programa $\mathrm{C} / \mathrm{C}++\mathrm{e}$, como tal, pode ser escrito para ser executado linearmente, cada procedimento numa ordem previamente estabelecida. Por outro lado, também pode ser escrito para uma execução não-linear, usando-se para isso uma Máquina de Estados Finitos (MEF) para controle do fluxo do script, por exemplo.

O uso de MEFs é uma das possíveis formas de se fazer controle de fluxo em um programa, sendo especialmente adequada quando é necessário lidar com entradas de usuário. O que torna o uso de MEFs interessante, nestas situações, é a possibilidade que elas trazem de uma mudança radical da atividade do software, a 
qualquer instante, sem a adição de muitas complexidades na programação. Assim, é possível permitir que o usuário mude o curso de sua ação de forma intuitiva, sem a necessidade de passos adicionais. Maiores detalhes sobre MEFs e controle de fluxo de software baseados em MEFs podem ser verificados no Anexo F.

Seguindo esta proposta, com a finalidade de colher os dados necessários e fornecer as informações da solução para o usuário, será definida uma máquina de estados com 3 estados básicos:

1- Estado "sem origem nem destino", onde a origem é solicitada.

2- Estado "com origem e sem destino", onde o destino é solicitado.

3- Estado "com origem e destino", onde a solução é apresentada ao usuário.

A navegação entre estes estados é representada pelo diagrama da figura $3.10 \mathrm{e}$ detalhes sobre cada um destes estados são apresentados em seguida.

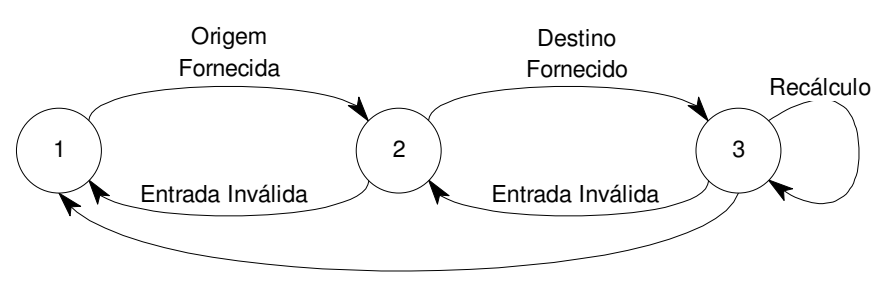

Fig. 3.10 - Diagrama de Estados da Interface

\section{$\underline{1 . \text { Estado "sem origem nem destino" }}$}

Neste estado são apresentadas ao usuário todas as informações necessárias para que ele escolha seu ponto de origem. Pode ser, por exemplo, mostrado um mapa da região onde o usuário poderá selecionar sua origem. Podem ser apresentados também os modos de transporte disponíveis, para a configuração do cálculo de rota, ou seja, quais modos estarão disponíveis para o cálculo do caminho mínimo. 
Neste momento deve ser solicitado que o usuário indique o ponto de onde ele deseja partir, clicando no mapa, por exemplo. Um exemplo de como o software pode ser apresentado durante este estado é representado na figura 3.11, onde está representada, como um exemplo, a rede de transporte dos ônibus circulares da Cidade Universitária Armando de Salles Oliveira, em São Paulo.

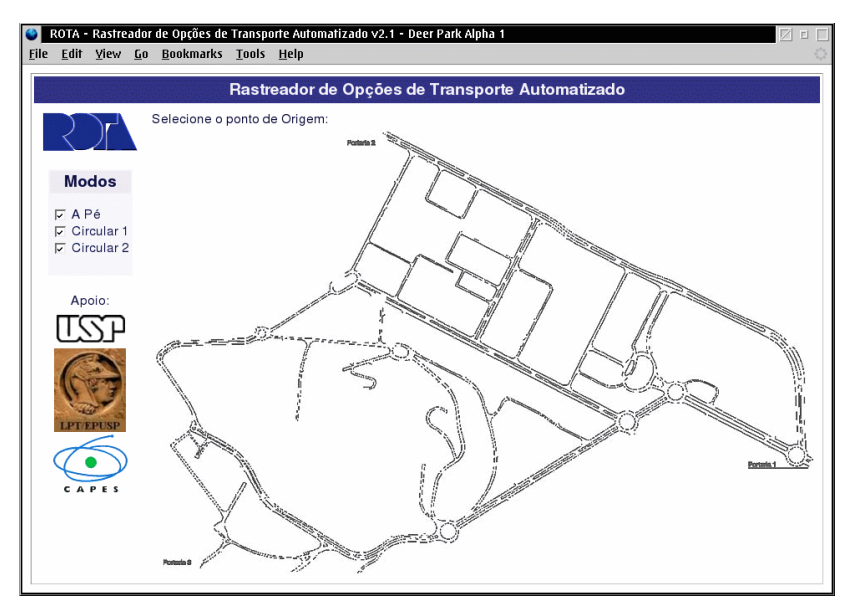

Fig. 3.11 - Exemplo de Estado "sem origem nem destino"

\section{$\underline{\text { 2. Estado "com origem e sem destino" }}$}

Neste estado deve ser calculado o ponto de entrada na rede mais próximo do ponto que o usuário indicou, no estado 1. Se a entrada for inválida, o script deve voltar ao estado 1, requisitando novamente o ponto de origem. Se a entrada for válida, este primeiro trecho de caminhada deve ser indicado ao usuário, sendo mostrado, por exemplo, no mapa a ser apresentado neste estado.

É possível permitir outras opções de configuração ainda neste estado, como as opções de configuração do cálculo de rota, uma vez que o usuário ainda poderá alterá-las. 
Neste ponto deve ser solicitado que o usuário indique seu destino, clicando no mapa, por exemplo. A figura 3.12 mostra um exemplo de como o software pode ser apresentado neste estado. Mais uma vez a figura mostra a rede de transporte do circulares da Cidade Universitária, já indicando o ponto de partida na Portaria 1, neste exemplo.

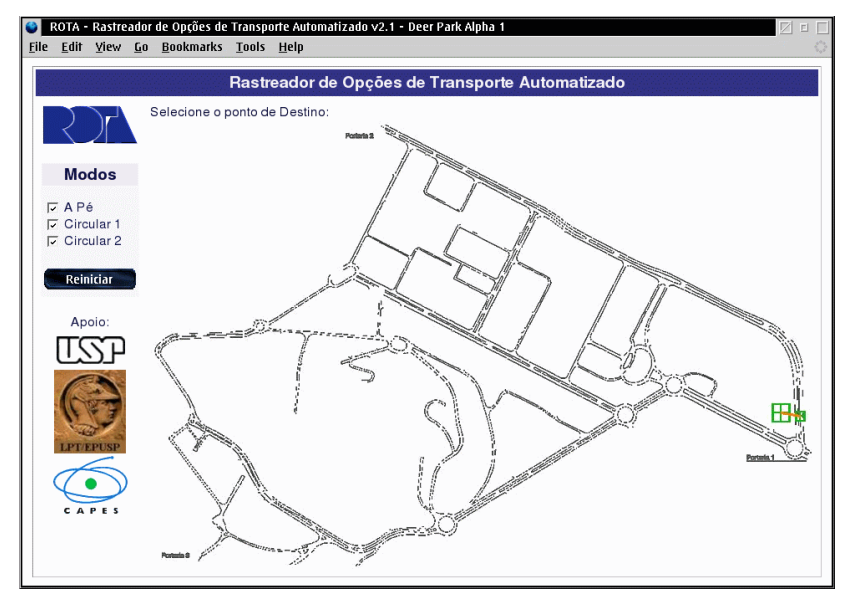

Fig. 3.12 - Exemplo de Estado "com origem e sem destino"

\section{Estado "com origem e destino"}

Neste estado deve ser calculado o ponto de saída da rede mais próximo do ponto que o usuário indicou, no estado 2. Se a entrada for inválida, o script deve voltar ao estado 2. Se for válida, o script deve solicitar ao Servidor de Cálculo que calcule a melhor rota, fornecendo os dados passados pelo usuário, aguardando então o aviso de solução.

Uma descrição textual deverá ser então preparada, baseada nas informações agora disponíveis no Servidor de Informações, bem como o tempo e custo real estimados para a viagem. Estas informações devem ser apresentadas ao usuário acompanhadas de uma representação gráfica da solução, em um mapa, por exemplo. 
Deve ainda ser possível que o usuário requisite um recálculo da rota, alterando os modos de transporte, obtendo outras soluções. Um exemplo de como o software pode ser apresentado durante este estado é representado na figura 3.13, onde é mostrada uma rota completa da Portaria 1 até o edifício da Engenharia Mecânica na Escola Politécnica. Ainda na figura é possível observar, no topo da imagem, os modos de transporte permitidos na solução e o botão de recálculo, bem como a descrição textual da solução.

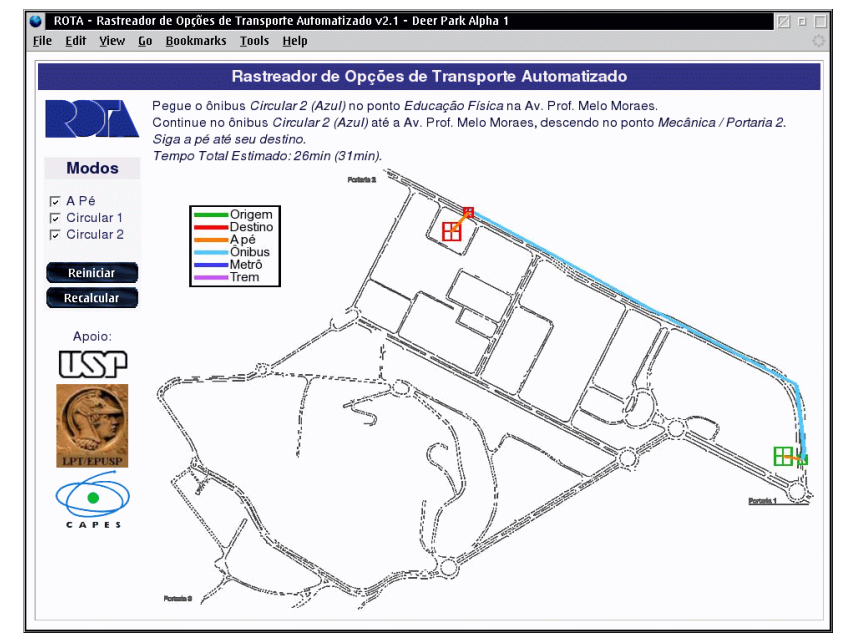

Fig. 3.13 - Exemplo de Estado "com origem e destino"

\subsubsection{O protocolo de descrição de rotas}

Uma vez que uma descrição textual da rota precisa ser elaborada, bem como uma representação gráfica, o formato utilizado na descrição de uma rota no banco de dados torna-se um protocolo de comunicação entre o servidor de cálculo e o módulo responsável pela geração do texto e da imagem que, neste caso, é o Servidor Web.

Uma vez que este protocolo é uma interface entre componentes do sistema, é interessante que ele seja descrito em detalhes, por mais simples que seja, para garantir a perfeita comunicação entre estes diferentes componentes. Isto é importante porque é este protocolo que garante que as informações fornecidas pelo Servidor de 
Cálculo sejam livres de ambigüidades, permitindo uma informação consistente para uso posterior (TANENBAUM, 2003a).

É sempre interessante projetar um protocolo flexível (REICH, 1995), permitindo modificações na saída de dados do gerador de soluções sem que os software que interpretem esse protocolo precisem ser reprogramados. Tal reprogramação deve ser necessária apenas quando for pretendida a apresentação de novas informações, que não estavam antes disponíveis.

$\mathrm{Na}$ implementação pretendida, o protocolo será bem simplificado, mas seu planejamento visa a permitir que ele seja expandido futuramente, se necessário. Isto é conseguido através de uma organização de dados isolados por separadores especiais.

Nesta organização de dados, a unidade fundamental é chamada "nodeinfo", sendo este um bloco que contém as informações de um nó específico de uma solução. Os blocos "nodeinfo" devem aparecer na ordem da solução, da origem para o destino, sendo a vírgula (, ) o separador entre tais blocos.

Internamente, os blocos "nodeinfo" são constituídos de uma série de informações sobre um dado nó da solução, sendo o separador entre estes dados a barra ( / ). Os dados de cada bloco devem ser, na ordem:

1- Número do nó, que serve para identificar o nó no banco de dados, de forma que seja possível obter sua posição no espaço, dentre outras informações.

2- Grupo do nó, que indica a qual subrede ele pertence (uma linha de ônibus, por exemplo).

3- Tipo do nó, que especifica a qual rede ele pertence (a rede de ônibus, por exemplo).

4- Tempo gerneralizado parcial do nó, que indica o tempo generalizado acumulado até aquele nó (não utilizado na implementação de interface). 
A expansibilidade do protocolo, sem afetar as aplicações, está justamente na utilização de separadores distintos para os dados internos do bloco e para os blocos em si. Para que esta expansibilidade seja garantida, os aplicativos e serviços que se utilizarem de dados recebidos neste formato não devem presumir a quantidade de dados dentro de um "nodeinfo", apenas sua ordem. Assim, um interpretador de soluções que respeite esta regra será capaz de apresentar a solução descrita por meio deste protocolo, mesmo que o número de dados dentro do "nodeinfo" cresça, em possíveis evoluções do software.

\subsection{O Terminal de Consulta}

Pelo fato de ter sido escolhida a internet como meio de comunicação para a utilização do serviço, com o desenvolvimento apoiado em um Servidor Web, o Terminal de Consulta poderá ser o mais genérico possível.

Desta forma, qualquer equipamento atual, que seja capaz de ser conectado à internet, tem a possibilidade de se utilizar do sistema, sendo que as maiores exigências com relação ao usuário são, possivelmente, a capacidade de ler e identificar locais em um mapa. Considera-se que tais características tornarão o sistema bastante acessível, tornando-se automaticamente disponível a quaisquer equipamentos capazes de acessar a world wide web, como computadores e telefones celulares. A disponibilidade pode ser melhorada ainda mais com terminais de consulta do tipo quiosque, nas proximidades dos pontos de acesso aos transportes coletivos. 


\subsection{Considerações Finais}

Neste capítulo foram detalhados os aspectos mais importantes da metodologia de implementação do sistema, bem como a estruturação global do sistema e a descrição de seus componentes.

As informações necessárias para o desenvolvimento (ou reprodução) do sistema foram fornecidas neste capítulo. Outros detalhes, como coeficientes de cálculo e modelagem de rede, serão apresentados no próximo capítulo, anteriormente à apresentação dos resultados dos testes do sistema. 


\section{CAPÍTULO 4 - APLICAÇÃO A UM CASO}

\subsection{Introdução}

O Capítulo 3 apresentou uma descrição detalhada dos módulos que o sistema de apoio ao usuário deve possuir, bem como cada um deles deve se comportar para que os objetivos do sistema sejam atingidos.

Neste capítulo será apresentado um estudo feito sobre uma implementação realizada baseada na descrição do Capítulo 3, com o objetivo de avaliar a viabilidade técnica do sistema, bem como testar sua funcionalidade. Para esta finalidade, será necessária também a alimentação do sistema com informações, tendo sido escolhido para isso o sistema de transporte interno da Cidade Universitária Armando de Salles Oliveira, composto por linhas de ônibus circulares.

O sistema de transporte da Cidade Universitária é de pequeno porte, facilitando sua implementação, ainda que não seja obrigatória sua consideração de forma isolada, sendo possível expandí-lo, interligando-o às opções de transporte disponíveis na cidade de São Paulo. Mas esta característica, associada à facilidade de obtenção dos dados sobre este sistema, uma vez que ele é parte de um ambiente controlado e bem conhecido, foi fundamental na escolha deste sistema de transporte.

Estas características vêm ao encontro das necessidades de avaliação da validade do sistema, possibilitando uma implementação em tempo hábil. Entretanto, uma vez que o sistema não foi desenvolvido com base em características especiais da Cidade Universitária, sua adaptação para sistemas de maior porte não envolve grandes mudanças, sendo apenas uma questão de atualização do banco de dados e, eventualmente, algumas novas classes especializadas, visando a refletir as novas 
possibilidades de modos de transporte disponíveis e arcos de rede que venham a ser necessários.

Assim, nas próximas seções serão apresentados detalhes sobre a Cidade Universitária e seu sistema de transporte, bem como coeficientes e detalhes de modelagem aplicados. Após estas informações, serão apresentados os testes realizados e as análises dos resultados obtidos.

\subsection{O Transporte na Cidade Universitária}

A Cidade Universitária Armando de Salles Oliveira, localizada na região oeste da cidade de São Paulo, possui uma área aproximada de cerca de quatro quilômetros quadrados.

Esta área é coberta basicamente por seis avenidas e uma rua principal, além de diversas travessas menores. As avenidas e a rua principal são:

- Avenida Professor Melo Moraes

- Avenida da Universidade

- Avenida Professor Luciano Gualberto

- Avenida Professor Ernesto de Morais Leme

- Avenida Professor Lineu Prestes

- Avenida Professor Almeida Prado

- Rua do Matão

Uma vez que os edifícios existentes (unidades de ensino e pesquisa, centro poliesportivo, restaurantes, unidades administrativas, etc.) estão dispostos de forma bastante dispersa na área da Cidade Universitária, em algumas situações podem ser necessárias caminhadas de vários quilômetros entre pontos de interesse. 
Como uma alternativa às caminhadas existem duas linhas de ônibus circulares, gratuitas, e também três pontos de táxi (Praça da Reitoria, Hospital Universitário e Faculdade de Economia, Admnistração e Contabilidade). Além disso, diversas linhas de ônibus externas passam por dentro do campus, entrando pela Avenida da Universidade (Portaria 1) e tendo seu ponto final na Avenida Professor Almeida Prado (próximo à Portaria 2).

Ambas as linhas de ônibus circulares percorrem todas as principais vias do campus. Tais linhas foram denominadas "Circular 1" e "Circular 2", sendo o sentido de seus trajetos contrários entre si, como pode ser observado na figura 4.1.

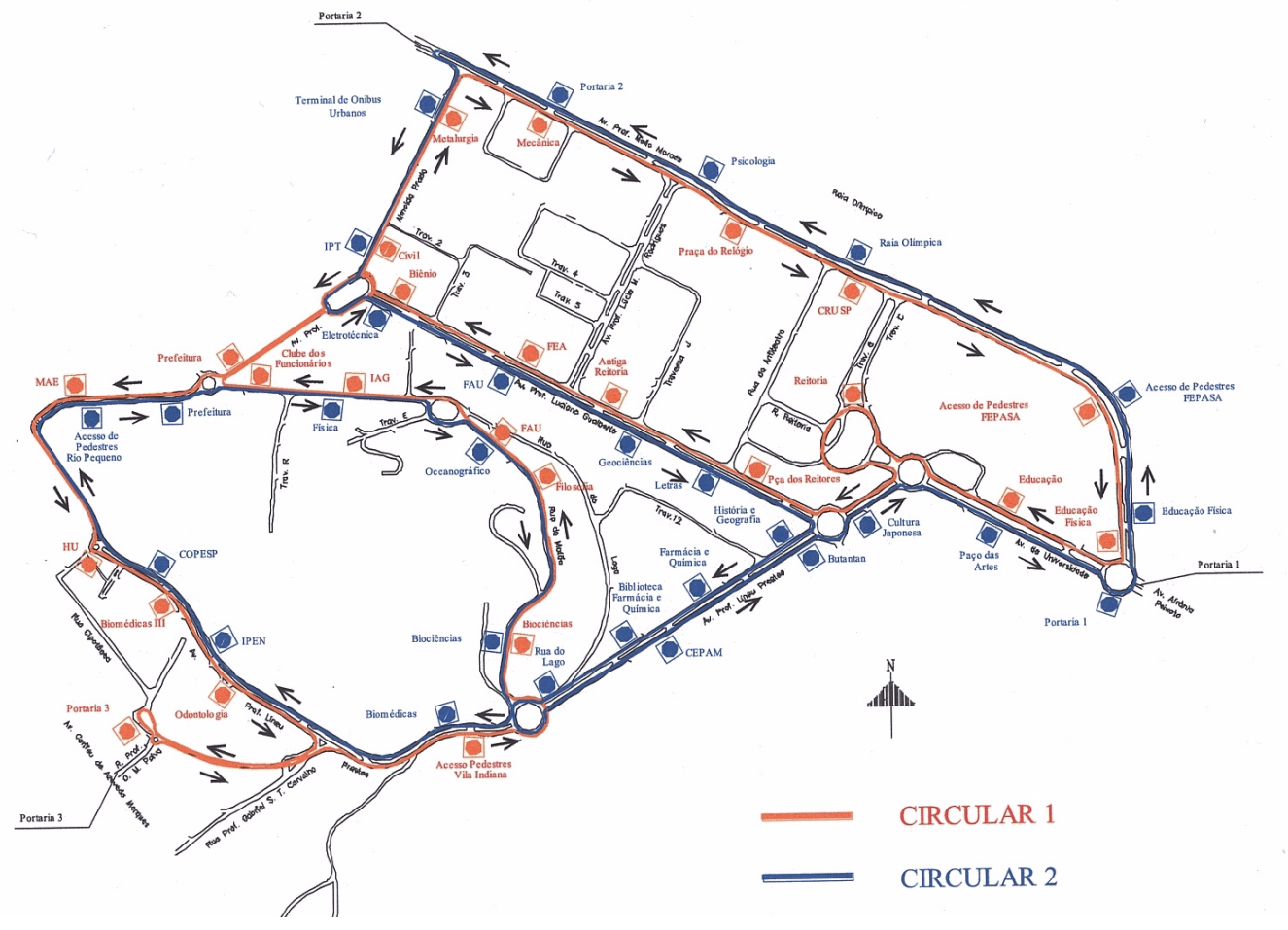

Fig. 4.1 - Linhas de ônibus da Cidade Universitária (Fonte: LPT-EPUSP)

Segundo pesquisa e simulação realizados pelo Laboratório de Planejamento e Operação de Transportes (LPT-EPUSP) e pelo Departamento de Engenharia Naval (PNV-EPUSP), o tempo de ciclo médio varia de acordo com a velocidade média, como pode ser verificado no gráfico da figura 4.2. 


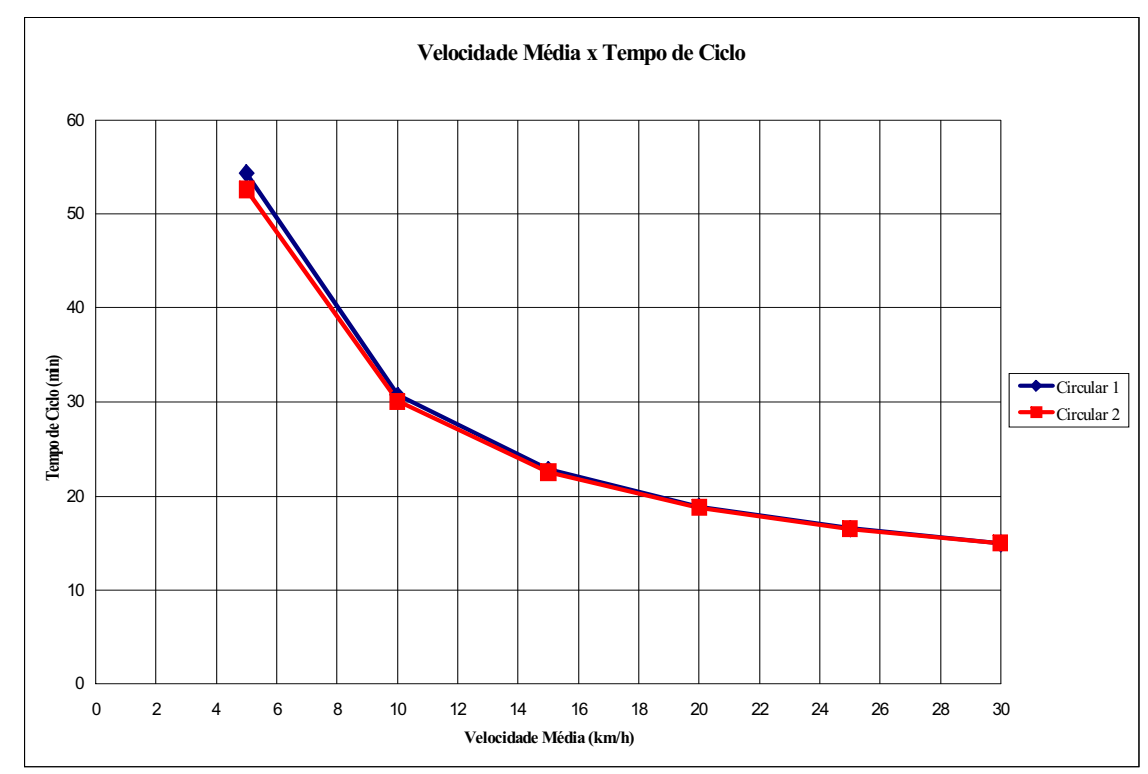

Fig. 4.2 - Gráfico Velocidade Média x Tempo de Ciclo dos circulares (Fonte: LPT-EPUSP)

Sendo a velocidade média dos circulares na faixa de 10 a $12 \mathrm{~km} / \mathrm{h}$, o tempo de ciclo de cada um deles varia entre 25 e 30 minutos. Entretanto, este tempo pode chegar a uma hora, devido ao maior tempo de parada em alguns locais (pontos finais).

Para realizar estas viagens, quatro ônibus trafegam durante dezoito horas por dia, das 6:00 às 24:00, sendo que cada motorista cumpre seis horas na operação do circular, com um intervalo de 15 minutos após a terceira hora de trabalho.

Devido à similaridade dos tempos de ciclo e o fato de ambas as rotas de circulares passarem praticamente pelas mesmas regiões do campus, existe margem para dúvida sobre qual opção seria a mais adequada para ir de um ponto a outro, de uma determinada unidade a outra. Além disso, existe ainda a dúvida quanto a ir a pé ou tomar um dos ônibus circulares, enfrentando tempos de trajeto e de espera, para se deslocar de uma unidade a outra.

Para auxiliar o usuário nestas decisões, o sistema oferecido atualmente pela prefeitura da Cidade Universitária é bastante limitado, possuindo apenas alguns 
mapas estáticos e listas que indicam as rotas dos circulares (acessíveis pela internet). Além disso, os horários de passagem dos circulares em cada ponto são pré-determinados, mas tais horários são pouco confiáveis. Uma vez que tais horários nem sempre são cumpridos, eles possuem uma utilidade bastante limitada no apoio à decisão do usuário.

\subsection{Premissas e Coeficientes}

A fim de possibilitar a modelagem e implementação em tempo hábil, algumas simplificações foram feitas sobre o sistema a ser modelado. Tais simplificações, relacionadas aos modelos apresentados no Anexo A e B, são:

Usuários jovens: Os usuários foram considerados como sendo jovens e, portanto, a velocidade a pé pode ser considerada relativamente alta e fixa. Esta hipótese é razoável, dado que a grande maioria dos usuários do transporte coletivo na Cidade Universitária é composta por alunos e trabalhadores. A velocidade admitida para a caminhada nesta implementação foi de $4 \mathrm{~km} / \mathrm{h}$.

Apenas ônibus circulares: O sistema de transporte da Cidade Universitária foi limitado às linhas dos circulares disponíveis, em composição com a possibilidade de caminhada. Esta simplificação, mais uma vez, visa a uma implementação em tempo hábil, já que a consideração de outros modos de transporte tornaria a rede bastante grande.

Intensidade de tráfego constante: $\mathrm{O}$ sistema foi considerado sem variações de tráfego ao longo do dia. É sabido que o tráfego dentro da Cidade Universitária sofre variações nos períodos de entradas e saídas de alunos. Estes eventos ocorrem por volta das 7:30 da manhã, 13:00 e 18:00. Entretanto, o aumento de tráfego provoca 
lentidão interna por cerca de 30 minutos, sendo a aproximação considerada válida para todos os outros horários.

Ônibus com velocidade constante: Como decorrência da consideração de uma intensidade de tráfego constante, foi admitida uma velocidade constante para os ônibus em todos os trechos do campus. A velocidade adotada foi a de $10 \mathrm{~km} / \mathrm{h}$.

Ônibus sem horários definidos: Uma vez que os horários dos ônibus circulares nem sempre são respeitados, a utilização dos mesmos foi considerada inadequada. Assim, optou-se por adotar um tempo de espera médio, baseado no intervalo entre a passagem dos ônibus e não na programação de viagens. O tempo de espera médio foi considerado como a metade do supracitado intervalo, segundo os gráficos de Velocidade x Tempo de Ciclo, já apresentado na figura 4.2.

Inexistência de transbordos diretos: Para a modelagem, foi considerado que a transferência de um modo de transporte a outro deve ocorrer sempre por intermédio da rede de deslocamento a pé.

Base no coeficiente de custo do ônibus: Para o cálculo de custo e tempo generalizados, conceito que é apresentado com detalhes no Anexo A, é necessário estabelecer relações de custo entre os diferentes tipos de modo de transporte (por ônibus, a pé, etc.), espera (no ponto de ônibus, etc.) e penalização por transferência. Foram adotados os parâmetros:

- Coeficiente de tempo dentro do ônibus (base): 1.0

- Coeficiente de tempo de caminhada: 2.0

- Coeficiente de tempo de espera por ônibus: 3.0

- Penalização por transferência desconsiderada. 
Excluindo-se a penalização por transferência, tais coeficientes estão em consonância com os parâmetros apresentados na literatura (FARIA, 1985); (FARIA, 1991); (GIACAGLIA, 1993); (HORN, 2003), embora estes valores não sejam necessariamente perfeitos para a realidade do campus. No caso da penalização por transferência, esta foi admitida já contemplada pela espera média, dada a não existência de transbordo direto de um modo a outro.

Tal decisão não causa, no entanto, grandes impactos nos resultados, uma vez que os tempos de viagem dentro da Cidade Universitária são relativamente curtos com relação aos tempos de espera, fazendo com que soluções que usem os dois circulares sejam raras.

Uma consideração importante é que a obtenção de valores precisos para os coeficientes de custo/tempo generalizado só é possível mediante uma ampla pesquisa com os usuários do sistema. Entretanto, a aplicação e análise deste tipo de pesquisa foge ao escopo do presente trabalho, podendo ser realizada a posteriori, já que a correção destes valores para o sistema de apoio ao usuário envolve uma simples modificação no banco de dados.

\subsection{A Modelagem}

O sistema de transporte completo do campus da Cidade Universitária, a ser modelado, é o que foi apresentado anteriormente, na figura 4.1. Foram feitas as considerações da seção anterior e, com base neste sistema, foi definida uma rede básica que representa os possíveis deslocamentos pelas vias principais do campus, independente do modo de transporte, que será a base para os deslocamentos a pé. 
Tal rede é composta por 47 nós (numerados de 1 a 47), sendo que cada interligação do arruamento é composta por dois arcos, cada um indicando um sentido de movimento, possibilitando deslocamentos a pé nos dois sentidos, entre os nós.

Uma demonstração esquemática desta parte da rede pode ser observada na figura 4.3, onde cada conexão representa uma ligação de sentido duplo, ou seja, representa dois arcos.

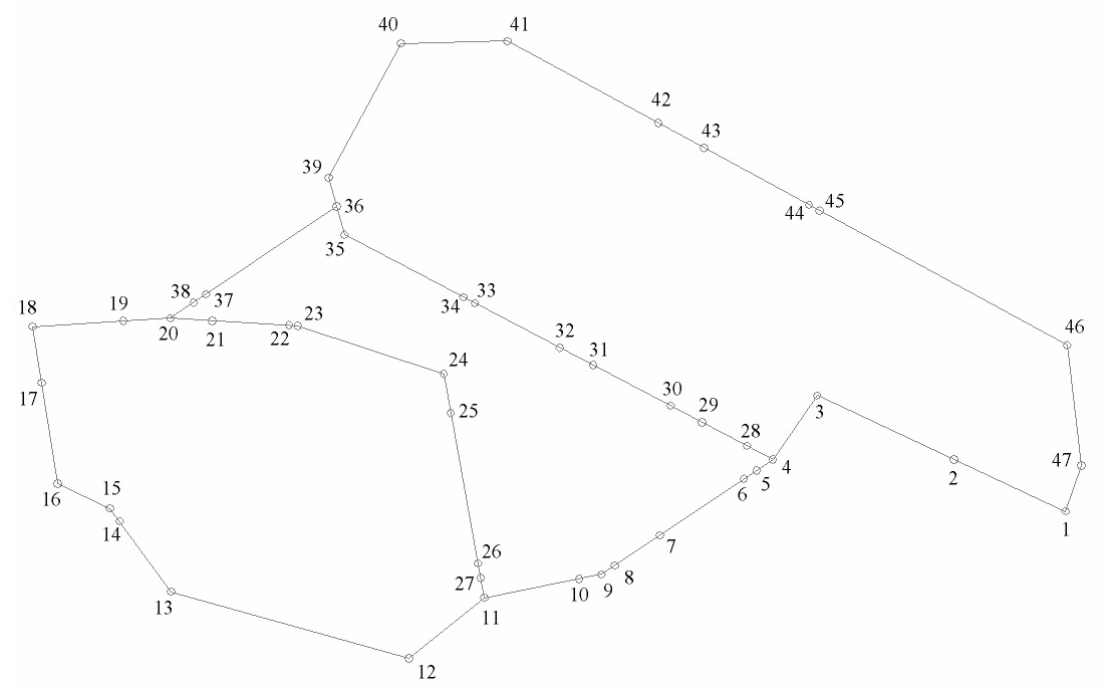

Fig. 4.3 - Rede básica das ruas principais do campus

Cada um dos nós desta rede representa locais onde os usuários podem entrar na rede, bem como nós em que podem trocar de modo de transporte (a pé para ônibus e vice-versa). As redes dos ônibus são representadas por duas sub-redes: uma de 25 nós (numerados de 201 a 225), representando a linha Circular 1 (laranja) e outra de 29 nós (numerados de 101 a 129), representando a linha Circular 2 (azul).

Nestas redes, cada conexão representa um único arco, sendo que seu sentido é definido pelo sentido da linha de ônibus ao qual ele se refere. A representação das redes de ônibus pode ser verificada na figura 4.4. 


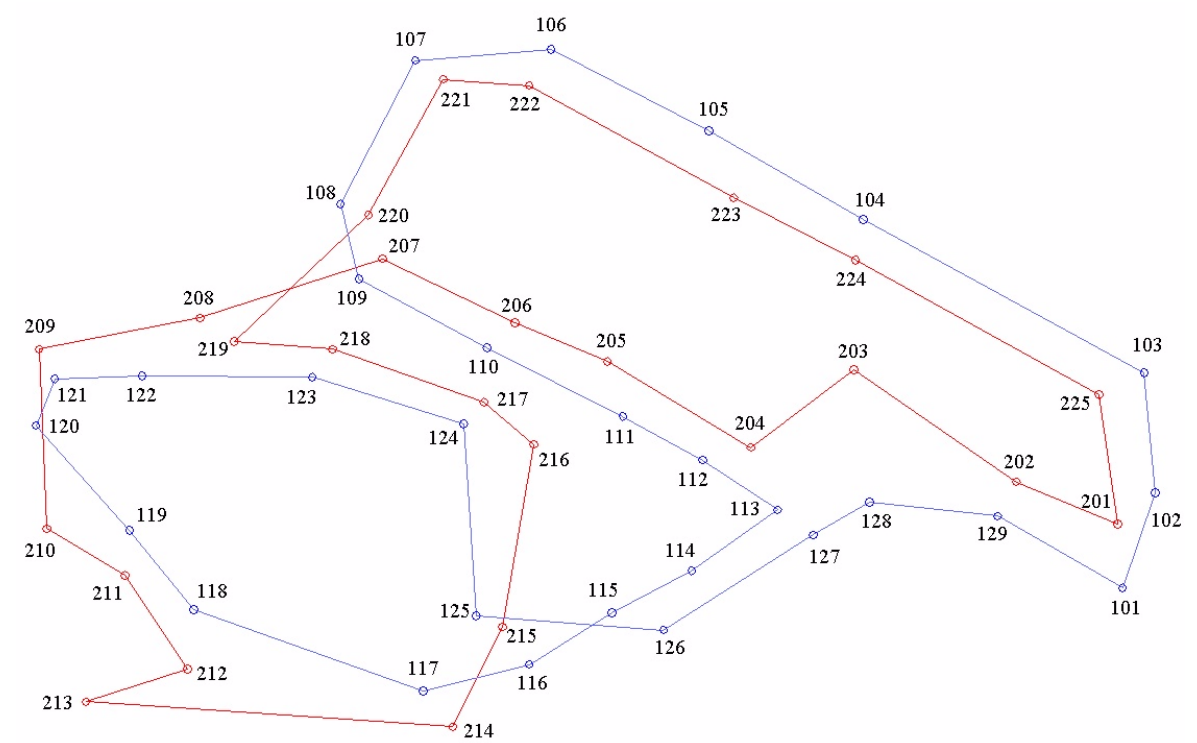

Fig. 4.4 - Rede básica das linhas de ônibus do campus (interconexão dos pontos)

As redes (a pé e por ônibus) precisam ser interligadas. Tais interligações foram representadas por arcos fictícios, que incorporam os eventuais custos de mudança de modo de transporte, incluindo tempos de espera. A rede simplificada completa pode ser verificada na figura 4.5.

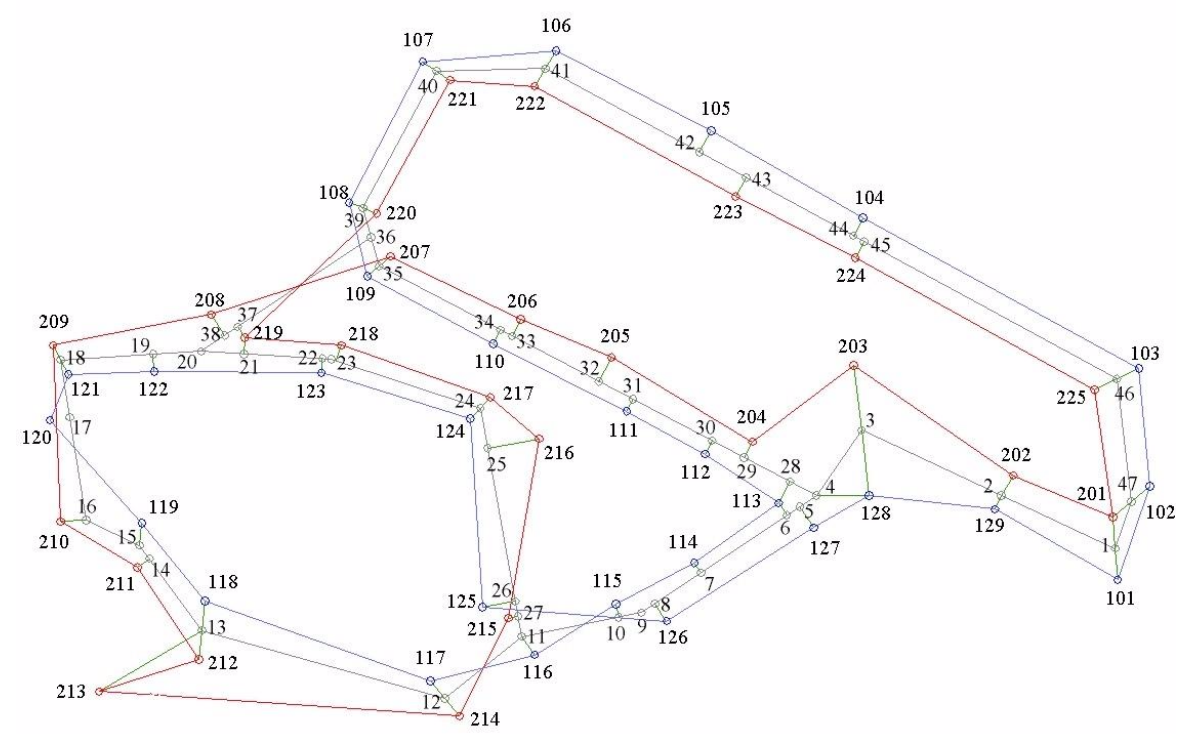

Fig. 4.5 - Rede completa 
As interligações que representam os transbordos estão representadas como conexões em verde, que representam dois arcos (um para cada sentido). As demais conexões representadas são meras reproduções das figuras anteriores. Em sua configuração final, este modelo simplificado possui 101 nós e 266 arcos.

Vale ressaltar que este modelo simplificado poderia ainda incorporar linhas de onibus externas e possivelmente rotas de trem e metrô, para que fosse possível uma visão global das características das viagens dos usuários da Cidade Universitária. Além disso, a rede básica poderia também incorporar as ruas não principais e ter seu número de nós e arcos bastante ampliado, para que a representação gráfica da rede coincidisse com o arruamento representado no mapa.

De qualquer forma, a opção por não realizar estas modificações não interfere na validade dos resultados obtidos, dentro dos objetivos propostos. Além disso, o modelo simplificado atende melhor às necessidades de avaliação de funcionamento do sistema de apoio proposto, permitindo a implementação no tempo disponível e uma validação mais simples, sendo estas as principais razões para sua adoção.

\subsection{Análise de Dados e Resultados}

A fim de avaliar o cumprimento de seus objetivos, o teste do software foi dividido em duas partes: testes de desempenho de cálculo e testes de apresentação.

A primeira parte é relativa à eficiência de processamento do Servidor de Cálculo, ou seja, o tempo que este demora para fornecer uma solução. A segunda é relativa ao funcionamento da coleta e apresentação de dados, ou seja, se o sistema coleta corretamente os dados e se fornece uma solução correta e de fácil identificação pelo usuário. 
Tanto o tempo de processamento quanto a facilidade de interação com o usuário são importantes, uma vez que são requisitos chave para a eficiência e eficácia do sistema. O tempo de processamento é fundamental, visto que o usuário usualmente não está disposto a esperar mais do que alguns segundos pela resposta. Por sua vez, a facilidade de interação também é importante, para que o usuário possa requisitar e receber do sistema exatamente a informação que deseja.

\subsubsection{Desempenho de Cálculo}

A análise de desempenho de cálculo é fundamental, por proporcionar uma medida do número de requisições que o sistema de cálculo é capaz de atender, para um dado tempo máximo de espera. Esta é uma avaliação que indica o limite teórico de processamento do sistema implementado, desprezando latências e limitações de banda de transferência da rede.

Na prática, tais latências e limitações de banda de transferência existem, mas sempre podem ser mitigadas, melhorando a qualidade e a quantidade de equipamentos dos servidores. Entretanto, tais características dependem também do equipamento de consulta, que pode ter as características mais variadas, sendo esta a razão pelo interesse em uma análise que independa do mesmo.

Assim, o objetivo desta seção é verificar o limite teórico de cálculo do sistema, considerando o número de requisições a serem atendidas por unidade de tempo - simultâneas ou não, para o sistema de transportes da Cidade Universitária.

Vale ressaltar, entretanto, que todos os serviços necessários ao cálculo da rede estarão sendo executados em um mesmo equipamento, de um único processador, que é a configuração que se supõe suficiente no caso teste. Esta configuração possui 
vantagens e desvantagens do ponto de vista de tempo de cálculo, sendo positivo ressaltá-las.

Dentre as vantagens, destaca-se o fato de a latência ser mínima e a taxa de transferência ser máxima entre os módulos de cálculo e de informações. Isso faz com que o resultado se aproxime bastante do máximo teórico, onde a latência tende a zero e a taxa de transferência tende ao infinito.

Quanto às desvantagens, destaca-se a concorrência por recursos de sistema entre os processos de cálculo e consulta de banco de dados. Esta concorrência é crítica, pois, em algumas situações, esta competição de recursos pode fazer com que os processos de banco de dados tornem a execução dos processos de cálculo sensivelmente mais lenta. Mesmo que os processos de banco de dados se utilizem primariamente do armazenamento permanente (disco) e este acesso seja feito por DMA (Direct Memory Access), minimizando os recursos de sistema gastos com estes processos, ainda assim serão processos que concorrerão por tempo de processamento com os processos de cálculo, reduzindo a janela de tempo disponível para cada um deles.

Uma vez definida essa opção de configuração de sistema e feitas as considerações acerca de suas vantagens e desvantagens, é importante indicar também as condições de compilação e configuração do sistema para a obtenção dos dados que serão apresentados. O módulo de cálculo foi compilado com o compilador OpenWatcom versão 1.3, com otimização máxima para Pentium e superiores, usando alinhamentos de estruturas de dados em 8 bytes e expansão de loops. O servidor de banco de dados utilizado foi o MySQL versão 4.1.7, compilado com otimizações para Pentium e com configurações padrão de comunicação, sendo a comunicação entre os módulos realizadas por soquetes TCP/IP. 


\subsubsection{Teste de desempenho para requisição única}

Apesar de ser não ser uma situação geral, é interessante realizar testes de desempenho de sistema para uma requisição única, uma vez que este teste permite minimizar a influência do efeito de concorrência entre processos na avaliação de desempenho do algoritmo, além de permitir o cálculo do máximo teórico para requisições perfeitamente em série, isto é, a requisição $i+1$ será realizada exatamente no instante em que a requisição $i$ for completada.

Para a realização deste teste, foi feito um pequeno script que simula uma requisição de solução ao servidor de cálculo, inserindo os dados pertinentes no banco de dados e solicitando em seguida que o software de cálculo prossiga com sua função.

Uma vez que, neste teste, não será utilizado o Servidor Web, que é o módulo que faz a conversão entre os dados internos do sistema e sua representação gráfica no mapa, as soluções obtidas serão apresentadas na forma numérica. Assim, é importante indicar graficamente a numeração da rede, para facilitar a compreensão das soluções fornecidas pelo sistema. Tal numeração está representada na figura 4.6.

Serão executados os seguintes testes origem-destino: 1-17; 3-40; 26-46; $39-14$; 45-11; 12-40, num computador Pentium 4 2.4GHz com 512MB de RAM e todos os dispositivos onboard. Este último dado é importante, visto que o desempenho do processamento pode ser sensivelmente prejudicado devido ao uso da placa de vídeo onboard, que compartilha a mesma memória que o processador central. Os resultados obtidos, para uma única requisição por vez, estão apresentados na tabela 4.1.

Como é possível observar, esta tabela apresenta o TTV (Tempo Total de Viagem), o TTGV (Tempo Total Generalizado de Viagem), bem como o TCSO 
(Tempo de Cálculo Sem Ordenação de nós) e TCCO (Tempo de Cálculo Com

Ordenação de nós), sendo estes dois últimos os dados relevantes neste instante.

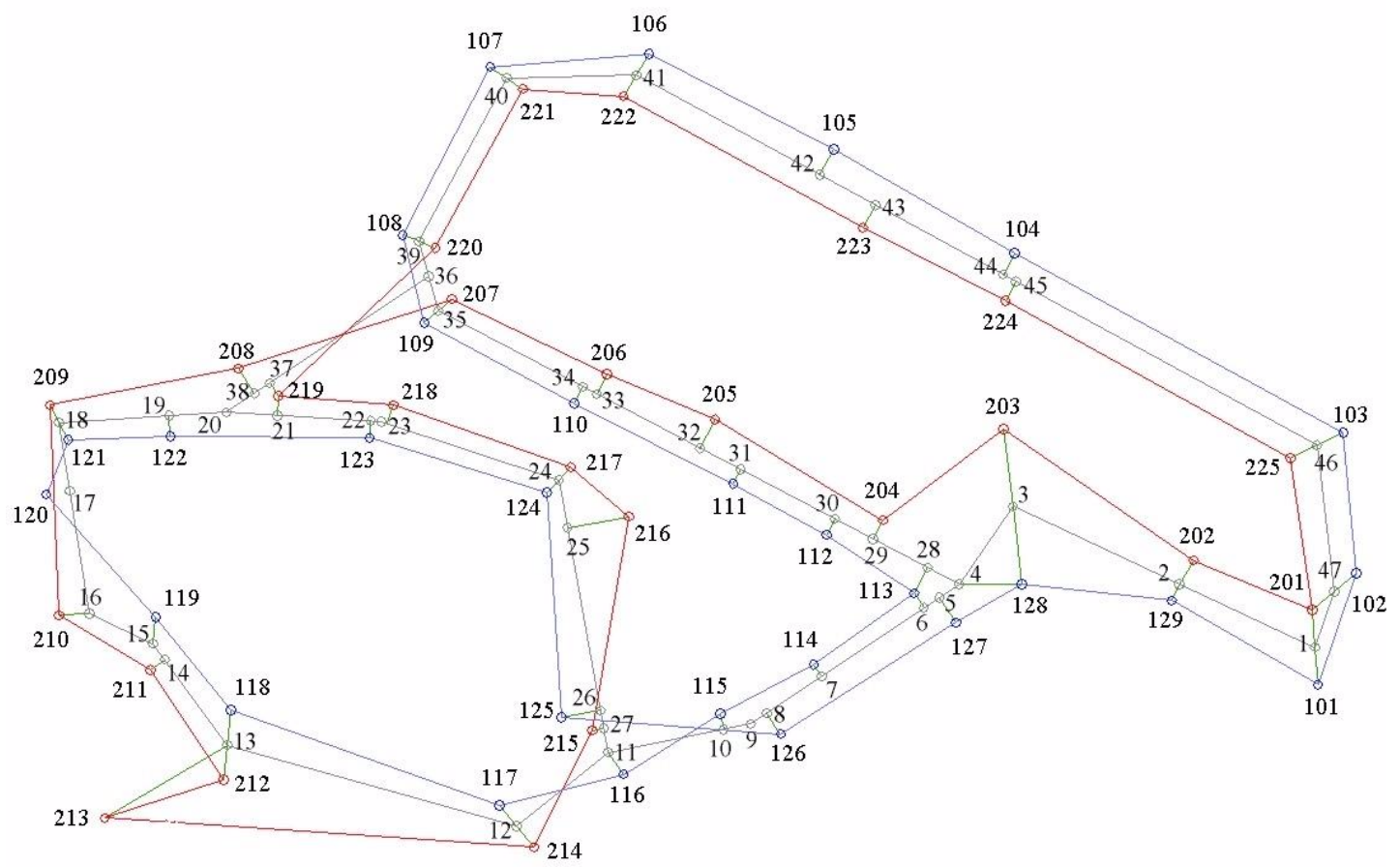

Fig. 4.6 - Rede completa

Tabela 4.1 - Tempos de resposta de solução completa pelo Servidor de Cálculo

\begin{tabular}{|c|c|l|c|c|c|c|}
\hline $\mathbf{O}$ & $\mathbf{D}$ & \multicolumn{1}{|c|}{ Solução } & $\begin{array}{c}\text { TTV } \\
(\mathbf{m i n})\end{array}$ & $\begin{array}{c}\text { TTGV } \\
(\mathbf{m i n})\end{array}$ & $\begin{array}{c}\text { TCSO } \\
(\mathbf{s})\end{array}$ & $\begin{array}{c}\text { TCCO } \\
(\mathbf{s})\end{array}$ \\
\hline 1 & 17 & $1-201-202-203-204-205-206-207-208-209-18-17$ & $31^{\prime} 58^{\prime \prime}$ & $37^{\prime} 56^{\prime \prime}$ & 0,059 & 0,111 \\
\hline 3 & 40 & $3-4-28-29-30-31-32-33-34-35-36-39-40$ & $26^{\prime} 42^{\prime \prime}$ & $31^{\prime} 57^{\prime \prime}$ & 0,065 & 0,109 \\
\hline 26 & 46 & $26-125-127-128-129-101-102-103-46$ & $27^{\prime} 16^{\prime \prime}$ & $33^{\prime} 17^{\prime \prime}$ & 0,057 & 0,111 \\
\hline 39 & 14 & $39-36-37-38-20-19-18-17-16-15-14$ & $21^{\prime} 18^{\prime \prime}$ & $25^{\prime} 29^{\prime \prime}$ & 0,058 & 0,110 \\
\hline 12 & 40 & $12-214-215-216-217-218-219-220-221-40$ & $26^{\prime} 44^{\prime \prime}$ & $32^{\prime} 19^{\prime \prime}$ & 0,058 & 0,110 \\
\hline 45 & 11 & $45-44-104-105-106-107-108-109-110-111-112-113-114-115-116-11$ & $35^{\prime} 22^{\prime \prime}$ & $41^{\prime} 26^{\prime \prime}$ & 0,062 & 0,107 \\
\hline
\end{tabular}

Ambos os valores (TCSO e TCCO) representam o tempo completo de processamento para obtenção das soluções, incluindo o tempo de requisição de dados da rede e sua construção na memória do micro, conforme foi realizada esta implementação. A diferença entre eles reside na forma de manutenção de uma das estruturas de dados do algoritmo utilizado: em um dos casos (TCSO), a lista de "próximo nó a ser calculado" é mantida sem ordenação; no outro caso (TCCO), esta 
mesma lista é mantida ordenada, sendo que os próximos nós a serem calculados serão sempre movidos para o topo da lista e os que acabaram de ser calculados serão sempre movidos para o fim da lista.

Dado que a cada iteração do algoritmo esta lista é varrida seqüencialmente em busca do próximo nó a ser calculado (maiores detalhes no Capítulo 3 e no Anexo B), acredita-se que, se uma rede possui um número grande de nós, o desempenho seja melhor com ordenação de nós ativada, sendo o resultado oposto em redes com poucos nós, como a desta implementação.

Tal suposição vem do fato de que o custo computacional da ordenação da lista de nós é alto frente ao custo de uma busca seqüencial em uma lista contendo uma pequena quantidade de nós. Entretanto, considerando-se uma implementação de lista ligada, a relação tende a se inverter com o crescimento do número de nós, já que o custo de ordenação permanecerá praticamente o mesmo, mas as buscas seqüenciais se tornarão significativamente mais lentas.

Apesar de ter sido considerado mais adequado, para o problema teste, a utilização do algoritmo sem ordenação dos nós desta lista, os testes serão sempre apresentados também com os tempos referentes ao algoritmo com ordenação de nós, de forma a avaliar diferença de desempenho entre eles.

Pela tabela 4.1, é possível observar que a implementação nesta configuração de equipamento se mostra bastante eficiente, quando considerando uma única requisição. $\mathrm{O}$ tempo de processamento das duas versões do algoritmo foi considerado compatível com a aplicação, sendo que o pior caso considerado, com o algoritmo tecnicamente mais lento para essa instância do problema, foi da ordem de um décimo de segundo. 
É possível observar também que, para este problema, a solução que não ordena os nós é realizada num tempo inferior, da ordem de 2 vezes mais rápida. Isto mostra que, para este caso, não vale a pena ordenar os nós na execução do algoritmo Label Correcting.

Por outro lado, além destes tempos de processamento globais, é possível avaliar, de forma simulada, qual seria o tempo de resposta do servidor de cálculo caso ele operasse na forma de um servidor de fato, situação em que a rede seria construída apenas uma vez, sendo possível gerar soluções sem a necessidade de reconstruí-la a cada requisição.

Este valor pode ser obtido descontando-se o tempo utilizado para requisição de informações no banco de dados e construção da rede do tempo de cálculo total. A tabela 4.2 apresenta os valores de TCSO e TCCO obtidos desta forma, juntamente com os valores para o cálculo completo.

Tabela 4.2 - Tempos de cálculo de soluções pelo do Servidor de Cálculo

\begin{tabular}{|c|c|c|c|c|c|c|c|}
\hline Origem & Destino & $\begin{array}{c}\text { TTV } \\
(\mathbf{m i n})\end{array}$ & $\begin{array}{c}\text { TTGV } \\
(\mathbf{m i n})\end{array}$ & $\begin{array}{c}\text { TCSO } \\
\text { Completo (s) }\end{array}$ & $\begin{array}{c}\text { TCSO } \\
\text { Só Cálculo (s) }\end{array}$ & $\begin{array}{c}\text { TCCO } \\
\text { Completo (s) }\end{array}$ & $\begin{array}{c}\text { TCCO } \\
\text { Só Cálculo (s) }\end{array}$ \\
\hline 1 & 17 & $31^{\prime} 58^{\prime \prime}$ & $37^{\prime} 56^{\prime \prime}$ & 0,059 & 0,003 & 0,111 & 0,037 \\
\hline 3 & 40 & $26^{\prime} 42^{\prime \prime}$ & $31^{\prime} 57^{\prime \prime}$ & 0,065 & 0,003 & 0,109 & 0,036 \\
\hline 26 & 46 & $27^{\prime} 16^{\prime \prime}$ & $33^{\prime} 17^{\prime \prime}$ & 0,057 & 0,004 & 0,111 & 0,035 \\
\hline 39 & 14 & $21^{\prime} 18^{\prime \prime}$ & $25^{\prime} 29^{\prime \prime}$ & 0,058 & 0,004 & 0,110 & 0,032 \\
\hline 12 & 40 & $26^{\prime} 44^{\prime \prime}$ & $32^{\prime} 19^{\prime \prime}$ & 0,058 & 0,002 & 0,110 & 0,035 \\
\hline 45 & 11 & $35^{\prime} 22^{\prime \prime}$ & $4^{\prime} 26^{\prime \prime}$ & 0,062 & 0,004 & 0,111 & 0,038 \\
\hline
\end{tabular}

Como é possível observar, o tempo de construção da rede, incluindo aqui os tempos de requisição de informações ao banco de dados, tem uma forte influência no tempo de execução. Pelos valores apresentados, uma implementação como servidor de fato tornaria o processamento cerca de 20 vezes mais rápido no caso de cálculo sem ordenação e da ordem de 4 vezes mais rápido no caso de processamento com ordenação de nós. 
Outra informação que é possível obter destes valores é que, para a instância do problema testada, o algoritmo sem ordenação de nós é da ordem de 10 vezes mais rápido, considerando apenas o tempo de cálculo da rede, e da ordem de 2 vezes mais rápido, considerando também o tempo de construção da rede. A queda da relação, de 10 para 2 vezes, é explicada pelo tempo gasto na construção da rede no segundo caso, que torna a diferença de desempenho dos algoritmos menos significativa para o tempo global de processamento.

\subsubsection{Teste de desempenho para requisições múltiplas}

Ainda que o teste de requisição simples seja interessante para comparações de desempenho da implementação do algoritmo, tal teste é deficiente na avaliação do desempenho do sistema em situações críticas de uso.

Para poder avaliar este tipo de situação, é necessário que sejam consideradas múltiplas requisições simultâneas, já que, na prática, esta situação de fato ocorre. Nestas situações ocorre uma grande concorrência por tempo de processamento entre os diversos processos de cálculo, de forma que, em um sistema monoprocessado, a execução simultânea de diversos processos de cálculo tem como efeito uma ampliação no tempo de cálculo de todos estes processos de cálculo.

Isto não é impróprio, uma vez que neste problema e nesta implementação todos os processos de cálculo são considerados igualmente importantes, ou seja, têm a mesma prioridade. Além disso, esta implementação, com um processo distinto para executar cada operação, facilita a modificação do sistema para o uso de múltiplas filas de execução, permitindo tirar proveito de sistemas de processamento paralelo (em equipamentos com mais de uma CPU operando paralelamente).

Entretanto, como um agravante, a administração dos diversos processos simultâneos tem um custo computacional que é especialmente sentido quando é 
utilizada uma máquina monoprocessada, além da grande disputa, entre os processos, por dispositivos como memória e disco.

Visando a avaliar o comportamento do sistema em uma condição bastante adversa, foram definidos alguns parâmetros de teste:

Equipamento: $\mathrm{O}$ mesmo dos testes de requisição única, possibilitando comparação entre os resultados obtidos em ambos os testes.

Número de requisições: o número de requisições será variável, de forma a possibilitar a avaliação do desempenho do sistema em diversas situações de carga do sistema.

Solução de teste: ao invés de gerar uma situação mais realista, onde as origens e destinos calculados poderiam seguir algum tipo de distribuição pré-definida, optou-se por escolher uma solução fixa, para a qual o tempo de cálculo do sistema para uma única requisição foi o maior, dentre os testes realizados na seção anterior. Tal solução foi a do ponto 45 ao ponto 11 da rede, levando 0,062 segundos para o cálculo da solução sem ordenação e 0,111 segundos para o cálculo da solução com ordenação.

Com base nestes parâmetros, foi elaborado um pequeno script que dispara uma quantidade pré definida de requisições da solução de trajeto dos pontos 45 a 11, de forma praticamente instantânea, registrando os tempos de solução em cada requisição. Foram realizados testes para 1, 10, 25, 50 e 100 requisições simultâneas, sendo que a tabela 4.3 resume os resultados obtidos, os quais estão representados graficamente nas figuras 4.7 e 4.8 .

Pelos gráficos é possível observar que, em um intervalo médio de 10 segundos para a resposta, é possível resolver cerca de 70 requisições simultâneas 
para o caso com ordenação de nós e cerca de 80 requisições simultâneas, sem a ordenação.

Tabela 4.3 - Tempos de cálculo de soluções, com múltiplas requisições e reconstrução da rede a cada requisição

\begin{tabular}{|c|c|c|c|c|}
\cline { 2 - 5 } \multicolumn{1}{c|}{} & \multicolumn{2}{c|}{ Sem Ordenação de Nós } & \multicolumn{2}{c|}{ Com Ordenação de Nós } \\
\hline $\begin{array}{c}\text { Requisições } \\
\text { Simultâneas }\end{array}$ & $\begin{array}{c}\text { Tempo de Cálculo } \\
\text { Médio (s) }\end{array}$ & $\begin{array}{c}\text { Desvio } \\
\text { Padrão }\end{array}$ & $\begin{array}{c}\text { Tempo de Cálculo } \\
\text { Médio (s) }\end{array}$ & $\begin{array}{c}\text { Desvio } \\
\text { Padrão }\end{array}$ \\
\hline 1 & 0,062 & 0,000 & 0,111 & 0,000 \\
\hline 10 & 0,586 & 0,048 & 0,772 & 0,129 \\
\hline 25 & 2,211 & 0,133 & 3,047 & 0,614 \\
\hline 50 & 5,186 & 0,456 & 6,083 & 0,085 \\
\hline 100 & 13,590 & 1,153 & 15,475 & 0,489 \\
\hline
\end{tabular}

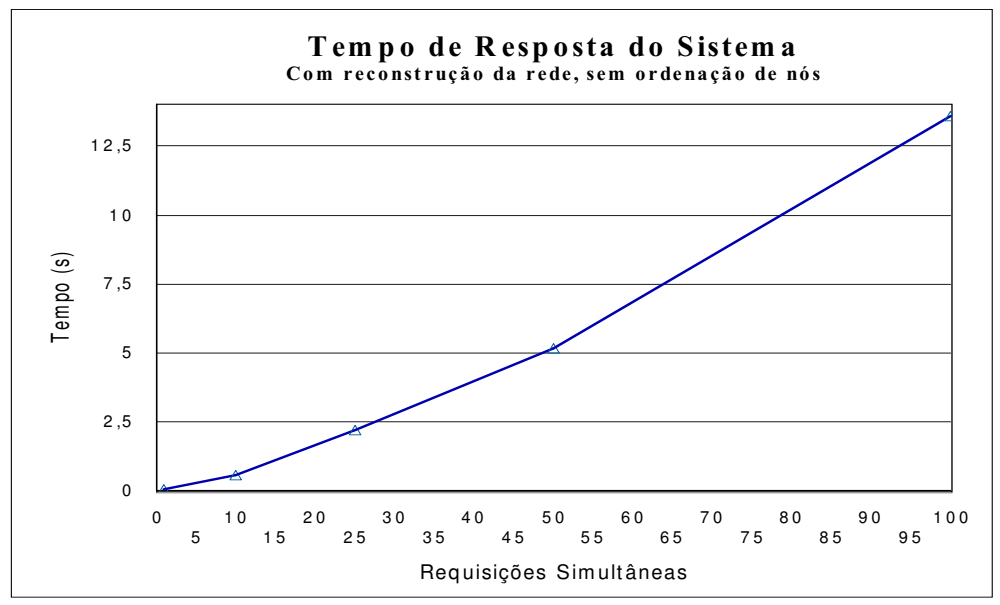

Fig. 4.7- Gráfico de tempo de resposta do sistema com reconstrução da rede, sem ordenação de nós

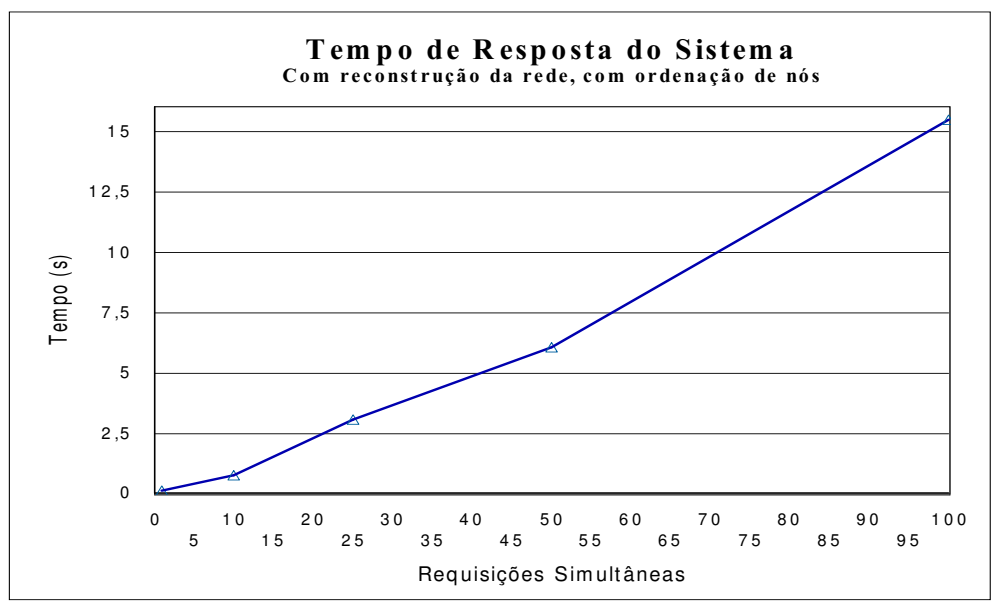

Fig. 4.8 Gráfico de tempo de resposta do sistema com reconstrução da rede, com ordenação de nós 
Este é um valor expressivo, visto que, na pior situação possível (requisições simultâneas), considerando a taxa 70 soluções a cada 10 segundos, seria possível atender a até 25.000 soluções em uma hora, o que permite cerca de 600.000 requisições diárias, chegando a cerca de 18.000.000 de requisições em um mês, o que capacidade para atender, em até 10s de espera, cerca de 9 vezes o número de acessos de sites similares, como o Apontador (http://www.apontador.com.br, consultado em Julho de 2005), cujo departamento comercial informa um número de acessos mensais de 2.000.000 de acessos.

É interessante notar que a condição de todas as requisições simultâneas é a pior situação possível. Se ao invés de considerar requisições simultâneas forem consideradas requisições perfeitamente em série, é possível obter o máximo número de requisições atendidas dividindo o tempo disponível pelo tempo de processamento individual de cada requisição.

Assim, considerando que a requisição individual mais lenta era respondida em cerca de um décimo de segundo, temos que seria possível atender a até 100 requisições em 10 segundos. Compondo este resultado de "melhor caso" com o anteriormente calculado, é possível dizer que a capacidade de processamento do servidor é a de atender entre 70 e 100 requisições a cada 10 segundos.

Entretanto, este cálculo é uma indicação média, considerando acessos perfeitamente distribuídos ao longo de tempo, o que infelizmente não ocorre na prática. Entretanto, ainda que um quarto de todas requisições de um mês de um site como o Apontador, que atende ao público nacional, ocorram em um único dia, de forma distribuída ao longo deste dia, ainda assim o sistema seria capaz de atender às requisições dentro de 10 segundos. Seriam 500.000 acessos num único dia, razoavelmente abaixo das 650.000 requisições diárias que o sistema é capaz de atender. 
É certo, porém, que esta análise exclui a banda de comunicação da rede e também o consumo de processamento do Servidor Web. Mas, mesmo que se considere que metade dos 10 segundos seja usada para o Servidor Web, os outros 5 segundos de processamento restantes são suficientes para atender de 40 a 50 requisições simultâneas, o que é um valor substancial, em especial se considerado o público alvo da aplicação teste, a Cidade Universitária Armando de Salles Oliveira, onde seria possível atender a uma população de 15.000 estudantes em pouco mais de uma hora, respeitando a espera máxima de 10 segundos, se as consultas fossem realizadas de uma forma razoavelmente distribuída ao longo desta hora.

Por esta razão, os valores dos testes apresentados foram considerados compatíveis com a realidade de uso, mediante a rede utilizada. Entretanto, é visível que, dada a grande influência do tempo de constituição da rede a cada requisição, para redes maiores o desempenho pode degradar-se de forma bastante acentuada, tornando a implementação realizada ineficaz.

Uma das propostas de evolução deste trabalho é justamente a modificação do Servidor de Cálculo em um servidor de fato e é interessante avaliar qual seria o limite teórico imposto pelo cálculo em si, caso a rede fosse construída apenas quando o servidor é iniciado, ao invés de tal processo ser realizado a cada requisição.

Para a realização desta análise, foi repetido o teste de várias requisições simultâneas, mas desta vez ignorando o tempo gasto com a construção da rede, considerando apenas o tempo de configuração da rede e sua solução. Os resultados deste teste estão apresentados na tabela 4.4 e nos gráficos das figuras 4.9 e 4.10 .

Em ambos os gráficos é possível observar que o tempo de solução permanece praticamente inalterado, independente do número de requisições. Entretanto, por se tratar de uma simulação em que não existe de fato um servidor respondendo às solicitações e sim vários processos sendo disparados praticamente simultaneamente, 
não é possível tomar este resultado como se o número de requisições simultâneas fosse praticamente infinito.

Tabela 4.4 - Tempos de cálculo de soluções, com múltiplas requisições sem o tempo de reconstrução da rede

\begin{tabular}{|c|c|c|c|c|}
\cline { 2 - 5 } \multicolumn{1}{c|}{} & \multicolumn{2}{c|}{ Sem Ordenação de Nós } & \multicolumn{2}{c|}{ Com Ordenação de Nós } \\
\hline $\begin{array}{c}\text { Requisições } \\
\text { Simultâneas }\end{array}$ & $\begin{array}{c}\text { Tempo de Cálculo } \\
\text { Médio (s) }\end{array}$ & $\begin{array}{c}\text { Desvio } \\
\text { Padrão }\end{array}$ & $\begin{array}{c}\text { Tempo de Cálculo } \\
\text { Médio (s) }\end{array}$ & $\begin{array}{c}\text { Desvio } \\
\text { Padrão }\end{array}$ \\
\hline 1 & 0,004 & 0,000 & 0,038 & 0,000 \\
\hline 10 & 0,004 & 0,001 & 0,037 & 0,001 \\
\hline 25 & 0,005 & 0,001 & 0,038 & 0,001 \\
\hline 50 & 0,005 & 0,001 & 0,038 & 0,001 \\
\hline 100 & 0,004 & 0,001 & 0,039 & 0,002 \\
\hline
\end{tabular}

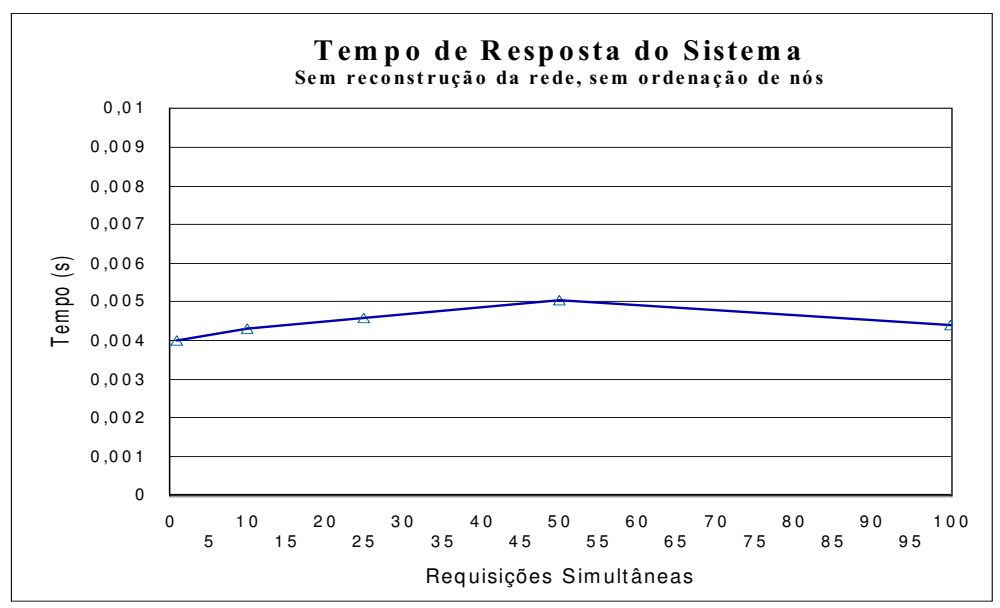

Fig. 4.9- Gráfico de tempo de resposta do sistema sem reconstrução da rede, sem ordenação de nós

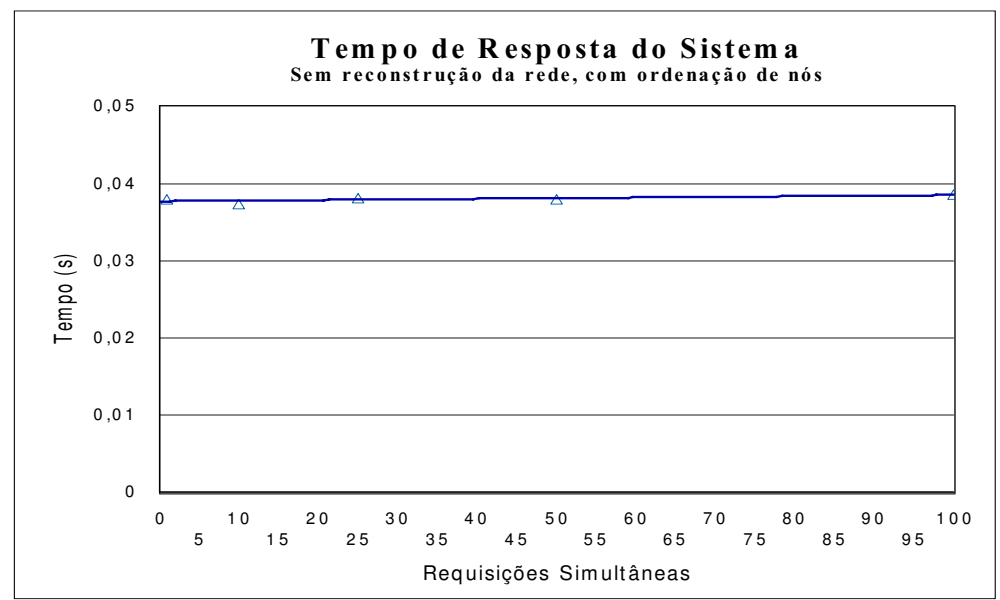

Fig. 4.10 Gráfico de tempo de resposta do sistema com reconstrução da rede, com ordenação de nós 
Para avaliar este resultado, é preciso ressaltar o fato de que o sistema operacional demora um certo tempo para criar cada novo processo. Este intervalo é considerado curto para a maioria das situações, mas não tão curto que possa ser desprezado em casos onde o tempo de cálculo é da mesma ordem de grandeza ou inferior a este tempo, como acontece aqui.

O que este resultado indica é que as requisições não estão ocorrendo, de fato, de forma simultânea. Apesar de muito rapidamente, o tempo que o sistema demora para criar o processo de uma requisição, incluindo a constituição da rede, é superior ao tempo que o sistema demora para realizar o cálculo da solução, fazendo com que cada processo de cálculo possa ser executado praticamente sozinho.

Uma vez que o tempo médio de solução sem a ordenação é de 0,004 segundos e de 0,038 segundos com a ordenação, por existir apenas uma CPU no sistema, poder-se-ia dizer que o limite teórico de soluções para um servidor de cálculo deste tipo, em 10 segundos, seria 2500 para o caso sem ordenação e 263 para o caso com ordenação. Entretanto, estes tempos só seriam válidos em uma execução perfeitamente seqüencial, ou seja, sem concorrência real entre processos.

Ainda que estas informações não sejam determinantes, é possível dizer que o benefício de uma conversão do Servidor de Cálculo para um servidor de fato é bastante claro, minimizando a vinculação do desempenho do cálculo ao desempenho do banco de dados, tornando-o dependente quase que exclusivamente do poder de processamento da(s) máquina(s) usada(s) para sua execução.

\subsubsection{Teste de Apresentação}

Apesar da importância do desempenho do cálculo e do tempo de resposta do sistema, não é possível avaliar o desempenho global de um sistema de informações 
apenas por este aspecto: é preciso também avaliar a apresentação de suas informações e alternativas que ele oferece, verificando se os resultados fornecidos realmente são coerentes com as necessidades dos usuários.

Uma forma adequada de realizar uma avaliação de um sistema deste tipo, contemplando sua flexibilidade e facilidade de uso, é por meio de uma pesquisa de campo. Entretanto, a complexidade e o tempo necessário para a realização de uma pesquisa deste tipo foge ao escopo deste trabalho, ficando como uma proposta de evolução futura, para melhoria da interface com o usuário.

Por outro lado, é possível realizar uma avaliação alternativa, focando nos ganhos proporcionados pelas soluções fornecidas frente a soluções alternativas, como a realização do caminho apenas por caminhada. A inspeção visual das soluções apresentadas também é interessante, verificando se as informações são apresentadas de forma simples e clara.

Com o objetivo de realizar tais testes, foram selecionados alguns trajetos que apresentam situações variadas de deslocamento dentro do campus da Cidade Universitária, onde serão verificadas a adequação da solução apresentada, frente a uma solução alternativa.

Entretanto, a interface com o usuário não fornece a seqüência de nós na forma numérica, dado que o número de cada nó é uma informação relevante apenas para o Servidor de Cálculo. Buscando uma rápida identificação da rota por parte do usuário, a interface fornece soluções nas formas textual e gráfica.

Sendo assim, a identificação de rotas por "origem" e "destino" numéricos não é mais adequada, neste caso. Alternativamente, os trajetos serão indicados com os nomes dos pontos de origem e destino, sejam eles nomes de logradouro ou pontos de 
ônibus. Os trajetos escolhidos para esta avaliação, os quais serão detalhados em seguida, são:

- Da Portaria 1 até o MAE

- Da Casa de Cultura Japonesa até o Terminal de Ônibus Urbano

- Do Acesso de Pedestres FEPASA até o Instituto Oceanográfico

- Do Prédio da Engenharia Civil até o IPEN

- Do Acesso a Pedestres Vila Indiana até o Terminal de Ônibus Urbano

- Do CRUSP até o Acesso a Pedestres Vila Indiana

\subsubsection{Da Portaria 1 até o MAE}

Ao acessar o serviço, a primeira imagem é a mostrada na figura 4.11. Nela é solicitado que o usuário selecione a origem da viagem, o que pode ser feito clicando nas proximidades da Portaria 1.

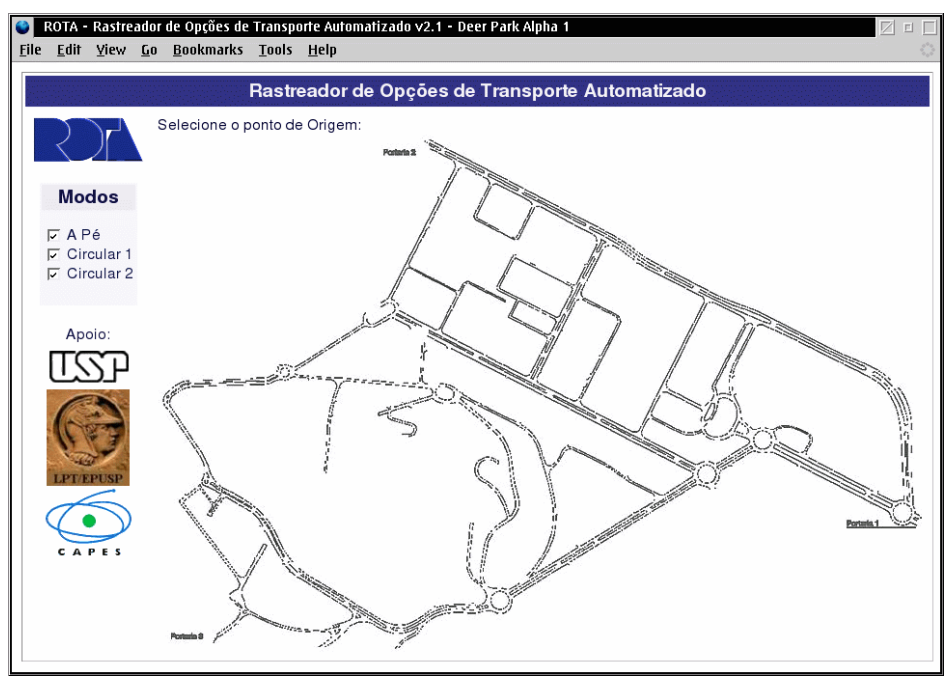

Fig. 4.11 - Imagem inicial do serviço

O software localizará o ponto de entrada na rede mais próximo e o indicará no mapa, como mostrado na figura 4.12. 


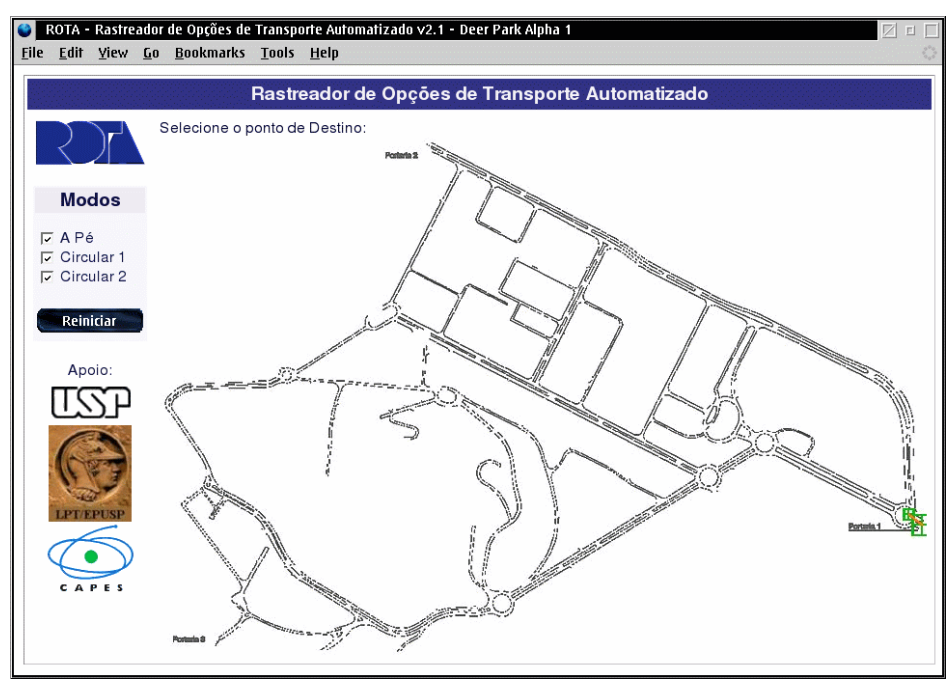

Fig. 4.12 - Portaria 1 indicada como origem

Neste instante é solicitado que o usuário indique o destino da viagem, o que pode ser feito clicando nas proximidades do MAE. Novamente o software irá calcular o ponto de saída da rede mais próximo e então mostrar todo o trajeto no mapa, como na figura 4.13 .

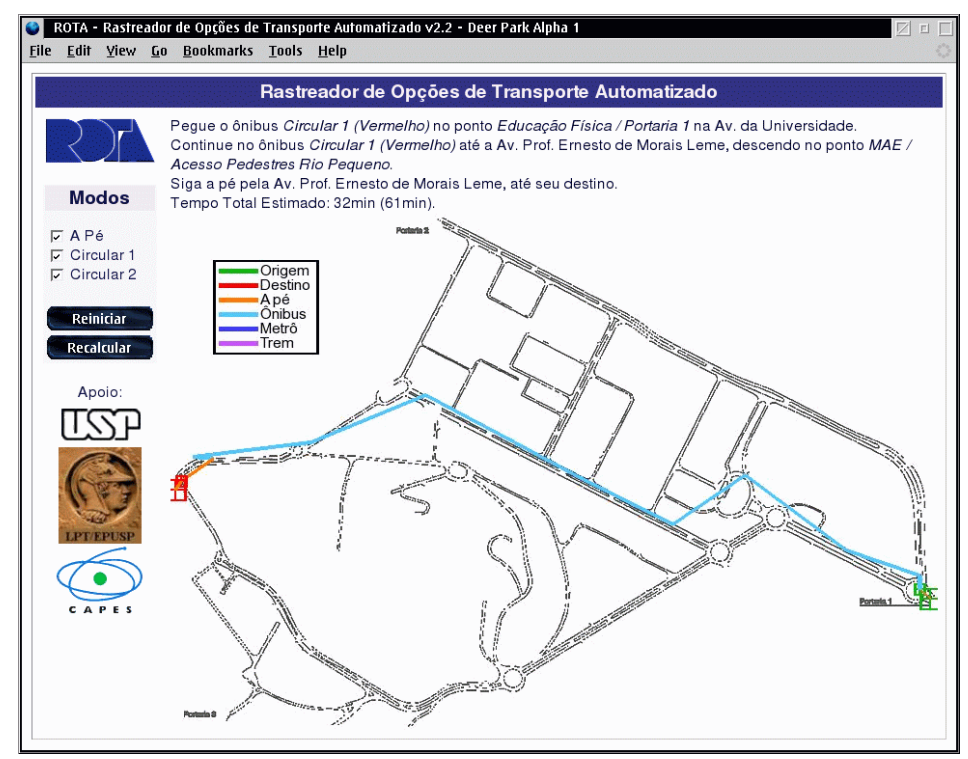

Fig. 4.13 - Solução Portaria 1 até MAE

É possível perceber que é necessário tomar um dos circulares, descendo nas proximidades do MAE e seguir a pé por um pequeno trecho, como indicado no mapa, sendo que a descrição do caminho também é apresentada: 
Pegue o ônibus Circular 1 (Vermelho) no ponto Educação Física / Portaria 1 na Av. da Universidade.

Continue no ônibus Circular 1 (Vermelho) até a Av. Prof. Ernesto de Morais Leme, descendo no ponto MAE / Acesso Pedestres Rio Pequeno.

Siga a pé pela Av. Prof. Ernesto de Morais Leme, até seu destino.

Tempo Total Estimado: 32min (61 min).

Note que, na descrição textual, dois tempos são exibidos nesta versão do software, especial para este trabalho, apresentando o tempo total de viagem e, entre parênteses, o tempo total generalizado de viagem. Na versão para o usuário final, entretanto, apenas o tempo total de viagem deve ser apresentado.

No canto superior esquerdo da tela existem três opções marcadas: "A Pé", "Circular 1" e "Circular 2". Estas opções indicam quais modos de transporte serão disponíveis para a busca da melhor solução. Como a solução usou o Circular 1, é possível verificar qual a segunda melhor opção de caminho, caso o Circular 1 não esteja disponível, desmarcando a opção Circular 1 e pressionando o botão recalcular. A nova solução é apresentada na figura 4.14.

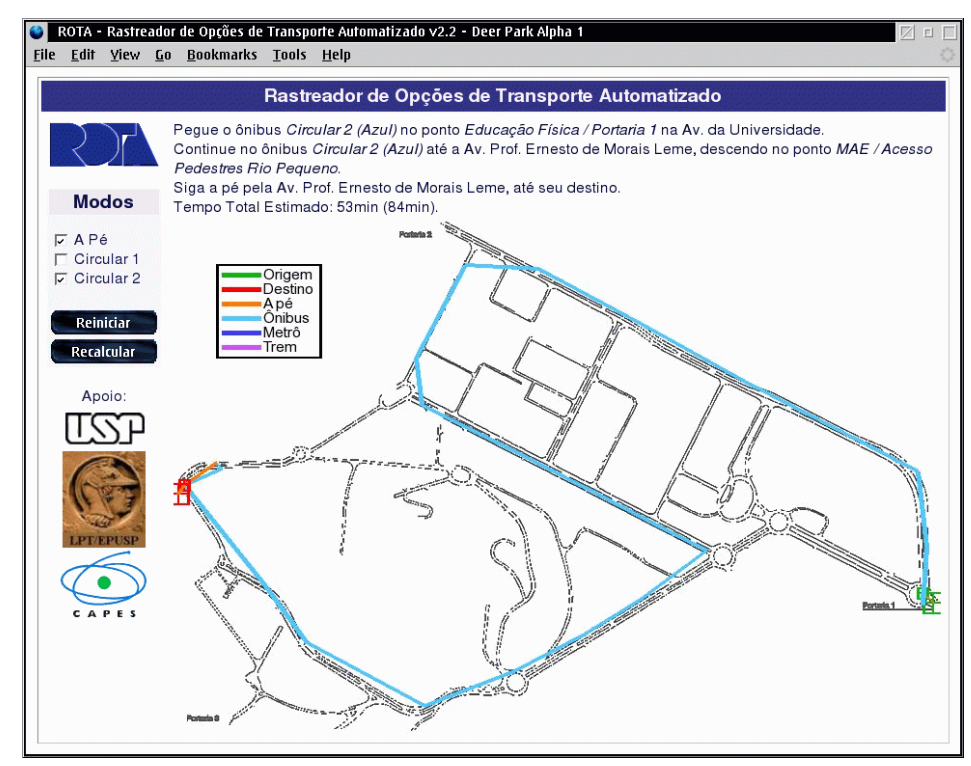

Fig. 4.14 - Solução Portaria 1 até MAE alternativa, sem Circular 1

Agora a melhor solução possível é a do Circular 2, seguido de um pequeno trecho de caminhada. 
Pegue o ônibus Circular 2 (Azul) no ponto Educação Física / Portaria 1 na Av. da Universidade.

Continue no ônibus Circular 2 (Azul) até a Av. Prof. Ernesto de Morais Leme, descendo no ponto MAE / Acesso Pedestres Rio Pequeno.

Siga a pé pela Av. Prof. Ernesto de Morais Leme, até seu destino.

Tempo Total Estimado: 53min (84min).

Como é possível observar, a diferença de tempo é de cerca de 21 minutos, quase dobrando o tempo de viagem, dada a enorme volta que o Circular 2 precisa dar para alcançar o ponto destino.

Proibindo também o uso do Circular 2, é possível forçar uma outra solução, obrigando um trajeto completo de caminhada. Tal solução pode ser obtida desmarcando a opção Circular 2 e pressionando o botão recalcular. O resultado pode ser conferido na figura 4.15 .

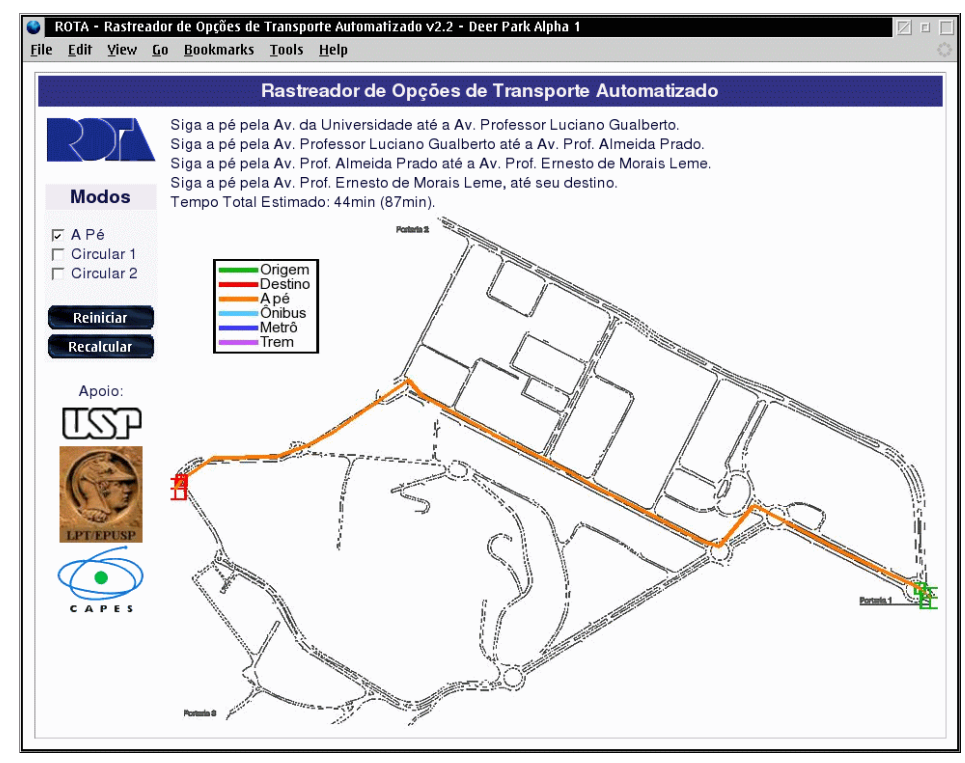

Fig. 4.15 - Solução Portaria 1 até MAE alternativa, apenas com caminhada

A descrição apresentada é:

Siga a pé pela Av. da Universidade até a Av. Prof. Luciano Gualberto.

Siga a pé pela Av. Prof. Luciano Gualberto até a Av. Prof. Almeida Prado.

Siga a pé pela Av. Prof. Almeida Prado até a Av. Prof. Ernesto de Morais Leme.

Siga a pé pela Av. Prof. Ernesto de Morais Leme, até seu destino.

Tempo Total Estimado: 44min (87min). 
Note que, nesta solução, o tempo total de viagem é inferior ao tempo total de viagem da solução que se utiliza do Circular 2, em 9 minutos. Entretanto, pelo tempo total generalizado de viagem, a viagem a pé é mais custosa em 3 minutos generalizados. Mesmo considerando o tempo real de viagem, esta solução ainda é 12 minutos mais demorada do que a solução com o Circular 1.

Este é um bom exemplo em que a utilização do tempo generalizado para o cálculo de alternativas modifica o resultado de acordo com o interesse do usuário. A eleição da solução com o Circular 2 como melhor que a de caminhada, ainda que o tempo real de caminhada seja inferior, significa que, segundo os coeficientes de tempo generalizado utilizados, 44 minutos de caminhada é ligeiramente pior para o usuário do que uma viagem de ônibus com um tempo total de 53 minutos, dos quais uma parte foi um tempo de espera.

\subsubsection{Da Casa de Cultura Japonesa até o Terminal de Ônibus Urbano}

Selecionando-se como origem as proximidades da Casa de Cultura Japonesa e como destino as proximidades do Terminal de Ônibus Urbano, o melhor trajeto fornecido é apresentado na figura 4.16 .

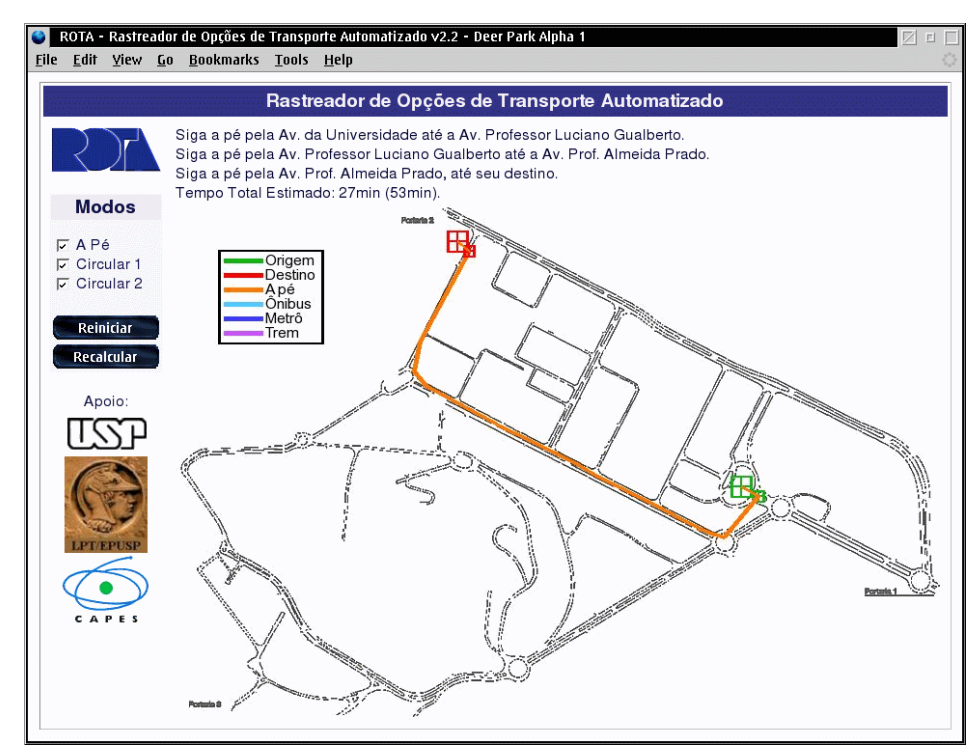

Fig. 4.16 - Solução Casa de Cultura Japonesa até Terminal de Ônibus 
A solução é apresentada com a seguinte descrição textual:

Siga a pé pela Av. da Universidade até a Av. Prof. Luciano Gualberto.

Siga a pé pela Av. Prof. Luciano Gualberto até a Av. Prof. Almeida Prado.

Siga a pé pela Av. Prof. Almeida Prado, até seu destino.

Tempo Total Estimado: 27min (53min).

Neste caso, a melhor solução não se utiliza de nenhum dos circulares, sendo este comportamento causado, provavelmente, pela curta distância envolvida no deslocamento. Entretanto, é possível verificar uma solução sem caminhada, desligando a opção "a pé" e forçando o uso dos circulares. Tal solução é apresentada na figura 4.17.

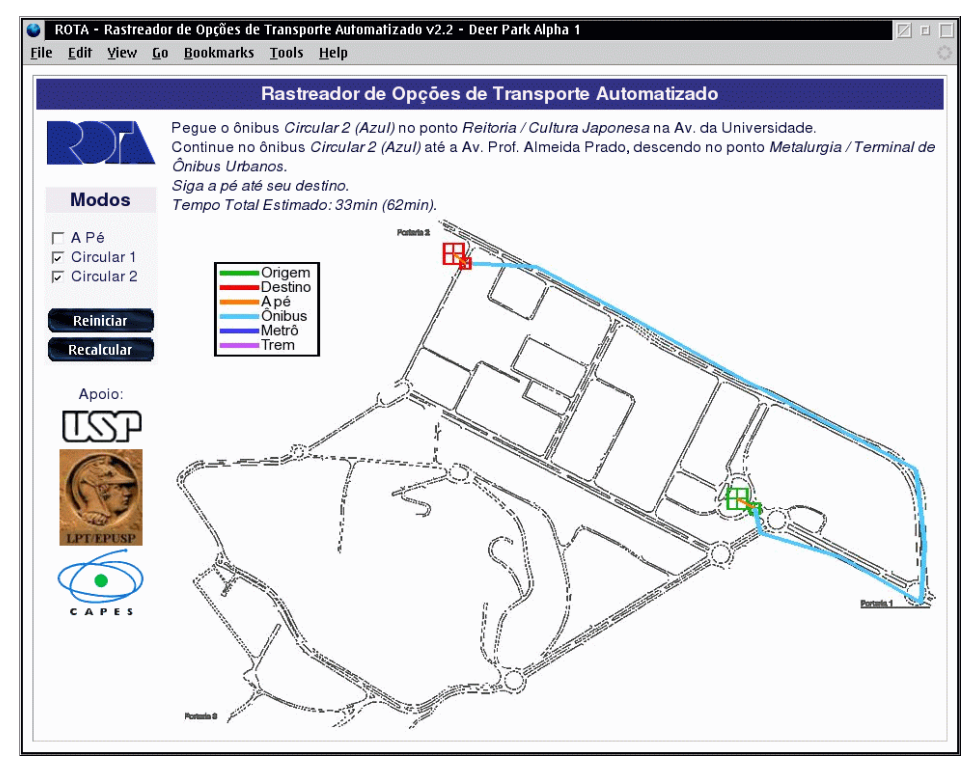

Fig. 4.17 - Solução Casa de Cultura Japonesa até Terminal de Ônibus, sem caminhada

A descrição textual é:

Pegue o ônibus Circular 2 (Azul) no ponto Reitoria / Cultura Japonesa na Av. da Universidade.

Continue no ônibus Circular 2 (Azul) até a Av. Prof. Almeida Prado, descendo no ponto Metalurgia / Terminal de Ônibus Urbanos.

Siga a pé até seu destino.

Tempo Total Estimado: $33 \mathrm{~min}$ (62min). 
Nesta solução foi utilizado o Circular 2 e o tempo cresceu cerca de 6 minutos, sendo que este aumento deve-se basicamente ao tempo relativamente alto de espera média pela passagem do circular, considerando-se um trajeto curto.

É possível ainda obrigar que o Circular 1 seja utilizado na solução, eliminando-se também o Circular 2 das possibilidades de solução, o que resulta na solução apresentada na figura 4.18.

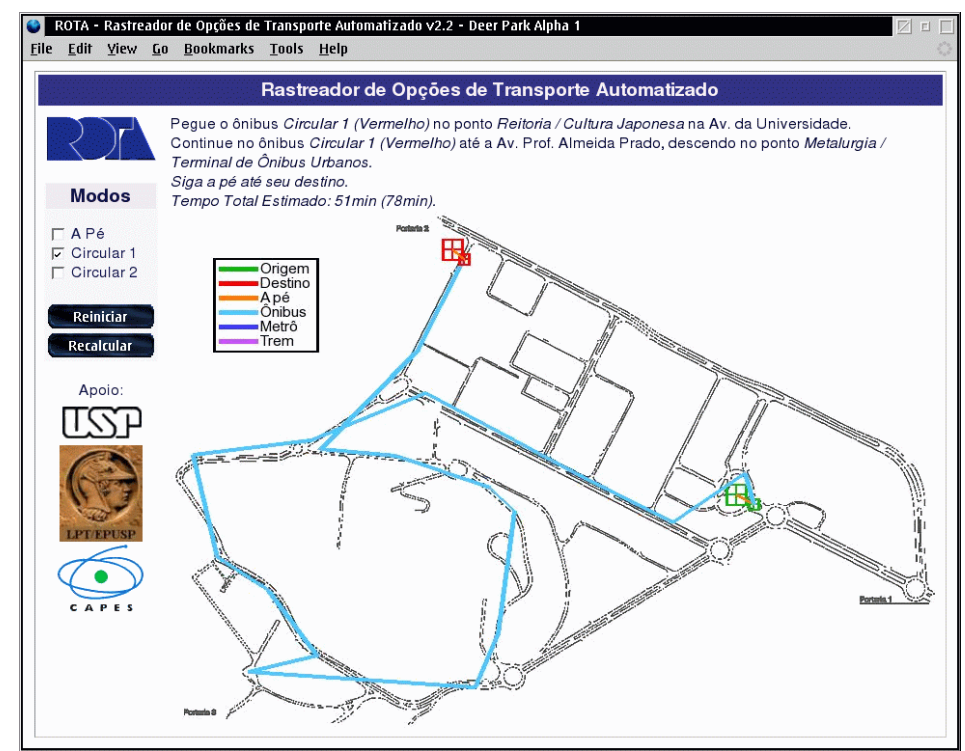

Fig. 4.18 - Solução Casa de Cultura Japonesa até Terminal de Ônibus, só Circular 1

A descrição textual é:

Pegue o ônibus Circular 1 (Vermelho) no ponto Reitoria / Cultura Japonesa na Av. da Universidade.

Continue no ônibus Circular 1 (Vermelho) até a Av. Prof. Almeida Prado, descendo no ponto Metalurgia Terminal de Ônibus Urbanos.

Siga a pé até seu destino.

Tempo Total Estimado: $51 \mathrm{~min}$ (78min).

Nesta solução, o tempo praticamente dobrou com relação ao tempo de trajeto a pé. Uma questão importante é que, aparentemente, a melhor solução neste último caso seria o usuário descer do Circular 1 na frente do Biênio da Poli, na Avenida Professor Luciano Gualberto, e seguir a pé até o Terminal. Entretanto, segundo o modelo e coeficientes, isso não ocorre e a razão é direta: a caminhada foi 
deliberadamente desativada na solução. E, se for considerada, a espera pelo Circular 1 é custosa demais, valendo mais a pena seguir a pé.

Caso sejam utilizados coeficientes diferentes, aumentando o custo da caminhada frente ao custo de espera do circular, por exemplo, é possível que a solução mista Circular 1 / Caminhada seja atingida.

\subsubsection{Do Acesso de Pedestres FEPASA até o Instituto Oceanográfico}

Selecionando-se como origem as proximidades acesso de pedestres FEPASA e como destino as proximidades do Instituto Oceanográfico, o melhor trajeto fornecido é apresentado na figura 4.19.

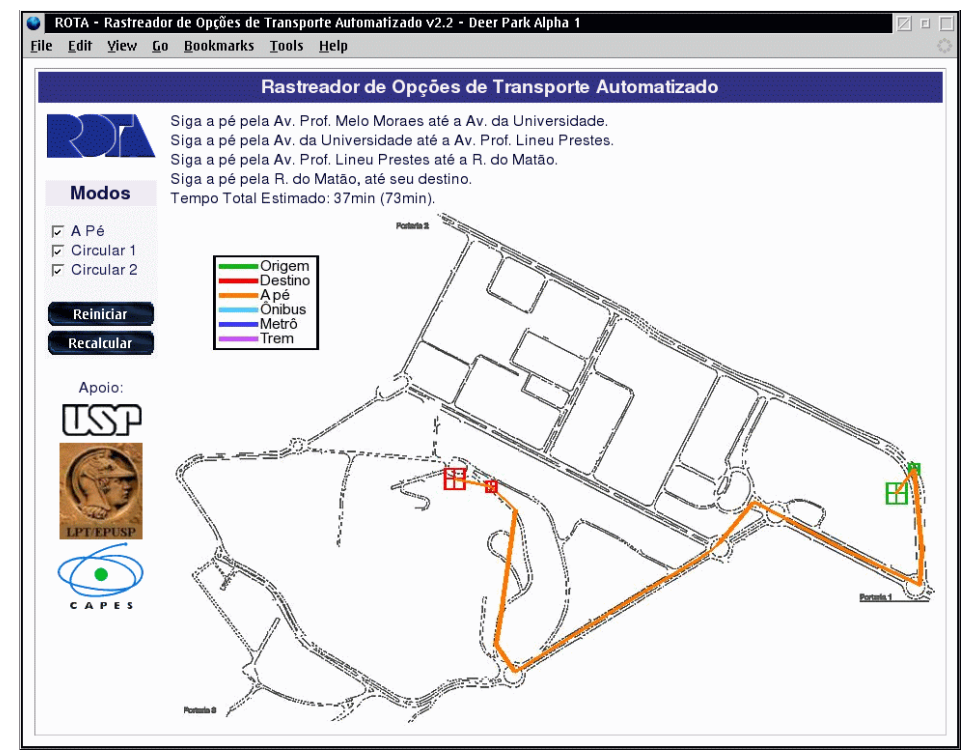

Fig. 4.19 - Solução Acesso FEPASA até Instituto Oceanotgráfico

A descrição textual é:

Siga a pé pela Av. Prof. Melo Moraes até a Av. da Universidade.

Siga a pé pela Av. da Universidade até a Av. Prof. Lineu Prestes.

Siga a pé pela Av. da Universidade até a Rua do Matão.

Siga a pé pela Rua do Matão, até seu destino.

Tempo Total Estimado: $37 \mathrm{~min}$ (73min). 
Apesar do enorme tempo generalizado, a melhor opção para esta rota é a caminhada. Entretanto, este resultado é bastante compreensível, se forem analisadas as alternativas.

Para tanto, pode-se proibir a caminhada, por exemplo, e a melhor alternativa será a apresentada na figura 4.20.

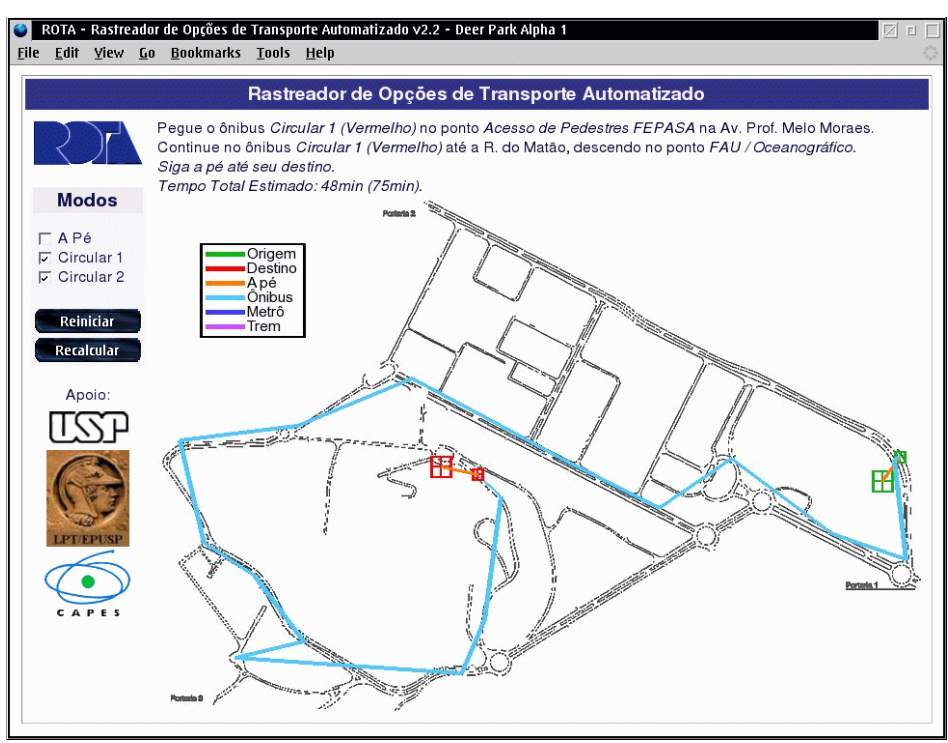

Fig. 4.20 - Solução Acesso FEPASA até Instituto Oceanotgráfico, sem caminhada.

A descrição textual é:

Pegue o ônibus Circular 1 (Vermelho) no ponto Acesso de Pedestres FEPASA na Av. Prof. Melo Moraes. Continue no ônibus Circular 1 (Vermelho) até a R. do Matão, descendo no ponto FAU / Oceanográfico.

Siga a pé até seu destino.

Tempo Total Estimado: 48min (75min).

Com esta solução é possível observar que, ao optar pelo Circular 1 ao invés da caminhada, ocorre um aumento de cerca de 11 minutos no tempo total de viagem. Isto se deve não apenas ao tempo de espera elevado para a utilização do circular, mas também à grande volta que o ônibus circular precisa dar para ir de um ponto a outro. Entretanto, a diferença no tempo generalizado da solução apenas por caminhada e na solução usando o Circular 1 é de apenas 2 minutos generalizados. Isso significa que mesmo uma pequena modificação no sistema, seja para reduzir o trajeto do ônibus, 
seja para reduzir o tempo de espera, poderia causar uma modificação na melhor solução, fazendo com que o circular se tornasse a melhor opção para esta rota, sob o ponto de vista do usuário.

Ainda é possível verificar qual seria a solução se obrigatoriamente o Circular 2 fosse utilizado. Esta solução é apresentada na figura 4.21.

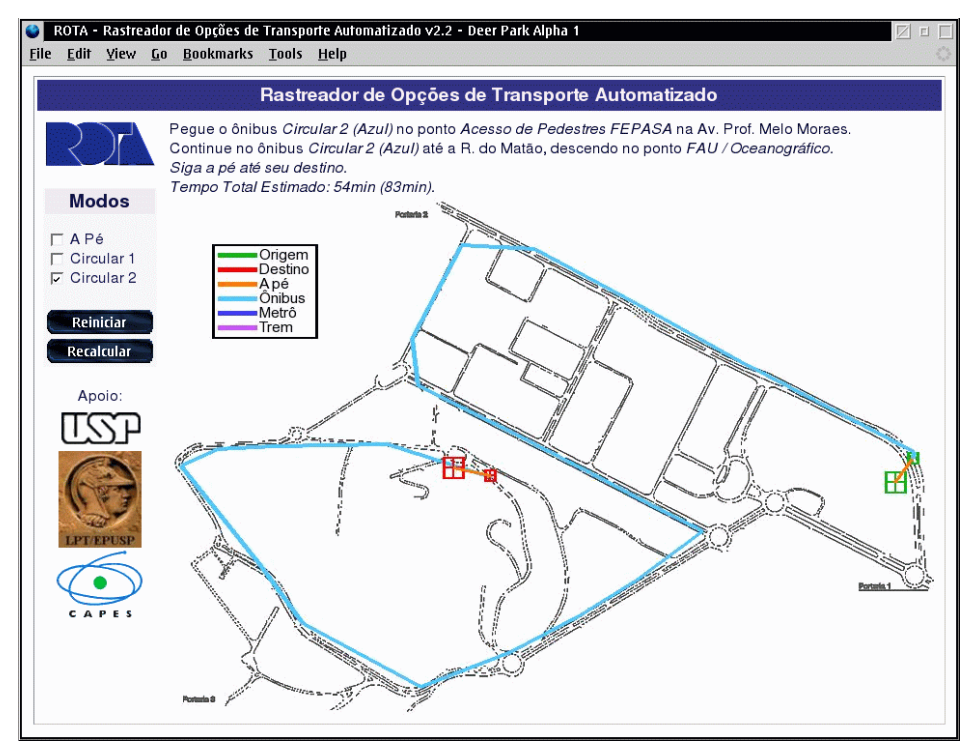

Fig. 4.21 - Solução Acesso FEPASA até Instituto Oceanotgráfico, só Circular 2

Esta solução tem a seguinte descrição textual:

Pegue o ônibus Circular 2 (Azul) no ponto Acesso de Pedestres FEPASA na Av. Prof. Melo Moraes.

Continue no ônibus Circular 2 (Azul) até a R. do Matão, descendo no ponto FAU / Oceanográfico.

Siga a pé até seu destino.

Tempo Total Estimado: $54 \mathrm{~min}$ (83min).

Aqui, tanto o tempo real quanto o tempo generalizado são bastante altos, denotando uma qualidade inferior, sob o ponto de vista do usuário, com relação à caminhada, justificando, em parte, a melhor solução apontada ser a de caminhada. Entretanto, é importante notar que se existisse uma ligação na rede de caminhada ligando a Av. Luciano Gualberto diretamente ao ponto do Instituto Oceanográfico, o uso de um dos circulares combinado com um trecho de caminhada seria provavelmente uma boa solução. 
Embora esta solução seja inviável na rede modelada, o sistema seria perfeitamente capaz de encontrá-la com uma modelagem mais refinada da rede de transporte.

\subsubsection{Do Prédio da Engenharia Civil até o IPEN}

Selecionando-se como origem as proximidades do prédio da Engenharia Civil e como destino as proximidades do IPEN, o melhor trajeto é mostrado na figura 4.22.

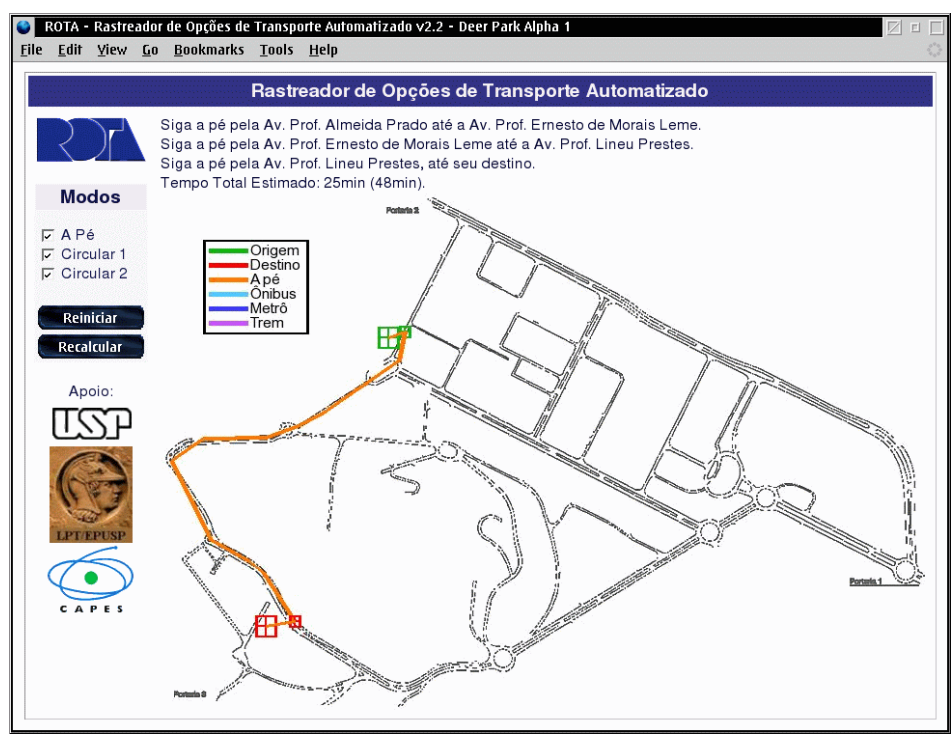

Fig. 4.22 - Solução Engenharia Civil até IPEN

A descrição textual é:

Siga a pé pela Av. Prof. Almeida Prado até a Av. Prof. Ernesto de Morais Leme.

Siga a pé pela Av. Prof. Ernesto de Morais Leme até a Av. Prof. Lineu Prestes.

Siga a pé pela Av. Prof. Lineu Prestes, até seu destino.

Tempo Total Estimado: 25min (48min).

A melhor solução apresentada utiliza apenas a caminhada. Eliminando a caminhada como opção, tem-se a solução da figura 4.23. 


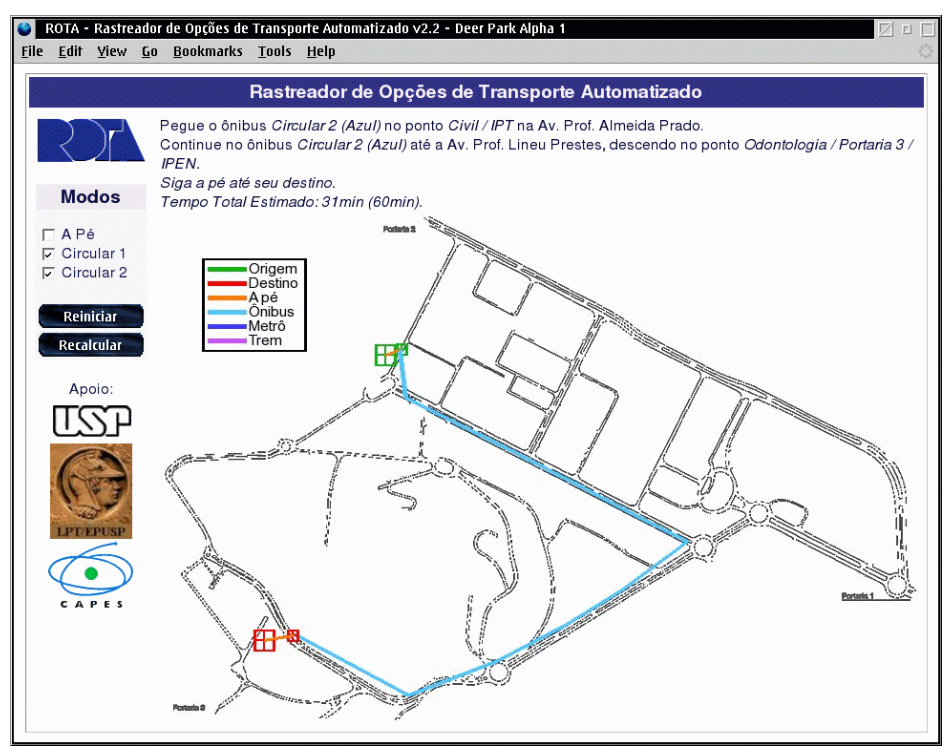

Fig. 4.23 - Solução Engenharia Civil até IPEN, sem caminhada

A descrição textual é:

Pegue o ônibus Circular 2 (Azul) no ponto Civil / IPT na Av. Prof. Almeida Prado.

Continue no ônibus Circular 2 (Azul) até a Av. Prof. Lineu Prestes, descendo no ponto Portaria 3 / IPEN.

Siga a pé até seu destino.

Tempo Total Estimado: $31 \mathrm{~min}$ (60min).

A solução pelo Circular 2 apresentou-se ligeiramente pior que a solução com caminhada. Entretanto, se o usuário se utilizasse do Circular 1, a solução seria bastante pior, como pode ser visto na figura 4.24.

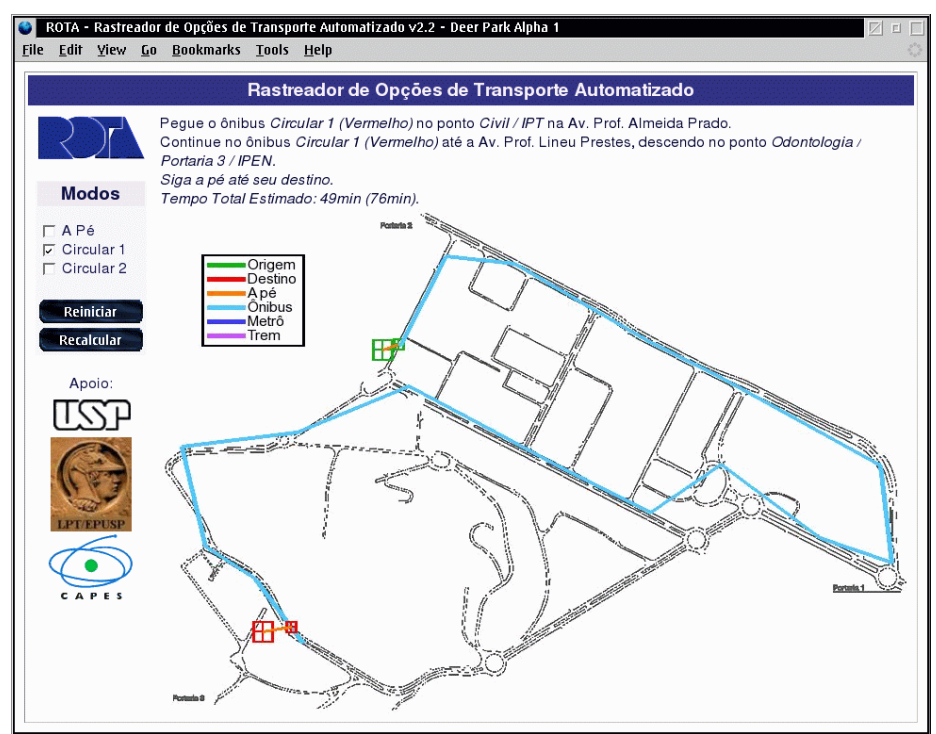

Fig. 4.24 - Solução Engenharia Civil até IPEN, só Circular 1 
A descrição textual é:

Pegue o ônibus Circular 1 (Vermelho) no ponto Civil / IPT na Av. Prof. Almeida Prado.

Continue no ônibus Circular 1 (Vermelho) até a Av. Prof. Lineu Prestes, descendo no ponto Odontologia / Portaria 3 / IPEN.

Siga a pé até seu destino.

Tempo Total Estimado: 49min (76min).

Neste caso, dado o longo tempo de espera e o longo trajeto, o tempo de viagem estimado é praticamente o dobro daquele de uma viagem apenas por caminhada. É interessante notar, mais uma vez, a limitação imposta pela interface: existe uma solução que não foi considerada pelo software, que é a de caminhada até a Av. Prof. Luciano Gualberto quando então seria tomado o ônibus Ciruclar 1.

Esta opção não está disponível; a forma de impedir a caminhada utilizada pela interface é o desligamento completo desta rede, ao invés de ter seu peso de tempo generalizado incrementado. Com uma pequena modificação no software, fazendo com que ele aumente o coeficiente de tempo generalizado da caminhada para 4.0 ao invés de desligá-la totalmente, a melhor solução continua sendo aquela baseada somente na caminhada. Entretanto, a segunda melhor solução passa ser aquela que foi descrita no parágrafo anterior, conforme ilustrado na figura 4.25

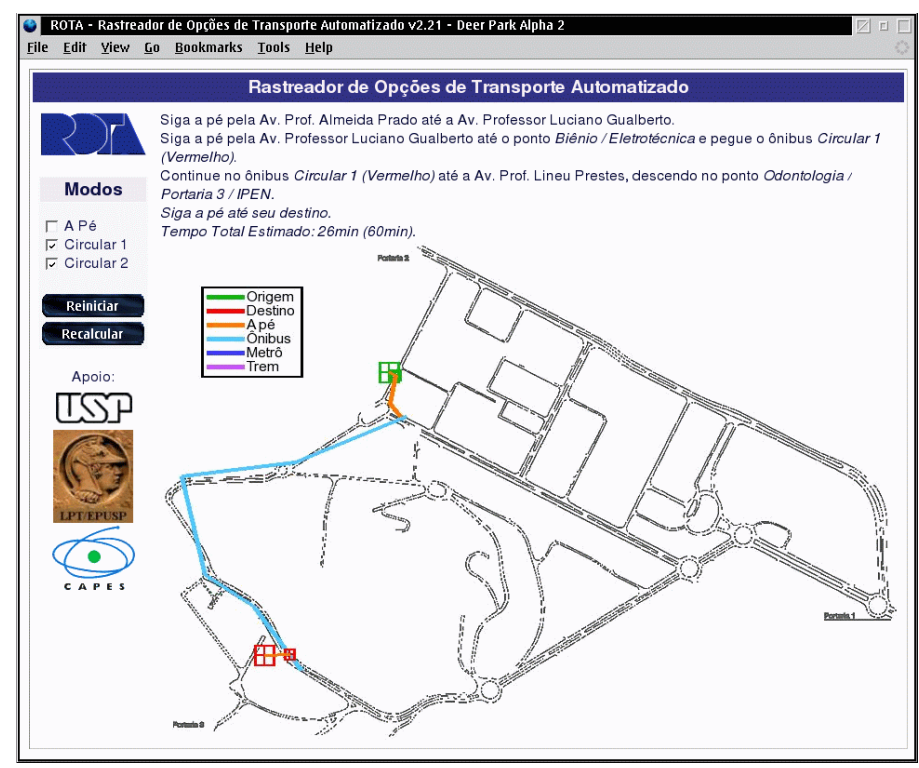

Fig. 4.25 - Solução Engenharia Civil até IPEN, evitando a caminhada 
A descrição textual é:

Siga a pé pela Av. Prof. Almeida Prado até a Av. Prof. Luciano Gualberto.

Siga a pé pela Av. Prof. Luciano Gualberto até o ponto Biênio / Eletrotécnica e pegue o ônibus Circular 1 (Vermelho).

Continue no ônibus Circular 1 (Vermelho) até a Av. Prof. Lineu Prestes, descendo no ponto Odontologia / Portaria 3 / IPEN.

Siga a pé até seu destino.

Tempo Total Estimado: 26min (60min).

O tempo de viagem neste caso é apenas um minuto maior que o da melhor solução. Entretanto, o tempo total generalizado aqui não pode ser comparado com os anteriores, visto que houve uma modificação dos coeficientes para a obtenção desta resposta.

A opção por excluir um dado modo de transporte ao invés de forçá-lo a ser menos atraente foi tomada simplesmente para tornar a interface simples e consistente com a idéia de que, se um modo de transporte foi desligado das opções, ele não deve ser usado na solução, não sendo esta, entretanto, uma limitação inerente ao software desenvolvido.

\subsubsection{Do Acesso a Pedestres Vila Indiana até o Terminal de Ônibus Urbano}

Selecionando-se como origem as proximidades do acesso a pedestres Vila Indiana e como destino as proximidades do Terminal de Ônibus, o melhor trajeto fornecido é o apresentado na figura 4.26, cuja descrição textual é:

Pegue o ônibus Circular 1 (Vermelho) no ponto Acesso Pedestres Vila Indiana / Biomédicas na Av. Prof. Lineu Prestes.

Continue no ônibus Circular 1 (Vermelho) até a Av. Prof. Almeida Prado, descendo no ponto Metalurgia / Terminal de Ônibus Urbanos.

Siga a pé até seu destino.

Tempo Total Estimado: 27min (54min). 


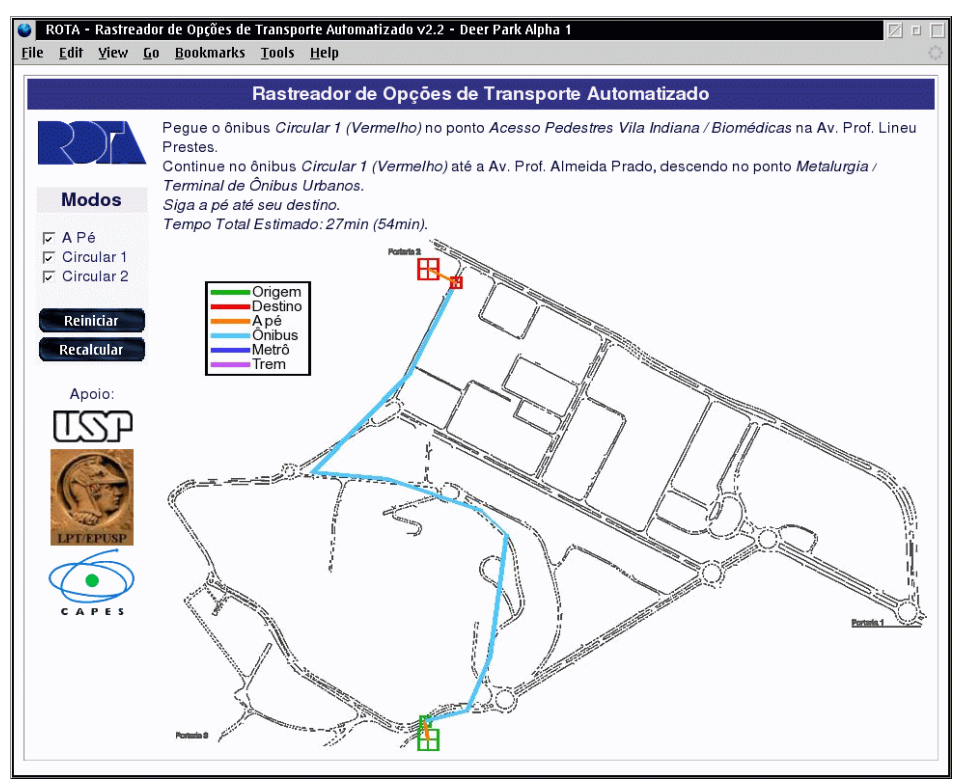

Fig. 4.26 - Solução acesso Vila Indiana até Terminal de Ônibus

A melhor solução apresentada se utiliza do Circular 1, com um tempo total de viagem de 27 minutos. Realizando novamente a consulta, impedindo a utilização do Circular 1, para a mesma origem e destino, tem-se a solução apresentada na figura 4.27 .

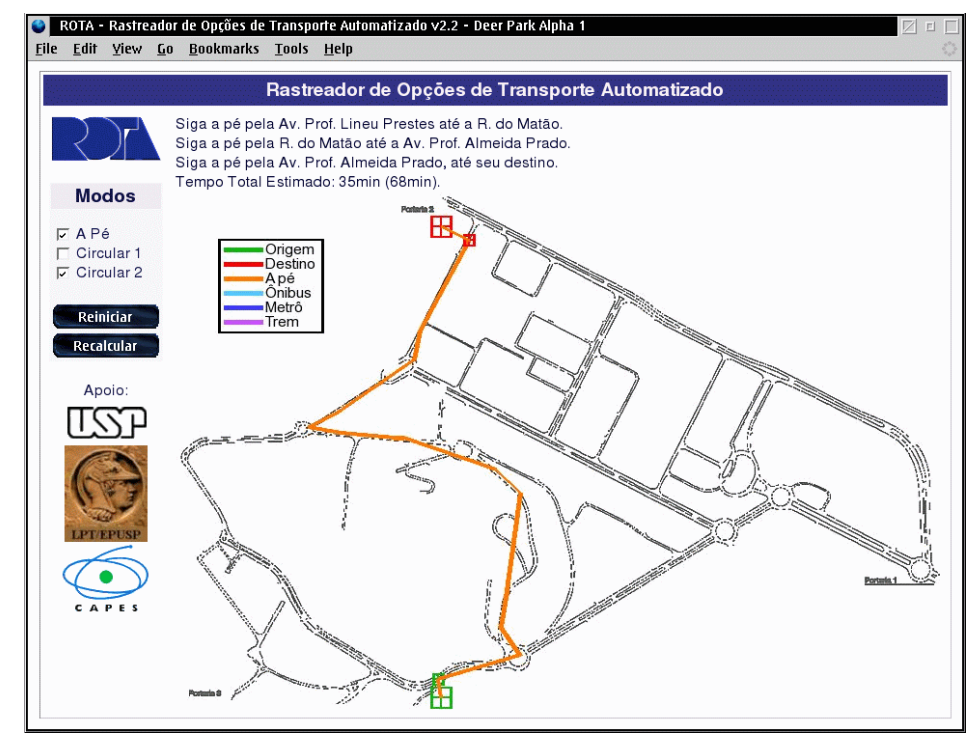

Fig. 4.27 - Solução acesso Vila Indiana até Terminal de Ônibus, sem Circular 1

A descrição textual é: 
Siga a pé pela Av. Prof. Lineu Prestes até a R. do Matão.

Siga a pé pela R. do Matão até a Av. Prof. Almeida Prado.

Siga a pé pela Av. Prof. Almeida Prado, até seu destino.

Tempo Total Estimado: 35min (68min).

Pelo resultado, um trajeto com duração de 35 minutos, é possível observar que o uso do Circular 1, neste trajeto, gera uma economia de cerca de 7 minutos, com relação à caminhada.

Se a caminhada for também proibida, a nova solução é a apresentada na figura 4.28 .

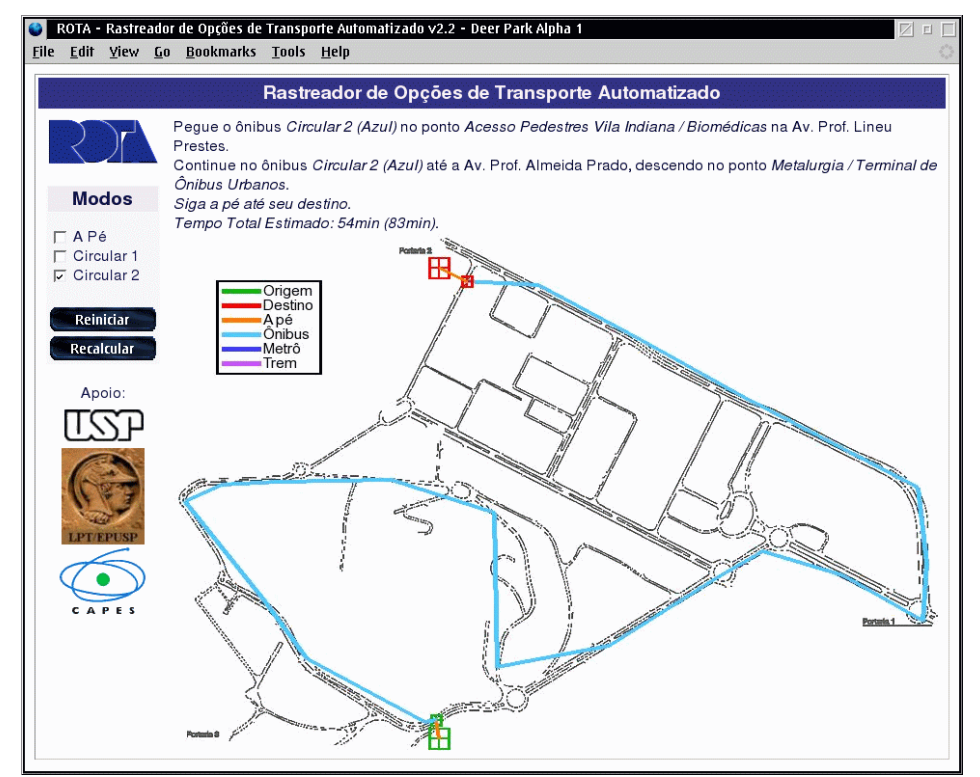

Fig. 4.28 - Solução acesso Vila Indiana até Terminal de Ônibus, só Circular 2

A descrição textual é:

Pegue o ônibus Circular 2 (Azul) no ponto Acesso Pedestres Vila Indiana / Biomédicas na Av. Prof. Lineu Prestes.

Continue no ônibus Circular 2 (Azul) até a Av. Prof. Almeida Prado, descendo no ponto Metalurgia / Terminal de Ônibus Urbanos.

Siga a pé até seu destino.

Tempo Total Estimado: $54 \mathrm{~min}$ (83min). 
Comparando o tempo de viagem desta solução com o da melhor solução, é possível observar que o mesmo praticamente dobrou. $\mathrm{O}$ tempo generalizado não cresceu de forma tão radical, mas também foi expressivo, o que denota uma solução de qualidade claramente inferior.

\subsubsection{Do CRUSP até o Acesso a Pedestres Vila Indiana}

Selecionando-se como origem as proximidades do CRUSP, na Avenida Professor Melo Moraes, e como destino as proximidades do acesso a Pedestres da Vila Indiana, o melhor trajeto fornecido é apresentado na figura 4.29.

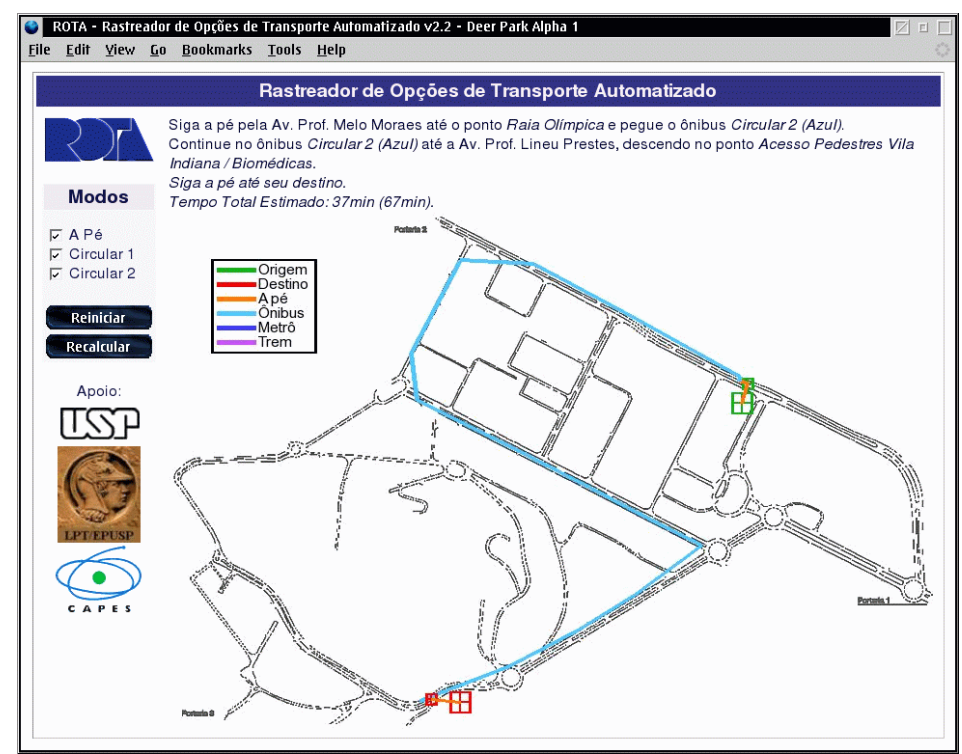

Fig. 4.29 - Solução CRUSP até acesso Vila Indiana

A descrição textual é:

Siga a pé pela Av. Prof. Melo Moraes até o ponto Raia Olímpica e pegue o ônibus Circular 2 (Azul).

Continue no ônibus Circular 2 (Azul) até a Av. Prof. Lineu Prestes, descendo no ponto Acesso Pedestres Vila Indiana / Biomédicas.

Siga a pé até seu destino.

Tempo Total Estimado: 37min (67min).

Esta solução é composta por um curto trecho de caminhada e pelo uso do Circular 2. Proibindo o uso do Circular 2, a solução será a da figura 4.30 


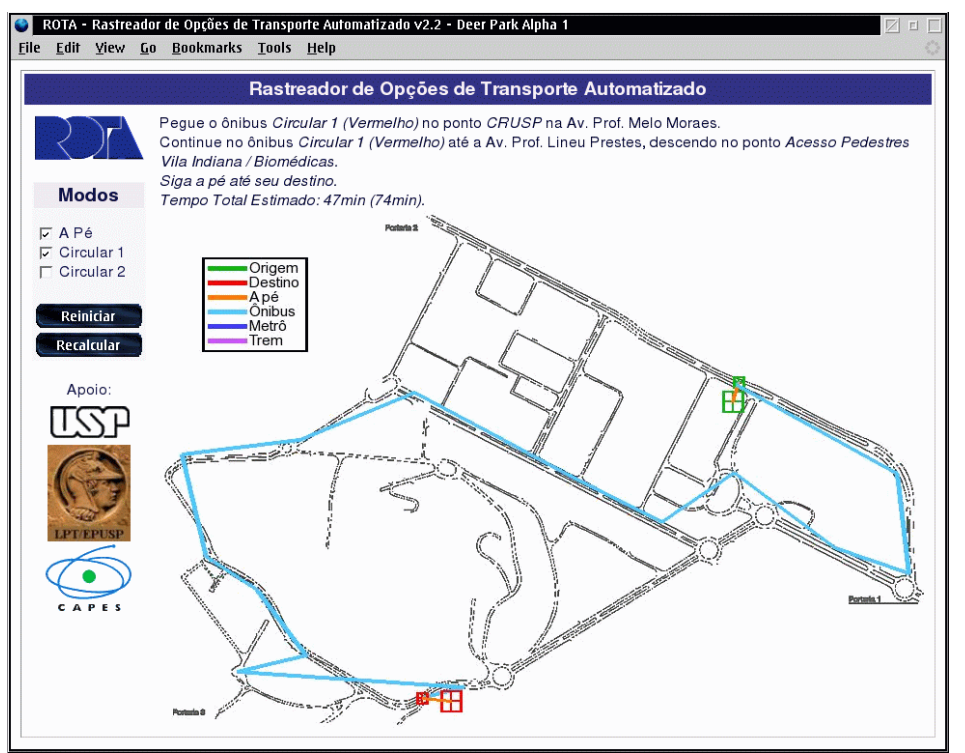

Fig. 4.30 - Solução CRUSP até acesso Vila Indiana, sem Circular 2

A descrição textual é:

Pegue o ônibus Circular 1 (Vermelho) no ponto CRUSP na Av. Prof. Melo Moraes.

Continue no ônibus Circular 1 (Vermelho) até a Av. Prof. Lineu Prestes, descendo no ponto Acesso Pedestres Vila Indiana / Biomédicas.

Siga a pé até seu destino.

Tempo Total Estimado: $47 \mathrm{~min}$ (74min).

Por inspeção visual já é possível verificar que esta rota é bem mais longa que a da melhor solução. Observando os números, é possível perceber que o uso do Circular 2 nesta rota gera, com relação ao uso do Circular 1, uma economia de cerca de 10 minutos.

Impedindo o uso do Circular 1, forçando uma caminhada, obtemos a solução apresentada na figura 4.31, cuja descrição textual é: 


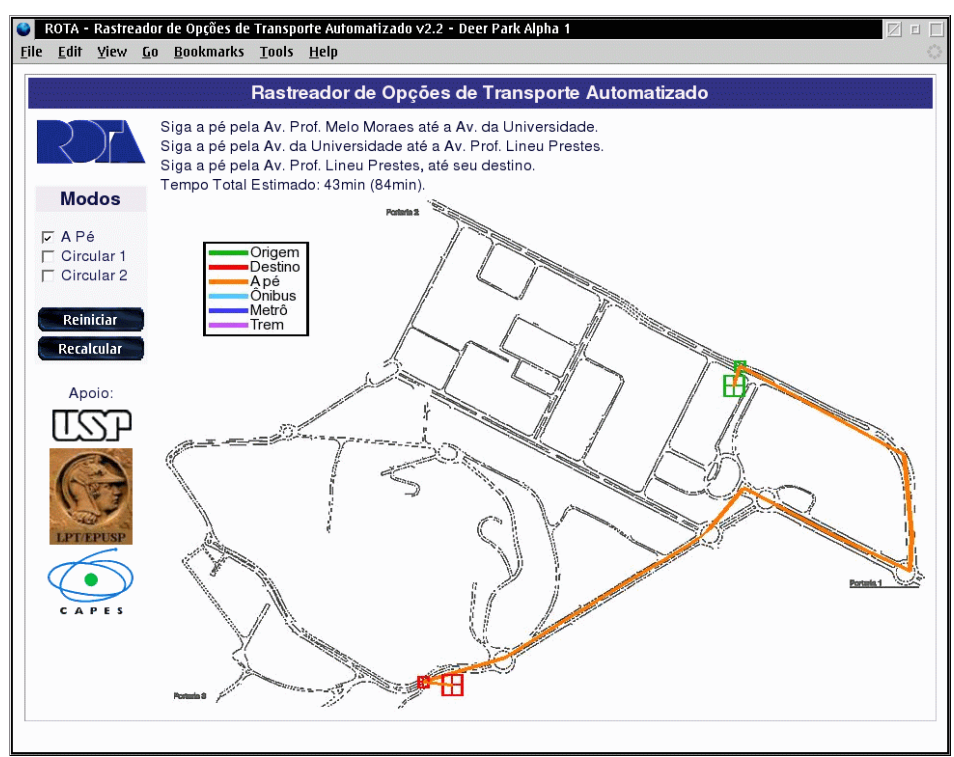

Fig. 4.31 - Solução CRUSP até acesso Vila Indiana, apenas por caminhada.

Como é possível observar, o tempo de viagem desta solução é cerca de 4 minutos inferior ao tempo de viagem da solução que se utiliza do Circular 1. Entretanto, o tempo generalizado é superior, indicando um maior desconforto do usuário pela longa caminhada. Desta forma, esta solução é considerada pelo sistema como inferior.

\subsubsection{Resumo dos Resultados de Apresentação}

Como é possível observar na seção anterior, um grande número de resultados pode ser gerado com a seleção das opções para cada uma das rotas testadas. Para efeito de simplificar a comparação dos ganhos de tempo, serão apresentadas tabelas comparativas.

A tabela 4.5 apresenta a comparação dos tempos de viagem entre a rota ótima apresentada ao usuário e a rota que se utiliza apenas da caminhada. Quando a rota ótima for a rota de caminhada, é considerado o tempo de viagem da melhor rota possível com a caminhada proibida, para efeito comparativo. 
Tabela 4.5 - Tabela comparativa de tempos de viagem da rota a pé com a rota ótima*.

\begin{tabular}{|c|c|c|c|c|c|}
\hline Origem & Destino & $\begin{array}{c}\text { Tempo } \\
\text { Ótimo }\end{array}$ & $\begin{array}{c}\text { Tempo } \\
\text { Comparativo }\end{array}$ & Ganho & $\begin{array}{c}\text { Ganho } \\
\mathbf{( \% )}\end{array}$ \\
\hline Portaria 1 & MAE & $31^{\prime} 58^{\prime \prime}$ & $43^{\prime} 57^{\prime \prime}$ & $1^{\prime \prime} 59^{\prime \prime}$ & 27,3 \\
\hline Casa de Cultura Japonesa & Terminal de Ônibus & $26^{\prime} 42^{\prime \prime}$ & $32^{\prime} 21^{\prime \prime} * *$ & $5^{\prime} 39^{\prime \prime}$ & 17,5 \\
\hline Acesso FEPASA & Instituto Oceanográfico & $36^{\prime} 45^{\prime \prime}$ & $47^{\prime} 55^{\prime \prime} * *$ & $1^{\prime} 11^{\prime \prime}$ & 23,3 \\
\hline Engenharia Civil & IPEN & $24^{\prime} 18^{\prime \prime}$ & $30^{\prime} 51^{\prime \prime} * *$ & $6^{\prime} 33^{\prime \prime}$ & 21,2 \\
\hline Acesso Vila Indiana & Terminal de Ônibus & $26^{\prime} 44^{\prime \prime}$ & $34^{\prime} 21^{\prime \prime}$ & $7^{\prime} 37^{\prime \prime}$ & 22,2 \\
\hline CRUSP & Acesso Vila Indiana & $36^{\prime} 48^{\prime \prime}$ & $42^{\prime} 09^{\prime \prime}$ & $5^{\prime} 21^{\prime \prime}$ & 12,7 \\
\hline
\end{tabular}

(*) Nesta tabela é sempre feita a comparação entre o melhor tempo fornecido pelo software e o tempo de caminhada comparativo. Quando o melhor tempo for o de caminhada, o tempo comparativo será referente à melhor rota com a caminhada proibida.

$(* *)$ Tempo da melhor rota com a caminhada impedida, visto que a melhor rota foi por caminhada.

Pelos valores apresentados na Tabela 4.5, é possível verificar que, para os testes feitos, em termos de tempo de viagem, a rota apresentada ao usuário é significativamente melhor que a rota de comparação. Eliminando-se os extremos (12,7\% na solução "CRUSP - Vila Indiana" e 27,3\% na solução "Portaria 1 - MAE"), o ganho no tempo real de viagem da melhor rota variou entre $17,5 \%$ e $23,3 \%$ sobre o tempo de viagem da rota comparativa.

A tabela 4.6 apresenta novamente dados de tais rotas, mas desta vez considerando o tempo generalizado de viagem, a fim de estipular o ganho de tempo generalizado ou, em outras palavras, o quanto a melhor rota é mais confortável que a rota comparativa.

Tabela 4.6 - Tabela comparativa de tempos generalizados de viagem da rota a pé com a rota ótima*.

\begin{tabular}{|c|c|c|c|c|c|}
\hline Origem & Destino & $\begin{array}{c}\text { Tempo } \\
\text { Ótimo }\end{array}$ & $\begin{array}{c}\text { Tempo } \\
\text { Comparativo }\end{array}$ & Ganho & $\begin{array}{c}\text { Ganho } \\
(\mathbf{\%})\end{array}$ \\
\hline Portaria 1 & MAE & $61^{\prime} 55^{\prime \prime}$ & $87^{\prime} 54^{\prime \prime}$ & $25^{\prime} 59^{\prime \prime}$ & 29,6 \\
\hline Casa de Cultura Japonesa & Terminal de Ônibus & $53^{\prime} 24^{\prime \prime}$ & $62^{\prime} 21^{\prime \prime} * *$ & $8^{\prime} 57^{\prime \prime}$ & 14,4 \\
\hline Acesso FEPASA & Instituto Oceanográfico & $73^{\prime} 30^{\prime \prime}$ & $75^{\prime} 55^{\prime \prime} * *$ & $2^{\prime} 25^{\prime \prime}$ & 3,2 \\
\hline Engenharia Civil & IPEN & $48^{\prime} 36^{\prime \prime}$ & $60^{\prime} 51^{\prime \prime} * *$ & $1^{\prime} 2^{\prime \prime} 15^{\prime \prime}$ & 20,1 \\
\hline Acesso Vila Indiana & Terminal de Ônibus & $54^{\prime} 44^{\prime \prime}$ & $68^{\prime} 42^{\prime \prime}$ & $13^{\prime} 58^{\prime \prime}$ & 20,3 \\
\hline CRUSP & Acesso Vila Indiana & $67^{\prime} 15^{\prime \prime}$ & $84^{\prime} 18^{\prime \prime}$ & $14^{\prime} 03^{\prime \prime}$ & 20,2 \\
\hline
\end{tabular}

(*) Nesta tabela é sempre feita a comparação entre o melhor tempo fornecido pelo software e o tempo de caminhada comparativo. Quando o melhor tempo for o de caminhada, o tempo comparativo será referente à melhor rota com a caminhada proibida.

(**) Tempo da melhor rota com a caminhada impedida, visto que a melhor rota foi por caminhada. 
Pelos valores apresentados na Tabela 4.6, é possível verificar que, para os testes feitos, em termos de tempo generalizado de viagem, a rota apresentada ao usuário é também significativamente melhor que a rota de comparação. Eliminando-se os extremos $(3,2 \%$ na solução "Acesso FEPASA - Instituto Oceanográfico" e 29,6\% na solução "Portaria 1 - MAE"), o tempo generalizado de viagem da melhor rota variou entre $14,4 \%$ e $20,3 \%$ sobre o tempo generalizado de viagem da rota comparativa.

Além de fornecer informações adequadas, todas as soluções são também apresentadas de forma clara, tanto textualmente quanto graficamente, facilitando a identificação da rota a ser seguida pelo usuário, bem como os modos de transporte envolvidos em sua viagem, proporcionando assim uma forma eficiente e eficaz de informação.

É importante ressaltar que, apesar do sistema desenvolvido efetuar todos os possíveis cálculos de custo monetário e custo generalizado de viagem, a apresentação destes valores foi suprimida da interface no caso do sistema tratado, uma vez que nele não há cobrança de tarifas.

O tempo decorrido, em cada teste, entre a última interação com o usuário e a apresentação dos resultados, para requisições simples, foi praticamente instantâneo (variando de 2 a 3 segundos). Considerando que a banda disponível para transferência de dados do servidor utilizado é de apenas $16 \mathrm{~KB} / \mathrm{s}(128 \mathrm{Kbits} / \mathrm{s})$ e que as imagens transmitidas com a solução possuem em torno de $50 \mathrm{~KB}$, este tempo pode ser considerado bom, pois é praticamente o tempo de transferência da própria imagem.

Além da limitação de banda, é importante ressaltar que todos os Servidores (Informações, Cálculo, e Web) foram executados em um único equipamento, sendo este relativamente limitado: um AMD K6-2 500MHz com 384MB de RAM, 
executando conjuntamente uma série de outros serviços, o que torna o resultado ainda mais expressivo.

\subsection{Considerações Finais}

Frente aos resultados obtidos na implementação específica para a Cidade Universitária Armando de Salles Oliveira, em termos de adequabilidade de soluções, comunicação com o usuário e tempo de resposta do sistema às requisições do usuário, considera-se que o sistema correspondeu às expectativas, sendo seus resultados compatíveis com a proposta deste trabalho. 


\section{CAPÍTULO 5 - CONCLUSÃO}

A proposta do desenvolvimento deste trabalho teve como origem o desejo de informar ao usuário sobre o sistema de transporte público coletivo de uma forma simples e objetiva. Dada a complexidade que este pode atingir, a escolha modal e de trajeto para vencer uma determinada necessidade de transporte nem sempre é trivial, ocasionando muitas vezes num mal uso do sistema de transporte por parte dos usuários.

Uma vez que tal comportamento pode acarretar diversas conseqüências, como migração para o transporte particular individual, desperdício de recursos, desbalanceamento tarifário, dentre outros, é importante facilitar a obtenção de boas informações que tornem a viagem eficiente e eficaz para o indivíduo e, a partir da análise de viagens deste tipo, permitir uma otimização global do sistema.

Visando a atender os objetivos propostos, foi desenvolvido um sistema eficiente e eficaz, que fornece prontamente respostas adequadas às requisições, permitindo um alívio da ansiedade dos usuários, além de permitir que estes possam planejar suas viagens com antecedência.

A possibilidade de gerar soluções alternativas que o sistema fornece, através da eliminação de opções de transporte pelo usuário, também contribui no sentido de aliviar a ansiedade deste, uma vez que ele saberá que existem outras possibilidades de chegar ao seu destino, caso algum acontecimento inesperado venha a ocorrer.

O sistema apresenta as soluções em duas formas: textual e gráfica, indicando todo o trajeto a ser realizado, bem como informações pertinentes a tal trajeto (tempo de viagem, por exemplo). Essas características, combinadas à interface do tipo "apontar e clicar", fazem com que o sistema seja, possivelmente, mais acessível à população. 
Dado que a avaliação de uma "melhor opção" é uma decisão bastante subjetiva, acredita-se que a informações apresentadas e a flexibilidade de consultar rotas alternativas são características importantes para que o usuário possa fazer a escolha de trajetos mais adaptados às suas necessidades.

A implementação do sistema como um serviço de internet torna o sistema de consultas automaticamente disponível em praticamente qualquer parte do globo terrestre. A instalação de terminais de consulta (quiosques) pode ser feita com esta mesma implementação. Entretanto, a modularização do software permite que este seja adaptado às mais diversas necessidades, dotando-o de grande flexibilidade com relação à estrutura de funcionamento do sistema. Estas características permitem que ele seja tão acessível ao usuário quanto desejado.

Adicionalmente, o banco de dados de consultas realizadas, criado pelo sistema, amplia a utilidade do sistema, podendo fornecer informações de apoio a decisões de melhorias futuras do sistema de transporte. A existência de tal banco, aliada à modularização do sistema, torna possível a adição de novas características e opções que não apenas melhorem o sistema como uma ferramenta para o usuário, mas também como ferramenta de planejamento do sistema de transportes.

Com relação aos detalhes da implementação testada, a escolha de uma estrutura que possibilite distribuir o processamento mostrou-se adequada, uma vez que esta traz flexibilidade e escalabilidade, o que é considerado satisfatório.

A escolha do Sistema Gerenciador de Banco de Dados MySQL como Servidor de Informações mostrou-se adequada, desempenhando satisfatoriamente suas funções, com tempos de resposta compatíveis nas aplicações testadas. 
A escolha do sistema Apache/PHP como Servidor Web e de Conexões também correspondeu às expectativas, com resultados satisfatórios para esta implementação específica.

O algoritmo Label Correcting também apresentou resultados compatíveis com a realidade, quando combinado à modelagem de rede, com redundância de arcos de custos calculados com base no Tempo/Custo Generalizado.

A modelagem do sistema orientada a objetos e, em especial, a implementação orientada a objetos do Servidor de Cálculo, mostraram-se especialmente interessantes no decorrer do desenvolvimento do sistema, facilitando correções e melhorias, bem como permitindo a reusabilidade de código.

Finalmente, considerando que o sistema desenvolvido apresentou resultados positivos nos quesitos propostos, acredita-se que tal sistema é uma contribuição importante para a melhoria dos sistemas de informações ao usuário de transporte público utilizados atualmente no Brasil.

\subsection{Extensões Futuras e Recomendações}

Fruto da modelagem do sistema, baseada em componentes, o sistema desenvolvido é bastante expansível, sendo possíveis muitas melhorias e complementações, que podem ter como finalidade o aumento de desempenho, aumento de robustez, melhor interação com o usuário, obtenção de informações para melhoria do sistema, etc.

Como proposta para uma possível continuidade deste trabalho, são sugeridas as seguintes modificações: 


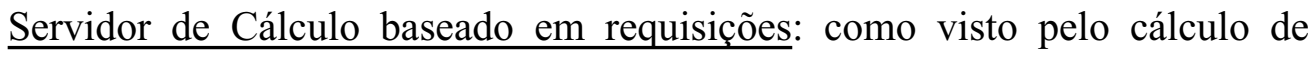
tempo simulado, no capítulo 4, a implementação do servidor de cálculo como um servidor baseado em requisições pode proporcionar um ganho significativo de velocidade do sistema, em especial em grandes redes, uma vez que o sistema não precisa reconstruir toda a rede a cada requisição. Trata-se, portanto, de uma interessante melhoria de desempenho e eficiência.

Sistema com busca de soluções prévias: com a existência do repositório de dados, onde são armazenadas soluções antigas, é possível evitar que um cálculo de rota já feito no passado precise ser realizado novamente, realizando-se uma busca em tal repositório e somente solicitando o cálculo ao servidor de cálculo se nenhuma solução for encontrada. Nesta busca, não apenas a origem e o destino da nova viagem devem ser os mesmos da solução armazenada, mas também todas as outras variáveis - incluindo a própria composição da rede, para garantir que o resultado a ser apresentado é o resultado esperado pelo usuário. Com este tipo de implementação, bastante eficiente num sistema modelado de forma estática, ganha-se em eficiência, reduzindo a carga de processamento do sistema.

Melhorias no sistema de banco de dados: a partir dos dados apresentados no capítulo 4, é possível verificar que as consultas ao banco de dados podem representar, em alguns casos, um limitante no número de requisições simultâneas. Uma forma de mitigar este problema é a utilização de um sistema de banco de dados distribuído, seja através de espelhamento do banco de dados, seja com distribuição das informações - como o repositório de dados e o banco de dados de informações da rede - em sistemas distintos. Neste caso, deve ser especial o cuidado na elaboração da estrutura do banco de dados, para manter a garantia de consistência dos dados. Também pode ser interessante a utilização de um sistema de bancos de dados mais robusto do que o MySQL, utilizado nesta implementação. Trata-se de uma melhoria para o tempo de resposta e confiabilidade do sistema, traduzidos em um serviço de maior qualidade. 
Sistema tolerante a falhas: o sistema implementado pode apresentar problemas em caso de interrupção da linha de comunicação com o terminal de consulta. Uma implementação com execução local no terminal de consulta pode ser uma alternativa, ao menos para os terminais mais importantes, levando em conta todos os cuidados de uma implementação com banco de dados distribuído. Trata-se, portanto, de uma melhoria na eficácia e confiabilidade do sistema.

Melhorias no Servidor de Cálculo: o Servidor de Cálculo pode ter seu algoritmo otimizado para sistemas de transporte muito maiores - processando a rede em partes, por exemplo. Além disso, é possível modificar a implementação do algoritmo para tirar proveito explícito do uso de equipamentos com vários processadores trabalhando paralelamente. Trata-se, portanto, de uma melhoria na eficiência e eficácia do sistema.

Melhorias na interação com o usuário: através de uma pesquisa específica, bem como da realização de uma implantação piloto e pesquisas com o usuário do sistema, é possível identificar melhorias adequadas na interface com o usuário, disponibilização de mais opções e informações de apoio à decisão do usuário. Trata-se, portanto, de uma melhoria na apresentação do sistema, para que ele esteja mais de acordo com as expectativas dos usuários.

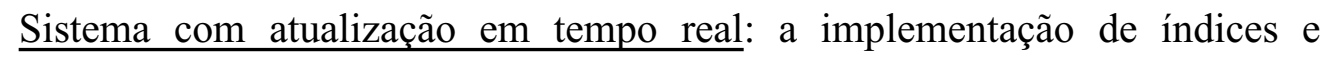
coeficientes variáveis com o tempo podem criar um valor ainda maior para o sistema, embora requeiram cuidado adicional se o banco de dados utilizado for distribuído com redundância - ou for utilizado o sistema de busca por soluções prévias. Como exemplo, poderiam ser citados coeficientes que reflitam situações de congestionamentos nas vias, atualização da posição dos veículos de transporte coletivo (com uso de GPS), usando os tempos de chegada estimados como tempo de 
espera para troca de modo dentre outros. Trata-se, portanto, de uma melhoria na qualidade da informação.

Módulo de Planejamento de Viagem Personalizada: um módulo que permita que o usuário entre com suas características e as características da viagem, para que o sistema possa, a partir das características do usuário, calcular coeficientes de custo generalizado mais adaptados ao usuário, gerando soluções "melhores" para este. Trata-se, portanto, de uma melhoria de eficácia e qualidade da informação, visando um melhor atendimento das necessidades dos usuários.

Módulo de Análise de Informações: um módulo que permita a visualização e a análise dos dados de consulta registrados pelo sistema, fornecendo informações de apoio para decisões táticas e estratégicas com relação ao futuro do sistema. Trata-se, portanto, de uma melhoria de cunho administrativo, visando ao planejamento tático e estratégico do sistema de transportes.

Aumento da Disponibilidade: a instalação de quiosques de consulta em terminais de ônibus e estações de metrô, de forma que qualquer usuário tenha acesso simples e direto às informações do sistema. Os custos deste tipo de implementação não são baixos, mas com a adoção de terminais fisicamente seguros (proteção contra vandalismo) e utilização de comunicação de rede wireless, podem melhorar substancialmente a disponibilidade de consulta, ao mesmo tempo em que minimizam os custos de manutenção do sistema.

Coeficientes de tempo generalizado auto-adaptáveis: com o desenvolvimento de uma melhoria que possibilite captar as opções realizadas pelo usuário, é possível que se utilize técnicas de inteligência artificial - como redes neurais - para realizar correções nos coeficientes de Tempo/Custo Generalizado, seja no sistema global ou 
para um determinado quiosque/terminal de consulta, de forma que suas soluções sejam cada vez mais de acordo com as expectativas dos usuários.

Ampliação da abrangência do sistema: ampliação da abrangência do sistema para além de sua área de atuação principal, incorporando sistemas de transporte que fazem interligação da região servida pelo sistema de informações com regiões externas, de forma que as viagens de entrada e saída da região servida pelo sistema possam também ser melhor planejadas. 


\section{ANEXO A - CONFORTO DO USUÁRIO E CUSTO GENERALIZADO}

\section{A.1. Introdução}

Uma das principais características do sistema de informações a ser desenvolvido neste trabalho é o cálculo de rotas que minimizam o tempo de viagem levando também em consideração o conforto do usuário.

Entretanto, o conforto do usuário não é uma medida facilmente quantificável, exigindo um trabalho criterioso na constituição de fórmulas e obtenção de coeficientes empíricos que traduzam essa percepção com boa aderência. Embora a apresentação dos detalhes do desenvolvimento de tais fórmulas e seus coeficientes fuja ao escopo deste trabalho, é conveniente apresentar alguns resultados e formulações encontrados na literatura, bem como os tipos de fatores considerados e valores usuais para seus coeficientes.

Com este objetivo, esta seção apresenta informações sobre a consideração do conforto do usuário na forma de uma função de custo ou tempo generalizado. Tais funções refletem o "custo percebido" pelo usuário em uma dada viagem, servindo também como uma medida relativa de satisfação do usuário, ao se confrontar duas ou mais rotas para uma mesma viagem.

\section{A.2. Avaliação do transporte de passageiros}

Uma avaliação completa do custo de transporte de passageiros deve levar em consideração três tipos de características: características ligadas ao tempo de viagem, características ligadas ao desempenho do sistema e características ligadas ao conforto do usuário (FARIA, 1985). 
É importante ressaltar, entretanto, que existe uma diferença de julgamento, de acordo com a classe social do usuário, em cada uma das características envolvidas na determinação de a qualidade de serviço (FARIA, 1991). Assim, a ordem das características mais influentes, bem como o fator de influência de cada uma delas, podem sofrer variações significativas de indivíduo para indivíduo.

Esta dificuldade de avaliação do nível de serviço do ponto de vista de cada usuário como indivíduo leva, em geral, a um privilégio das características físicas do sistema, em detrimento de sua interação com o ser humano (FARIA, 1991).

Entretanto, essa dificuldade não deve reduzir os esforços na tentativa de quantificar tais características, visando sempre à melhoria do nível de serviço do sistema de transporte. Tal postura é importante, uma vez que a melhoria do nível de serviço é um fator fundamental para que ocorra, por exemplo, um aumento da atratividade do transporte coletivo frente às outras alternativas de transporte individuais (FARIA, 1991).

Esta preocupação vem do fato que a atratividade é baseada na "qualidade de serviço" que, em termos de transporte, implica uma satisfação total do consumidor, sendo similar à idéia de "qualidade total", que abrange todas as etapas de um processo (FARIA, 1991).

A seguir são descritas cada uma das características que influem no cálculo de custo de uma viagem e que influem na percepção do usuário.

\section{A.3. Características ligadas ao tempo de viagem}

O tempo de viagem tem uma importância direta na avaliação de um meio de transporte pelo usuário. Em geral, se houver dois meios de transporte que atendem ao 
usuário com todas as características iguais, mas tempos de viagem diferentes, o usuário optará pelo de tempo de viagem mais curto.

Os fatores de tempo de viagem que mais influem na percepção do tempo de viagem são (FARIA, 1985):

- Tempo de espera.

- Intervalo (headway).

- Tempo total de viagem.

- Disponibilidade de veículos para substituição.

- Regularidade nos horários.

Entretanto, no caso do transporte de passageiros, estes tempos não podem ser considerados como o "tempo físico" e sim o "tempo percebido pelo usuário". Essa distinção ocorre devido ao fato de que o tempo, como um bem econômico, é escasso diante da impossibilidade de ser comprado ou vendido. Desta forma, as pessoas fazem alocações pessoais de tempo, procurando maximizar sua utilidade global eliminando os tempos de espera (FARIA, 1985).

\section{A.3.1. Tempo de espera}

O tempo de espera é o tempo decorrido entre o momento da chegada do usuário ao ponto onde deve trocar seu meio de transporte e o momento em que ele efetivamente troca o meio de transporte. Por exemplo: um passageiro que chega a pé em um ponto de ônibus e precisa esperar a chegada do ônibus pretendido.

Considerando intervalos curtos de espera e que a chegada do meio de transporte esperado obedece a uma distribuição de Poisson, o tempo de espera médio pode ser considerado como a metade do intervalo (TURNQUIST, 1978 apud FARIA, 
1985). Este é um dado importante, uma vez que a relação entre este tempo de espera e o tempo total de viagem fornece uma indicação da qualidade de um dado trajeto ou meio de transporte.

Entretanto, quando é feita a consideração do incômodo e da ansiedade do usuário, a percepção do usuário é de 2 a 3 vezes o tempo físico (FITCH, 1980 apud FARIA, 1985). Isso significa que, para um usuário que pretende tomar um onibus que tem um intervalo médio de 10 minutos, o tempo de espera percebido será de $10 \mathrm{a}$ 15 minutos, mesmo que o tempo de espera real seja, em média, 5 minutos.

Esta consideração é importante, uma vez que o tempo que o usuário considera ao fazer a opção por um meio de transporte ou outro é o tempo percebido e não o tempo físico.

\section{A.3.2. Intervalo (headway)}

O intervalo é o tempo decorrido entre as passagens sucessivas de um modo de transporte numa mesma linha e sentido.

Uma vez que a freqüência é o inverso do período, pode-se dizer que a freqüência de um dado transporte é o inverso de seu intervalo. Como a freqüência é determinada pela demanda de passageiros, tal demanda é que determina o intervalo máximo daquele modo de transporte.

\section{A.3.3. Tempo total de viagem}

O tempo total de viagem é composto pelo tempo de acesso e egresso ao sistema, tempo de espera, tempo de embarque e desembarque nos modos de transporte utilizados, além do tempo de deslocamento. 
O tempo total de viagem tem uma grande influência na opção do usuário por um ou outro modo de transporte, em especial nas viagens pendulares, devido aos horários de trabalho, tendo uma relação inversa com o nível de serviço de uma dada viagem: quanto menor o tempo total de viagem, maior o nível de serviço.

Uma possível equacionamento para o cálculo do tempo de viagem (FARIA, 1985) seria o da form.(2).

$$
\left.T T V=\frac{L}{D} \cdot\left(t p+t a d+3,6 \cdot \frac{D-d a d}{V O}\right)+a \cdot \frac{(2 \cdot D}{(4 \cdot v p)}+\frac{d c}{v p}+E\right)
$$

Onde:

TTV - Tempo Total de Viagem (s).

L - Distância média de viagem (m).

D - Distância média entre os pontos de parada (m).

tp - tempo médio de embarque/desembarque nos pontos de parada (s).

tad - tempo de aceleração e desaceleração nos pontos de parada (s).

dad - distância percorrida enquanto decorre o tempo tad (m).

vo - velocidade comercial do ônibus $(\mathrm{km} / \mathrm{h})$

dc - Distância média de caminhada do passageiro (m)

vp - velocidade média de caminhada do passageiro $(\mathrm{m} / \mathrm{s})$

\section{A.3.4. Disponibilidade de veículos para substituição}

Apesar de não ser facilmente quantificável pelo usuário, a disponibilidade de veículos para substituição é um fator determinante na escolha de um dado modo de transporte.

Quando uma dada opção de transporte apresenta falhas e o usuário é deixado sem alternativas para terminar o seu trajeto (ou tem de esperar muito para poder 
finalizá-lo), usualmente ele irá procurar outras alternativas menos sujeitas a falhas para realizá-lo. Tal comportamento é especialmente verificado em viagens de trabalho, cujo tempo máximo de viagem é limitado pelo horário de trabalho do usuário.

É interessante, portanto, que as empresas prestadoras de serviço de transporte tenham uma reserva de cerca de $10 \%$ da frota (no caso de ônibus, por exemplo) para prover o usuário com uma alternativa em caso de falhas, em um curto intervalo de tempo (FARIA, 1985).

\section{A.3.5. Regularidade dos horários}

Diz-se que um modo de transporte atende à uma regularidade de horários quando ele está disponível ao usuário num determinado local em horários previamente estabelecidos, com uma margem de variação relativamente pequena.

Tal regularidade é mais importante em trajetos de menor freqüência, uma vez que o tempo de espera médio pode tornar-se alto. Se o horário é regular, o usuário tende a se programar para chegar alguns instantes antes da passagem do veículo de transporte, reduzindo seu tempo de espera e aumentando seu conforto.

Por esta razão é também considerado que a variação com relação aos horários pré-estabelecidos deve ser sempre positiva, isto é, o veículo de um dado modo de transporte deve sempre atender um determinado local no horário pré-estabelecido ou, caso isso não seja possível, poucos instantes depois do horário pré-estabelecido, nunca antes. A razão para isso é evitar que o usuário que chegue na hora correta perca o transporte, porque o veículo passou antes do horário estabelecido. 


\section{$\underline{\text { A.4. Características ligadas ao desempenho do sistema }}$}

A influência do desempenho do sistema no conforto do usuário e em sua percepção do tempo é também muito importante. Isso ocorre porque o tempo percebido pelo usuário tende a ser tão mais próximo do tempo físico quanto for sua sensação de que está se locomovendo em direção ao seu destino da forma mais eficiente possível, minimizando sua sensação de tempo perdido.

Os fatores de desempenho que mais influem na percepção do tempo de viagem (FARIA, 1985) são:

- Velocidade média

- Custo da viagem

- Acessibilidade e distância média entre os pontos de parada

- Transferências

A seguir são descritos estes itens e sua relação com a percepção do usuário.

\section{A.4.1. Velocidade média}

A velocidade média é um fator que influencia grandemente o tempo físico de viagem e, portanto, na percepção de tempo pelo usuário. Desta forma, é um fator determinante na escolha de um modo de transporte ou outro.

De maneira geral, quanto maior for a velocidade média, menor será o tempo real de viagem e, por conseqüência, o tempo percebido de viagem. Esta característica está ligada ao fato de que o usuário tende a associar baixas velocidades com o fato de chegar atrasado ao seu destino, sendo a percepção deste tempo ampliada pela ansiedade, que tem origem no medo de um possível atraso para seu compromisso. 
A velocidade média pode ser calculada de duas formas principais (FARIA, 1985), como apresentado nas form.(3) e form.(4).

$$
\text { VOP }=\frac{d}{\text { tmov }}
$$

Onde:

$$
\begin{aligned}
& \text { VOP - Velocidade Média de Operação }(\mathrm{km} / \mathrm{h}) \\
& \text { d - distância percorrida }(\mathrm{km}) \\
& \text { tmov - tempo em movimento }
\end{aligned}
$$

Ou ainda:

$$
\mathrm{VCOM}=\frac{\mathrm{d}}{\text { ttotal }}
$$

Onde:

$$
\begin{aligned}
& \text { VCOM - Velocidade Média Comercial }(\mathrm{km} / \mathrm{h}) \\
& \text { d - distância percorrida }(\mathrm{km}) \\
& \text { ttotal - tempo total de viagem }
\end{aligned}
$$

Entretanto, estas velocidades não são um fator intrínseco ao veículo de um dado modo de transporte, sendo influenciadas pela qualidade da via, curvas, tráfego em vias compartilhadas, embarque e desembarque de passageiros, dentre outros.

\section{A.4.2. Custo da viagem}

O custo (monetário) de viagem é composto basicamente pelas tarifas e outros custos extraordinários. Como em qualquer outra situação, o custo monetário é também uma característica fundamental na escolha do modo de transporte.

Entretanto, o usuário pode ser flexível com relação ao custo de viagem, muitas vezes estando disposto a pagar um pouco mais em troca de um maior nível de 
serviço. É essa flexibilidade que proporciona a troca de um meio de transporte como o ônibus pelo veículo particular.

O custo monetário de um dado modo de transporte pode ser fixo (pagando-se um valor fixo é possível viajar por um determinado tempo, independente das trocas de modo e veículo realizadas), fixo por trecho (valor fixo, pagando-se novamente para cada troca de modo ou veículo), variável (paga-se um valor diferente de acordo com o modo, distância percorrida e tempo de viagem) ou ainda um misto de todos estes.

É possível observar que, na prática, tarifas fixas de qualquer tipo costumam levar a uma dispersão populacional. Sendo o custo do transporte fixo, os usuários de baixa renda tendem a estabelecer sua morada em regiões distantes de seus trabalhos, diminuindo também seus gastos com moradia. Entretanto, esta prática faz com que os tempos de viagem destes indivíduos sejam bastante altos, reduzindo drasticamente o nível de serviço do modo de transporte.

Nesta situação, a escolha de um modo de transporte alternativo nem sempre existe, dado que em áreas muito dispersas não é economicamente viável dispor de uma rede de transportes com muitas opções. Assim, as tarifas fixas acabam por condenar os usuários de baixa renda a um transporte de baixo nível de serviço, deteriorando ainda mais sua qualidade de vida.

Esta é uma questão importante a ser considerada em melhorias futuras do sistema de transporte, uma vez que a alternativa que implica um menor custo monetário ao usuário num dado momento nem sempre é a melhor alternativa a longo prazo. 


\section{A.4.3. Acessibilidade e distância média entre pontos de parada}

A distância média entre os pontos de acesso aos modos de transporte é bastante importante na avaliação daquele modo pelo usuário. Entretanto, para a determinação da distância ideal entre dois pontos, é preciso acomodar uma dicotomia.

Ao mesmo tempo que o usuário deseja sempre pontos mais adequados às suas necessidades (minimizando seus tempos de caminhada, por exemplo), um número excessivo de pontos de acesso acaba por diminuir sensivelmente a velocidade comercial de uma dada linha de um modo de transporte, uma vez que o número de paradas aumenta. Um critério comum, que visa a atender ambos os requisitos, é dispor os pontos nas regiões de maior concentração de demanda.

\section{A.4.4. Transferências (transbordos)}

As transferências são as mudanças de modo de transporte que o usuário precisa realizar para a chegada até seu destino, dados os modos de transporte necessários para cumprir um trajeto.

As transferências são custosas para o usuário por diversas razões, como a incerteza do tempo de transferência, ou seja, o tempo entre sair de um modo e conseguir entrar em outro, as caminhadas necessárias entre os pontos de acesso aos diferentes modos de transporte, local de espera inadequado (desprotegido, perigoso etc), além do custo monetário de se utilizar de um novo transporte e do desconforto direto da transferência em si. 


\section{A.5. Características ligadas ao conforto do usuário}

Alguns dos fatores considerados com relação ao conforto do usuário estão relacionados abaixo. Os valores entre parênteses são as condições consideradas ideais (FARIA, 1985):

- Ventilação dentro do veículo (20 trocas de ar completas ou mais, por hora).

- Temperatura dentro do veículo $\left(18^{\circ} \mathrm{C}\right.$ a $\left.24^{\circ} \mathrm{C}\right)$.

- Ruído dentro do veículo (abaixo de 90dB).

- Vibração do veículo (mínima possível, no máximo 2,5 a 3,0Hz).

- Intensidade de aceleração e desaceleração do veículo (até $2,94 \mathrm{~m} / \mathrm{s}^{2}$ para passageiros sentados na direção do deslocamento e até $2,45 \mathrm{~m} / \mathrm{s}^{2}$ para passageiros sentados perpendicularmente à direção do deslocamento).

- Espaço disponível para cada usuário no veículo (maior que $0,18 \mathrm{~m}^{2} / \mathrm{pax}$ ).

- Iluminação dentro do veículo (200 a 500 lux)

- Condição do assento (deve ser cômodo para 95\% dos usuários).

A consideração de tais fatores é bastante complexa, dado que a influência de cada uma delas no que seria o custo de viagem é um fator de essência subjetiva.

Tal influência varia de acordo com as características do usuário (sexo, faixa etária, profissão, motivo da viagem) bem como todas as outras características de tempo de viagem e desempenho do sistema.

\section{A.6. Características mais influentes na opção de modo}

Embora a ordem dos fatores mais influentes variem ligeiramente com o número de viagens realizadas por dia e o modo de transporte, em geral a preocupação do usuário fica em torno de 3 fatores: freqüência, tarifa e regularidade (FARIA, 
1985), sendo que a preocupação com a tarifa usualmente supera a preocupação com a qualidade do serviço. A distância entre os pontos de acesso não apresenta grande influência quando a população tratada é de jovens e o tempo de viagem fica em segundo plano quando as viagens são curtas (FARIA, 1985).

Além disso, o não conhecimento de um sistema ou modo de transporte por parte do usuário implica sua sumária exclusão das opções de transporte disponíveis. Assim, a disponibilidade de informações sobre o sistema de transporte é de fundamental influência na escolha de modos de transporte (FARIA, 1985).

\section{$\underline{\text { A.7. } O \text { custo generalizado }}$}

Uma vez que muitos parâmetros subjetivos modificam a influência dos custos e tempos de viagem quando a questão é transporte de passageiros, é preciso fazer uma correção no cálculo de custo, de forma a possibilitar tais considerações, sendo importante ressaltar que o valor exato de tais fatores variam de acordo com o usuário (HORN, 2003). A este custo corrigido por coeficientes de percepção do usuário dá-se o nome de custo generalizado.

O Custo Total Generalizado de Viagem (CTGV), que é a soma dos custos generalizados de cada etapa da viagem, pode ser calculado com auxílio do Tempo Total Generalizado de Viagem (TTGV), como apresentado na form.(5), baseada nas formulações da literatura (NOVAES, 1986); (FARIA, 1985); (FARIA, 1991).

$$
\mathrm{CTGV}=\mathrm{TTGV} \times \mathrm{CT}
$$

Onde:

CTGV - Custo total generalizado de viagem

TTGV - Tempo total generalizado de viagem

CT - Custo monetário por unidade de tempo 
Como o TTGV é baseado em uma modificação do Tempo Total de Viagem (TTV), primeiramente será apresentada a formulação para o TTV, na form.(6).

$$
T T V=\sum_{i} T C_{i}+\sum_{j} T E_{j}+\sum_{k} T V_{k}
$$

Onde:

$$
\begin{aligned}
& \text { TTV - Tempo total de viagem } \\
& \text { TCi - Tempo da caminhada } \mathrm{i} \\
& \text { TEj - Tempo da espera } \mathrm{j} \\
& \text { TVk - Tempo da viagem } \mathrm{k}
\end{aligned}
$$

No entanto, esta forma de cálculo não reflete a percepção de tempo pelo usuário, já que ela usa o "tempo físico" e não o "tempo percebido pelo usuário". Embora não seja possível considerar claramente todos os fatores subjetivos envolvidos, são adotados pesos em cada um dos tipos de tempo, com o objetivo de transformar um "tempo físico" em um "tempo percebido pelo usuário".

Uma vez que serão atribuídos pesos, é necessário que estes pesos signifiquem uma relação com algum dos parâmetros. É comum adotar como parâmetro base o tempo em viagem dentro de um dos modos de transporte (ônibus, por exemplo) como sendo a medida de tempo básica, ou seja, cujo peso é igual a 1.

Tal consideração significa que para cada intervalo de tempo físico $t$ dentro de um ônibus, por exemplo, o usuário tem a percepção exatamente de uma quantia $t$ de tempo. É possível, entretanto, promover alterações neste valor em linhas ou horários específicos, por exemplo, para considerar situações de ônibus lotado, problemas de ventilação, etc. 
O tempo de espera, por sua vez, é mais custoso para o usuário. Tal peso deve levar em consideração uma série de fatores, como incerteza do horário de chegada, condições da espera, etc. A literatura tem adotado valores entre 2 e 3 como peso para o tempo de espera (FITCH, 1980 apud FARIA, 1985).

A faixa comumente adotada para o peso de tempo de caminhada varia entre 1 e o valor do peso do tempo de espera. Em outras palavras, para o usuário, caminhar é ligeiramente mais custoso do que se locomover em um ônibus. Além disso, esperar por um dado transporte é ainda mais custoso do que caminhar.

Outra possibilidade usualmente adotada no custo generalizado é a definição de penalidades temporais para os transbordos. Assim, uma possível formulação para o TTGV, baseada naquelas existentes na literatura (FARIA, 1985); (NOVAES, 1986); (FARIA, 1991), levando em consideração tais fatores, é a da form.(7).

$$
T T G V=f c \times \sum_{i} T C_{i}+f e^{\times} \sum_{j} T E_{j}+f v \times \sum_{k} T V_{k}+p t \times N T+\frac{C F}{C T}
$$

Onde:

TTGV - Tempo total generalizado de viagem

fc - Fator de caminhada (1 a 2).

TCi - Tempo da caminhada i

fe - Fator de espera (2 a 3).

$\mathrm{TEj}$ - Tempo da espera $\mathrm{j}$

fv - Fator de deslocamento no veículo $(\sim 1)$.

TVk - Tempo da viagem $\mathrm{k}$

pt - Penalidade temporal de transbordo

NT - Número total de transbordos

$\mathrm{CF}$ - Custo monetário total da viagem

CT - Custo monetário por unidade de tempo 
Com este valor, é possível obter o Custo Total Generalizado de Viagem, com a formulação já apresentada na form.(5).

Como são diretamente proporcionais, tanto o Custo Total Generalizado de Viagem quanto o Tempo Total Generalizado de Viagem podem ser usados para verificar e compreender as opções de transporte adotadas pelos usuários, sendo essa avaliação mais completa do que uma feita usando apenas critérios de tempo real e custo monetário de uma viagem.

\section{A.8. Considerações finais}

Como foi visto nesta seção, a avaliação da qualidade dos vários modos de transporte, bem como a definição de "melhor modo de viagem", é uma questão bastante delicada e de difícil solução.

Acredita-se, entretanto, que o modelo de Custo Generalizado/Tempo Generalizado reflita a reação do usuário com suficiente qualidade para fundamentar a decisão de escolha modal. Desta forma, este foi o modelo selecionado para a implementação do sistema proposto, como base para o cálculo de custo de viagem.

Maiores detalhes sobre conforto do usuário e custo generalizado podem ser verificados em Faria (1985), Novaes (1986), Faria (1991), Strambi (1991), Marques (1998), Timpf (2002) e Horn (2003), dentre outros. 


\section{ANEXO B - FLUXO EM REDE E CAMINHO MÍNIMO}

\section{B.1. Introdução}

Considerando a função de fornecer rotas de transporte ao usuário do sistema a ser desenvolvido, é necessário modelar o sistema de transporte de forma que tal função possa ser cumprida com sucesso.

Assim, esta seção apresenta uma introdução aos problemas de fluxo em rede e caminho mínimo, bem como alguns algoritmos para resolução de tais problemas, fazendo algumas considerações sobre suas vantagens e desvantagens.

O objetivo é verificar um algoritmo que possa ser utilizado para a resolução do problema de caminho mínimo tratado neste trabalho, com todas as suas especificidades, além de fazê-lo com uma complexidade computacional aceitável, ou seja, em um tempo computacional relativamente baixo.

\section{B.2. Problemas de Fluxo em Rede}

Um problema de otimização muito comum na pesquisa operacional é aquele que visa à redução de custo de transporte, seja ele de uma única ou de múltiplas origens, um único ou múltiplos destinos, com ou sem limitações de canais de escoamento.

São problemas de distribuição de cargas, transporte de passageiros e mesmo outros problemas como o cálculo de frentes críticas de uma obra, mediante uma ligeira adaptação. E todos eles podem ser resolvidos usando a idéia de fluxo em rede. 
A maioria destes problemas pode ser corretamente descrito e solucionado por técnicas de programação linear. Não há dúvidas que, dada uma modelagem adequada - alguma variação de um modelo de conservação de massa - estes problemas todos podem ser resolvidos pelo método Simplex (BRADLEY; HAX; MAGNANTI, 1977); (WINSTON, 1994). Entretanto, esta nem sempre é uma abordagem possível, dada a dimensão que estes problemas podem adquirir (em termos de números de variáveis e equações), situação na qual o Simplex se torna lento e desajeitado em seu tratamento, em termos computacionais.

Por outro lado, os problemas de fluxo em rede possuem características comuns que permitiram que algoritmos específicos fossem desenvolvidos, buscando soluções mais rápidas e mais eficientes computacionalmente (BRADLEY; HAX; MAGNANTI, 1977); (GALLO; PALOTINO, 1984); (WINSTON, 1994).

Dentre estes algoritmos especiais é possível citar algoritmos como Network Simplex (BRADLEY; HAX; MAGNANTI, 1977); (CHVATAL, 1983); (WINSTON, 1994), método Out-of-Kilter (GUALDA, 1975); (SILVA, 2001), Label Setting e Label Correcting (BRADLEY; HAX; MAGNANTI, 1977); (GALLO; PALOTINO, 1984); (WINSTON, 1994), dentre outros, que têm grande utilidade para casos específicos de fluxo em rede.

Todos os algoritmos citados foram desenvolvidos visando à sua aplicação em situações específicas, embora possam ser utilizados para outros tipos de problemas. As principais situações de uso destes algoritmos são:

Label Setting e Label Correcting: Encontrar o caminho mais curto (com base em algum critério estipulado) entre dois pontos (uma única entrada e uma única saída), sem limitação de capacidade. Ambos são variações do algoritmo de Dijkstra. 
Network Simplex e Out-of-Kilter: Encontrar os caminhos mais curtos (com base em algum critério arbitrário) que escoe uma dada quantidade de produto de várias fontes a vários sorvedouros, respeitando os limites de capacidade de cada trecho da rede.

Os algoritmos Network Simplex e Out-of-Kilter, apesar de serem capazes de resolver problemas de caminhos mínimos entre dois pontos, são voltados a problemas mais complexos. O Network Simplex é voltado a problemas com limitações de fluxo nos arcos, além de tratar de problemas de múltiplas fontes e múltiplos sorvedouros. O Out-of-Kilter, por sua vez, pode ser usado para tratar de problemas de características similares aos do Network Simplex, mas sua principal utilização é voltada a resolver problemas de circulação em redes de transporte.

Por tratarem de problemas mais complexos, tais algoritmos apresentam um desempenho computacional inferior ao tratar de problemas de caminho mínimo, quando confrontados com algoritmos desenvolvidos especificamente para resolver este tipo de problema, como o de Dijkstra.

Por esta razão, quando o objetivo é encontrar o menor caminho entre dois pontos, sem limitação de capacidade nos arcos e nós, os algoritmos usualmente adotados são o Label Setting ou o Label Correcting, eventualmente com alguma modificação.

\section{B.3. O problema do caminho mínimo}

Um problema de caminho mínimo pode ser monomodal ou multimodal, dependendo de envolver um único modo de transporte ou vários deles. Existe uma diferença de tratamento na modelagem de cada uma destas classes de problemas, e portanto tais modelagens serão apresentadas separadamente. 


\section{B.3.1. Modelagem de um problema de caminho mínimo monomodal}

Como um exemplo de modelagem de um problema de caminho mínimo monomodal, consideremos um problema onde pretende-se partir de um ponto $\mathrm{O}$ (origem) e pretende-se chegar a um ponto D (destino), percorrendo o menor caminho possível, considerando aqui a distância como o critério de custo.

O primeiro passo da modelagem implica eliminar todas as informações irrelevantes para a resolução do problema, explicitando todos os dados que sejam importantes para a solução.

Como se trata de um problema particular de fluxo em rede, a modelagem do problema como uma rede é bastante natural. Nesta modelagem, os nós representam as interseções (ou pontos notáveis da rede) e os arcos representam as vias (interligações entre os nós). Nesta forma, com as distâncias de cada via associadas a cada arco, é possível calcular o comprimento de um caminho somando-se o comprimento dos arcos que o compõem.

Com estas considerações, é possível representar a rede como na figura B.1, onde a representação do ponto de entrada $(\mathrm{O})$ é feita com a indicação de que uma unidade entrou no sistema naquele nó. A representação do ponto de saída (D) é feita com a indicação de que uma unidade saiu do sistema naquele nó.

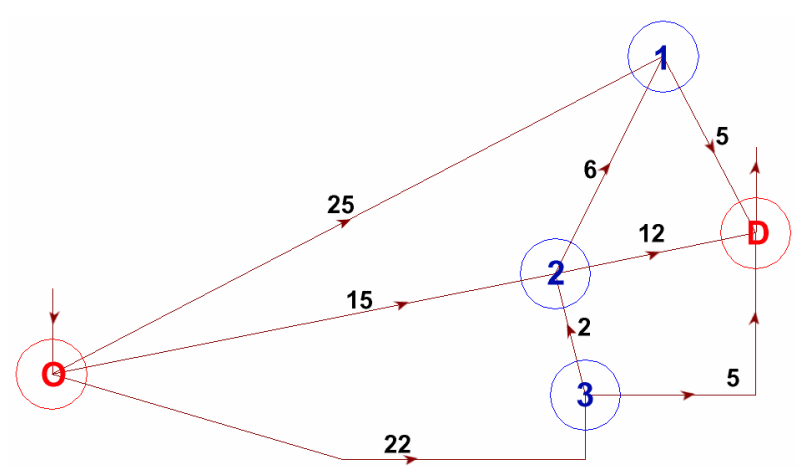

Fig. B.1 - Representação em rede do problema monomodal 
Entretanto, essa indicação torna a rede "desbalanceada". Isso significa que os nós não estão em equilíbrio: no nó origem chega uma unidade, mas não sai nenhuma. No nó destino, ao contrário, sai uma unidade, mas não chega nenhuma.

É necessário então associar variáveis a cada um dos arcos, que indiquem a passagem de unidades por aquele arco ou não, para que seja possível reequilibrar a rede. $\mathrm{Na}$ situação de equilíbrio é dito que a rede está "balanceada". Em outras palavras, ela representa uma solução viável, como representado na figura B.2.

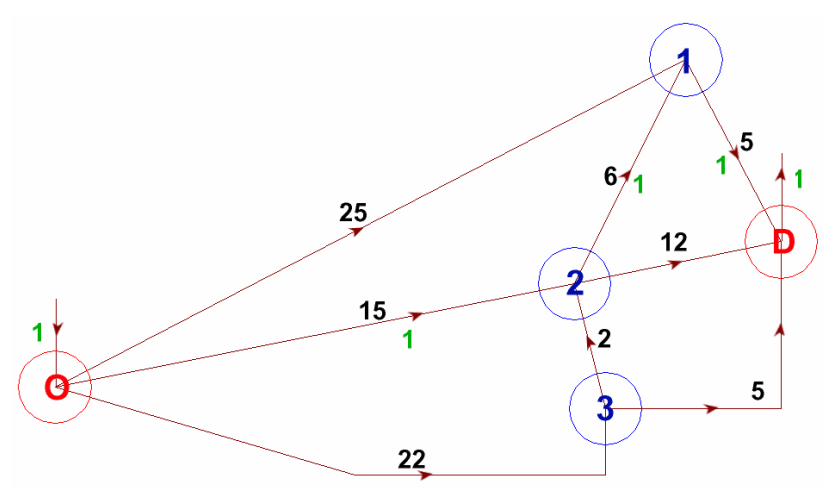

Fig. B.2 - Representação de uma solução viável

A partir da modelagem gráfica, é possível estabelecer uma modelagem matemática. Para isso, a primeira variável a ser definida é a variável que indica se existe o fluxo em um determinado arco. Por exemplo, pode-se definir a variável $\mathbf{x}_{\mathbf{i j}}$ que indica se existe fluxo do nó i para o nó j.

A condição de equilíbrio da rede, a primeira restrição, será que a soma do fluxo de todos os arcos que chegam em um dado nó sejam iguais à soma do fluxo de todos os arcos que saem deste mesmo nó, como na figura B.3, para todos os nós. 


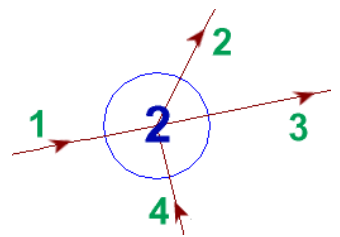

Fig. B.3 - Equilíbrio em um nó

Considerando que A seja o conjunto de todos os $\operatorname{arcos}(m, n)$ existentes na rede, pode-se representar matematicamente esta restrição para o nó i com a form.(8).

$$
\sum_{(n, i) \in A} \mathbf{X}_{n i}-\sum_{(i, m) \in A} \mathbf{X}_{i m}=0
$$

Esta representação funciona bem para nós genéricos, entretanto não é válida para os nós $\mathrm{O}$ (origem) e $\mathrm{D}$ (destino), já que nestes não há o equilíbrio por natureza, uma vez que fazem interface do sistema (a rede representada) com o ambiente (o restante do universo, não representado pela rede).

Para proporcionar o equilíbrio nestes nós, as equações são ligeiramente modificadas, como nas form.(9) e form(10).

Nó de Origem:

$$
1+\sum_{(n, i) \in A} \mathbf{x}_{n i}-\sum_{(i, m) \in A} \mathbf{x}_{i m}=0 \Rightarrow \sum_{(n, i) \in A} \mathbf{x}_{n i}-\sum_{(i, m) \in A} \mathbf{x}_{i m}=-1
$$

Nó de Destino:

$$
-1+\sum_{(n, i) \in A} \mathbf{x}_{n i}-\sum_{(i, m) \in A} x_{i m}=0 \Rightarrow \sum_{(n, i) \in A} x_{n i}-\sum_{(i, m) \in A} x_{i m}=1
$$

O que nos leva então a uma restrição de equilíbrio genérica, como a da form.(11). 


$$
\sum_{(n, i) \in A} x_{n i}-\sum_{(i, m) \in A} x_{i m}=b
$$

Sendo que $\mathrm{b}=-1$ para o nó origem, $\mathrm{b}=1$ para o nó destino e $\mathrm{b}=0$ para todos os outros nós. Com isso, está completa a restrição do problema, que garante que a rede esteja balanceada em todos os nós.

Entretanto, esta restrição garante tão somente uma solução viável. É preciso que a função objetivo garanta a solução de menor custo possível. Como cada arco tem um custo $\mathbf{c}_{\mathrm{ij}}$ e a variável $\mathbf{x}_{\mathbf{i j}}$ indica 0 se o arco não tem fluxo e 1 se o arco tem fluxo, para calcular o custo de uma dada solução basta somar $\mathbf{c}_{\mathrm{ij}}{ }^{*} \mathbf{x}_{\mathrm{ij}}$ para todos os arcos da rede. Com isso, a função objetivo, que é de minimizar este custo, fica como apresentado na form.(12).

$$
[\min ] \sum_{(i, j) \in A} \mathrm{C}_{i j} \cdot \mathbf{x}_{i j}
$$

Em outras palavras, a função objetivo garante que a soma do custo de todos os arcos presentes na solução seja mínima.

Por esta modelagem é possível observar que teremos praticamente uma equação de restrição para cada nó do sistema, sendo que cada uma delas terá tantas variáveis quantos forem os arcos do sistema, o que significa que para problemas grandes o número de restrições e variáveis será enorme, complicando bastante a solução de problemas reais com o uso de um algoritmo genérico como o Simplex. 


\section{B.3.1.1. O algoritmo Label Setting}

Uma vez que a abordagem por Simplex é inadequada para a solução de casos reais deste tipo de problema, a alternativa é buscar algum algoritmo que resolva o problema se utilizando de características específicas deste.

Uma forma de fazer isso é resolver o problema por partes. A partir do nó de origem calcula-se o menor caminho para todos os nós seguintes, de forma iterativa, baseando-se na distância total acumulada até aquele nó, pelos diversos caminhos possíveis. Sempre que for encontrado um caminho melhor até um dado nó, o caminho aceito anteriormente para aquele nó é descartado e o novo é registrado. Essa é a essência do algoritmo Label Setting (BRADLEY; HAX; MAGNANTI, 1977); (GALLO; PALOTINO, 1984); (WINSTON, 1994), que pode assim ser explicitado:

1. Cria-se uma "etiqueta" em todos os nós, indicando uma distância acumulada de "0" e o nó "-1" como o nó anterior, ou seja, sem antecessor.

2. Marca-se o nó 0 (origem) como sendo antecessor de si mesmo (0) e distância até a origem igual a "0".

3. Dentre os nós que ainda não possuem antecessores (-1), seleciona-se um que todos os arcos que chegam a ele tenham origem em nós com antecessores (diferente de -1). Se todos os nós já possuem antecessores, fim do processo.

4. Calcula-se separadamente a distância total no nó selecionado, considerando a chegada por cada um dos nós possíveis, sendo que a distância total acumulada neste novo nó será a soma da distância total até o nó antecessor somado com o comprimento do arco que liga o nó antecessor ao nó atual.

5. Indica-se a distância total acumulada no nó atual como sendo a menor distância calculada no passo 4, sendo que o antecessor do nó atual é marcado como sendo o nó antecessor que resultou na menor distância total acumulada.

6. Voltar ao passo 3. 
Em outras palavras, anota-se, em cada nó, o nó anterior que proporciona o melhor caminho até ele, bem como o comprimento de tal caminho, até que todos os nós tenham um antecessor definido. A solução ótima será aquela definida seguindo-se, a partir do nó destino, de antecessor em antecessor.

Entretanto, além de encontrar a solução ótima em si, o algoritmo Label Setting também encontra a solução ótima do nó de origem para todos os demais nós da rede. Tal característica pode ser muito importante na resolução de uma série de problemas como, por exemplo, para uma empresa que faz entregas únicas sempre a partir de uma determinada base.

\section{B.3.1.2. O problema dos ciclos}

O algoritmo Label Setting é bastante eficiente. Entretanto, na forma como foi apresentado, ele apresenta uma limitação bastante grande: não permite a resolução de redes que possuam ciclos, uma vez que nestes casos sempre haverá nós cujos cálculos serão interdependentes. Analisando a figura B.4, é possível verificar que tal rede possui ciclos e, portanto, não se pode ser aplicado o algoritmo Label Setting.

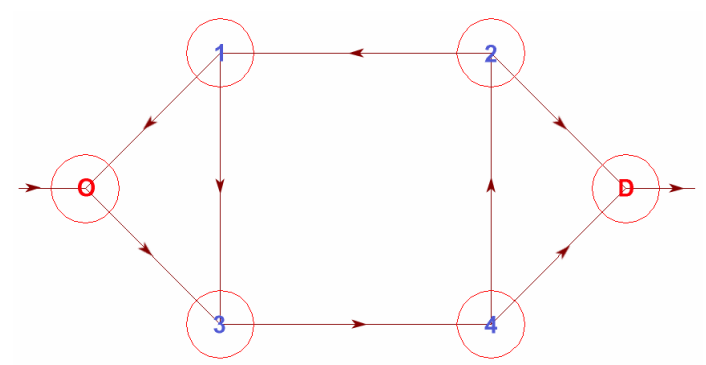

Fig. B.4 - Representação de uma rede com ciclos

Uma forma prática para verificar se uma rede contém ou não ciclos é analisar a possibilidade de representá-la em camadas ordenadas, sendo que a movimentação dos arcos deve sempre ir de uma camada para a seguinte, nunca para a mesma camada ou a camada anterior. A rede do problema resolvido pelo algoritmo Label 
Setting na seção anterior, por exemplo, pode ser representada em cinco camadas como representado na figura B.5.

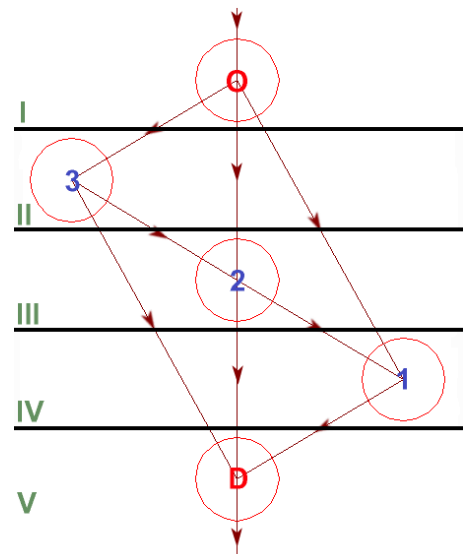

Fig. B.5 - Uma rede sem ciclos representada em camadas

É possível notar que não há como representar a rede da figura B.4 num formato como este, sendo que inevitavelmente haverá arcos ligando nós de níveis mais altos em direção a nós de níveis mais baixos, evidenciando assim a existência de ciclos.

Uma alternativa para contornar o problema dos ciclos pode ser a prévia utilização de um algoritmo de remoção de ciclos e, apenas depois disso, lançar mão da utilização do Label Setting. Entretanto, esta pode não ser uma forma apropriada, já que a eliminação de ciclos pura e simples pode remover arcos que fariam parte da melhor solução e, sendo assim, deteriorando a qualidade da solução do problema.

Por esta razão, é necessária uma alternativa ao Label Setting que seja capaz de lidar com o problema dos ciclos, garantindo que a solução ótima seja atingida. Esta é a base da proposta do Label Correcting. 


\section{B.3.1.3. O algoritmo Label Correcting}

O algoritmo Label Correcting (GALLO; PALOTINO, 1984) foi desenvolvido para lidar com os casos em que o algoritmo Label Setting não se comporta bem, ou seja, aqueles que possuem ciclos. De forma geral, o Label Correcting nada mais é que uma variação do Label Setting, onde foi modificada a ordem de cálculo dos nós e o critério de parada.

Sendo assim, a essência do Label Setting permanece, com algumas pequenas variações:

- Existe um novo indicador na etiqueta: 0 se o nó não precisa ter seus sucessores recalculados e 1 se ele precisa ter seus sucessores recalculados.

- A partir de um nó com antecessor (já etiquetado) e que esteja marcado para ter seus sucessores recalculados, são calculados todos os nós sucessores deste, substituindo a etiqueta anterior do sucessor se o novo caminho até ele for mais eficiente.

Estas duas modificações fundamentais alteram todo o mecanismo do Label Setting, transformando-o no que foi chamado de Label Correcting. Uma possível sistematização para o Label Correcting é:

1. Cria-se uma etiqueta em todos os nós, indicando a distância acumulada "0" e "-1" como o nó antecessor. Indica-se também em todas as etiquetas que seus sucessores não precisam ser calculados, com o valor "0".

2. Marca-se o nó 0 (origem) como sendo antecessor de si próprio, indicando "0" em sua etiqueta, distância total acumulada "0" e indicando que este nó precisa ter seus sucessores calculados, indicando "1" na etiqueta. 
3. Dentre todos os nós marcados para que seus sucessores sejam calculados, seleciona-se aquele que tem menor distância acumulada. Se não houver qualquer nó com indicação de recálculo de sucessores, fim do processo.

4. Para o nó selecionado, calcula-se a distância total acumulada para todos os nós sucessores deste, sendo esta distância a soma da distância total acumulada até o nó atual com o comprimento do arco que liga este nó ao referido sucessor.

5. Caso o nó sucessor não tenha ainda sido etiquetado com um antecessor ou ainda que a nova distância seja inferior à anteriormente indicada na etiqueta do sucessor, indica-se no nó sucessor a nova distância acumulada, o novo nó antecessor e também se deve indicar que seus descendentes precisam ser recalculados.

6. Voltar ao passo 3.

Embora ligeiramente mais complexo, este algoritmo resolve inclusive casos com ciclos, embora isso signifique um aumento significativo na quantidade de cálculos necessários para a solução do problema.

Uma outra característica positiva deste algoritmo é que ele permite que novos nós e arcos sejam adicionados na rede, aproveitando-se o resultado da rede já calculada. Para tanto, basta marcar todos os nós originais aos quais são ligados novos arcos de saída como sendo necessitando recálculo de seus descendentes.

\section{B.3.2. Modelagem de um problema de caminho mínimo multimodal}

Até agora foi apresentada uma modelagem que funciona muito bem para o caso monomodal, ou seja, não envolve troca de modos de transporte que possuam características distintas entre si e/ou em que exista custos de transição.

Entretanto, para estes problemas multimodais, a modelagem apresentada até o instante tem utilidade reduzida, visto que ela não leva em consideração 
características como, por exemplo, a velocidade no desenvolvimento do trajeto, ou ainda tempos de espera de embarque e desembarque.

Tais aspectos são de fundamental importância, uma vez que os diferentes modos de transporte possuem variações significativas nestes (e em outros) parâmetros, que influenciam diretamente uma solução de caminho mínimo, dependendo do critério adotado para sua escolha.

Assim, é preciso incorporar tais características ao modelo, de forma que elas possam ser consideradas na resolução do problema e o algoritmo utilizado passe a gerar, de fato, soluções ótimas segundo os critérios selecionados.

Há duas formas diretas de se incorporar tais características ao modelo: utilizar atributos nos arcos e nós que reflitam as características dos diferentes modos de transporte disponíveis naquele arco/nó (HORN, 2003) ou modificar a rede com arcos e nós redundantes, entre cada par de pontos onde existir mais de um modo de transporte (GUALDA, 1975); (SILVA, 2001), sendo que cada arco que liga tais pontos representam uma das formas de transporte possíveis entre estes nós.

$\mathrm{Na}$ modelagem matemática, ambas as modificações são apresentadas de forma semelhante, existindo variáveis distintas para cada modo de transporte. Entretanto, na implementação em algoritmos como o Label Correcting, existem diferenças fundamentais tanto em termos de equipamento necessário quanto em variações na garantia de otimalidade. Com o objetivo de ressaltar algumas destas características, ambas as formas serão discutidas com mais detalhes a seguir.

\section{B.3.2.1. Arcos e nós com atributos de modo}

A utilização de atributos nos arcos e nós para definir quais modos de transporte estão disponíveis, bem como as características de tais modos (HORN, 
2003), é talvez a abordagem mais tradicional. Tal postura não é sem razão: considerar os diferentes modos de transportes como atributos dos arcos, em geral, resulta em uma utilização de memória bastante eficiente.

De fato, a utilização racional da memória do equipamento de processamento de dados é algo sempre positivo, uma vez que não deteriore o desempenho do software nem a qualidade de seu resultado. Entretanto, o que ocorre na implementação usual de modos de transporte como atributos dos arcos é justamente uma deterioração de ambos: tanto no desempenho quanto no resultado.

Isso ocorre devido ao fato de que a implementação usual considera, na formação da solução, uma variável a mais para cada nó, indicando qual foi o modo de transporte utilizado naquele arco. Entretanto, essa abordagem torna o algoritmo míope. Essa miopia advém do fato de que esta implementação faz a seguinte consideração: uma vez que um modo foi definido para um dado arco, ele não mais é alterado. Isto é inadequado por uma razão fundamental: não se sabe qual é o modo de transporte melhor para cruzar um determinado trecho até que se chegue ao fim do processo.

A figura B.6 apresenta um exemplo hipotético de uma pequena rede onde tal algoritmo falha. É possível verificar que o usuário pode subir e descer do ônibus nos pontos $\mathrm{A}$ e $\mathrm{C}$ e que o ônibus passa nos $\operatorname{arcos}(\mathrm{A}, \mathrm{B})$ e $(\mathrm{B}, \mathrm{C})$. A pé é possível andar pelos $\operatorname{arcos}(A, B),(B, C)$ e $(D, B)$. No trecho $(A, B)$, por qualquer razão, o ônibus demora $\underline{1 \text { minuto }}$ para passar, e a pé o usuário demora $\underline{30 \text { segundos }}$. No trecho $(\mathrm{B}, \mathrm{C})$ o ônibus demora $\underline{10 \text { segundos }}$, enquanto a pé o usuário demora $\underline{1 \text { minuto }}$.

Se o usuário pretende ir de $\mathrm{A}$ para $\mathrm{C}$, a solução óbvia é que ele deve pegar o ônibus no ponto $\mathrm{A}$ e descer no ponto $\mathrm{C}$, demorando 1 minuto e 10 segundos no trajeto. Entretanto, o algoritmo não tem essa visão global. Seu procedimento é avaliar primeiro de $\mathrm{A}$ para $\mathrm{B}$, onde a pé se revela o melhor modo com 30 segundos. A 
seguir, é verificado qual o melhor modo de B para C, que é ônibus, com 10 segundos. Entretanto, não é possível usar este modo, pois não é possível subir ou descer no ônibus no ponto B. Desta forma, a única alternativa é continuar a pé, encontrando uma solução não ótima de 1 minuto e 30 segundos.

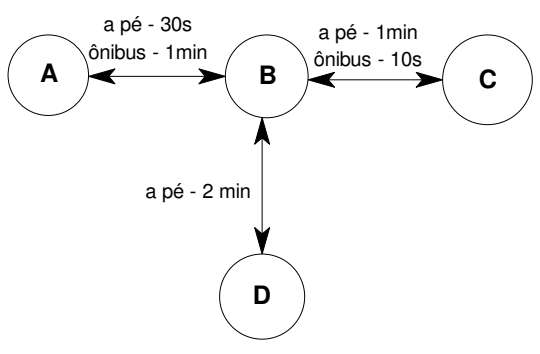

Fig. B.6 - Uma rede com modos de transporte como atributos

A solução para tal problema é fazer um rastreamento preditivo o que, em outras palavras, significa que o algoritmo passa a ter que rastrear os nós seguintes da rede para obter fundamentos sólidos para decidir qual modo é o mais adequado para um determinado arco, processo este que é implementado no algoritmo Dijskstra Forward (HORN, 2003).

Infelizmente, esta técnica não é necessariamente um processo eficiente do ponto de vista computacional, pois muitas vezes exige que a rede seja varrida até o último de seus nós para a determinação do melhor modo para um determinado arco. Como isso é computacionalmente ineficiente (o custo computacional é similar ao de resolver a rede inteira para cada arco a ser calculado), adota-se um parâmetro de profundidade de busca, que estabelece o número máximo de níveis a progredir na rede para a decisão do melhor modo para um determinado arco. E é exatamente neste parâmetro em que se perde a garantia da otimalidade da solução. 


\section{B.3.2.2. Arcos e nós redundantes}

Em oposição à abordagem por atributos em arcos e nós, de forma geral o uso de arcos e nós redundantes é preterido exatamente por ter a característica oposta: abusa do uso da memória, visando acelerar o processamento.

Esta abordagem consiste em aumentar grandemente o número de nós e arcos da rede, sendo que haverá diversas redes interligadas (GUALDA, 1975); (SILVA, 2001), cada uma representando um modo de transporte, com arcos que representam unicamente as características daquele modo.

A interligação entre estas redes é feita por "arcos fictícios" (GUALDA, 1975); (SILVA, 2001), não existentes fisicamente, mas que representam situações reais (como os tempos de espera, custos de troca de modo de transporte, etc.). $\mathrm{Na}$ figura B.7 é possível verificar a diferença de aspecto de uma mesma rede onde a linha de ônibus é definida por atributos dos arcos e onde esta mesma linha de ônibus é uma rede paralela à rede $a$ pé.

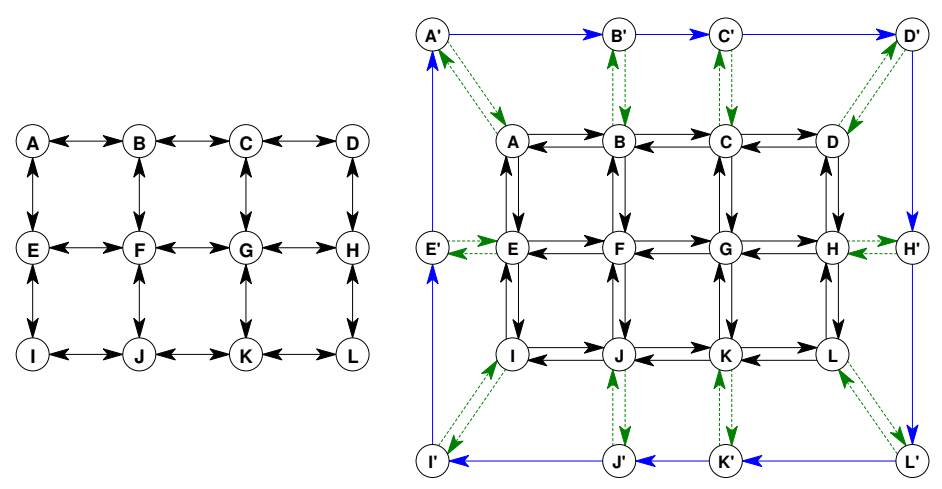

Fig. B.7 - Comparação entre o uso de atributos (esq.) e arcos e nós redundantes (dir.)

Não é preciso ir muito longe para verificar que esta abordagem faz a rede crescer de forma sensível. Considere um dado arruamento onde existam $\mathrm{N}$ nós e $\mathrm{M}$ vias. Nestas vias devem circular pessoas e taxis, todas as ruas com mão dupla e em 
todos os pontos é possível que o indivíduo pegue um táxi ou desça do táxi. Se numa representação por atributos teríamos $\mathrm{N}$ nós e $\mathrm{M}$ arcos para representar esta rede, para uma representação por arcos e nós redundantes esta rede teria:

Número de nós da rede de cálculo: $N+N=2 * N$

Número de arcos da rede de cálculo: $2 * M+2 * M+2 * N=4 * M+2 * N$

$\mathrm{O}$ número de nós da rede de cálculo é $2 * \mathrm{~N}$ porque existem $\mathrm{N}$ nós da rede de táxi e $\mathrm{N}$ nós da rede de pessoas. $\mathrm{O}$ número de arcos da rede de cálculo é $4 * \mathrm{M}+2 * \mathrm{~N}$ porque existem $2 * \mathrm{M}$ arcos para a rede de táxi (duas mãos), $2 * \mathrm{M}$ arcos para a rede de pessoas (duas mãos) e mais $2 * \mathrm{~N}$ arcos para interligar cada um dos nós das redes.

Entretanto, com este tipo de modelagem, mesmo o algoritmo Label Correcting usual, sem qualquer tipo de modificação, é capaz de encontrar a solução ótima. Isto se deve ao fato de que, como existe um conjunto de arcos e nós para cada modo de transporte, é possível calcular a melhor solução exata em cada ponto, pois sempre é possível verificar qual é a melhor forma de se chegar a um dado ponto, sem a necessidade de qualquer tipo de análise preditiva.

\section{B.3.2.3. Uma comparação entre as duas formas de modelagem}

Como é possível observar, existe um trade-off importante a ser considerado: complexidade de cálculo versus consumo de memória. Se por um lado a definição de modos de transporte como atributos dos arcos economiza memória, por outro o processamento para garantir soluções de fato ótimas cresce enormemente em complexidade e, portanto, tempo.

Inversamente, a utilização de arcos e nós redundantes simplifica grandemente o processamento, tornando a solução de problemas multimodais praticamente 
inalterada com relação à solução de problemas monomodais. Por outro lado, o consumo de memória cresce grandemente em proporção ao tamanho da rede.

Para redes pequenas e médias, tal consumo não chega a ser preocupante, mas para redes com milhões de arcos e nós, tal consumo facilmente chega à casa de vários gigabytes.

Há de se notar, entretanto, que embora a memória ainda seja um recurso razoavelmente limitado, a economia de memória é um aspecto que tem tido sua importância reduzida sensivelmente à medida que o tempo passa. Em 20 anos a quantidade de memória comum nos equipamentos aumentou de 64 quilobytes para 512 megabytes. Isso significa um aumento de 8192 vezes e a tendência é que a memória disponível nos equipamentos - a um baixo custo - seja cada vez maior.

A "memória permanente" do computador (usualmente o disco rígido) também teve um aumento considerável de tamanho nos últimos 20 anos, passando dos 10 megabytes para 120 gigabytes, um aumento de mais de 12000 vezes, sendo que os tempos de acesso deste tipo de memória também se tornaram sensivelmente menores, com discos cada vez mais rápidos.

Por outro lado, o processamento nestes mesmos 20 anos cresceu de 5 megahertz em 16 bits para quase 4 gigahertz em 32 bits. Grosso modo, isso significa um aumento entre 800 e 1600 vezes na velocidade de processamento. Embora impressionante e de ordem de grandeza similar ao aumento da memória residente do micro, a diferença é sensível, em especial quando comparada com a capacidade de armazenamento da memória permanente do computador.

Embora não seja uma garantia que futuramente esta progressão continue nestas mesmas taxas, é possível observar que a tendência tem sido a de um aumento maior no armazenamento que no processamento. Assim, métodos mais eficientes 
computacionalmente, mesmo que à custa de um maior consumo de memória, tornam-se mais atrativos à medida que o tempo passa.

Obviamente esta mudança de paradigma não justifica desperdício de recursos. Doravante, uma implementação mais custosa em processamento deve ser otimizada para que tal processamento seja o mais eficiente possível. Da mesma forma, uma implementação mais custosa em termos de memória deve ser otimizada de forma que a memória seja utilizada da forma mais racional possível.

Assim como no caso dos algoritmos baseados em modos de transporte como atributos de arcos e nós, é possível a utilização da profundidade de busca como uma heurística para promover eficiência do algoritmo, para o caso de arcos e nós redundantes, é possível utilizar técnicas de rede dinâmica. Com esta técnica, calcula-se uma rede básica e sem seguida são adicionados arcos, à medida em que as soluções são encontradas, na busca de soluções cada vez melhores sem, contudo, obrigar o carregamento de todos os arcos de todas as redes na memória.

Vale frisar, entretanto, que ambas as otimizações de algoritmo podem ter impacto negativo nas soluções. No primeiro caso, só se garante a solução ótima se a profundidade de busca for tal que a rede toda é verificada em cada arco calculado. No segundo caso, só se garante a solução ótima após adicionar todos os arcos possíveis à rede. Em ambos os casos ter-se-á recaído no caso sem a otimização do algoritmo para garantir a otimalidade do resultado.

\section{B.4. Considerações finais}

Dadas as condições e restrições apresentadas nos itens anteriores, acredita-se que a utilização de uma implementação do algoritmo Label Correcting, em associação com uma representação da rede em um grafo com arcos e nós 
redundantes, seja uma boa forma de enfrentar o problema de caminho mínimo multimodal proposto neste trabalho.

Maiores informações sobre modelagem de redes e algoritmos de fluxo em rede podem ser vistos em Gualda (1975), Bradley; Hax; Magnanti (1977), Chvatal (1983), Gallo; Pallottino (1984), Novaes (1986), Giacaglia (1993), Winston (1994), Silva (2001), Chuang; Kung(2003), Horn (2003), entre outros. 


\section{ANEXO C - BANCOS DE DADOS}

\section{C.1. Introdução}

Uma vez que uma das etapas do sistema proposto neste trabalho envolve a resolução de uma rede, é necessário que os dados necessários para a construção de tal rede estejam armazenados de uma forma que sejam facilmente acessíveis ao sistema. Ao mesmo tempo, é interessante que alterações e atualizações de tais dados possam também ser realizadas de forma simples.

Uma das diversas formas de armazenar este tipo de informação e oferecer tais recursos é pelo uso de um sistema gerenciador de bancos de dados, sendo conveniente, então, apresentar uma introdução sobre os bancos de dados, bem como sobre bancos de dados relacionais, evidenciando suas principais características, qualidades e aplicações.

Tal exposição tem por objetivo apresentar os fatores que tornam esta maneira de armazenar dados atraente para a implementação do sistema proposto por este trabalho.

\section{C.2. Bancos de dados}

Talvez uma das aplicações mais antigas da computação, os bancos de dados eletrônicos foram criados para reduzir o espaço despendido com o armazenamento de informações, substituindo enormes quantidades de documentos físicos, bem como para possibilitar a recuperação e geração de estatísticas sobre tais informações de forma rápida e eficiente. 
Entretanto, antes que se possa definir com precisão o que é um banco de dados, é preciso que se defina o que é um "dado". Um dado é um símbolo que descreve um aspecto de uma entidade ou evento no mundo real, sendo que mundo real é o mundo cotidiano, através do qual experimentamos os nossos sentidos e falamos com linguagem comum (BUTZEN; FORBES, 1997).

Existem diversos tipos de dados, sendo os "estatísticos" os mais comuns: nominal, ordinal, intervalo e proporcional. A diferença básica entre tais tipos de dados é o domínio que eles representam, sendo as principais operações realizadas sobre eles as de comparação e as aritméticas (BUTZEN; FORBES, 1997).

Assim, pode-se definir que um banco de dados é um corpo de dados organizados em alguma forma lógica. Pode-se definir também um Sistema Gerenciador de Banco de Dados como sendo o sistema capaz de manter um corpo de dados. Manter um corpo de dados significa cuidar de todas as operações envolvidas em sua manutenção, como inserção, recuperação, eliminação e atualização de dados, mantendo sempre a integridade da estrutura lógica que torna tal corpo de dados um banco de dados (BUTZEN; FORBES, 1997).

Os dados armazenados em um banco de dados não precisariam necessariamente guardar uma relação entre si. Entretanto, no caso geral, esta relação existe, uma vez que os dados inseridos em um banco usualmente são agrupados em uma certa forma, seguindo alguma lógica. Em outras palavras, pode-se dizer que, em geral, os dados de um banco de dados estarão relacionados entre si (BUTZEN; FORBES, 1997). 


\section{$\underline{\text { C.3. Bancos de dados relacionais }}$}

Diversos tipos de organização de bancos de dados haviam sido sugeridas até o fim da década de 1960, embora nenhuma alternativa realmente satisfatória tivesse surgido. A estrutura de tabelas, até então adotada na maioria dos sistemas gerenciadores de bancos de dados, fazia com que os dados fossem armazenados em uma estrutura muito rígida e, como agravante, esta estrutura não era de forma alguma transparente para aplicações que consultassem o banco de dados. Em outras palavras, um programa que consultasse o banco de dados precisava saber todas as características da estrutura física de armazenamento dos dados. (BUTZEN; FORBES, 1997).

Não é preciso ir muito longe para perceber que tal tipo de organização era problemática. Neste tipo de implementação, mesmo quando as mudanças realizadas no banco de dados são simples alterações da ordem dos dados nas tabelas, em muitos casos se tornam obrigatórias revisões de todos os programas desenvolvidos que usem tal banco de dados, para que estes continuem funcionando corretamente. Mudanças ainda mais contundentes podem se tornar necessárias nas aplicações, se a estrutura interna do banco de dados for alterada mais profundamente (BUTZEN; FORBES, 1997).

Visando a uma alternativa para contornar estes problemas, um matemático da IBM chamado Edward Fitzgerald Codd propôs, em 1969, uma estruturação que mais tarde ficou conhecida como "modelo relacional". Esta nova proposta fez com que houvesse uma mudança no paradigma de modelagem de banco de dados, tornando a antiga estrutura de tabelas, anteriormente bem aceita, uma estrutura considerada ineficaz (BUTZEN; FORBES, 1997).

A proposta de Codd definia que a organização dos dados não deveria ser ligada à estrutura física de implementação do banco de dados e, para atingir a este 
objetivo, tais dados deveriam ser armazenados na forma de "tuplas" de uma relação. Uma tupla é um conjunto de dados relacionados entre si, sendo que cada um destes dados, seja um atributo ou evento, tem uma descrição que constitui o "cabeçalho da relação". As diversas tuplas que seguem tal cabeçalho formam o "corpo da relação" (BUTZEN; FORBES, 1997).

Com base na definição das tuplas, Codd determinou também que a ordem em que os dados são armazenados no banco de dados deve ser indiferente para as aplicações que o consultam. Em outras palavras, uma aplicação que consulte o banco de dados deve solicitar determinados atributos que guardem uma relação específica, e o sistema gerenciador de banco de dados deve fornecê-los na ordem solicitada pela aplicação (BUTZEN; FORBES, 1997).

Uma outra característica importante, definida por Codd, é que os dados de uma tupla devem ser atômicos. Isto quer dizer que os dados não podem ser matematicamente divisíveis. Em outras palavras, um dado não pode ser, por exemplo, uma fórmula cujo resultado seria o valor do atributo, nem mesmo uma estrutura complexa. Em especial, um dado não pode ser uma outra relação (BUTZEN; FORBES, 1997).

O processo de desagregação de dados complexos, que visa à obtenção de dados atômicos para armazenamento no banco de dados, é denominado normalização. A normalização é o que garante que não exista redundância de informações em um banco de dados, garantindo que ele ocupe o menor espaço necessário, além de facilitar a manutenção da integridade dos dados armazenados (BUTZEN; FORBES, 1997).

Finalmente, uma relação não pode ter tuplas duplicadas. Ainda que os dados armazenados possam ser repetidos, como, por exemplo, em várias vendas de um mesmo tipo de produto, é necessário que exista uma diferenciação entre estas tuplas. 
Ou seja: no mínimo, é necessário que haja um número de identificação da tupla, diferente para cada uma delas, dentro de uma mesma relação. (BUTZEN; FORBES, 1997).

Nem sempre esta identificação é necessária na geração de estatísticas, mas ela será de fundamental importância para a manutenção do banco de dados, uma vez que é preciso que cada tupla seja endereçável de forma direta, para o caso de necessidade de edição ou eliminação de uma dada entrada. $\mathrm{O}$ atributo ou o conjunto de atributos que permite a identificação de cada tupla é denominado a "chave primária" da tupla (BUTZEN; FORBES, 1997).

Todos estes conceitos definem a base do modelo relacional de bancos de dados e os Sistemas Gerenciadores de Bancos de Dados que seguem tal modelo são classificados como Relacionais.

Durante toda a década de 1970 Codd continuou a aperfeiçoar o modelo, culminando com o desenvolvimento da Structured Query Language (SQL), que definia todas as bases de uma linguagem de consulta ao banco de dados. Estava assim estabelecida a interface padrão entre o banco de dados e as aplicações, tornando o Banco de Dados, mais do que nunca, um componente independente de qualquer sistema que o utilize (BUTZEN; FORBES, 1997).

\section{C.4. Consideracões finais}

A quantidade de informações necessária para o funcionamento de um sistema de informações de transporte público coletivo é bastante grande, contendo informações sobre ruas, linhas/trajetos de transporte público, horários, velocidades, etc. Uma vez que a obtenção e o armazenamento de tais dados é complexa e custosa, 
é interessante que esse banco de dados possua flexibilidade de uso e facilidade de manutenção.

Entretanto, se tal banco de dados for implementado por meio de uma estrutura de tabelas simples, tanto a flexibilidade quanto a manutibilidade ficam extremamente prejudicadas. Esta razão, bem como a praticidade e modularização fornecida pelos Sistemas de Gerenciamento de Bancos de Dados Relacionais existentes, torna a adoção de um banco de dados relacional extremamente atraente para o armazenamento dos dados do sistema de apoio ao usuário.

Talvez a única desvantagem de se utilizar um banco de dados relacional, neste caso, seja uma possível queda de desempenho no acesso aos dados. Entretanto, este problema, frente à flexibilidade e manutibilidade do banco de dados, é um trade-off que pode ser considerado na implementação do sistema, visando mitigá-lo.

Apesar do assunto Bancos de Dados ser bastante amplo, acredita-se que as características apresentadas são as qualidades fundamentais que levaram à adoção de um sistema gerenciador de bando de dados relacional no sistema informatizado proposto por este trabalho.

Maiores detalhes sobre estrutura interna, operação e projeto de banco de dados podem ser verificados em Butzen; Forbes (1997), Silberchatz; Korth; Sudarrshan, (1999) e Date (2000). Detalhes sobre a utilização de bancos de dados, no caso particular de sistemas de transportes, podem ser verificados em Giacaglia (1998). 


\section{ANEXO D - ANÁLISE E PROJETO ORIENTADO A OBJETOS}

\section{D.1. Introdução}

Uma vez que o sistema de informações proposto neste trabalho é complexo e pretende ser expansível e de fácil manutenção, foi adotado para seu desenvolvimento a metodologia de análise e projeto orientados a objetos.

Esta seção apresenta, então, uma breve introdução sobre a idéia por trás da análise e projeto baseados em objetos, bem como algumas características importantes da programação orientada a objetos, apontando as características que foram determinantes para sua escolha para o desenvolvimento do sistema proposto.

\section{D.2. A "evolução" da Análise de Sistemas}

Quando se pretende implementar um sistema para resolver um problema do mundo real, o primeiro passo é sempre a compreensão do domínio deste problema. Em outras palavras, é necessário compreender o problema em cada um de seus detalhes, para que seja possível definir requisitos que norteiem a criação de um sistema que seja capaz de resolvê-lo (COAD; YOURDON, 1992).

Esta primeira etapa, denominada Análise de Sistemas, é fundamental para que o sistema possa atender às necessidades de seus usuários, bem como permitir que soluções para necessidades futuras possam ser incorporadas ao sistema sem que o mesmo precise de uma completa remodelagem. Esta última característica é interessante, uma vez que raramente é possível prever, num primeiro instante, todas as características que um sistema deve possuir (JACOBSON et al., 1992). 
Visando cumprir estes objetivos, algumas metodologias de análise de sistemas foram desenvolvidas ao longo do tempo, cada uma baseada em conceitos específicos. As seções seguintes apresentam algumas destas metodologias e alguns dos conceitos que as embasam.

\section{D.2.1. Análise de Sistemas "clássica"}

Desde os princípios da atividade de desenvolvimento de software já existiam algumas vertentes básicas na análise de sistemas e projeto de software, cada uma focando um determinado aspecto envolvido no projeto. Estas vertentes eram (COAD; YOURDON, 1992):

- Vertente da decomposição funcional: o projeto de software deve ser direcionado de acordo com as funções necessárias para resolver o problema, sendo que os módulos são definidos por afinidade das funções que o constituem.

- Vertente do fluxo de dados: o projeto de software deve ser direcionado de acordo com a necessidade do processamento dos dados, sendo que os tipos de processamento de dados é que ditam a modularização do software.

Infelizmente, em grandes projetos, múltiplas equipes eram responsáveis pelo projeto e, em geral, cada equipe optava por uma vertente diferente. Tal postura trazia, eventualmente, problemas na etapa de implementação do sistema, devido a incoerências entre os projetos de cada uma destas equipes (COAD; YOURDON, 1992).

Mesmo com muitos anos de discussão não foi possível que a comunidade chegasse a um consenso. Embora, em geral, prevalecessem as idéias das equipes da 
vertente do Fluxo de Dados, tal fato não era necessariamente positivo para a qualidade do projeto (COAD; YOURDON, 1992).

\section{D.2.2. A Orientação a Objetos}

A decisão por qual das vertentes de análise de sistemas seguir se tornou ainda mais complexa quando, em meados à década de 1960, surgiu uma nova forma de programação: a programação orientada a objetos, que oferecia um novo conceito de representação da realidade, para o qual os antigos métodos de análise se mostravam inadequados (JACOBSON et al., 1992); (YOURDON; ARGILA, 1999).

Enquanto os métodos de análise se baseavam em características intrínsecas das antigas linguagens de programação, seguindo critérios analíticos, a programação orientada a objetos se baseava em um elemento completamente distinto: o mundo real (YOURDON; ARGILA, 1999).

Em uma modelagem orientada a objetos, um sistema é modelado como um conjunto de objetos que interagem entre si. Uma vez que a própria realidade é composta por objetos que interagem entre si, a transição para o modelo é quase direta, com pequenas diferenças semânticas (JACOBSON et al., 1992).

Duas principais qualidades que a semelhança entre componentes da realidade e da modelagem trouxeram para o desenvolvimento de sistemas foram a facilidade de compreensão do modelo, uma vez que o modelo possui uma representação bem próxima da realidade, e a facilidade de modificação, uma vez que a maioria das modificações serão apenas locais, dentro de um único objeto (JACOBSON et al., 1992). 
Entretanto, tais benefícios do uso de um modelo orientado a objetos só ficam claros quando enunciadas algumas definições e propriedades fundamentais de tal modelo, que são apresentadas a seguir.

\section{D.2.2.1. Objetos}

Quando se fala em objetos, no contexto de orientação a objetos, é importante definir o que esta palavra significa. Um objeto é um ente caracterizado por um conjunto de operações e um estado que reflete o efeito destas operações, sendo que um objeto pode ser composto de outros objetos (JACOBSON et al., 1992).

É um fato importante que a descrição básica de um objeto indica "o que ele faz" e "o que ele armazena" e não "como ele faz" ou "como ele armazena", sendo esta característica denominada encapsulamento (JACOBSON et al., 1992).

\section{D.2.2.2. Classes}

Pela definição de objetos anteriormente fornecida, é possível que sejam definidos objetos como "carro verde", "carro vermelho" ou "carro azul". É possível imaginar que muitas das características destes carros podem ser exatamente as mesmas e, na verdade, talvez eles sejam diferentes apenas pela cor, uma característica que define um estado do objeto.

Quanto existem vários objetos semelhantes, apenas diferindo por seu estado atual, diz-se que estes objetos pertencem a uma mesma "classe". Na orientação a objetos, o sentido de classe é ligeiramente distinto deste, ainda que semanticamente próximo: uma classe é uma descrição de como um novo objeto deve ser criado, indicando exatamente "o que ele faz" e "o que ele armazena" (JACOBSON et al., 1992). 
Assim, uma classe carro que possua um atributo de cor poderá dar origem a objetos carro, sejam eles azuis, vermelhos ou verdes, por exemplo, uma vez que esta cor define apenas um estado. Ao processo de criar um objeto a partir de uma classe é dado o nome de instanciação (JACOBSON et al., 1992).

\section{D.2.2.3. Polimorfismo}

O polimorfismo é uma das características mais importantes para a modelagem orientada a objetos, pois grande parte da flexibilidade dos componentes desta modelagem são advindos desta característica (JACOBSON et al., 1992). Entretanto, a compreensão do conceito é bastante facilitada através do uso de um exemplo.

Com este objetivo, é possível pensar na modelagem de um indivíduo dirigindo um carro. Para esta modelagem serão necessários pelo menos dois objetos: um objeto da classe "carro", como o "carro azul", anteriormente citado, e também um objeto da classe "pessoa".

É possível descrever a classe "pessoa" como possuindo a operação "dirigir" e, na descrição do modelo, associar essa classe "pessoa" à classe "carro". De forma implícita, o que está sendo dito é que o objeto da classe carro pode ser operado por objetos da classe pessoa.

Entretanto, se for implementada uma classe "caminhonete" com a mesma interface que a classe "carro", do ponto de vista da ação "dirigir" desempenhada pela classe pessoa, qualquer objeto da classe "pessoa" poderá também operar um objeto da classe "caminhonete", através da mesma operação "dirigir". Isso significa que, na realidade, o objeto da classe "pessoa" nem precisa ter conhecimento do tipo de objeto que ele opera com a ação "dirigir", desde que este objeto da classe que ele opera respeite aquela determinada interface, que neste caso poderia ser representada como 
operações do tipo "apertar pedal do freio", "girar direção", etc. É esta independência do tipo de objeto controlado que recebe o nome de polimorfismo.

Em outras palavras, polimorfismo é a característica que faz com que o objeto que executa uma operação sobre outro não precisa ter conhecimento sobre a classe do objeto que recebe aquela operação (JACOBSON et al., 1992).

Existem várias formas de se garantir o polimorfismo, mas a mais comum delas é através da propriedade da herança (JACOBSON et al., 1992).

\section{D.2.2.4. Herança}

Anteriormente foram citados os exemplos das classes "carro" e "caminhonete". Uma análise de tais classes revelam que, provavelmente, ambas possuem muitas características comuns, muito embora possuam também várias diferenças. Algumas semelhanças, já citadas, são todas as operações relativas à direção do veículo. Entre as diferenças podem ser citadas as operações relativas à carga e descarga do veículo, por exemplo.

Uma forma mais adequada de definir este modelo seria, então, criar uma classe mais genérica, a classe "veículo", que possuísse todas as características e operações comuns entre as classes "carro" e "caminhonete" e então fossem criadas novas classes baseadas na classe "veículo", apenas adicionando as características distintas em cada um dos casos. A existência desta possibilidade é garantida pela propriedade chamada de herança.

Em outras palavras, a herança é a propriedade que permite que, a partir de uma classe genérica, como a classe "veículo", sejam derivadas classes especializadas, como as classes "carro" e "caminhonete". Como as classes "carro" e "caminhonete" 
derivam da classe "veículo", ambas possuem todas as estruturas de informação e operações desta última. (JACOBSON et al., 1992).

\section{D.2.3. Análise Baseada em Objetos}

Com a utilização de objetos, classes e suas características e propriedades anteriormente citados, a descrição de modelos baseados no mundo real torna-se mais simples, devido à proximidade semântica entre componentes do problema real e componentes do modelo. E foi esta característica que provocou, então, um esforço em utilizar a orientação a objetos já na etapa de análise de sistemas (JACOBSON et al., 1992).

Tal forma de representar a realidade e seus problemas trouxe inúmeras vantagens com relação às modelagens clássicas - fluxo de dados e decomposição funcional, pois permitiu uma maior facilidade na elaboração, compreensão, e gerenciamento do sistema, tanto na fase de desenvolvimento quanto na fase de implantação e manutenção (COAD; YOURDON, 1992); (JACOBSON et al., 1992).

Estas vantagens são ainda mais expressivas quando é levado em consideração que, via de regra, o mundo real e seus problemas possuem elementos estáveis, sendo que as necessidades de mudanças mais freqüentes envolvem apenas a forma de interação entre tais elementos (COAD; YOURDON, 1992); (JACOBSON et al., 1992).

Da mesma forma, em geral são as funções de um sistema que sofrem alterações ao longo da sua vida útil; por outro lado, os elementos envolvidos no cumprimento de tais funções são, em geral, bem mais estáveis. Como, na modelagem orientada a objetos, os componentes do sistema são definidos de acordo com os elementos que fazem parte do sistema e não na forma como o problema em si é 
resolvido, a manutenção do sistema fica bastante simplificada, usualmente envolvendo apenas mudanças locais, nas ações desempenhadas por um dado objeto (JACOBSON et al., 1992).

Além destas vantagens, a estruturação de um sistema por uma análise orientada a objetos leva a uma concepção modular do sistema que permite o reuso não só de trechos de código, mas também de módulos inteiros do sistema, uma característica interessante que pode viabilizar também o desenvolvimento de sistemas futuros (JACOBSON et al., 1992).

Ainda assim, com todos estes benefícios, muitos anos se passaram desde o surgimento de linguagens que trabalhavam com a orientação a objetos até o desenvolvimento de uma metodologia de análise e projeto orientados a objetos (COAD; YOURDON, 1992).

\section{D.3. Projeto Baseado em Objetos}

Como produto da Análise de Sistemas é constituída uma documentação que descreve o sistema de uma forma independente da implementação a ser realizada. $O$ projeto é a etapa que vem imediatamente em seguida e cuja função é acrescentar elementos que reflitam detalhes de implementação à documentação, proporcionando a posterior implementação do sistema (COAD; YOURDON, 1993).

Uma vez que tenha sido realizada uma análise de sistemas orientada a objetos, toda a documentação estará modelada de acordo com esta ideologia. Assim, nada mais natural que a etapa do projeto também siga uma metodologia orientada a objetos. 
Apesar do processo de desenvolvimento ser, usualmente apresentado de maneira seqüencial, na forma "análise-projeto-programação-teste", esta não é a única maneira de conduzir o desenvolvimento de um sistema. É possível que as etapas de "análise e projeto" tenham um período de sobreposição, assim como "projeto e programação" e "programação e teste". É possível ainda realizar vários ciclos seqüenciais até serem atingidos os requisitos propostos (JACOBSON et al., 1992); (COAD; YOURDON, 1993).

Por esta razão, é ainda mais interessante que as documentações de todos os estágios de desenvolvimento sigam a mesma ideologia, para permitir um processo contínuo de interação entre as diversas equipes que conduzem o desenvolvimento, sendo interessante que também a etapa de programação seja orientada a objetos (JACOBSON et al., 1992).

\section{D.4. Programação orientada a objetos}

Para implementar um sistema cujo projeto é orientado a objetos não é necessário que se utilize uma linguagem orientada a objetos. As especificações resultantes de um projeto orientado a objetos podem ser suficientemente genéricas para permitir que o sistema seja implementado com qualquer linguagem de programação. Tal característica é especialmente vantajosa quando existem vários módulos com funções muito distintas, sendo que para cada um deles pode ser mais interessante o uso de uma ou outra linguagem.

Entretanto, o uso de uma linguagem orientada a objetos pode facilitar enormemente a implementação de um projeto deste tipo, pela conseqüente sintonia entre as filosofias das etapas de análise e projeto e da etapa de programação. Em especial, como dito anteriormente, quando todas as etapas são orientadas a objeto desde a análise até a programação, é possível existir grande coerência entre as 
documentações dos diversos estágios do desenvolvimento, usando a mesma notação e linguagem em todas elas (JACOBSON et al., 1992).

As linguagens orientadas a objeto, como $\mathrm{C}++$ ou SmallTalk, possuem total suporte ao encapsulamento, herança e polimorfismo (no caso do $\mathrm{C}++$, através do suporte a redefinição e sobrecarga de funções), sendo assim perfeitas para implementar um modelo de um projeto baseado em objetos com a menor distância possível entre projeto e implementação (JACOBSON et al., 1992).

\section{$\underline{\text { D.5. Considerações finais }}$}

Dadas as características da orientação a objetos, não é difícil perceber as vantagens em se utilizá-la tanto no projeto quanto na implementação de sistemas de grande porte.

Tais características facilitam a expansão do sistema, permitem uma maior reusabilidade de código, além de reduzirem as chances de defeitos que venham a afetar todas as partes do sistema.

Além disso, a possibilidade de alta modularização associada à independência de desenvolvimento de cada um destes módulos são de grande valia para o desenvolvimento e manutenção do sistema como um todo, reduzindo sensivelmente a complexidade de implementação e também de futuras expansões.

Maiores detalhes sobre projeto e programação orientados a objeto podem ser obtidos em Jacobson et al. (1992), Coad; Yourdon (1992), Coad; Yourdon (1993), Holzner (1995), Reich (1995), Yourdon; Argila (1999), Hyde (2003). 


\section{ANEXO E - ARQUITETURA CLIENTE/SERVIDOR}

\section{E.1. Introdução}

Uma vez que pretende-se adotar a arquitetura cliente/servidor para a implementação do sistema, é conveniente fazer uma breve introdução à estruturação deste tipo de arquitetura, apresentando algumas de suas características, vantagens e desvantagens.

O objetivo desde capítulo é, portanto, apresentar características que embasaram a opção por este tipo de arquitetura para o sistema proposto neste trabalho.

\section{E.2. Características e vantagens da arquitetura cliente/servidor}

Dentre as muitas formas de se constituir um sistema computacional distribuído, existem duas que são as mais comumente difundidas atualmente: a arquitetura ponto a ponto (peer to peer ou $\mathrm{P} 2 \mathrm{P}$ ) e a arquitetura cliente/servidor.

A arquitetura P2P é aquela em que todos os módulos de sistema possuem iguais capacidades de processamento e operação. Todos os módulos possuem os mesmos serviços e não há nenhum tipo de centralização de informações ou de processamento.

A arquitetura cliente/servidor, por sua vez, é aquela em que existem dois módulos básicos de operação do sistema: o servidor, que fornece um serviço qualquer, e um ou mais clientes, que utilizam este serviço. A relação entre clientes e servidores pode ser observada na figura E.1. 


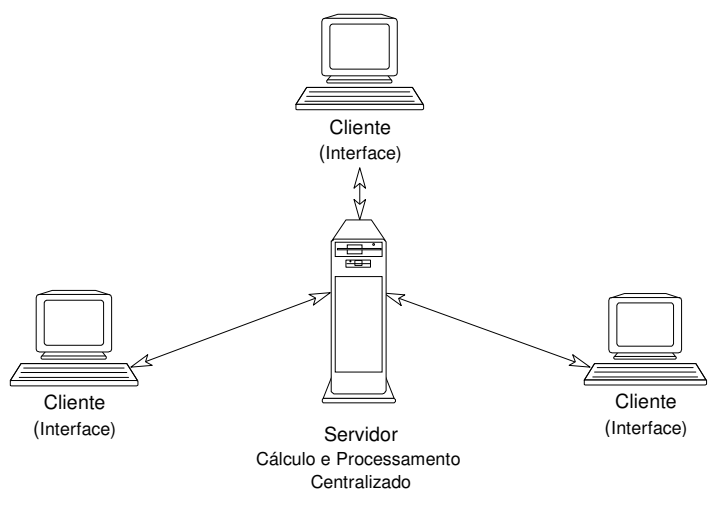

Fig. E.1 - Representação física usual da arquitetura cliente/servidor

Neste contexto, é importante ressaltar, um servidor não precisa ser, necessariamente, um único equipamento. É possível que um conjunto de equipamentos desempenhe um determinado serviço, formando um cluster e, neste caso, todo o conjunto será considerado "o servidor" (maiores detalhes sobre clusters na seção E.2.4).

Em muitos casos, quando as características deste tipo de arquitetura forem compatíveis com as necessidades da aplicação, a separação entre clientes e servidores pode ser bastante benéfica. A arquitetura cliente/servidor possibilita as seguintes características, dentre outras:

- Centralização de informações

- Independência entre a interface de um serviço e o serviço em si.

- Execução de processamento intensivo em equipamento(s) adequado(s).

- Maior facilidade de processamento distribuído.

- Racionalização dos recursos computacionais.

Estas características são mais aparentes quando a implementação do sistema é feita segundo a arquitetura multi-tier, que é um tipo de arquitetura cliente/servidor em que uma aplicação é executada por mais que um agente de software distinto. Um exemplo deste tipo de software seria uma aplicação que usa um middleware para 
atender a requisições de dados entre um usuário e um banco de dados (WIKIPEDIA, 2005d).

Este tipo de arquitetura permite uma boa sintonia com um projeto orientado a objetos, sendo possível modelar cada agente de software que compõe a aplicação como um componente independente, ou seja, uma unidade padrão que é utilizada para desenvolver aplicações (JACOBSON et al., 1992).

A seguir será feita uma análise das características da arquitetura cliente/servidor supracitadas, mostrando algumas das situações em que elas são úteis.

\section{E.2.1. Centralização de informações}

Uma das características mais úteis, possível pela arquitetura do tipo cliente/servidor, fica evidente quando são tratadas grandes massas de dados, como um banco de dados. Nestes casos, a arquitetura cliente/servidor permite manter os dados em um "servidor" e todos os "clientes" passam a acessar aquela informação neste local.

A manutenção de grandes massas de dados, quando estes não estão agregados, é um problema bastante comum. Em sistemas largamente distribuídos, onde os bancos de dados não são centralizados, a atualização de todos eles pode se estender por longos períodos de tempo e, muitas vezes, surgem conflitos de difícil solução.

Isso ocorre porque, quando um mesmo banco é atualizado em diferentes locais, com uma sincronia executada posteriormente, podem surgir discrepâncias que prejudiquem completamente a operação e a consistência do sistema, podendo torná-lo não confiável. 
Um exemplo fictício onde fica evidente a necessidade de um sistema centralizado é o do sistema bancário. Supondo uma situação em que não exista a centralização, um cliente que tenha uma dada quantia no banco poderia sacar essa quantia total em praticamente todos os caixas daquele banco, até que fosse realizada uma sincronia.

Entretanto, quando fosse realizada essa sincronia, o cliente estaria com uma grande dívida com o banco e, talvez, este mesmo cliente jamais houvesse tomado conhecimento de tal fato. Isso porque, após o primeiro saque, cada um dos caixas eletrônicos que ele consultou o teria informado um saldo incorreto. É evidente que um sistema deste tipo não é interessante e, por isso mesmo, não é assim que o sistema bancário funciona.

Por outro lado, a centralização tem também seus aspectos negativos. Um grande banco de dados centralizado tem, eventualmente, diversos tipos usuários, com necessidades distintas. Além da possível existência de diversos tipos de usuários tornar complexa a concepção do banco de dados em si, a existência de muitos usuários causa ainda um problema da sobrecarga do servidor, o que é indesejável.

Embora esse problema possa ser mitigado com o uso de um servidor de banco de dados distribuído ou com o uso de clusters, ainda assim é necessário um cuidado especial com o equipamento que realiza a comunicação principal com os clientes, redistribuindo as conexões e/ou processamento para outros equipamentos.

Esse cuidado deve existir porque, uma vez que todos os clientes estarão ligados àquele servidor, ocorrendo algum problema com este servidor ou com os cabos de rede que fazem as interconexões entre os clientes e ele, grande parte do sistema - ou até o sistema inteiro - pode deixar de funcionar (TANENBAUM, 2003a). 
Se o problema for no equipamento servidor, apesar de ter sua solução também centralizada, todo o sistema ficará inativo até que uma ação seja tomada. Se o problema for na interligação da rede, a solução nem sempre é tão simples, dado que inicialmente é preciso localizá-lo. Neste caso, também, a abrangência do problema é variável, dado que o número de clientes afetados depende do ponto onde a falha de interligação ocorreu (TANENBAUM, 2003a).

Por outro lado, problemas no lado do cliente podem ocorrer em qualquer que seja a arquitetura utilizada, tornando o serviço também indisponível, ainda que de forma bastante localizada (TANENBAUM, 2003a). Nestes casos, uma solução é a existência de equipamentos redundantes.

Entretanto, mesmo que todas as partes do sistema cliente/servidor estejam em perfeito estado de funcionamento, se há uma rede de interligação entre os equipamentos, há também a possibilidade de um outro problema: a latência da rede (TANENBAUM, 2003a).

A latência da rede é o tempo que se desenvolve entre o momento da requisição de um serviço por um cliente e o momento em que este mesmo cliente recebe a resposta de sua requisição. Dependendo da configuração da rede, da quantidade de dados sendo trocada e outros fatores, a latência pode chegar a vários segundos, ou até mesmo minutos, em casos extremos (TANENBAUM, 2003a). Uma possível latência de grande magnitude pode restringir seriamente a definição da estrutura da rede, podendo chegar até mesmo a inviabilizar este tipo de arquitetura para diversas aplicações. 


\section{E.2.1.1. Uso misto de servidor remoto e servidor local}

Para evitar a indisponibilidade do servidor devido à falha na rede ou no próprio servidor, bem como evitar os problemas de latência da rede, é comum que, em alguns sistemas, existam duas instâncias de servidores: o servidor remoto e o servidor local.

O servidor remoto é aquele que funciona em um equipamento diferente do equipamento cliente, sendo estes interligados por uma rede. O servidor local é aquele em que o equipamento cliente e o equipamento servidor são o mesmo equipamento, sendo este também responsável pela interligação entre ambas as partes.

Neste caso, com o uso misto dos servidores, o cliente usualmente consulta o servidor local para realizar suas operações. O servidor remoto, por sua vez, é utilizado para sincronizar o servidor local a cada dado intervalo de tempo.

Este tipo de configuração é bastante comum em sistemas onde os clientes são utilizados apenas para consultar o banco de dados e as informações não são extremamente sensíveis ao tempo. Nesta configuração, todas as alterações são sempre feitas no servidor remoto, o qual é utilizado para a atualização de todos os servidores locais, presentes em cada cliente (ou rede cliente).

Como dito, este tipo de configuração é interessante apenas no caso em que uma desatualização dos dados do servidor local não for problemática, sendo o intervalo máximo de sincronia entre os servidores remoto definido pelo nível de desatualização aceitável para os dados do servidor local. Em outras palavras, o servidor local deve ser atualizado sempre antes que as informações que ele contém se tornem inadequadas para o sistema prestar seu serviço. 
Caso esta desatualização seja potencialmente problemática e deva ser evitada a todo o custo, uma alternativa é modificar a forma de consulta. Neste caso, usualmente o cliente deve consultar o servidor remoto, que estará sempre atualizado. Só no caso do servidor remoto estar indisponível é que o cliente consultará o servidor local. Esta abordagem elimina o problema da indisponibilidade do servidor remoto central e possíveis falhas na rede, mas não elimina a latência da comunicação. Além disso, ela apenas mitiga o problema da desatualização do servidor local, não eliminando totalmente suas conseqüências.

\section{E.2.2. Independência entre a interface de um serviço e o serviço em si}

Uma ótima possibilidade da arquitetura cliente/servidor é o isolamento entre o serviço em si e sua interface com o usuário, sendo cada uma destas atividades exercidas por componentes distintos.

Embora a adoção de sistemas monolíticos, em alguns casos, facilite o desenvolvimento, tal abordagem tem sérias implicações. Dentre elas pode-se destacar:

- Dificuldade de manutenção futura do código

- Redução da portabilidade do código

- Possível redução da eficiência do código

- Redução da flexibilidade do software

Dificuldade de manutenção futura do código: usualmente, o código do serviço prestado é linear estruturado, e o código da interface é orientado a eventos. A concepção destes dois tipos de códigos varia enormemente e misturar ambos cria sérios problemas de legibilidade de código (REICH, 1995). Além disso, as interfaces estão mudando constantemente, já o serviço não. Como existe uma parte do código 
que precisa ser constantemente modificada (interface) e outra que não (o código que realiza o serviço em si), é interessante manter tais partes separadas, diminuindo a chance de alterações em uma causar danos à outra (JACOBSON et al., 1992).

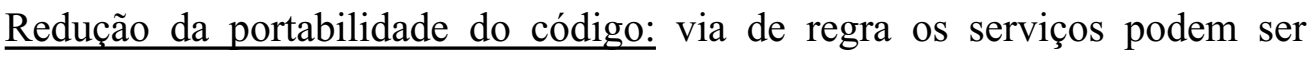
implementados de forma independente de plataforma. Com o uso de linguagens padronizadas, como ANSI $\mathrm{C} / \mathrm{C}++$, é possível gerar códigos que realizem as operações necessárias e sejam compiláveis em praticamente qualquer sistema existente com pouca ou nenhuma modificação. Por outro lado, os códigos de interface costumam ser totalmente ligados a um dado sistema operacional e/ou equipamento. Assim, se o código da interface estiver isolado do código que realiza o serviço, a portabilidade depende basicamente de rescrever a interface para a nova arquitetura, sendo que o funcionamento interno do serviço permanece essencialmente o mesmo e sem a adição de nenhum defeito. Se estes códigos estiverem misturados, entretanto, a portabilidade se torna um pesadelo que pode implicar em uma necessidade de um novo projeto de software (JACOBSON et al., 1992); (REICH, 1995).

Possível redução da eficiência do código: A execução de um serviço pelo computador e a interação com o usuário são atividades que ocorrem em ritmos absolutamente diferentes. Enquanto a execução de um serviço qualquer geralmente ocorre com processamento total até que este seja terminado, a interface com o usuário fica longos períodos em inatividade entre os comandos do usuário. No caso de uma interface e serviços misturados, nem sempre é possível compatibilizar estes dois ritmos de forma eficiente, sem fazer com que o sistema perca tempo demais checando entradas do usuário ou demore muito a checar as entradas do usuário, fazendo com que a interface tenha um tempo de resposta muito longo (REICH, 1995). 


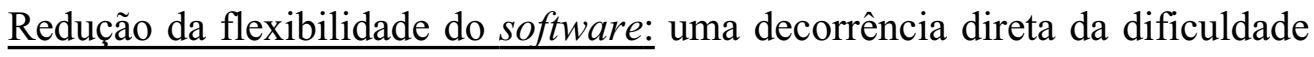
de portabilidade e do não isolamento entre interface e serviço propriamente dito é a dificuldade de adaptação do servido para diferentes mídias, exigindo, muitas vezes, um novo projeto de software. Considerando as vantagens decorrentes do isolamento entre a implementação do serviço e sua interface, a situação é inversa: um mesmo servidor pode fornecer informações para clientes distintos, em equipamentos distintos e com arquiteturas distintas. Isto torna possível - e de forma menos complexa - a implementação de um mesmo serviço através de, por exemplo, aparelhos de telefonia celular, terminais dedicados, internet e outros.

Ainda que a independência dos componentes de serviço e de interface permitam a superação de tais implicações, esta característica também introduz uma complexidade no desenvolvimento: uma vez que a interface e o serviço são módulos distintos, é necessária a existência de uma "língua de comunicação" entre eles. Esta "língua" é denominada "protocolo" (TANENBAUM, 2003a).

A existência de protocolos de comunicação usualmente introduz uma complexidade a mais no desenvolvimento do sistema e em sua manutenção, visto que, para uma coexistência pacífica entre versões novas e antigas, os protocolos futuros precisam ser compatíveis com os protocolos passados. Caso contrário, é preciso que seja possível atualizar os clientes sempre que o protocolo for modificado (REICH, 1995).

\section{E.2.3. Execução de processamento intensivo em equipamento(s) adequado(s)}

Depois da possibilidade de centralização de informações, talvez a característica que mais vezes leve à adoção de uma arquitetura cliente/servidor seja a possibilidade de centralizar, em um grupo de máquinas, o processamento mais 
pesado. Isto é especialmente interessante quando o número de equipamentos clientes é grande, mas grande parte não é utilizada na maior parte do tempo.

Nestes casos, a característica é desejável para reduzir o custo dos equipamentos de consulta (clientes), mantendo apenas alguns computadores realmente capazes de realizar os cálculos necessários (servidores). Como os equipamentos de consulta são, usualmente, em grande número, qualquer redução de custo que possa ser conseguida tem uma grande repercussão no custo final de implantação do sistema.

Além disso, caso uma capacidade computacional maior seja necessária no futuro, basta para isso trocar os servidores ou transformá-los em clusters, muitas vezes sendo desnecessária qualquer modificação nos equipamentos de consulta (clientes).

\section{E.2.4. Maior facilidade de processamento distribuído}

Uma outra vantagem da centralização dos cálculos no servidor é a menor dificuldade em se adaptar um software servidor para que ele opere em um cluster.

Um cluster nada mais é do que um conjunto de computadores que, interligados localmente, podem ser utilizados conjuntamente na solução de um único problema complexo, o que será feito em uma fração do tempo que um único computador demoraria.

A técnica utilizada é chamada de "processamento paralelo distribuído", que utiliza equipamentos distintos para o cálculo de cada uma das longas etapas de um processamento, dado que tais cálculos sejam independentes. 
Embora o uso de clusters seja muito mais difundido no processamento digital de imagens, seu uso não se limita a isso, podendo ser de grande valia a uma infinidade de aplicações de cálculo.

\section{E.2.5. Racionalização dos recursos computacionais}

Uma decorrência de todas as características da arquitetura cliente/servidor é que, de forma geral, o uso dos recursos disponíveis se torna mais racional.

Quando temos equipamentos distintos para a execução das tarefas de cálculo (o serviço em si) e de consulta (interface), os equipamentos podem ser desenvolvidos para que seu custo seja o menor possível e atendam da melhor forma cada uma de suas funções. Tal fato fica evidente se forem consideradas as diferenças fundamentais entre estas duas partes de um sistema de informações, por exemplo.

Se a interface exige uma grande capacidade de apresentar imagens com alta definição e ter um sistema altamente sensível aos comandos do usuário, bem como ter uma resposta rápida, a necessidade de cálculo e armazenamento desta parte sistema é mínima.

Por outro lado, um serviço pode exigir uma grande capacidade de cálculo e muitas vezes requer uma grande capacidade de armazenamento. Entretanto, sua capacidade de mostrar imagens e sua capacidade de interagir com o usuário podem ser praticamente nulas.

Como citado anteriormente, tal característica pode implicar em uma redução de custos significativa na implantação do sistema, já que apenas os servidores necessitarão de grande capacidade de processamento, armazenagem, cópias de segurança, etc. 


\section{$\underline{\text { E.3. Considerações finais }}$}

Dadas as características apresentadas neste capítulo, optou-se por adotar uma arquitetura do tipo cliente/servidor para a estruturação do sistema proposto, para intercomunicação entre os diversos módulos principais que o compõem, a ser realizada pela internet.

Considera-se que esta é a implementação que proporciona mais eficiência do uso computacional ao mesmo tempo em que mantém a flexibilidade e acessibilidade do sistema.

Maiores informações sobre arquiteturas de sistemas e computação distribuída bem como algumas de suas aplicações podem ser verificados em Jacobson et al. (1992), Pressman (1992), Reich (1995), Marte (2000), Silberschatz; Galvin (2000), Tanenbaum (2003a), Tanenbaum (2003b), WikiPedia (2005b), WikiPedia (2005d), dentre outros. 


\section{ANEXO F - MÁQUINAS DE ESTADOS FINITOS}

\section{F.1. Introdução}

Dado que uma das principais características de um sistema de informações é a interação com o usuário, é fundamental que sua interface com o usuário seja simples e, principalmente, de comportamento intuitivo.

Uma das formas de definir o comportamento de um software é descrevendo-o a partir de um modelo denominado Máquina de Estados Finitos. Tendo sido este o modelo adotado para descrever a interface do sistema proposto, é interessante apresentar uma introdução a ele, apresentando suas principais características, vantagens e algumas aplicações.

O objetivo é apresentar as características que tornam as Máquinas de Estados Finitos um bom modelo de estruturação para alguns tipos de software, como é o caso da interface com o usuário do sistema proposto por este trabalho.

\section{F.2. Os autômatos}

$\mathrm{Na}$ vida real, vários dispositivos são descritos como a interligação de outros dispositivos mais simples. No entanto, em muitas situações, uma descrição "macroscópica" é mais adequada, lidando com um dado dispositivo como uma "caixa preta" (VELOSO, 1979).

Foi este fato, o de certas propriedades de um sistema serem melhor compreendidas quando os detalhes de seu funcionamento interno são abstraídos, que 
motivou o aparecimento de teorias como as de sistemas e autômatos (VELOSO, 1979).

A origem da teoria dos autômatos está ligada ao projetos de circuitos seqüenciais, como circuitos de comutação telefônica, sendo também utilizada no projeto de equipamentos eletrônicos digitais. Posteriormente, tal teoria passou a ser bastante utilizada em diversos ramos da engenharia de software, para codificação/decodificação de mensagens e controle de fluxo de execução dos mais diversos tipos de software (VELOSO, 1979).

Nestas aplicações, um autômato age como uma "caixa preta" que possui um estado interno e, dada uma entrada, produz uma saída. Tal saída pode ou não ser dependente da entrada, mas sempre será dependente do estado interno do autômato. Os autômatos podem ser de diversos tipos (VELOSO, 1979):

- Transdutor: recebe uma seqüência de símbolos de entrada e os transforma em uma seqüência de símbolos de saída.

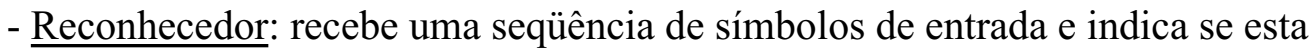
seqüência é reconhecida ou não.

- Gerador: produz uma seqüência de símbolos de saída, independente da entrada.

Todos estes tipos são maneiras distintas de se definir de forma finita um objeto infinito, sendo este um dos principais objetivos da teoria dos autômatos (VELOSO, 1979). 


\section{F.3. Máquinas de Estados Finitos}

Os autômatos classificados como transdutores finitos também recebem o nome de máquinas (VELOSO, 1979) ou, mais especificamente, Máquinas de Estados Finitos. Uma Máquina de Estados Finitos também pode ser definida como uma máquina abstrata que tem uma quantidade finita e constante de estados (WIKIPEDIA, 2005c).

A característica fundamental de uma MEF é que ela possui um estado. É o estado da MEF que define qual será o comportamento da máquina diante de um dado de entrada: se aquela entrada ocasiona uma determinada saída ou ainda se o estado corrente da máquina será alterado.

Ainda é possível classificar as MEFs em subcategorias (WIKIPEDIA, 2005c):

- Máquinas Determinísticas - Autômatos em que, para cada par "estado/entrada", existe um estado seguinte pré-determinado.

- Máquinas Não-determininísticas - Autômatos em que, para cada par "estado/entrada", podem existir vários possíveis estados seguintes.

- Máquinas Two-way - Autômatos que lêem valores e calculam sua soma de acordo com o tipo de número fornecido como entrada.

- Máquinas Não-determinísticas Genéricas - São Autômatos Não-determinísticos em que as transições de estados podem ser definidas por qualquer tipo de expressão regular.

É importante ressaltar que as classificações "não-determinísticas" nada têm a ver com números aleatórios e sim com o fato de que a saída gerada por um estado pode ser dependente de mais de uma entrada ou, em outras palavras, não é possível determinar qual a próxima saída a partir de uma único par estado-entrada. 
Uma outra forma de classificar as MEFs é pela maneira como sua saída é constituída (WIKIPEDIA, 2005c) :

- Máquinas Moore - Autômatos em que as saídas dependem exclusivamente do estado atual.

- Máquinas Mealy - Autômatos em que as saídas são determinadas pelo estado atual e pela entrada.

Embora a utilização mais comum das MEFs seja na descrição do comportamento de circuitos digitais, uma outra área onde elas são empregadas é no controle de fluxo de software. Nesta última aplicação, as MEFs mais comuns são as Máquinas de Estados Determinísticas.

Neste trabalho será detalhada a Máquina de Estados Determinística, que será utilizada na constituição da interface do sistema proposto. A descrição dos demais tipos de máquinas de estados podem ser verificados em diversos outros trabalhos como de Gill (1962), Kohavi (1978), Veloso (1979) e Wikipedia (2005c).

\section{F.3.1. A máquina de Estados Finitos Determinística}

Matematicamente, uma MEF Determinística pode ser definida por uma 5-tupla: (S, s, T, s, A). Tais elementos são definidos como (WIKIPEDIA, 2005c):

- S : Um conjunto finito de estados

$-\Sigma:$ Um conjunto finito denominado alfabeto

- T : Uma função de transição $(\mathrm{T}: \mathrm{S} \times \Sigma \rightarrow \mathrm{S})$

- $\mathrm{s}:$ Um estado inicial $(\mathrm{s} \in \mathrm{S})$

- A : Um conjunto de estados de aceitação $(A \subseteq S)$ 
Seja $\mathbf{M}$ uma máquina $\mathbf{M}=(S, \Sigma, T, s, A)$ e seja $\mathbf{X}=x_{1}, x_{2} \ldots x_{n}$ uma string no alfabeto $\Sigma$. $\mathbf{M}$ aceitará a string $\mathbf{X}$ se existe uma seqüência de estados $r_{0}, r_{1}, \ldots, r_{n}$ em $S$ tal que as seguintes condições se confirmem:

$$
\begin{aligned}
& -r_{0}=s \\
& -r_{i+1}=T\left(r_{i}, x_{i}\right), \text { para } i=0, \ldots, i=\mathrm{n}-1 \\
& -r_{n} \in A
\end{aligned}
$$

Em outras apalavras, a máquina deve iniciar no estado $s$. Para cada valor $x_{i}$, a transição $T$ leva ao próximo estado $r_{i+1}$. A seqüência é aceita se, após todo o processamento, o último estado registrado estiver no conjunto de estados de aceitação definido por $A$.

Como um exemplo clássico, temos o autômato que determina se a entrada tem um número par de dígitos zero, segundo um alfabeto binário. A definição da máquina é feita pela tupla:

$\mathrm{M}=(S, \Sigma, T, s, A)$, sendo que:

$S=\left\{\mathrm{S}_{1}, \mathrm{~S}_{2}\right\}$

$\Sigma=\{0,1\}$

$\mathrm{S}=\mathrm{S}_{1}$

$\mathrm{A}=\left\{\mathrm{S}_{1}\right\}$

T é definido pela tabela de transição:

$\begin{array}{lcccc}\text { Estado: } & \mathrm{S}_{1} & \mathrm{~S}_{1} & \mathrm{~S}_{2} & \mathrm{~S}_{2} \\ \text { Dígito: } & 0 & 1 & 0 & 1 \\ \text { Estado Seguinte: } & \mathrm{S}_{2} & \mathrm{~S}_{1} & \mathrm{~S}_{1} & \mathrm{~S}_{2}\end{array}$


Como é possível ver, o estado $\mathrm{S}_{1}$ indica quando um número de dígitos zero é par $(0,2,4,6 \ldots)$ e o estado $S_{2}$ é quando este número é ímpar, sendo que a ocorrência de um dígito zero na seqüência sempre provoca uma transição de estado. A ocorrência de dígitos 1 na seqüência não provoca qualquer tipo de transição. A aceitação ocorre se, ao fim do processamento da seqüência, o estado final for o estado $\mathrm{S}_{1}$. O diagrama que representa tal máquina de estado pode ser visto na figura F.1.

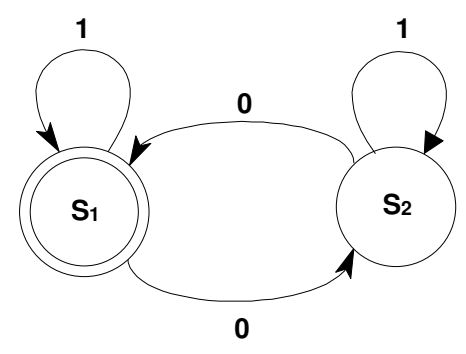

Fig. F.1 - O diagrama de uma máquina de estados

\section{F.3.2. O uso de MEFs no controle de fluxo de um programa}

Programas de computador são, por definição, um conjunto de instruções seqüenciais que, quando interpretadas pelo computador, produzem um resultado ou executam uma dada tarefa.

No caso geral, os programas são desenvolvidos com uma estruturação linear-seqüencial, em que é seguida uma seqüência predeterminada de funções, após o que a execução termina, com a apresentação do resultado.

Desta forma, estes programas são bastante eficientes na realização de cálculos e execução de tarefas que possuem uma seqüência pré-definida, ou seja, quando a ordem das ações é conhecida antes mesmo de sua execução. Basta que o computador siga aquela seqüência especificada que, no final, o resultado será obtido. 
Entretanto, esta estruturação não é a mais eficiente em todos os casos, como aqueles em que a ordem de execução não é previamente conhecida. Esta situação, bastante comum, ocorre quando o resultado apresentado pelo programa depende de interação com o usuário durante sua operação (REICH, 1995); (YAO, 1995).

Como um exemplo é possível citar um editor de textos. Quando o usuário executa um editor de textos, a ação que será executada a seguir pelo programa imprimir o texto, executar o corretor ortográfico, abrir um outro documento, fechar o programa etc. - depende totalmente e exclusivamente de uma ação do usuário.

Se o usuário, num programa linear, estiver na seção de impressão e quiser corrigir a ortografia antes de imprimir, ele terá que sair da seção de impressão, voltar ao menu principal, entrar na seção de corretor ortográfico, fazer a correção ortográfica, voltar para o menu principal, abrir novamente a seção de impressão e finalmente requisitar a impressão. O processo todo é demonstrado na figura F.2:

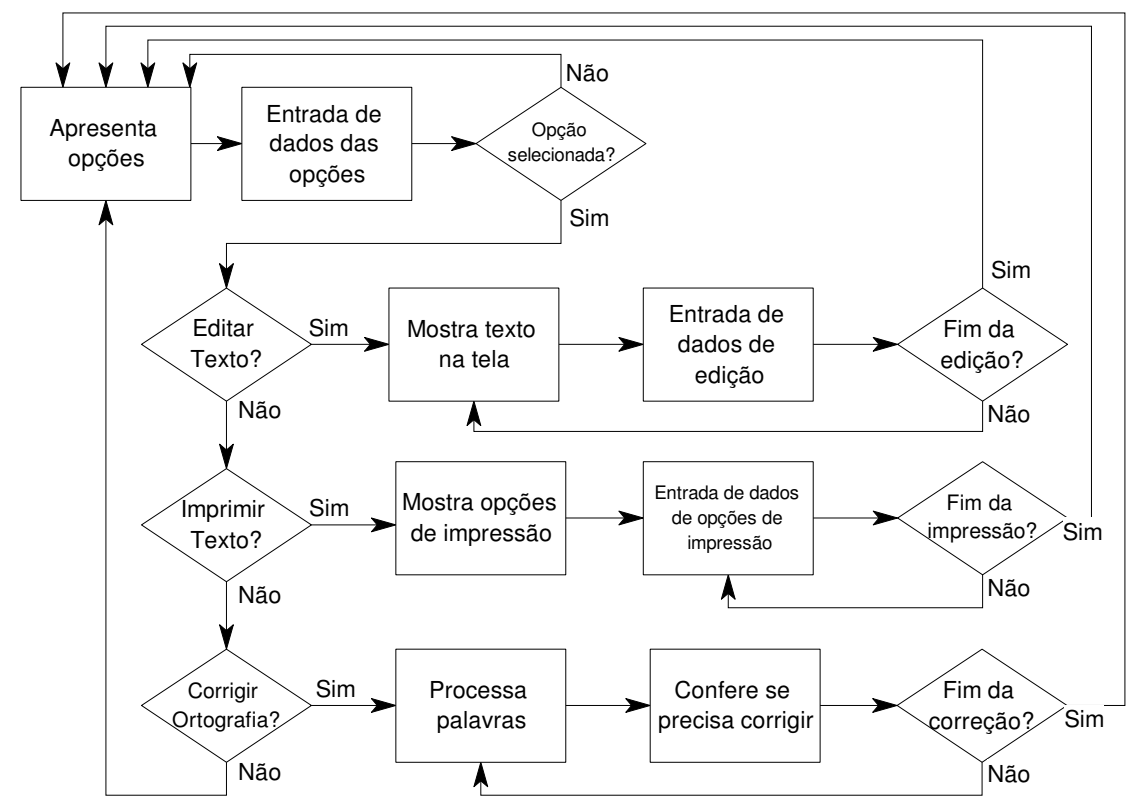

Fig. F.2 - Funcionamento de um editor de textos em programação seqüencial 
Embora seja perfeitamente possível, a operação de uma interface nesta forma é desajeitada, tornando-se tão mais desajeitada quanto maior for o número de sub-opções disponíveis. Para contornar este tipo de situação, seria necessário adicionar verificações para entrar em todas as opções e sub-opções dentro de cada uma das opções disponíveis, tornando o desenvolvimento complexo e propenso a erros.

Entretanto, um programa não precisa ter um desenvolvimento estritamente linear. De fato, a grande maioria dos programas que exigem uma grande interatividade por parte dos usuários são, hoje, desenvolvidos usando uma espécie de programação denominada "Programação Orientada a Eventos". Um grande exemplo deste tipo de software são tipicamente aqueles que são executados no ambiente Windows (YAO, 1995).

A programação orientada a eventos segue o modelo computacional de uma Máquina de Estados Finitos Determinística (MEF Determinística), sendo que seu alfabeto são as mensagens de evento disponíveis. Tal modelo permite que a execução das tarefas de um programa possa ser facilmente realizada de forma não seqüencial ou com sua seqüência definida pelo usuário. A seqüência passa a ser ditada pelos eventos.

Em outras palavras, cada atividade do programa é associada a um estado da MEF e as ações do usuário causam eventos que, ao serem reconhecidos pela MEF, causam uma mudança de estado, alterando a funcionalidade do programa de acordo com o desejo do usuário.

Uma máquina de estados com memória do(s) estado(s) anterior(es), além do estado atual, pode facilmente transitar entre estados. Com esta característica, tendo um estado para cada tarefa principal do programa, é possível pular de um estado para outro, retornando em seguida, sem a necessidade de maiores complicações na 
programação: basta que se comande uma alteração do estado atual e o programa já estará operando na nova seção e, ao terminar, pode voltar à seção anterior. Este tipo de funcionamento está representado na figura F.3:

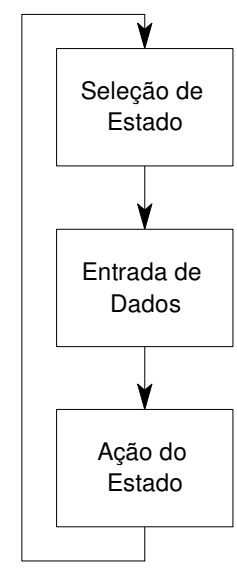

Fig. F.3 - Funcionamento de um software baseado em uma MEF

Por esta característica, a de proporcionar conforto à operação por parte do usuário sem que com isso a complexidade de programação aumente, as MEFs são, como dito anteriormente, uma boa maneira de implementar interfaces com o usuário. Elas podem lidar facilmente com a imprevisibilidade de ação do usuário, reagindo prontamente a tais ações.

\section{F.3.2.1. A estrutura de um programa orientado a estados}

A estrutura interna de um programa orientado a estados (ou eventos), ou seja, aquele cujo fluxo de funcionamento é controlado por uma máquina de estados, é simples: o programa fica à espera de um evento qualquer e executa, no momento correto, os procedimentos relativos ao estado atual.

Cada estado deve processar as informações que recebe como entrada sem jamais pressupor o estado anterior. Esta característica é fundamental para permitir a consistência e flexibilidade do sistema baseado na MEF. 
Além disso, cada estado de uma MEF pode ser também uma MEF, sendo que seus estados serão subestados do ponto de vista global do programa. O controle destes subestados deve ser de total responsabilidade do estado ao qual ele pertence. A figura E.4 mostra a utilização de MEFs aninhadas.

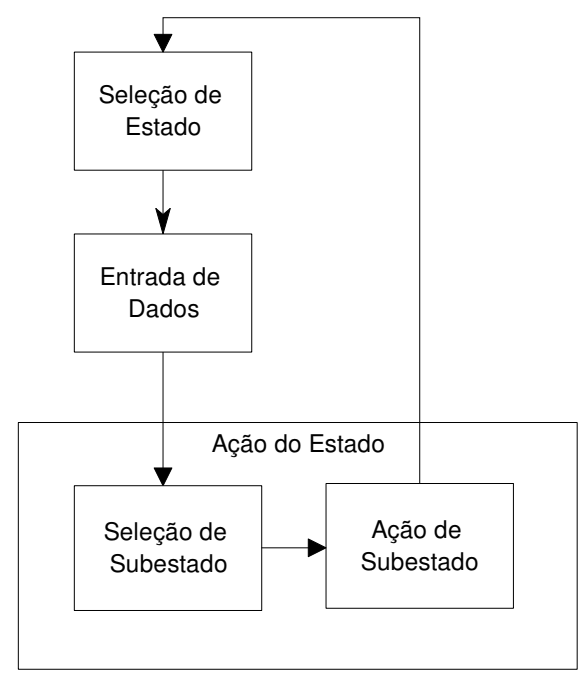

Fig. F.4 - Máquinas de Estado Finitos aninhadas

Em geral, num programa orientado a estados, a entrada do usuário é sempre repassada ao programa na forma de eventos, após o que é executada uma rotina que analisa estes eventos, tratando-os para o estado a ser executado. Outra tarefa desta rotina é identificar os eventos globais, que podem causar a mudança de um estado principal para outro.

\section{$\underline{\text { F.4. Considerações finais }}$}

Dada a praticidade de implementação e a comodidade de operação proporcionada ao usuário pela adoção de uma Maquina de Estados Finitos no controle de fluxo de operação da interface com o usuário, este tipo de implementação 
será adotada para tal módulo. Nos módulos de cálculo, entretanto, será adotado o modelo estrutural linear usual, devido às suas características intrínsecas.

Maiores informações sobre estruturação de programas, controle de fluxo de software, programação orientada a eventos e máquinas de estados podem ser obtidos em Gill (1962), Kohavi (1978), Veloso (1979), Pressman (1992), Reich (1995), Yao (1995), Schildt (1997), Hyde (2003), Wikipedia (2005c), dentre outros. 


\section{LISTA DE REFERÊNCIAS}

\section{BRADLEY, S. P.; HAX, A. C.; MAGNANTI, T. L. Applied mathematical} programming. Reading, Mass.: Addison-Wesley Pub. Co., 1977.

BUTZEN, F.; FORBES, D. Linux - bancos de dados. Rio de Janeiro: Editora Ciência Moderna, 1997.

CAMARGO, P. Desenvolvimento e organização das redes de transporte.

Dissertação - Escola Politécnica da Universidade de São Paulo. São Paulo, 1993.

COAD, P.; YOURDON, E. Análise baseada em objetos. Rio de Janeiro: Editora Campus, 1992.

_. Projeto baseado em objetos. Rio de Janeiro: Editora Campus, 1993.

CHUANG, T. N.; KUNG J. Y. The fuzzy shortest path lenght and the corresponding shortest path in a network. Transportation Research Part B: Methodological, v.37, n.7, p.641-660, ago. de 2003.

CHURCHMAN, C. W. Introdução à teoria dos sistemas. Rio de Janeiro: Editora Vozes, Petrópolis, 1972.

CHVATAL, V. Linear programming. New York: W. H. Freeman, 1983.

ELMASRI, R; NAVATHE, S. Fundamentals of database systems. S.I.:

Benjamins/Cummings, 1994. 
FARIA, C. A. Percepção do usuário com relação às características do nível de serviço do transporte coletivo urbano por ônibus. Dissertação - Escola de Engenharia de São Carlos. São Carlos, 1985.

Avaliação do nível de serviço do transporte coletivo urbano sob o ponto de vista do usuário. Tese - Escola Politécnica da Universidade de São Paulo. São Paulo, 1991.

GALLO, G; PALLOTTINO, S. Shortest path methods in transportation models. (M. Florian, ed.) Transportation Planning Models. North Holland, Elsevier Science Publishers. p. 227-256, 1984.

GIACAGLIA, M. E. Modelagem de redes de transporte multimodal pela análise orientada a objetos. Dissertação - Escola Politécnica da Universidade de São Paulo. São Paulo, 1993.

Modelagem de dados para planejamento e gestão operacional de transportes. Tese - Escola Politécnica da Universidade de São Paulo. São Paulo, 1998.

GUALDA, N. D. F. The out-of-kilter algorithm applied to the analysis of alternative limestone transport systems. Tese - The University of Texas. Austin, 1975.

HOLZNER, S. Borland C++ - programação for windows. 3.ed. São Paulo: Makron Books Editora, 1995.

HORN, M. E. T. An extended model and procedural framework for planning multimodal passenger journeys. Transportation Research Part B: Methodological, v.37, n.7, p.641-660, ago. de 2003. 
HYDE, R. The art of assembly language. San Francisco, Estados Unidos: No Starch Press, 2003.

JACOBSON, I.; CHRISTERSON, M.; JONSSON, P.; ÖVERGAARD, G.

Object-oriented software engineering: a use case driven approach. Essex, England: Addison-Wesley Longman Ltd., 1992.

MARQUES, H. N. Um sistema de informações para usuários de transporte coletivo em cidades de médio porte. Dissertação - Escola de Engenharia de São Carlos. São Carlos, 1998.

MCCORMACK, E. Using a GIS to enhance the value of travel diaries. Institute of Transportation Engineers. ITE Journal, v.69, n.1, p.38-43, jan. de 1999.

NOVAES, A. G. Sistemas de transportes. São Paulo: Editora Edgard Blücher Ltda., 1986.

REICH, D. E. Designing high-powered OS/2 Warp applications - The anatomy of multithreaded programs. Estados Unidos: John Wiley \& Sons Inc., 1995.

RICH, E.; KNIGHT, K. Inteligência artificial. São Paulo: Books do Brasil, 1993.

SILBERCHATZ, A.; GALVIN, P. B. Sistemas operacionais - conceitos. Quinta Edição. São Paulo: Prentice Hall Editora, 2000.

SILVA, G. P. Uma metodologia baseada na técnica de geração de arcos para o problema de programação de veículos. Tese - Escola Politécnica da Universidade de São Paulo. São Paulo, 2001. 
STRAMBI, O. Critérios de eficiência e equidade para análise de estruturas tarifárias para o transporte público urbano. Tese - Escola Politécnica da Universidade de São Paulo. São Paulo, 1991.

TANENBAUM, A. S. Redes de computadores. 4.ed. Rio de Janeiro: Editora Elsevier, 2003a..

Sistemas operacionais modernos. 2.ed. S.I.: Pearson Brasil Editora, 2003b.

TIMPF, S. Ontologies of wayfinding: a traveler's perspective. Networks and Spatial Economics, v.1, n.2, p.9-33, mar. de 2002.

\section{VELOSO, P. A. S. Máquinas e linguagens: uma introdução à teoria dos} autômatos. São Paulo: Escola de Computação do Instituto de Matemática e Estatística da USP, 1979.

WIKIPEDIA. Comparison of relational database management systems. Disponível em <http://en.wikipedia.org/wiki/Comparison_of_relational_database_management_systems > Acesso em: 05 de maio de 2005a.

. Distributed computing. Disponível em: < http://en.wikipedia.org/wiki/Distributed_system>. Acesso em: 17 de ago. de 2005b.

. Finite state machine. Disponível em: < http://en.wikipedia.org/wiki/Finite_state_machine> . Acesso em: 24 de jan. de 2005c.

Multitier architeture. Disponível em: < http://en.wikipedia.org/wiki/Multitier_architeture>. Acesso em 26 de jul. de 2005d. 
WINSTON, W. L. Operations research: applications and algorithms. S.I.:

International Thomson Publishing, 1994.

YAO, P. Borland C++ 4.0 - programação for windows. São Paulo: Makron Books Editora, 1995.

YOURDON, E.; ARGILA, C. Análise e projeto orientados a objetos - estudos de casos. São Paulo: Makron Books Editora, 1999.

YOURDON, E. Just enough structured analysis. Disponível em: <

http://www.yourdon.com/strucanalysis/>. Acesso em: 30 de ago. de 2005. 


\section{BIBLIOGRAFIA RECOMENDADA}

DATE, C. J. Introdução a sistemas de bancos de sados. Rio de Janeiro: Editora Campus, 2000.

FANTINATO, M. Critérios de teste funcional baseados em Máquinas de Estados Finitos estendidas. Dissertação - Faculdade de Engenharia Elétrica e de Computação - Universidade Estadual de Campinas. Campinas, 2002.

GILL, A. Introduction to the theory of finite state machines. S.I.: Editora McGraw-Hill Eletronic Science Series, 1962.

IBM Visual Age C++ for OS/2 C library reference. North York, Canadá: IBM Canada Ltd. Laboratory, 1995.

IBM Visual Age C++ for OS/2 language reference. North York, Canadá: IBM Canada Ltd. Laboratory, 1995.

IBM Visual Age C++ for OS/2 programming guide. North York, Canadá: IBM Canada Ltd. Laboratory, 1995.

KOHAVI, Z. Switching and finite automata theory. New York: Editora McGraw-Hill, 1978.

MARTE, C. L. Sistemas computacionais distribuídos aplicados em automação dos transportes. Tese - Escola Politécnica da Universidade de São Paulo. São Paulo, 2000. 
PHP: Hypertext provessor documentation. PHP Manual. Disponível em: < http://www.php.net/manual/en/>. Acesso em 15 de fev. de 2005.

PRESSMAN, R. S. Engenharia de software. São Paulo: Makron Books do Brasil Editora Ltda., 1992.

SCHILDT, H. Inteligência artificial utilizando linguagem C. São Paulo: McGraw-Hill Editora, 1989.

C completo e total. São Paulo: Makron Books Editora, 1997.

SILBERCHATZ, A.; KORTH, H. F.; SUDARRSHAN, S. Sistemas de banco de dados. 3.ed. São Paulo: Makron Books Editora, 1999.

SWAIT, J. D. Fundamentos computacionais, algoritmos e estruturas de dados.

São Paulo: Makron Books Editora, 1991. 